\title{
Ecological analysis of large floristic and plant-sociological datasets - opportunities and limitations
}

\author{
Dissertation for the award of the degree "Doctor rerum naturalium" (Dr.rer.nat.) \\ of the Georg-August-Universität Göttingen \\ within the doctoral program Biology \\ of the Georg-August University School of Science (GAUSS) \\ submitted by \\ Florian Goedecke \\ from Wernigerode
}

Göttingen, 2018 


\section{Thesis Committee}

Prof. Dr. Erwin Bergmeier, Department Vegetation und Phytodiversity Analyses, Albrecht von Haller Institute of Plant Sciences

University of Goettingen

Prof. Dr. Holger Kreft, Department Biodiversity, Macroecology \& Biogeography, University of Goettingen

\section{Members of the Examination Board}

Reviewer: Prof. Dr. Erwin Bergmeier, Department Vegetation und Phytodiversity Analyses, Albrecht von Haller Institute of Plant Sciences

University of Goettingen

Second Reviewer: Prof. Dr. Holger Kreft, Department Biodiversity, Macroecology \& Biogeography, University of Goettingen

\section{Further members of the Examination Board}

Prof. Dr. Markus Hauck, Department of Plant Ecology and Ecosystems Research, Albrecht von Haller Institute of Plant Sciences

University of Goettingen

PD. Dr. Ina Meyer, Department of Plant Ecology and Ecosystems Research, Albrecht von Haller Institute of Plant Sciences

University of Goettingen

Prof. Dr. Hermann Behling, Department of Palynology and Climate Dynamics, Albrecht von Haller Institute of Plant Sciences

University of Goettingen

PD. Dr. Matthias Waltert, Workgroup Endangered Species Conservation, Johann Friedrich Blumenbach Institute of Zoology and Anthropology

University of Goettingen

Date of the oral examination: $4^{\text {th }}$ May 2018 


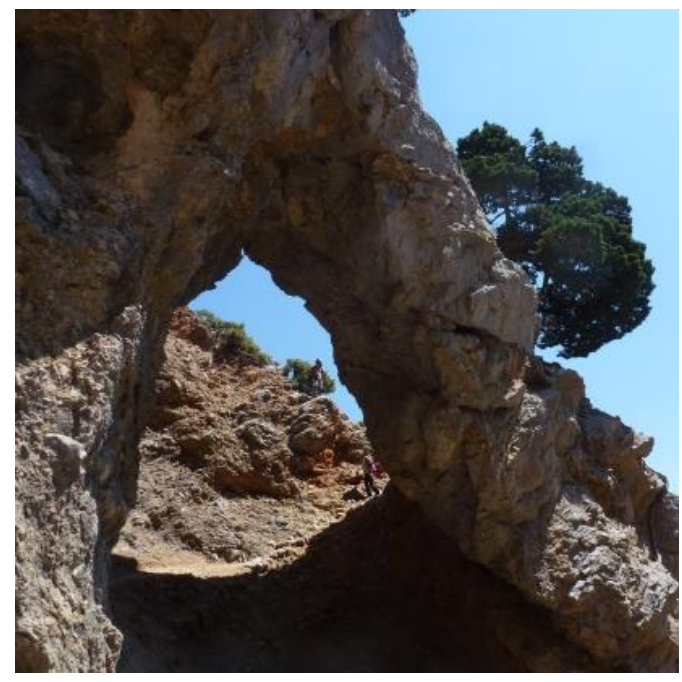

Ecological niches of species are not simple and some niches are simply not predictable. 


\section{Contents}

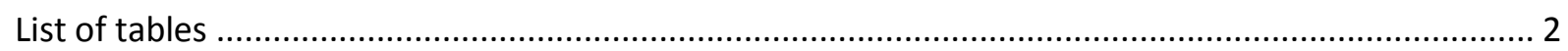

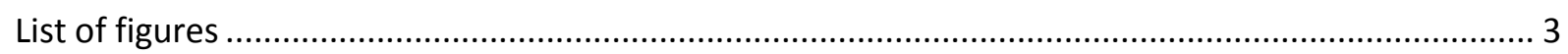

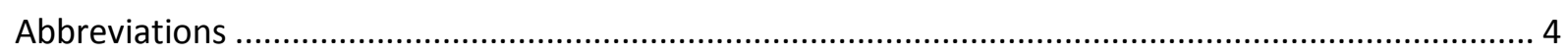

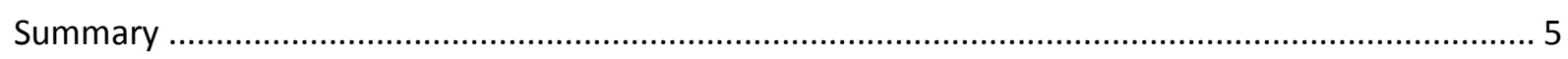

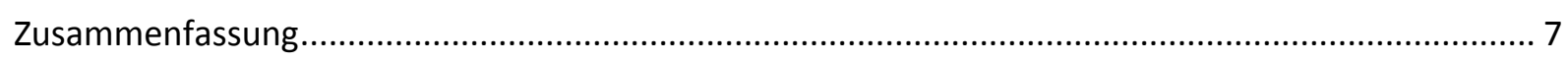

Chapter 1:

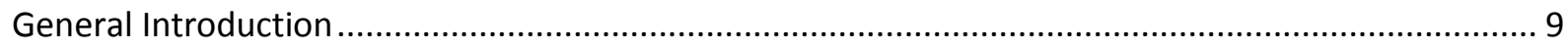

The Framework

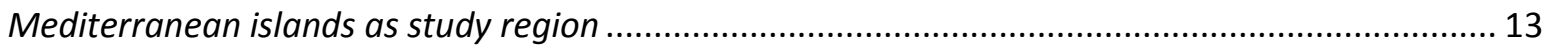

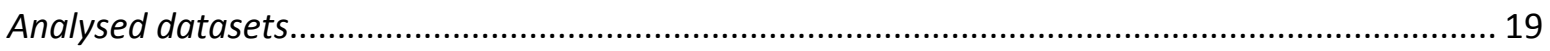

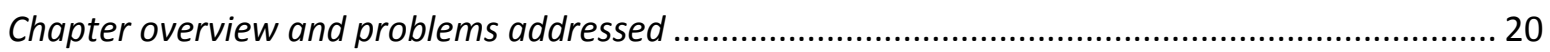

Chapter 2:

Quantified ecology and co-occurrence of Mediterranean woody species in a landscape context ...... 23

Chapter 3:

Platanus orientalis woodlands of Crete - diversity, distribution and conservation status

Chapter 4:

Ecology and potential distribution of the Cretan endemic tree species Zelkova abelicea

\section{Chapter 5:}

Geological data significantly reduce the model performance of species distribution models on broad spatial scales. A GIS - based approach from two Mediterranean Islands

Chapter 6:

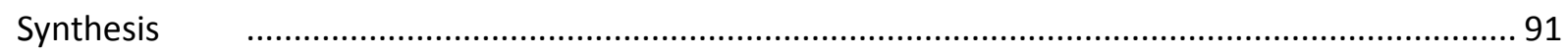

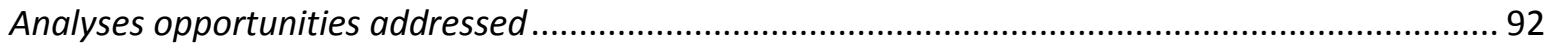

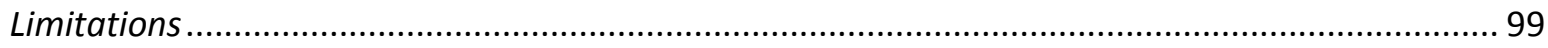

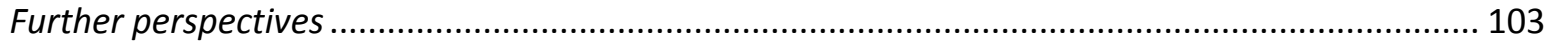

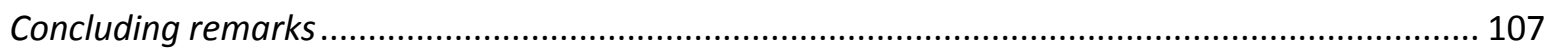

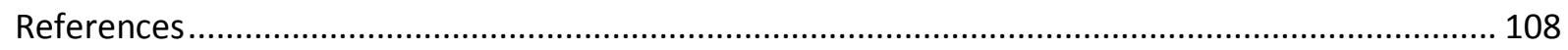

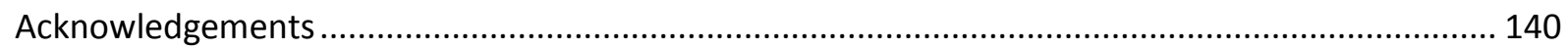

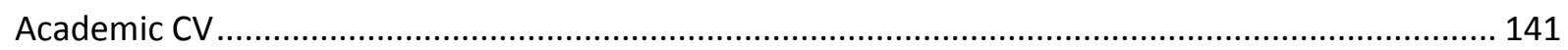

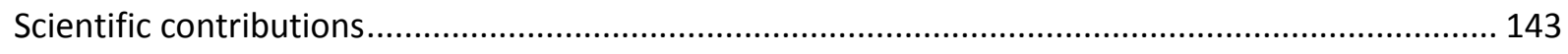

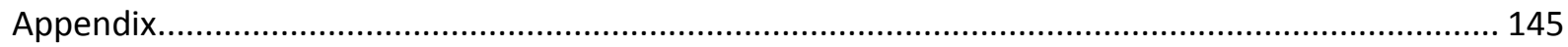




\section{List of tables}

Table 2.1 Databases contributing to the study. 27

Table 2.2 Mediterranean woody species sampled on Crete.

Table 2.3 Abiotic site parameters and raster data used in this study 29

Table 2.4 Geological units in Crete and percentages of total island surface 30

Table 3.1 Synoptic table for three associations of Cretan Platanus orientalis woods in Crete......

Table 4.1 Data collection for Zelkova abelicea populations of Crete. 63

Table 4.2 Populations of $Z$. abelicea in the Cretan mountain ranges. 64

Table 4.3 Environmental factors used to predict species distribution of Z. abelicea 64

Table 4.4 Sample predictions with tested populations for a species distribution 67

Table 4.5 Sample prediction values for combinations of populations. 67

Table 5.1 Taxa used in this study and their records for each island. 77

Table 5.2 Woody species on Crete and Sicily with their affinity to bedrock types (\% of records).... 81 Table 5.3 Jacknife testing for single variables for Crete and Sicily percentages 82 


\section{List of figures}

Figure 1.1 Regional topography and location of the studied islands Sicily and Crete........................13

Figure 1.2 Climate diagrams for three weather stations within the study area .................................14

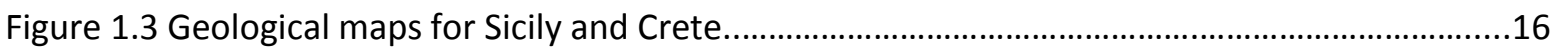

Figure 2.1 Map of the island of Crete with density of woody species records....................................2 29

Figure 2.2 Ecological heatmap for Mediterranean woody species on Crete. ......................................32

Figure 2.3 Plotted results of multivariate analysis (PCA) ................................................................... 33

Figure 2.4 Relative frequencies of 37 woody species within habitats from Crete............................... 34

Figure 3.1 Platanus orientalis woodlands in Crete (pictures) ............................................................. 44

Figure 3.2 Distribution of vegetation records of Platanion orientalis in Crete................................ 47

Figure 3.3 Natura 2000 habitat quality assessment of Crete for Platanion orientalis....................... 53

Figure 3.4 Platanus orientalis woodlands in Crete with observed pressures and threats................ 54

Figure 4.1 Map of distribution and altitudinal patterns for the Zelkova abelicea in Crete............... 61

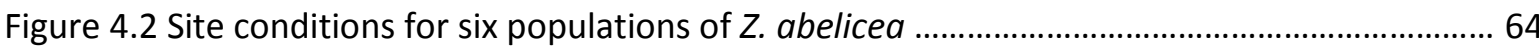

Figure 5.1 Differences of environmental factors for the two study regions.......................................77

Figure 5.2 Boxplots displaying variation in test AUC-values for woody species in Crete and Sicily..81

Figure 5.3 Modeled species distribution trained for Crete and Sicily for two species....................... 81 


\section{Abbreviations}

a.s.l. above sea level

AUC Area under the Curve of ROC

EEA European Environmental Agency

$C B D$ international Convention on Biological Diversity

DCA Detrended Correspondence Analysis

DEM Digital Elevation Model

ENM Environmental Niche Model

GIS Geographical Information System

LUCAS Land Use and Cover Area frame Statistical survey

PCA Principal Component Analysis

ROC Receiver Operating Characteristic

SDM Species Distribution Model

SD Standard Deviation

spp. (multiple) species

subsp. subspecies

syn. synonym 


\section{Summary}

This thesis comprises opportunities and limitations for the analysis of floristic and plant-sociological datasets and presents four related exemplary case studies. Woody plant species, their isolated (meta)populations and vegetation units are considered as study objects in a Mediterranean island context. Studies address the islands of Crete and Sicily. The first chapter introduces to general methodologies and positions the conducted studies within this frame.

The second chapter addresses the ecology and co-occurrence of woody species in Cretan landscape context. For precise coordinates of almost 9700 records of 37 species site-information on geology, geomorphology and climate were compiled. The resulting ecological spectra for each species were clustered by similarity, which revealed ecological species groups. These groups reflect distinct ecological units in the Cretan landscape and match partly with published vegetation and habitat schemes (EUNIS, Natura 2000, European vegetation classification). Results thus enable to compare plant ecological spectra of the woody flora of a region and their relation to vegetation patterns.

The third chapter deals with the numerical classification of plant sociological relevées of alluvial Platanus orientalis forests; thereby two new plant associations were described. They differ markedly from a third vegetation unit published earlier; for all three associations, species composition, ecology and distribution were discussed. Within 74 Platanus stands in Crete nature conservation monitoring was performed, addressing adverse effects and conservation status. About one third was in good conservation status, $42 \%$ had an inadequate status and $24 \%$ had a bad status; thereby water abstraction, pollution and garbage were the main adverse effects. The study revealed ecologically and floristically founded vegetation units within a regionally common but neglected vegetation type, which is severely threatened in habitat quality.

The study in the fourth chapter is an ecological comparison of (meta)populations of Zelkova abelicea, an endemic Tertiary relict in the mountains of Crete. The tree species occurs in isolation in high altitudes of the main mountain ranges, whereas a previous genetic study found intraspecific differences. The mesic woody species occurs in the drier eastern mountains merely on shady slopes, while in the west it may occupy a wider site spectrum. These differences influence the prediction of species distribution models in MaxEnt. Models trained on the larger Western (meta)populations fail to predict the smaller eastern ones. Isolation effects could apply even for these nearby mountains, which could explain (epi)genetic differentiation.

The fifth chapter comprises a study comparing 12 maquis species occurring in Crete and Sicily. Species records and environmental variables (geomorphology, climate, geology) were included into species distribution models, trained on one of the two islands and tested on the other. 
Methodological issues in conjunction with extrapolation are discussed. We provide hints for variable selection and adjustments, allowing for better models. Differences in ecological affinities hamper the extrapolation of species distribution in the test region, whereas species with broader ecological amplitude performed worse in models. Lowered isolation barriers with their according genetic uniformity and habitat filtering processes could be involved in the formation of such patterns.

The studies comprise examples for opportunities and limitations in the analysis of large floristic and plant-sociological datasets. A conclusion in the context of several (ecological) disciplines is given in the sixth and last chapter, where also future analysis options for the region or similar datasets are presented. 


\section{Zusammenfassung}

Diese Dissertation zeigt anhand von vier Studien Möglichkeiten und Grenzen für die Analyse von floristischen und pflanzensoziologischen Datensätzen auf. Gehölzarten, ihre isolierten Metapopulationen und ihre Vegetation werden im Mittelmeerraum bearbeitet, dabei beschränken sich die Arbeiten auf die Inseln Kreta und Sizilien. Im ersten Kapitel werden allgemeine Auswertungsmöglichkeiten, das Untersuchungsgebiet und die Ziele der Arbeit vorgestellt.

Die Studie im zweiten Kapitel bedient Aspekte der Pflanzenökologie und das gemeinsame Vorkommen von Gehölzarten auf Kreta. Für genaue Koordinaten von fast 9700 Funden von 37 Arten wurden Standortsangaben zu Geologie, Geomorphologie und Klima zusammengestellt. Die ökologischen Spektren der Standortsbedingungen wurden nach Ähnlichkeit klassifiziert, wodurch ökologische Artengruppen entstanden. Die Gruppen spiegeln abgrenzbare ökologische Einheiten in der kretischen Landschaft wider und stimmen teils mit Vegetationseinheiten aus der Literatur und Einheiten in Habitat-Handbüchern überein (EUNIS, Nature 2000, Europäische Vegetationsklassifikation). Damit erlauben die Ergebnisse einen Vergleich von pflanzenökologischen Spektren der regionalen Gehölzflora und deren Bezug zu Vegetationsmustern.

Das dritte Kapitel beschäftigt sich mit der Klassifikation von pflanzensoziologischen Aufnahmen von Platanus orientalis-Auwäldern; dadurch wurden zwei neue Pflanzengesellschaften beschrieben. Diese unterscheiden sich deutlich von einer früher beschriebenen Gesellschaft; für alle drei Assoziationen wurden die jeweilige Artenzusammensetzung, die Ökologie und die Verbreitung besprochen. Für 72 Platanenauwald-Bestände auf Kreta wurde zudem eine naturschutzfachliche Bewertung durchgeführt, nachdem negative Einflüsse und der Erhaltungszustand erfaßt wurden. Etwa ein Drittel der Bestände war in gutem Erhaltungszustand, 42 \% hatten einen unzureichenden Zustand und die restlichen 24 \% hatten einen schlechten Zustand; dabei waren Entwässerung, Wasserverschmutzung und Müll die entscheidendsten negativen Einflüsse. Die Studie zeigt ökologisch wie floristisch begründete Vegetationseinheiten in einem regional häufigen Vegetationstyp auf, welcher ernsthaft in seiner Ausdehnung und Habitatqualität bedroht ist.

Die Studie im vierten Kapitel stellt einen ökologischen Vergleich von Metapopulationen von Zelkova abelicea dar, einem endemischem Tertiärrelikt in den kretischen Bergen. Die Baumart tritt in isolierten Vorkommen in den Höhenlagen der wichtigsten Bergketten auf, wobei eine frühere genetische Untersuchung intraspezifische Unterschiede fand. Die mesophile Art ist im trockenen Osten hauptsächlich auf schattige Hänge beschränkt, während sie im Westen eine breitere Standortsamplitude einnimmt. Diese Unterschiede beeinflussen die Vorhersage von MaxEntModellen zur Verbreitung der Art; sodaß die kleineren östlichen Vorkommen schlecht über Modelle 
vorhergesagt werden können, welche die Westpopulationen als Grundlage haben. Es wirken vielleicht Isolationseffekte, die eine (epi)genetische Differenzierung erklären könnten.

Das fünfte Kapitel umfaßt eine Studie bei der 12 Macchia-Arten untersucht wurden, die auf Kreta und Sizilien vorkommen. Fundpunkte von Arten und Umweltvariablen (Geomorphologie, Klima, Geologie) wurden in Modellen zur Vorhersage von Artverbreitungen verwendet, um letztere auf einer Insel zu trainieren und auf der jeweils anderen zu testen. Unterschiede in den standörtlichen Spektren der Arten hemmen die Extrapolation von Artenverbreitungsmodellen im Testgebiet. Arten mit sehr speziellen Standortspräferenzen ließen sich gut auf der jeweils anderen Insel vorhersagen, während Arten mit breiter Standortsamplitude schlechter zu modellieren waren. Methodische Probleme im Zusammenhang mit Extrapolationen werden besprochen. Wir geben zudem Hinweise zur Auswahl von Variablen und Einstellungen die bessere Modelle erlauben. Geringe Isolationsbarrieren und entsprechende genetische Uniformität für Küstenarten und Habitatfilterprozesse könnten an der Entstehung solcher Muster beteiligt sein.

Die Studien enthalten Beispiele für die Möglichkeiten und Grenzen bei der Auswertung von großen floristisch-pflanzensoziologischen Datensätzen, die im sechsten und letzten Kapitel zusammengefaßt und im Kontext verschiedener (ökologischer) Disziplinen erörtert werden; außerdem werden dort Analyseoptionen aufgezeigt die sich in der Region oder mit ähnlichen Datensätzen in Zukunft ergeben könnten. 
Chapter 1: General Introduction 


\section{The Framework}

This thesis focusses on analysing several datasets collected in the Mediterranean region, to investigate regional species ecology and vegetation ecology and to solve questions of wide interest. Therefore big datasets are analysed; big data are more and more publicly recognized in the last years, as personal data are collected and analysed e.g. in social media. In the last decades datasets of growing size arose in various scientific fields and the availability of biological data from vast public and private collections opened perspectives also for ecologists, not least as gathering, storing and analyses of data improved. Organism-related datasets are stored in museums, herbaria and other collections, globally holding an estimated sum of 2.5 billion specimens (Lavoie 2013). For plantrelated studies further plot-based plant and vegetation records exist from literature or unpublished sources (Chytrý et al. 2016; Dengler et al. 2011; Dengler and sPlot Core Team 2014; GBIF 2017; Purschke et al. 2015). The higher the numbers of records and their density in a study, the higher is the statistical power of the results; and dependent on quantity and quality of data, various methodologies may apply.

The following section gives a brief overview of general approaches and methodologies used for analyses of floristic and plant-sociological datasets across disciplines, most of which are related to ecology. The two types of data used in such analyses comprise species records with their locations; the second type includes compositional data usually taken from vegetation relevées. At least for most of those plot based samples also information on site conditions are gathered and stored (see Dierschke 1994 for methods of plot based sampling). Such datasets are versatile and thus feature research in multiple disciplines, some of which overlap in used methodologies. Depending on the evaluated scale level and the research questions asked, different aspects of information are addressed (i.e. location in space, time, genetic identity, site conditions, etc.). Fields of interest may regard ecological questions connected to species and site conditions, focussing on causalities; common patterns of taxa may be analysed, when chorology is considered. When small scales apply, plant ecology, population ecology or vegetation ecology can be featured, while wider scale studies may relate to macroecology, phylogeography or biogeography; thereby overlaps may exist (for scale issues read Huston 2002). Approaches on different scale levels benefit from each other or are depending: wider scale analyses need local ecological studies for base data, and ecological results for interpretation and reasoning. Reversely local plant studies are often supported by studies in wider context. The scale-dependence of ecological studies has been frequently discussed (Austin and van Niel 2011; Cohen et al. 2015; Ellison 2002; Franklin et al. 2013; Giakoumi et al. 2013; Gotelli et al. 2009; Kang et al. 2014). The chapters of this thesis address various scales and diverse data sources and thus allow for a discussion across disciplines. The following section lists concepts and analytical 
approaches, which are mostly in relation to the performed case studies; the selection though is not comprehensive.

Distributions and diversity of organisms can be displayed in manifold ways. Floristic literature for regions, countries and larger units comprise descriptions and thematic maps. The latter display distribution patterns as points, grid cells, ranges or combinations thereof, some include further information such as data density and variation within taxa. The quality of such maps depends on the density of records, the map purpose, its generalisation, etc.; floristic atlases mainly comprise such distribution maps with layout and features being scale-dependent (e.g. Garve 1994; Haeupler and Schönfelder 2004; Jalas et al. 1996, 1999; Jalas and Suominen 1972-1994; Kurtto and et al. 20042018; Meusel et al. 1978; Perring and Walters 1990; Poppendieck 2011; San-Miguel-Ayanz et al. 2016; Strid 2016). For the interpretation of such maps ecological, geographical, geological, climatological and other background knowledge is helpful. Distribution patterns of plant species based on large datasets were analysed on regional (e.g. Law et al. 2009; Schmiedel 2014), national (e.g. Korsch 1999; Wasowicz et al. 2014) or global scale (e.g. Kier et al. 2005; König et al. 2017). Such patterns can be influenced by sampling intensity and may reflect the state of knowledge concerning taxonomy (Meyer et al. 2016; Yang et al. 2013, 2014). Distribution data of species were used to describe diversity patterns (Barthlott et al. 2007; Kier et al. 2005; Mutke et al. 2010) as well as centres of endemism (Kier et al. 2009; Médail and Quézel 1997; Myers et al. 2000). Species distribution and therewith diversity patterns depend on e.g. an interplay of abiotic conditions and various other environmental aspects like spatial constraints, connectedness and interactions with other organisms. Distributions of species also have relevance regarding time dimensions; i.e. distribution patterns can be compared for different points in time, including short term movements (e.g. migratory bird species; Bradsworth et al. 2017; Coxen et al. 2017), changes over years and decades (e.g. invasive organisms; Broennimann et al. 2007; Hanski and Gilpin 2008; Merow et al. 2017), but also range changes over historical and deep time periods (e.g. Graham et al. 2010; Jackson and Overpeck 2000; Svenning et al. 2011). Some of the mentioned studies comprised modeling approaches, which integrate environmental data and usually species data to predict potential species distribution or to assess (complex) species niches (Elith et al. 2006; Merow et al. 2014; Peterson et al. 2007; Peterson and Soberón 2012).

The complexity of environmental conditions along studied gradients deserves high attention in ecological studies. Environmental variables are (to varying extent) responsible for plant reactions and plant cover on various scales (biomes, vegetation zones, vegetation formations, vegetation patches, but also plant growth, etc.); whereas ecologists try to understand these plant-environment or vegetation-environment relations (e.g. Frey and Lösch 2010). A palette of quantitative 
measurements and qualitative parameters is used to assess the causal relations in ecological context; thereby each set of assessed environmental conditions represents a selection within the ecological space of the study object. Measurable conditions are limited proxies to circumscribe ecological spaces and the complexity of the latter is often underestimated (Peterson 2007). Based on the concept of Hutchinson (1957) the sum of site conditions for a species form the ecological niche. Depending on the working scale, different scientific methods of measurement are available. While for plant ecological approaches, ecophysiological measures can apply, on larger scales data from geoscientific fields are used, e.g. from remote sensing. High-resolution datasets were produced describing environmental aspects of major importance, such as geomorphology (Gorokhovich and Voustianiouk 2006; Nikolakopoulos et al. 2006; Siart et al. 2009), climate (Hijmans et al. 2005; Karger et al. 2016; Kottek et al. 2006), or soils (Ballabio et al. 2016; Bockheim and Gennadiyev 2010; Brogniez et al. 2015; Panagos et al. 2015). Coarse scale studies analysed and classified environmental conditions (König et al. 2017; Stein et al. 2015; Weigelt 2014). Accuracy and resolution of global environmental datasets can be limited; and thus fundamental issues may apply when such data is downscaled. While for some applications raw data and algorithms allow for downscaling (Fridley 2009; Salzmann 2006), in other cases downscaled results can be misleading (Scherrer et al. 2011; Scherrer and Körner 2009; Schmidli et al. 2007). Along gradients and various spatial scales the environmental variability has an impact on distribution and diversity of organisms and vegetation. In conjunction to the understanding of plant affinities to site conditions, plants and vegetation units may be indicative for environmental conditions. This way ecological indicator values can be assigned to species (Ellenberg 1974, see Chapter 2). In analogy to plant taxa, also plant communities may be indicators for a certain combination of site conditions.

Variation and hidden diversity are further important aspects of ecological studies. Intraspecific variation may consider phenotypes (Violle et al. 2012) or genetic differences (e.g. haplotype variation; Christe et al. 2014; Hampe et al. 2003; Petit et al. 2003; 2004). The importance of intraspecific genetic variation is widely accepted as component of diversity (CBD 2012), but specific sampling and elaborated genetic laboratory analysis are needed for its assessment and so many aspects thereof wait to be discovered. Gaps in sampling and in taxonomic knowledge affect diversity patterns (Giam et al. 2010; Stork 1993). For various species ecological and genetic variation were jointly analysed, while for the vast majority such relations are still unknown (Lowe et al. 2004). In certain cases differences are so pronounced, that new species are found even among else wellstudied organism groups (e.g. Pearson et al. 2007; Sattler et al. 2007; Shneyer and Kotseruba 2015). The growing field of landscape genetics, combines population genetics and landscape features (Holderegger et al. 2010; Manel et al. 2003; Manel and Holderegger 2013). 
Co-occurrences of plant species are usually assessed by sampling of vegetation plots. Such relevées comprise compositional data, with cover or frequencies of species and site attributes, and often additional information on management and structure. Datasets with plot data were for instance used to perform vegetation classification. For Europe, being the most densely sampled continent, vegetation plots were systematically conducted since the first half of the $20^{\text {th }}$ century (BraunBlanquet 1928; Guarino et al. 2018). The compilation of Mucina et al. (2016) gave an overview on vegetation classes, orders and alliances on European scale. Most recently also European beech-forest communities were analysed (Jiménez-Alfaro et al. 2018). The authors thereby evaluated the complex interactions of land use history, biogeographical region and species pool on vascular plant diversity. Classified vegetation units are descriptors for environmentally distinct vegetation and therewith apply for nature conservation and planning. The pressure of global change makes protection of resources and biological structures a necessity, which is regarded in international treaties, conventions and laws. Environmental protection laws integrate species and also vegetation units as central elements; e.g. the member states of the European Union agreed on the common Natura 2000 framework, which includes 233 habitat types (European Commission - DG Environment 2013).

\section{Mediterranean islands as study region}

All presented studies of this thesis focus on the islands Crete and Sicily (Figure 1.1), both located in the Mediterranean basin. The "Mediterranean" is defined differently depending on specific context and authors, related to either biological, climatic, cultural or other factors (Blondel and Aronson 2010). Most importantly climatic features are used to define the regions extent. The climate of the

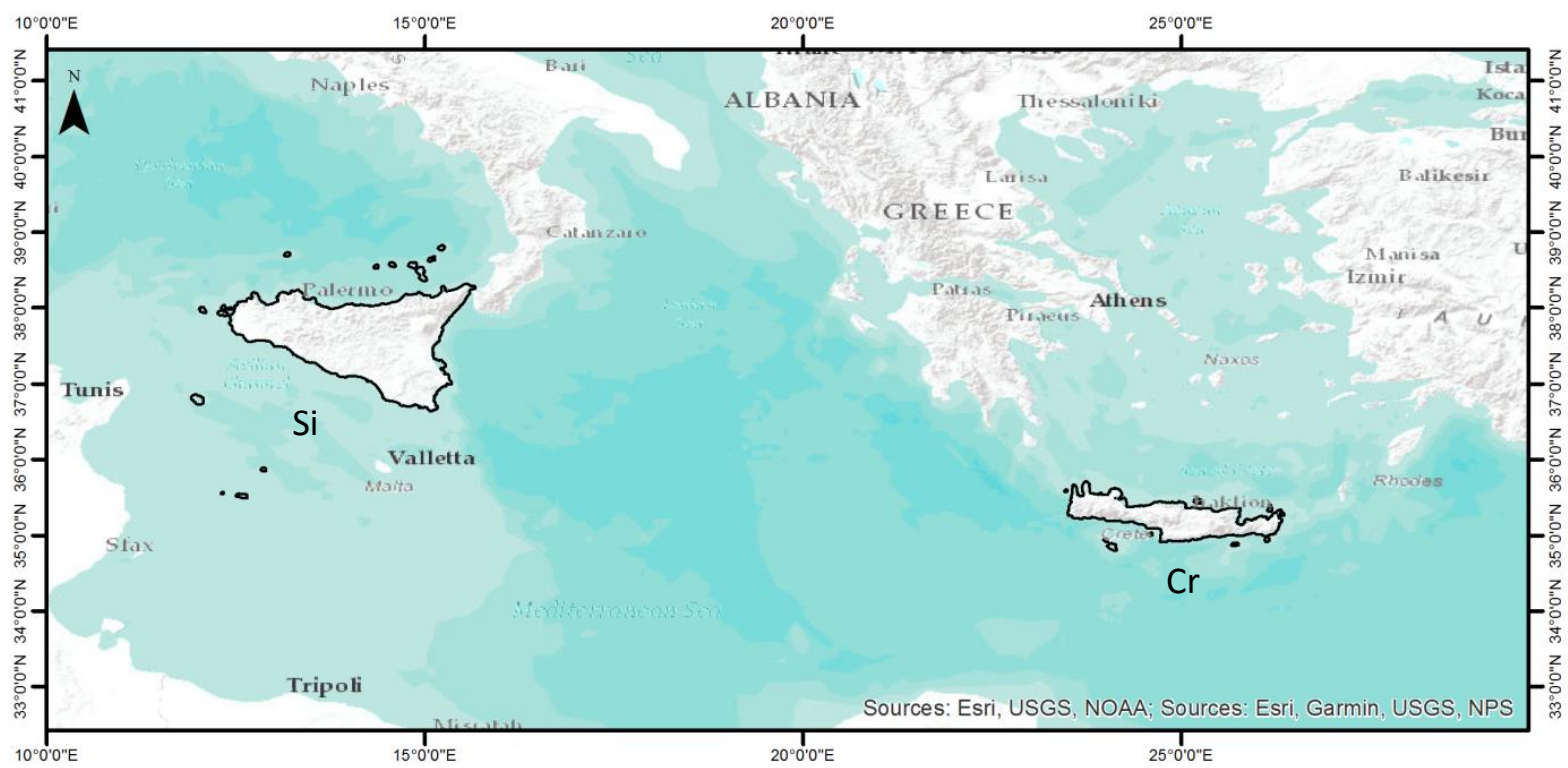

Figure 1.1 Regional topography and location of the studied islands Sicily ( $\mathrm{Si}$ ) and Crete (Cr), altitudinal variation based on ArcGis Online basemap (Esri, DigitalGlobe, GeoEye, i-cubed, USDA FSA, USGS, AEX, Getmapping, Aerogrid, IGN, IGP, swisstopo, and the GIS User Community). 
Mediterranean region features high temperatures in summer and mild temperatures in winter; summers are dry as principal precipitation arrives in winter (Lionello 2012). Different climate diagrams for the region (Figure 1.1) show general similarities in the magnitude of temperatures and the annual distribution of precipitation but also differences in absolute values. Inter-annual climatic variability is a common feature (Lionello 2012).

The Mediterranean region underwent tremendous changes in climate and topography in millions of years, which influenced distribution of species. It is located at the borders of the Eurasian and the African tectonic plates. Highly dynamic tectonic processes result in, e.g. volcanism, seismic activities, and surface deformations, i.e. oceanic deeps and mountains up-folding. The study region is affected differently by suchlike phenomena. In Crete active volcanoes probably had little direct impact (Bottema and Sarpaki 2003), while on Sicily Mount Etna dominates the eastern Island, being the highest volcano in Europe (3323 m a.s.l.). A period of massive mountain uplifts started approximately during Oligocene-Miocene boundary and is partly lasting until today. Through tectonic activities and sea level fluctuations, many Mediterranean islands were repeatedly isolated and reconnected to other islands and the mainland, e.g. during the Messinian salinity crisis the Mediterranean dried out almost completely for 1.5 million years until 5 Million years ago. Thereafter the fusion of Pliocene islands led to the formation of a Crete, similar to its present form (Greuter 1979b). Sicily was repeatedly connected to North Africa during the Messinian and possibly again during Pliocene to

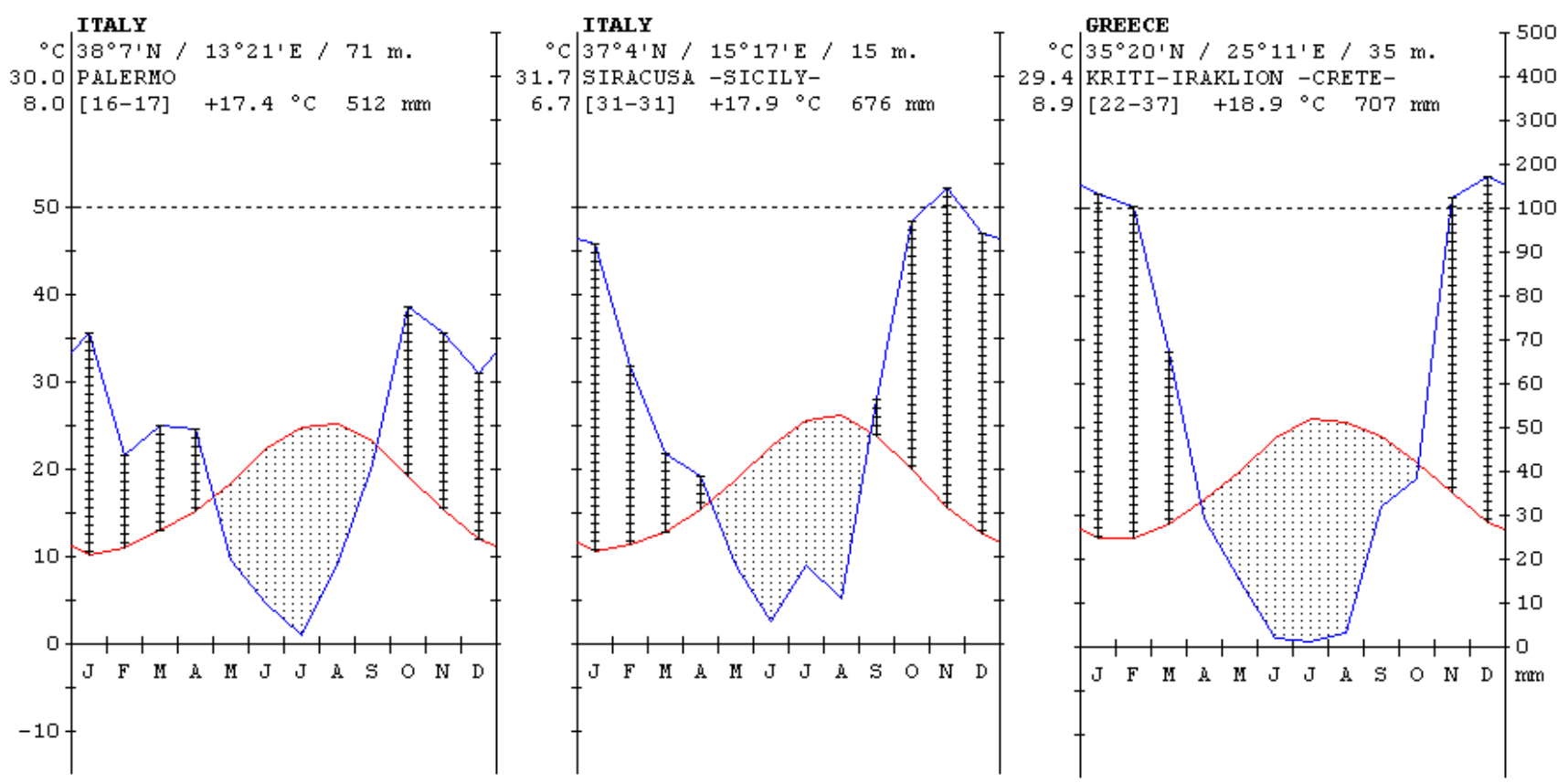

Figure 1.2 Climate diagrams for three weather stations within the study area (Palermo \& Siracusa, Sicily, Italy; Iraklion, Crete, Greece; modified from Rivas-Martínez 1996-2009), all stations are located in the lowlands and share a typical Mediterranean climate with a pronounced water deficit in summer, indicated by a drop of the precipitation (blue line), temperatures (red line) are mild in winter and hot in summer. 
Pleistocene (Azzaroli and Guazzone 1979; Stöck et al. 2008; Troia et al. 2012). Such ancient isolation and release processes, along with ecological gradients, were major drivers of the observed biogeographical patterns (Bonnano and Veneziano 2016; Greuter 1971; Rechinger and RechingerMoser 1951; Troia et al. 2011). For the South Aegean island arc, stretching from Peloponnese Peninsula over Kythera, Antikythera, Crete, Karpathos and Rhodes to South Anatolia, a biogeographical differentiation with gradual species turnover and specific endemics applies; within this row of islands Crete can be separated to a series of four distinct biogeographic units, each characterised by one of the main mountain massifs (Greuter 1971; Rechinger and Rechinger-Moser 1951).

Bedrock types are not equally distributed among the two islands (Figure 1.2); introductions to chapters 2 and 5 give in-depth information concerning geology. For Crete the geological overview maps of Creutzburg et al. (1977) and Seidel et al. (1982) are important references; in a map resolution of 1:50,000 further geological maps are available (HGME 1959-2002). A good geological reference in German is the field guide of Kull (2011). Fierotti (1988) produced a geological overview for Sicily in a map resolution 1:2,500,000. Bedrock types together with erosion, volcanic and tectonic processes shape the geomorphology of the two islands. Sedimentous rocks are characteristic and wide spread on both islands, they dominate valley bottoms, debris fans and coasts; and they feature hilly and plain land surfaces. On Sicily only, the exposed massifs of Mt. Etna, Mt. Lauro and few other places are dominated by volcanic rocks. In many parts of this island evaporites occur, which include massive minable layers of salts, but predominantly consist of gypsum. The latter bedrock occurs on small scales also on Crete. Metamorphic rocks cause usually acidic soil reactions and are merely restricted to Peloritani in Sicily, while they cover significant proportions of mountains and mid altitudes in Central and Western Crete. Limestones dominate large parts of the Cretan mountains and occur scattered in Sicilian Mountains like Madonie, Iblei and Sicani. This bedrock frequently results in a rough topography with diverse surface structures typical for karst landscapes, including dolines, sink holes and caves (Di Maggio et al. 2012; Egli 1991).

Soil layers are usually shallow in karstic landscapes, while merely in hollows and rock crevices a substantial accumulation applies. Such heterogeneous topographic structures feature different ecological conditions in close vicinity, e.g. poor and rich soils, or mesic and xeric conditions, with corresponding vegetation occurring site by site. In mid-altitudes of mountains, where mesic conditions apply, humus-rich soils are scattered allowing for small-scaled agriculture. Most of the agricultural lands though are bound to sediment areas, including softer flysch, in hilly landscapes, 


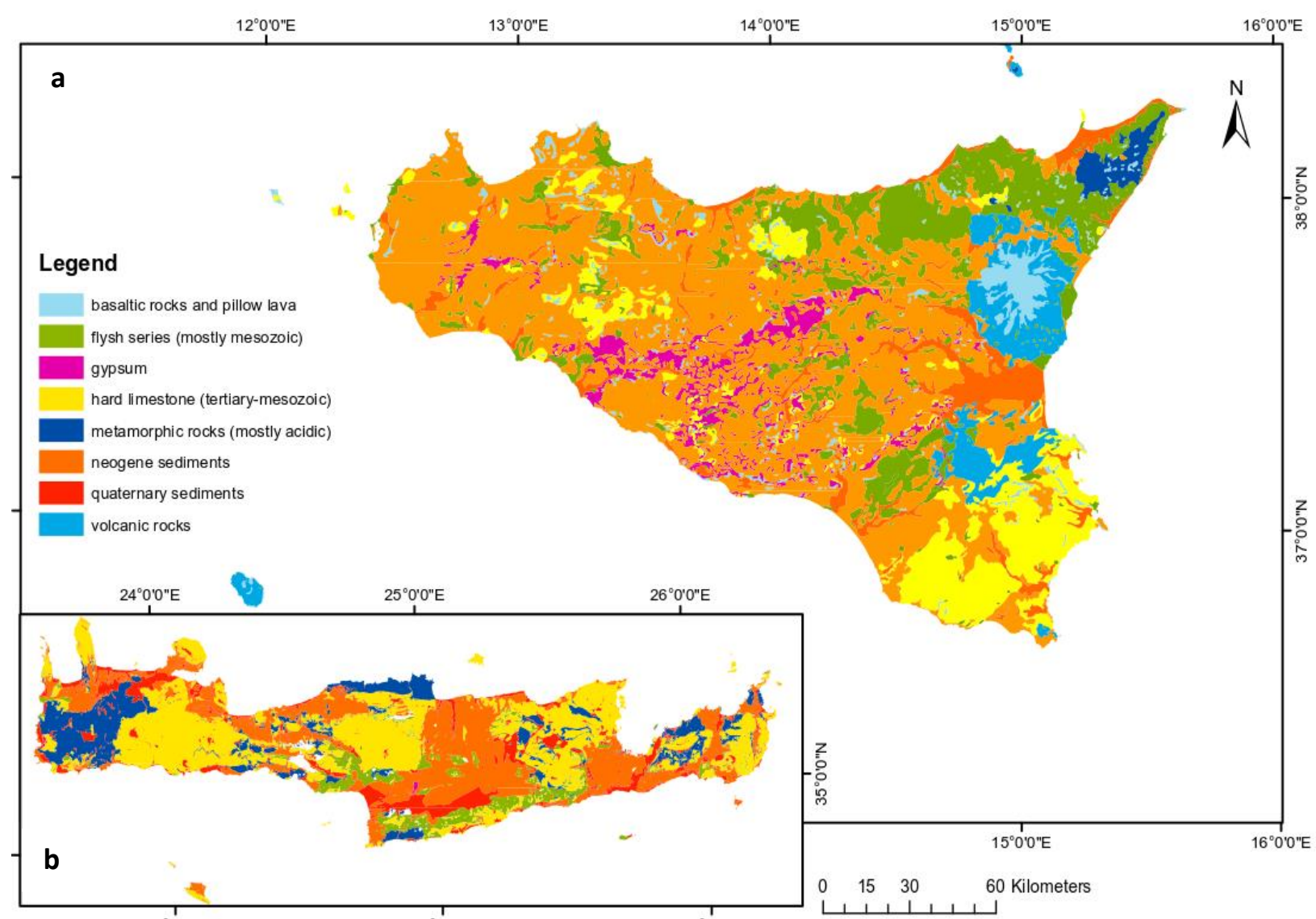

Figure 1.3 Geological maps for Sicily (a) and Crete (b) with a unified and simplified legend, based on published maps (Fierotti 1988; HGME 1959-2002).

plains and valleys, where deeper soils may have accumulated (Jahn and Schönfelder 1995; Venturella 2004). In the lowlands oxidation and long drought periods often hamper soil development, especially where vegetation is reduced and bare soils are exposed. Soils in the Mediterranean are influenced by the special regional climate, the often mountainous topography, significant Saharan dust immissions and long-lasting human impact (Macleod 1980; Suchodoletz et al. 2013; Yaalon 1997).

People have inhabited the Mediterranean area for a long time; through isotope dating the baseline of cultural activities was predated to at least 64,000 years (Hoffmann et al. 2018). The Mediterranean is of high cultural, historical, political and economic importance; several civilisations and empires grew and disappeared around the Mediterranean (Arabian, Cartagan, Egyptian, Greek, Minoan, Ottoman, Roman, Venetian etc.). Landscape and vegetation were thus shaped by millennia of cultivation and settlement (Blondel and Aronson 2010; Grove and Rackham 2001; Quézel 2004). Today coastal zones are densely inhabited, especially where urban centres spread and tourism flourishes. This leads to urban sprawl, land sealing, waste deposition and massive destruction of natural and semi-natural habitats. In contrast many mountainous and hinterland regions with traditional land use were abandoned. Only during the financial crisis of the last years, a reverse trend of people returning to the Mediterranean mountains gets obvious. Intensively irrigated olive and 
fruit plantations are extended in some parts of Crete at least. Goat and sheep densities, being high in parts of Crete, not least through EU-subsidies, maintain old open landscapes but also increase landscape degradation (Lorent et al. 2009). Also in Sicily such contrasting trends of land use intensification and abandonment are omnipresent. Intensification and abandonment of land use differ across the Mediterranean but may likewise threaten biodiversity (Caraveli 2000; Kerckhof et al. 2016; Nainggolan et al. 2012; Plieninger et al. 2013; Zdruli 2014).

Hotspots of biodiversity are considered as focal areas of biodiversity protection. The Mediterranean region is such a biodiversity hotspot in a global perspective, with high numbers of vascular plants and vertebrates (Myers et al. 2000). The authors regarded an extant of $2.362,000 \mathrm{~km}^{2}$ of primary vegetation with about 25,000 plant species. According to Médail and Quézel $(1997,1999)$ the Mediterranean basin features $9-10 \%$ of the global plant species on only $1.6 \%$ of the surface area. Their studies identified strong differences in the distribution of biodiversity within the Mediterranean basin, whereas Sicily and Crete were among the main centres of plant species richness. One reason for this species richness is the high proportion of endemic species. The Mediterranean area hosts strongholds of endemism, i.e. species with local restriction, especially on its islands and in mountain ranges. Endemics and relict stands of plant species are considered to be results of repeated long term environmental changes, which led to spread, retreat, extinction and isolation of species (Greuter 1972, 1979a, 1991, 2001). Environmental conditions in the region recurrently changed in millions of years, e.g. because of macroclimatic changes (Lionello 2012) and pronounced geological dynamics (Faccenna et al. 2014). In this context endemics can be a result of speciation (neoendemism) or survival of once widespread species (paleo-endemism, definitions see Cox and Moore 2010). For further details on Mediterranean endemics see chapter 4 . When the mentioned dynamics were a driving force, there must have been sites of relative stability where taxa could thrive under widely unfavourable conditions. Several such refugial areas were identified within the Mediterranean (Biltekin et al. 2015; Breton et al. 2006; Fuentes-Utrilla et al. 2014b; Gavin et al. 2014; MolinaVenegas et al. 2015; Orain et al. 2013; Petit et al. 2003; Salmerón-Sánchez et al. 2014). Refugial areas may indicate long-term survival of species and they frequently match with biodiversity hotspots (Harrison and Noss 2017; Médail and Diadema 2009).

The high species richness in the Mediterranean is not least featured by the multitude of environmental conditions, forming steep gradients. This allows for organisms with different environmental affinities, and from distinct biomes, to co-occur on small area. Around the Mediterranean basin mountainous areas create topographical and climatical variation, being a key for pronounced gradients and biodiversity (McNeill 1992; Regato and Salman 2008). Other reasons for high taxonomic diversity in the Mediterranean region are influences from neighbouring floristic 
regions. The global position of the region at the edges of main continents allowed floristic elements from South-Euro-Siberian, Saharo-Arabian, Irano-Turanian, Macaronesian, and other elements to mix-up in the region (Pignatti 1978; Schröder 1998); e.g. coastal spots in Sicily and Crete, as well as small islets around both islands comprise various African floristic elements (Bergmeier et al. 1997; 2001; 2011; Brullo and Guarino 2000; Pasta 1997a, 1997b); and in the mountains of both studied islands species and vegetation with (cool) temperate preferences exist (Bauer and Bergmeier 2011; Brullo et al. 2012; Marino et al. 2014).

When the big Mediterranean islands are further compared in their species composition, similarities and differences get obvious (Junikka et al. 2006). An ecological comparison for woody species in the Mediterranean region was performed as well (Quézel 1979a; Quézel and Médail 2003). For the biggest Mediterranean islands including Sicily and Crete Quézel (1988) gave a phytogeographical comparison. The latter author also compared the forest communities of Cyprus and Crete and extensively discussed species composition and distribution within the Eastern Mediterranean and beyond (Quézel 1979b); thereby he consulted various studies, e.g. in Southern Greece (Barbéro and Quézel 1976), in Anatolia (Akman et al. 1978) and in the Levant (Barbéro et al. 1976). Brullo et al. (2001b) write about coniferous woodlands in high altitudes for the Central and Eastern Mediterranean. Forest communities in Northern Algeria are related to those with wider Mediterranean distributions (Meddour et al. 2017). An overview to coniferous plant communities across Central and Eastern Mediterranean is given in Brullo et al. (2001b); a wider scale was also addressed for Quercus ilex woodlands by Barbéro et al. (1992). The ecology of Cretan woody vegetation and its species are discussed in various studies (e.g. Barbéro and Quézel 1980; Bauer and Bergmeier 2011; Bergmeier and Goedecke 2017; Egli 1998, 2000). For Sicily woody vegetation and its species composition were also described and analysed in various studies (e.g. Badalamenti et al. 2018; Brullo et al. 1995; 1999; Brullo and Marcenò 1985; Guarino and Pasta 2017; Marcenò and Guarino 2015; Marino et al. 2014).

Even though the last paragraphs comprised various studies for woody species, vegetation and ecology in the Mediterranean region, important scientific knowledge gaps for woodlands and beyond exist there (Scarascia-Mugnozza et al. 2000). The Mediterranean, not least due to its outstanding biological and environmental diversity and for its unique biogeographical features, is of high overall significance for the conservation of diversity across scales. The Mediterranean biodiversity is protected by major contracts and conventions (CBD 2012; European Commission - DG Environment 2013) and this gets especially important under globally changing conditions (Heywood 1999; Médail 2017). This thesis aims at contributing to the scientific investigation in the Mediterranean and thus at supporting conservation and management. 


\section{Analysed datasets}

One main database used (in chapter $2,4,5$ ) is the personal floristic database of Ralf Jahn. In it he gathered information on the distribution of plant species in the Cretan area (Crete, Karpathos, Kasos, Saria, and further small islands and islets in the South Aegean). The database is a collection of around 900,000 sets of locations of plant taxa, containing their coordinates and a variety of additional sitebased data gathered in the field. The collected information came from field studies and extractions from literature, details in terms of woody species are listed in chapter 2, 4 and 5. Initially, the preparation of the flora of Crete in German language made the author study the region (Jahn and Schönfelder 1995). Further publications of the data of R. Jahn are considered in several peer reviewed articles (Amigues and Greuter 2004; Bergmeier et al. 1997; 2001; 2011; Greuter et al. 2002; Jahn 2003; Mucina et al. 2009) and the data are included in a series of books (Strid 2016; Strid and Strid 2009-2013; Strid and Tan 2003). A second type of analysed datasets is the plot based database of Prof. Dr. E. Bergmeier containing more than 6,500 vegetation relevées, which is included as KRITI (Bergmeier 2012) in the European Vegetation Archive (EVA; Chytrý et al. 2016). It contains plots with all occurring species and their abundance from various vegetation units. For a study on the endemic Z. abelicea several records from literature and unpublished collections of records were combined (Table 4.1). For the more global study on the ecology of Cretan woody species the latter sources, were used as well as other published and unpublished data (Table 2.1). For Sicily a database of vegetation relevées was used comprising records from various sources (Table A 5.3). Relevées from all mentioned sources follow Braun-Blanquet methodology and the species are recorded in the extended 9-grade scale (Wilmanns 1998), plot sizes varied within the frame proposed by Chytrý \& Otýpková (2003). For one study composition data was analysed (chapter 3). All studies are subjected to woody plants, being selected as elements of potential climax vegetation, for their key role in ecosystems, but also for reasons of data availability and data quality.

Further information for the conservation status of habitats comes from a data survey performed in the framework of the European Union Natura 2000 network and the connected monitoring and mapping campaigns (Directive 92/43/EWG). From 2013 to 2015 a team of foresters and biologists was in charge with the monitoring of the conservation status for the habitats from Annex I of the Natura 2000 directive, which led to an evaluation and quantification of habitat types for all Greece. Also for all Natura 2000 protected areas in Crete and surrounding islets habitat polygons were assigned, which were stored as shape-files in a GIS. The abundance of typical species for each habitat was independently assessed for these polygons and for reference plots within. A specific protocol sheet for each habitat type was filled out during this assessment (Appendix Figure A 3.1; Field protocol for habitat type $92 \mathrm{CO}$ discussed in chapter 3). 
Abiotic variables for the two regions Crete and Sicily are as well stored in a GIS environment. Datasets containing precipitation and temperature data on a 1 ArcSec-scale $\left(\sim 1 \mathrm{~km}^{2}\right)$ used in the chapters 2, 3 and 4 were published by the European Food Safety Agency (European Commission Joint Research Centre 2012; Hijmans et al. 2005). Chelsa-climate data applied in chapter 5 refer to Karger et al. (2016). Further variables are calculated based on a Digital Elevation Model (DEM) available with a pixel resolution of $30 \mathrm{~m}$ at the website of the European Environmental Agency (EEA 2015). Information on the geological substrata was created for Crete using digitized geological maps with a map resolution of 1:50,000 (HGME 1959-2002). These maps were revised and unified for all the maps from different years and mapping institutions sources (Manthey and Goedecke, unpublished). To be able to work on a common geological base map for Crete and Sicily, the latter dataset was further simplified and combined with the digital geological map of Fierotti (1988); a unified legend scheme was produced therefore (Goedecke, Marcenò, Guarino, Jahn and Bergmeier, unpublished).

\section{Chapter overview and problems addressed}

This thesis contains studies on different methodological basis, so data base queries, an ecological classification and a vegetation classification were applied as well as species distribution modelling. Therewith the thesis gives examples for analytical approaches applicable for floristic and plantsociological data bases. It addresses problems in plant ecology, population ecology, vegetation ecology, biogeography and nature conservation. The study region Crete (chapters 2-4) together with Sicily (chapter 5) comprises $35,600 \mathrm{~km}^{2}$, and thus this spatial frame allows studies on various scale levels (supra-regional, regional, sub-regional). The diverse spatial frame in combination with different study objects (species, populations, vegetation units) allows to address a multitude of opportunities for the analyses of big datasets of floristic and plant-sociological data and to highlight limitations.

The presented approach in the second chapter aims to display spectra of site conditions for a large amount of individual sites for the woody species in a region. The methodology helps to assess species niches, through combining precise coordinates for large numbers of species records with site information in a geographical information system (GIS). Following questions are answered:

Which combinations of landscape-related site parameters (macroclimate, topoclimate and bedrock type) are associated with species and ecological species groups? Do these species groups reflect vegetation patterns?

The case study in the third chapter focusses on the regionally diverse vegetation of Platanus orientalis woodlands, presents results of a vegetation classification, a classical application in plantsociology and features a data query for a conservation status assessment. Aims of the study are: 
To explore the variation in vascular plant species composition and to describe the plant communities of Platanus orientalis woodlands in Crete; to provide a survey of the current quality and conservation status and of the impacts affecting the present state and the future of the Platanus woodland ecosystems.

In the fourth chapter models are used to predict species distribution. In a numerical algorithm locations of the species are combined with digital map data, aiming to extrapolate suitability of sites across the study area. In this context the distinct (meta)populations of the endemic species Zelkova abelicea from the main mountain ranges of Crete were ecologically analysed. We ask the following research questions:

How much do isolated populations of Zelkova abelicea differ in ecology, as expressed by abiotic variables? Are these differences related to known genetic patterns? Which environmental factors influence species distribution models most? How do predicted distribution patterns relate to known records? Do combined (meta)population samples improve the predictive value for known neighbouring populations?

In the fifth chapter species distribution modelling is performed for databases of species records for Crete and Sicily. Woody species from wide-spread maquis vegetation are compared by reciprocal extrapolation, whereby training of models applies for one island and the quality of distribution models is tested on the other island. Therewith following questions are answered:

To what extent can a model be calibrated on one island be a good predictor of the distribution of a given species on another island? Which are the most influential variables in our distribution modeling and are they the same on both islands for a given species? Is the observed shifting ecological behaviour (and related occurrence probability) of a given species more influenced by climatic, by geomorphological or by edaphic drivers?

The final sixth chapter concludes the overlapping issues of the four studies. Results are jointly discussed in relation to other studies. Subsections address species ecology, the role of intraspecific differences, ecological species groups in relation to vegetation units, and the assessment of complex environments. Further perspectives and ideas are discussed comprising neighbouring disciplines. Finally limitations concerning species-environment relations, intraspecific genetics and data bias are discussed. 


\section{Chapter 2: $\quad$ Quantified ecology and co-occurrence of Mediterranean woody species in a landscape context}

Goedecke, F.; Jahn, R. \& Bergmeier, E. (2018) Quantified ecology and cooccurrence of Mediterranean woody species in a landscape context. Plant Ecology 219: 481-496. 


\title{
Quantified ecology and co-occurrence of Mediterranean woody species in a landscape context
}

\author{
Abstract \\ Understanding co-occurrence and ecological affinities of plant species is essential in vegetation and \\ landscape ecology. In a case study, we analysed distribution records with high data density of all \\ commonly occurring tree and shrub species of Crete (Greece) with offshore islands. We present the \\ ecological range of widespread and more range-restricted species in the Mediterranean area, \\ visualising their affinities for macroclimate, topoclimate and geology by means of an ecological \\ heatmap. Complete linkage classification of combined ecological spectra revealed groups of \\ generalist species with broad ecological amplitude, groups related to zonal vegetation and chiefly \\ dependent on elevation, and species of azonal vegetation grouped mainly by topography and \\ substrates. Species and ecological groups with high affinity may be indicative of (a combination of) \\ site features. Our re-evaluation of plant distribution records links plant geographical and ecological \\ information, and thereby complements expert habitat and species assessments. Our case study \\ provides deeper understanding of ecological patterns, and at the same time allows for comparison \\ and extrapolation to other biomes.
}

Keywords: ecological heatmap; geospatial data; heatload; location-based geodata extraction; realised niche; topographical wetness index 


\section{Introduction}

Understanding plant species-environment relations is fundamental in ecology and in applications such as forestry, nature conservation and restoration. Plant physiological and environmental measures along with records of single species or plant communities in plots and transects are used to assess such relations. However, in situ measurements providing quantitative primary data may be unfeasible or too costly to get in difficult terrain. Alternatively, ecological preferences are often extrapolated from co-occurring species (Abs et al. 2008; Filella and Peñuelas 2003). Field records of site conditions such as soil properties (Ghosh et al. 2016) can be assigned to species that grow on the site. Ellenberg (1974) was among the first to class Central European plant species in ecological groups and to define indicator values, which inspired vegetation ecologists in other regions (Böhling et al. 2002; Guarino et al. 2012; Pignatti et al. 2005). Indicator values were proven and tested by field measures in various attempts (Marcenò and Guarino 2015; Schaffers and Sýkora 2000; Schwabe et al. 2007), but they remain essentially expert-based.

Location-based extractions of site features deliver ecological information about species and thus attempt to determine the realised niche (Hutchinson 1957). The accuracy of this approach depends on scale, quality and quantity of data. Recently, amounts and accessibility of distribution data have continuously increased, not least because niche modelling and distribution modelling are gaining importance (Calabrese et al. 2014; Elith et al. 2006; Reger et al. 2014) and high-resolution environmental datasets are increasingly available (Barry and Blanken 2016; Berry et al. 2016; Byrne and Pickard 2016; Copeland and Harrison 2015). Quantified species-environment relations were assessed in several regions (e.g. Aronson et al. 2015; Birnbaum et al. 2015; Parra-Quijano et al. 2012). Bilton et al. (2016) defined climatic niche groups to predict plant community responses to climate change. The analysis of plant species chorology in conjunction with ecological indicator values revealed coarse-grained landscape patterns (Korsch 1999). The latter approach is an example for quantified landscape classification, just like the study of Bölöni et al. (2011), who used occurrences of habitats within a country-wide grid. In a landscape context Corney et al. (2004) and Olthoff et al. (2016) assessed the ecology of forest species by using forest inventory plots. Both studies evaluated the importance of environmental parameters for woody vegetation and species distribution, the latter study additionally discussed niche separation. The ecology of co-occurring species relates vegetation to environmental variables in manifold ways: vegetation zones are coupled to macroclimatic gradients (Bazan et al. 2015), and vegetation depends on soil, topography and bedrock (Kopecký and Čížková 2010; Kosmas et al. 1993; Kruckeberg 2002). Environmental filtering and biotic interactions may influence patterns of co-occurrences on particular sites (for a review see Kraft et al. 2015). Environmental parameters influence vegetation patterns but reversely woody species have effects on a wide range of environmental conditions and processes such as microclimate, soil 
formation and nutrient accumulation (Ludwig and Tongway 1995; Shachak et al. 2008). Our quantifying approach can thus help to understand the formation of vegetation and productivity patterns in a landscape context.

Ecological surveys on woody vegetation exist for the Eastern Mediterranean region on small scale, based on different methods, and for particular species and vegetation types (e.g. Bergmeier 1995; Bergmeier and Goedecke 2017; Matthäs 1988; Søndergaard and Egli 2006). Several papers and reviews discussed woody species and their vegetation in the landscape context of Crete as a result of extensive field surveys (e.g. Barbéro and Quézel 1976, 1980; Bauer and Bergmeier 2011; Greuter 1975; Rechinger and Rechinger-Moser 1951; Zohary and Orshan 1965). A wider scale was applied for the ecological indicator assessment for the South Aegean (Böhling et al. 2002), for which the authors combined vegetation plots with on-site measures and soil analysis. We chose the Aegean island of Crete to quantify woody plant relations to macroclimate, bedrock type and topography. Crete is most suitable for such a case study as it comprises both high environmental and floristic diversity (Fielding and Turland 2005; Jahn and Schönfelder 1995; Rackham and Moody 1996). By visualising ecological spectra of species and by revealing co-occurrence patterns of species groups in a landscape context we add to current plant ecological knowledge. The use of a big dataset of records dispersed along steep ecological gradients allows for an objective quantification of site features across habitats. Our results allow for various applications as we related well-known taxa and mostly apparent site features on landscape scale. We addressed the following research questions: Which combinations of landscape-related site parameters (macroclimate, topoclimate and bedrock type) are associated with species and ecological species groups? Do these species groups reflect vegetation patterns?

\section{Methods}

\section{Study area and species addressed}

Crete (South Aegean, Greece), with a terrestrial surface area of $8729 \mathrm{~km}^{2}$, is the fifth largest Mediterranean island. While annual and local variation is high, the climate characteristics in the lowlands and mid altitudes are typically Mediterranean, with precipitation chiefly in the mild winter half year and a pronouncedly dry and hot summer (Jahn and Schönfelder 1995; Lionello 2012). Longer-lasting snow and frost periods occur in the high mountains. The island's geological uplift at the edge of a subduction zone exposed a variety of rock types and shaped a pronounced relief, with deep gorges and several high mountain massifs, interrupted by Neogene plains (Kull 2011). While woodlands are fragmented and occur mainly in the mountains (Bauer and Bergmeier 2011), shrublands (phrygana and maquis) predominate. About 1800 vascular plant taxa have been recorded, with about $10 \%$ being endemic to the island (Fielding and Turland 2005; Jahn 2003). The woody flora 
includes about 53 species of trees and taller shrubs, excluding dwarf shrubs. For this study, we gathered more than 13500 records of all native tree and shrub species present on Crete and its surrounding islets. Data were compiled from databases derived from various types of field surveys (Table 2.1). Older records without precise coordinates were ignored. To remove misplaced records we checked all locations visually using high-resolution satellite imagery (Ktimatologio 2016). Species records closer than $100 \mathrm{~m}$ were merged to reduce spatial auto-correlation and sampling bias. We disregarded about 16 rare woody species with 10 or fewer reliable records. After data validation we considered a total of 9692 records from 37 species of trees and higher shrubs (Table 2.2), covering the woody-vegetation in almost all of the islands' landscapes. The biological characteristics of the

Table 2.1 Databases contributing to this study, collector names indicated for > 100 records; with survey time span, related publication, data type, and number of records.

\begin{tabular}{|c|c|c|c|c|}
\hline Author & Sampling period & Publication & Data type & Records \\
\hline Bergmeier, E. & $1989-2014$ & $\begin{array}{l}\text { Bergmeier (2012) } \\
+ \text { Unpublished material }\end{array}$ & relevées & 3172 \\
\hline Jahn, R. & $1989-2014$ & Unpublished material & floristic/ relevées & 2728 \\
\hline Natura 2000 team & 2013-2015 & Unpublished material & vegetation mapping & 739 \\
\hline Risse, $\mathrm{H}$. & 1981-1986 & Unpublished material & floristic & 354 \\
\hline Egli, B. & $1998-2000$ & $\begin{array}{l}\text { Egli }(2000) \\
+ \text { Unpublished material }\end{array}$ & forest monitoring & 345 \\
\hline Greuter, W. & $1960-1983$ & $\begin{array}{l}\text { Greuter (1967) } \\
+ \text { Unpublished material }\end{array}$ & floristic & 318 \\
\hline Matthäs, U. & $1982-1986$ & Matthäs (1988) & floristic & 253 \\
\hline Zaffran, J. & 1964-1967 & Unpublished material & floristic & 162 \\
\hline miscellaneous & - & - & floristic/ relevées & 1621 \\
\hline total & & & & 9692 \\
\hline
\end{tabular}

studied species are given in Table 2.2. Despite the large number of records, data deficiencies occur, chiefly in cultivated and urban areas and in inaccessible terrain (Figure 2.1). The nomenclature follows Dimopoulos et al. $(2013,2016)$. Twenty species have a wide Mediterranean distribution, while eight species are restricted to the Eastern Mediterranean. Zelkova abelicea is endemic to the island of Crete. Many species occur as either shrubs or trees, i.e. they have high phenotypical variation depending on site conditions and management.

\section{Environmental data and habitat affinity}

Abiotic site variables and their data sources are given in Table 2.3. Map production and the handling of spatial data were performed in ArcGIS (ESRI 2013). Relief indices were calculated using the Geomorphometry and Gradient Metrics Toolbox (Evans et al. 2014). The wetness index (compound topographic index or cti) accounts for water movement; for each grid cell the natural logarithm of the quotient of upstream contributing surface area and the tangent of the slope within the grid cell is calculated, resulting in high values for sink areas (Gessler et al. 1995). The heatload index (heatload) maximises in steep south-western slopes (McCune and Keon 2002); and the solar radiation index 
Table 2.2 Mediterranean woody species sampled on Crete; see Dimopoulos et al. $(2013,2016)$ for nomenclature and chorology: Bk Balkan, EA European-SW Asian, EM E Mediterranean, Eu European, $M A$ Mediterranean/ Atlantic, Me Mediterranean, ME Mediterranean-European, MS Mediterranean-SW Asian, Pt Paleotemperate; * life form among phanerophytes (P) and chamaephytes (Ch): $N$ nano, caesp cespitose, pulv pulvinate, rept reptant, scap scapose (Jahn and Schönfelder 1995).

\begin{tabular}{|c|c|c|c|c|}
\hline taxon name & abbreviation & family & chorology & life form* \\
\hline Acer sempervirens $\mathrm{L}$. & Acesem & Aceraceae & EM & $\begin{array}{l}\text { P caesp/ P } \\
\text { scap }\end{array}$ \\
\hline Arbutus andrachne L. & Arband & Ericaceae & EM & $\begin{array}{l}\mathrm{P} \text { caesp/ P } \\
\text { scap }\end{array}$ \\
\hline Arbutus unedo L. & Arbune & Ericaceae & Me & $\begin{array}{l}\text { P caesp/ P } \\
\text { scap }\end{array}$ \\
\hline Berberis cretica L. & Bercre & Berberidaceae & EM & NP \\
\hline Castanea sativa Mill. & Cassat & Fagaceae & $\mathrm{Eu}$ & P scap \\
\hline Ceratonia siliqua L. & Cersil & Fabaceae & $\mathrm{Me}$ & $\begin{array}{l}\text { NP/ P caesp/ } \\
\text { P scap }\end{array}$ \\
\hline Crataegus monogyna Jacq. & Cramon & Rosaceae & $\mathrm{Pt}$ & $\begin{array}{l}\mathrm{P} \text { caesp/ P } \\
\text { scap }\end{array}$ \\
\hline Cupressus sempervirens L. & Cupsem & Cupressaceae & EM & P scap \\
\hline Erica arborea L. & Eriarb & Ericaceae & $\mathrm{Me}$ & NP/ P caesp \\
\hline Euphorbia dendroides L. & Eupden & Euphorbiaceae & $\mathrm{Me}$ & NP/ P scap \\
\hline Ficus carica L. & Ficcar & Moraceae & MS & P scap \\
\hline $\begin{array}{l}\text { Juniperus macrocarpa Sm. in Sibth. \& } \\
\text { Sm. }\end{array}$ & Junmac & Cupressaceae & Me & $\begin{array}{l}\text { NP/ P caesp/ } \\
\text { P scap }\end{array}$ \\
\hline $\begin{array}{l}\text { Juniperus oxycedrus subsp. deltoides } \\
\text { (R.P. Adams) N.G. Passal. in } \\
\text { Bernardo, Passalacqua \& Peruzzi }\end{array}$ & Junoxy & Cupressaceae & EM & $\begin{array}{l}\text { NP/ P caesp/ } \\
\text { P scap }\end{array}$ \\
\hline Juniperus turbinata Guss. & Juntur & Cupressaceae & MA & $\begin{array}{l}\text { NP/ P caesp/ } \\
\text { P scap }\end{array}$ \\
\hline Laurus nobilis L. & Launob & Lauraceae & Me & $\begin{array}{l}\text { P caesp/ P } \\
\text { scap }\end{array}$ \\
\hline Myrtus communis L. subsp. communis & Myrcom & Myrtaceae & $\mathrm{Me}$ & $\mathrm{P}$ caesp \\
\hline Nerium oleander L. subsp. oleander & Nerole & Apocynaceae & $\mathrm{Me}$ & $P$ caesp \\
\hline Olea europaea L. subsp. sylvestris & Oleeur & Oleaceae & $\mathrm{Me}$ & $\begin{array}{l}\text { NP/ P caesp/ } \\
\text { P scap }\end{array}$ \\
\hline Phillyrea latifolia L. & Philat & Oleaceae & $\mathrm{Me}$ & $\begin{array}{l}\text { NP/ P caesp/ } \\
\text { P scap }\end{array}$ \\
\hline Phoenix theophrasti Greuter & Phothe & Arecaceae & EM & P scap \\
\hline Pinus brutia Ten. & Pinbru & Pinaceae & $\mathrm{Me}$ & P scap \\
\hline Pistacia lentiscus L. & Pislen & Anacardiaceae & $\mathrm{Me}$ & $\begin{array}{l}\text { NP/ P caesp/ } \\
\text { P scap }\end{array}$ \\
\hline $\begin{array}{l}\text { Pistacia terebinthus subsp. } \\
\text { terebinthus L. }\end{array}$ & Pister & Anacardiaceae & Me & $\begin{array}{l}\text { P caesp/ P } \\
\text { scap }\end{array}$ \\
\hline Platanus orientalis L. & Plaori & Platanaceae & EM & P scap \\
\hline Prunus prostrata Labill. & Prupro & Rosaceae & $\mathrm{Me}$ & Ch rept \\
\hline Prunus webbii (Spach) Vierh. & Pruweb & Rosaceae & EM & $P$ caesp \\
\hline Pyrus spinosa Forssk. & Pyrspi & Rosaceae & $\mathrm{Me}$ & $\begin{array}{l}\text { NP/ P caesp/ } \\
\text { P scap }\end{array}$ \\
\hline Quercus coccifera L. & Quecoc & Fagaceae & Me & $\begin{array}{l}\text { P caesp/ P } \\
\text { scap }\end{array}$ \\
\hline Quercus ilex L. & Queile & Fagaceae & $\mathrm{Me}$ & $\begin{array}{l}\text { P caesp/ P } \\
\text { scap }\end{array}$ \\
\hline $\begin{array}{l}\text { Quercus ithaburensis subsp. } \\
\text { macrolepis (Kotschy) Hedge \& Yalt. in } \\
\text { Greuter }\end{array}$ & Queith & Fagaceae & $\mathrm{Me}$ & P scap \\
\hline Quercus pubescens Willd. & Quepub & Fagaceae & ME & $\begin{array}{l}\text { P caesp/ P } \\
\text { scap }\end{array}$ \\
\hline
\end{tabular}


continued

\begin{tabular}{|c|c|c|c|c|}
\hline $\begin{array}{l}\text { Rhamnus lycioides subsp. oleoides } \\
\text { (L.) Jahand. \& Maire }\end{array}$ & Rhalyc & Rhamnaceae & $\mathrm{Me}$ & NP \\
\hline $\begin{array}{l}\text { Rhamnus saxatilis subsp. prunifolia } \\
\text { (Sm.) Aldén in Strid }\end{array}$ & Rhasax & Rhamnaceae & Bk & Ch rept \\
\hline Salix alba L. & Salalb & Salicaceae & EA & P scap \\
\hline Styrax officinalis L. & Styoff & Styracaceae & $\mathrm{Me}$ & P caesp \\
\hline Vitex agnus-castus L. & Vitagn & Lamiaceae & MS & P caesp \\
\hline Zelkova abelicea (Lam.) Boiss. & Zelabe & Ulmaceae & endemic & $\begin{array}{l}P \text { caesp/ P } \\
\text { scap }\end{array}$ \\
\hline
\end{tabular}

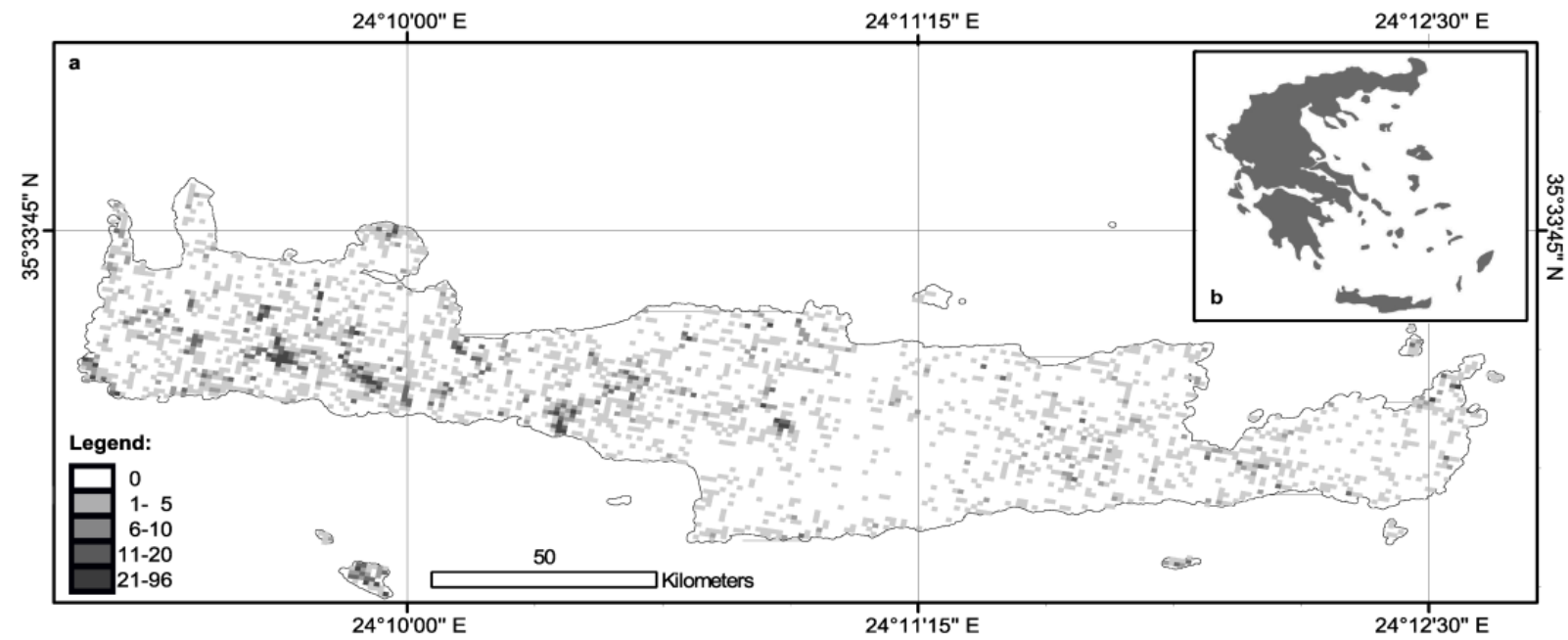

Figure 2.1 The island of Crete with (a) density of woody species records visualised in 1-km-grid cells and (b) its position within Greece.

Table 2.3 Abiotic site parameters and raster data used in this study.

\begin{tabular}{|c|c|}
\hline Dataset & Source \\
\hline $\begin{array}{l}\text { (i) altitude, digital elevation model (DEM), based on ASTER } \\
\text { satellite data, 30m raster resolution, elevation a.s.I. }[\mathrm{m}]\end{array}$ & EEA (2015) \\
\hline \multicolumn{2}{|l|}{ following derivatives are calculated from DEM: } \\
\hline $\begin{array}{l}\text { (ii) solarrad, point solar radiation for whole year by summed-up } \\
\text { monthly values }\left[\mathrm{MW} / \mathrm{m}^{2} / \mathrm{yr}\right]\end{array}$ & $\begin{array}{l}\text { Rich et al. (1994); Fu and Rich } \\
\text { (2002) }\end{array}$ \\
\hline (iii) cti, compound topographic index [no unit] & Gessler et al. (1995) \\
\hline $\begin{array}{l}\text { (iv) heatload, heatload index, } 3^{\text {rd }} \text { equation, constant } \\
\text { latitude }=35.5^{\circ} \text { [no unit] }\end{array}$ & McCune and Keon (2002) \\
\hline (v) slope $\left[^{\circ}\right]$ & Burrough and McDonell (1998) \\
\hline worldclim climate data, 30arcsec resolution $(=\sim 1 \mathrm{~km})$ & Hijmans et al. (2005) \\
\hline (vi) tmean, mean annual temperatures $\left[{ }^{\circ} \mathrm{C}\right]$ & \\
\hline (vii) prec_ann, mean annual precipitation sum [mm] & \\
\hline
\end{tabular}

(solarrad) sums annual solar energy, with mountain shade (viewshed restriction) causing lowered values (Rich et al. 1994). Geological substrates were digitised from published maps (HGME 19592002). Polygons $(n=7505)$ were assigned to twelve major stratigraphic geological units (Table 2.4). 
We generalised geological units in accordance with overview maps (Creutzburg et al. 1977; Seidel et al. 1982).

Table 2.4 Geological units in Crete; from digitalisation of geological maps 1:50,000 (HGME 19592002), area $\left[\mathrm{km}^{2}\right]$ and percentages of total island surface are displayed.

\begin{tabular}{llll}
\hline Geological unit & Abbreviation & Area $\left[\mathrm{km}^{2}\right]$ & $\%$ \\
\hline Neogene sediments & $\mathrm{N}$ & 2422.6 & 29.0 \\
Tripolitza limestone & TZ & 1264.4 & 15.1 \\
Phyllite-quartzite & $\mathrm{PQ}$ & 1076.3 & 12.9 \\
Plattenkalk limestone & $\mathrm{PK}$ & 1002.2 & 12.0 \\
Quaternary sediments & $\mathrm{Q}$ & 914.3 & 11.0 \\
Tripali limestone & TR & 539.3 & 6.5 \\
Pindos limestone & PD & 314.6 & 3.8 \\
Pindos flysch & PD-F & 292.8 & 3.5 \\
Tripolitza flysch & TZ-F & 290.3 & 3.5 \\
Ophiolites & $\mathrm{O}$ & 91.2 & 1.1 \\
Asteroussia crystalline rocks & AS & 71.9 & 0.9 \\
Asteroussia flysch & AS-F & 57.1 & 0.7 \\
\hline
\end{tabular}

To relate established knowledge and the ecological groups found in the present study, species cooccurrence patterns were compared to widely used phytosociological schemes (Mucina et al. 2016), EUNIS habitats (Janssen et al. 2016), and to Natura 2000 habitat types (European Commission 2013). We assessed the relative frequency of our studied species within the vegetation units of these schemes, addressing four levels of abundance (usually not occurring, occasional, common, (partly) dominant); therefore we used the latter references, our field notes and the works of Barbéro and Quézel (1976, 1980), Bauer and Bergmeier (2011), Bergmeier (1995), Bergmeier and Goedecke (2017).

\section{Statistical analyses}

Environmental complexity and its relations to species occurrences were visualised by Principle Component Analysis (PCA), using standard settings in Canoco (Ter Braak and Šmilauer 2012). We used the environmental variables given in Table 2.3 as a basis for the ordination; species and bedrock types were then added as supplementary variables. We calculated the first four canonical axes and applied centering and standardizing of data. All other plots were prepared using R version 3.24 ( $R$ Development Core Team 2017). Boxplots were used to display variation of numerical parameters. We produced an ecological heatmap with species grouped by similarity of spectra of environmental data (heatmap.2(), gplots package, Warnes et al. 2016). Environmental data for this plot comprised means of continuous environmental parameters and frequencies of geological substrates. These values were standardized in a first step [1] to create the heatmap; therewith underlying relative frequencies may increase the relative importance of environmental aspects, e.g. rare geological substrates are 
weighed higher in relation to more abundant ones. In a second step [2] we increased simplicity of the plot by grouping very similar bedrock types using a classification (complete linkage clustering, dendrogramm not shown). Thereafter four pairs of bedrock types with very similar patterns were merged (e.g. Asteroussia crystalline rock (AS) and Tripolitza flysch (TZ-F) to AS_TZ-F). This reduced the twelve geological units to eight columns in the matrix. In a last step [3] species in the final heatmap were grouped using another complete linkage clustering based on the reduced set of bedrock types and all continuous environmental parameters. The latter method outperformed several other clustering algorithms, in giving consistent species patterns with little chaining effect. We separated the classification tree along a uniform cut level of similarity, where a clear differentiation between clusters applied.

\section{Results}

\section{Ecological species groups}

Complete linkage clustering revealed seven groups of woody species, with two to nine species each. While group [1] comprises mainly widespread lowland species (Figure 2.2, Figure A 2.1), occurring in a variety of habitats and vegetation units (Figure 2.4), the others often depend on specific and infrequent habitat conditions. Group [1] comprises several fruit trees such as olive, carob and fig. The latter grows on exposed slopes, but also as subcanopy tree in alluvial forests. Pistacia lentiscus is the most frequently recorded woody plant in the lowlands and occurs in several vegetation units (Figure 2.4). Pinus brutia, Quercus coccifera, Rhamnus lycioides subsp. oleoides and Euphorbia dendroides grow chiefly on dry limestone slopes with low annual precipitation. Phillyrea latifolia and Rhamnus occur usually in mixed evergreen woodlands and shrublands and have raised relative affinity to tripolitza limestone. Group [2] includes two species with a regional preference for low heatload and a relative affinity to ophiolites. While Quercus pubescens is a woodland tree, Crataegus monogyna is a shrub often associated with these oak woods. Group [3] contains deciduous Pyrus spinosa, Prunus webbii and Vitex agnus-castus, being frequent on various kinds of flysch and on Asteroussia crystalline rock.

All species tolerate disturbance and are common in anthropogenic habitats. Vitex occurs chiefly in (dry) river beds, on alluvial fans and other disturbed sites down to the coastline (Figure A 2.2). Group [4] comprises two drought-tolerant extensive-rooted junipers, which occur scattered on sandy and other permeable substrates along the Cretan coasts and on a few of the small islands. Group [5] comprises seven riparian species - as indicated by the highest cti values - as well as Quercus ithaburensis subsp. macrolepis, a non-riparian species growing on deep soils. Platanus orientalis and Salix alba are riparian trees, the latter in wide stream beds, as indicated by low slope angle and 
highsolar radiation. Nerium oleander and Myrtus communis are riparian shrubs in the undergrowth of Platanus gallery wood or without tree canopy in seasonally dry valleys. Styrax officinalis and

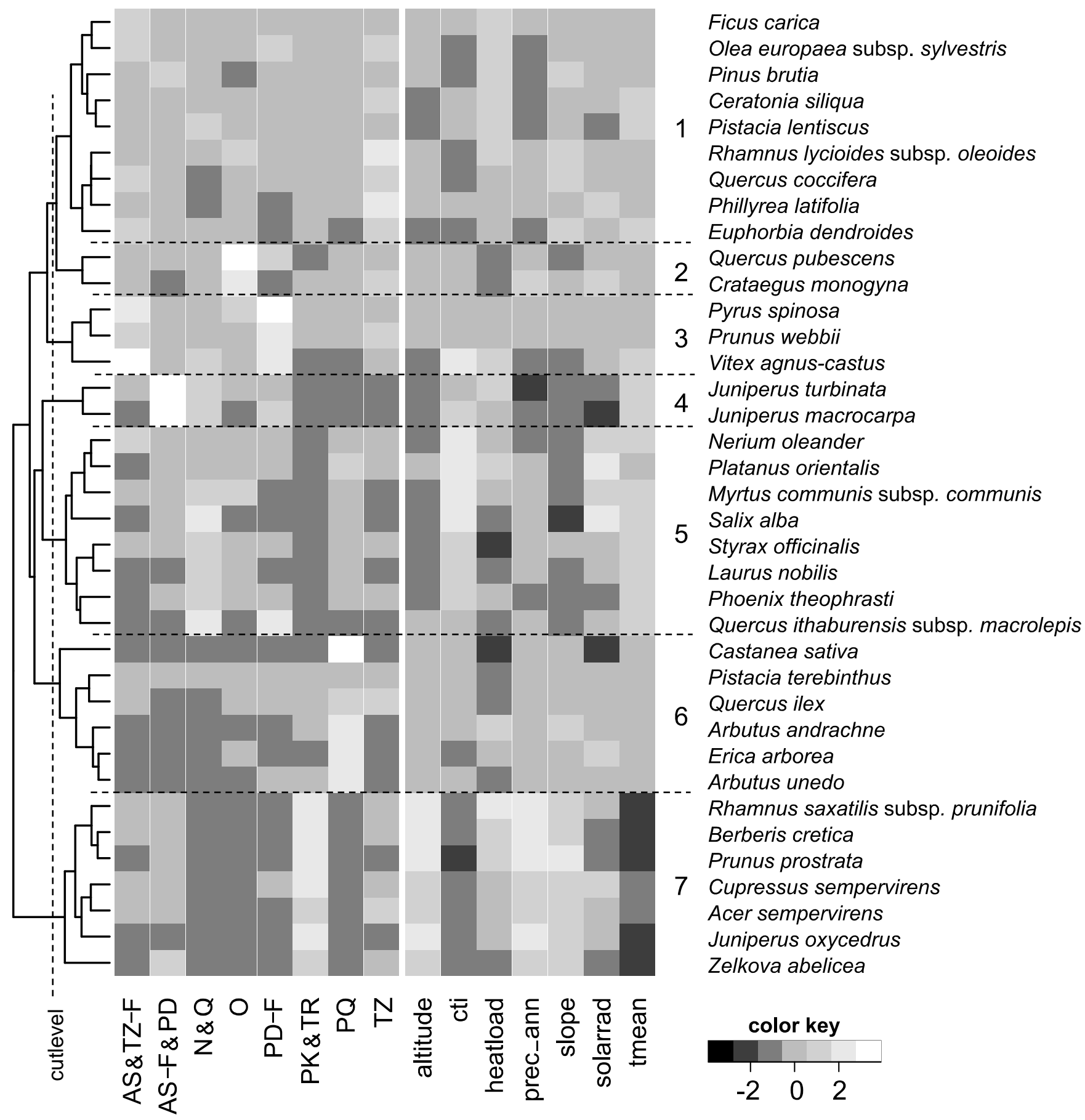

Figure 2.2 Ecological heatmap for Mediterranean woody species on Crete; based on complete linkage clustering of scaled values for environmental parameters and scaled percentage frequencies of geological substrate units (abbreviations in Table 2.4); group numbers 1-7, dashed lines indicate separation of dendrogram.

Laurus nobilis occur infrequently in wooded valleys with low heatload, avoiding high insolation. The only native palm Phoenix theophrasti occurs scattered along the coasts with groundwater supply, 
a

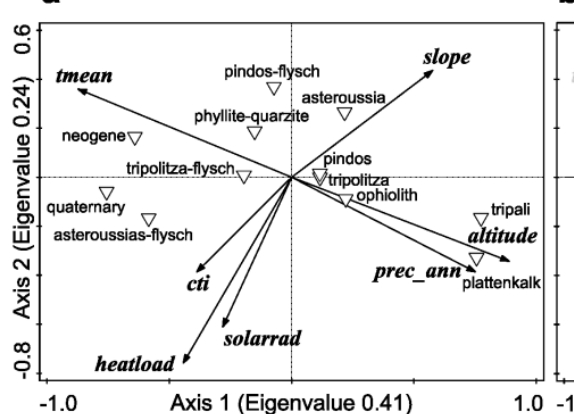

C

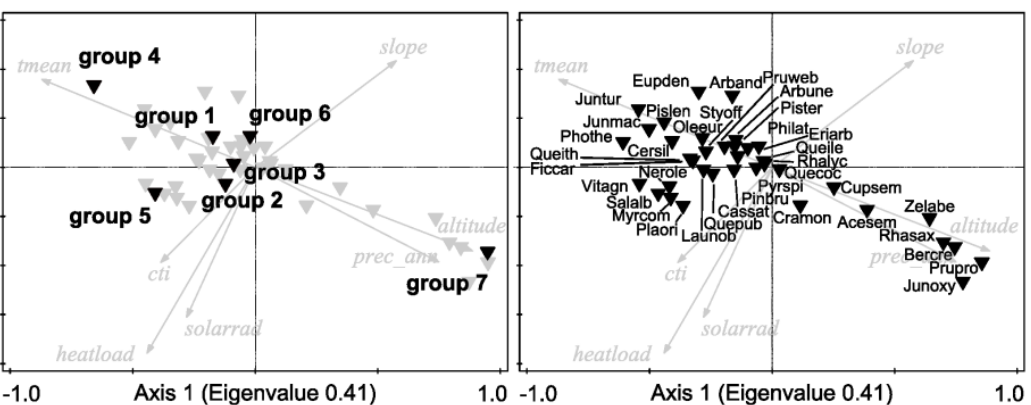

Figure 2.3 Plotted results of multivariate analysis (PCA); based on numerical environmental variables (italic), further supplementary data as centroids of nominal parameters: a) geological units, b) of ecological species groups, c) species (see Table 2.2 for abbreviations).

commonly together with Nerium. Group [6] includes six species of mainly phyllite-quartzite areas: Arbutus andrachne occurs in areas with high heatload, while Castanea sativa and Arbutus unedo favour low heatload and solar radiation. Similarly, Pistacia terebinthus and Quercus ilex prefer low heatload on both phyllite-quartzite and limestones. Group [7] comprises seven mountain species, occurring in sites with raised slope angle and annual precipitation, where low mean temperatures and hard limestones prevail. Sun-exposed mountain sites at and above the tree line are the habitat of the two commonly mat-forming shrubs, Prunus prostrata and Rhamnus saxatilis subsp. prunifolia. The first has the lowest cti of all species, indicating high water runoff. Cupressus and Acer form open mountain woods. Only the former tolerates sites with high solar radiation. Zelkova abelicea grows in cool mountain sites, according to low mean annual temperatures and low heatload.

\section{Abiotic parameters in relation to species groups}

Elevation is a central environmental variable explaining the formation of distinct ecological species groups, e.g., coastal [group 4] and mountain species [group 7] (Figure 2.3). Further species groups were characterised by their affinity to specific bedrock types [groups 3 and 6] or extreme topography [group 5]. Group [6] comprised valley and groundwater-dependent species linked to high cti. Positive (e.g. solar radiation and heatload, altitude and annual precipitation) and negative correlations (e.g. annual precipitation and mean annual temperatures) of environmental variables were reflected in the PCA plot (Figure 2.3). Hard tripali and plattenkalk limestones occur almost exclusively at medium to high altitudes, whereas Neogene sediments occur chiefly in the lowlands and foothills. Quaternary sediments fill valley bottoms and depressions, corresponding to high cti. The correlation of high heatload and quaternary sediments, surprising at first sight, is explained by the high proportion of south facing talus fans. The phyllite-quartzite unit, containing schistose rocks, is mainly distributed at low to medium altitudes in West and Central Crete, where raised precipitation and moderate temperatures prevail. For details on species-to-bedrock relations see Appendix Table A 2.1. The 


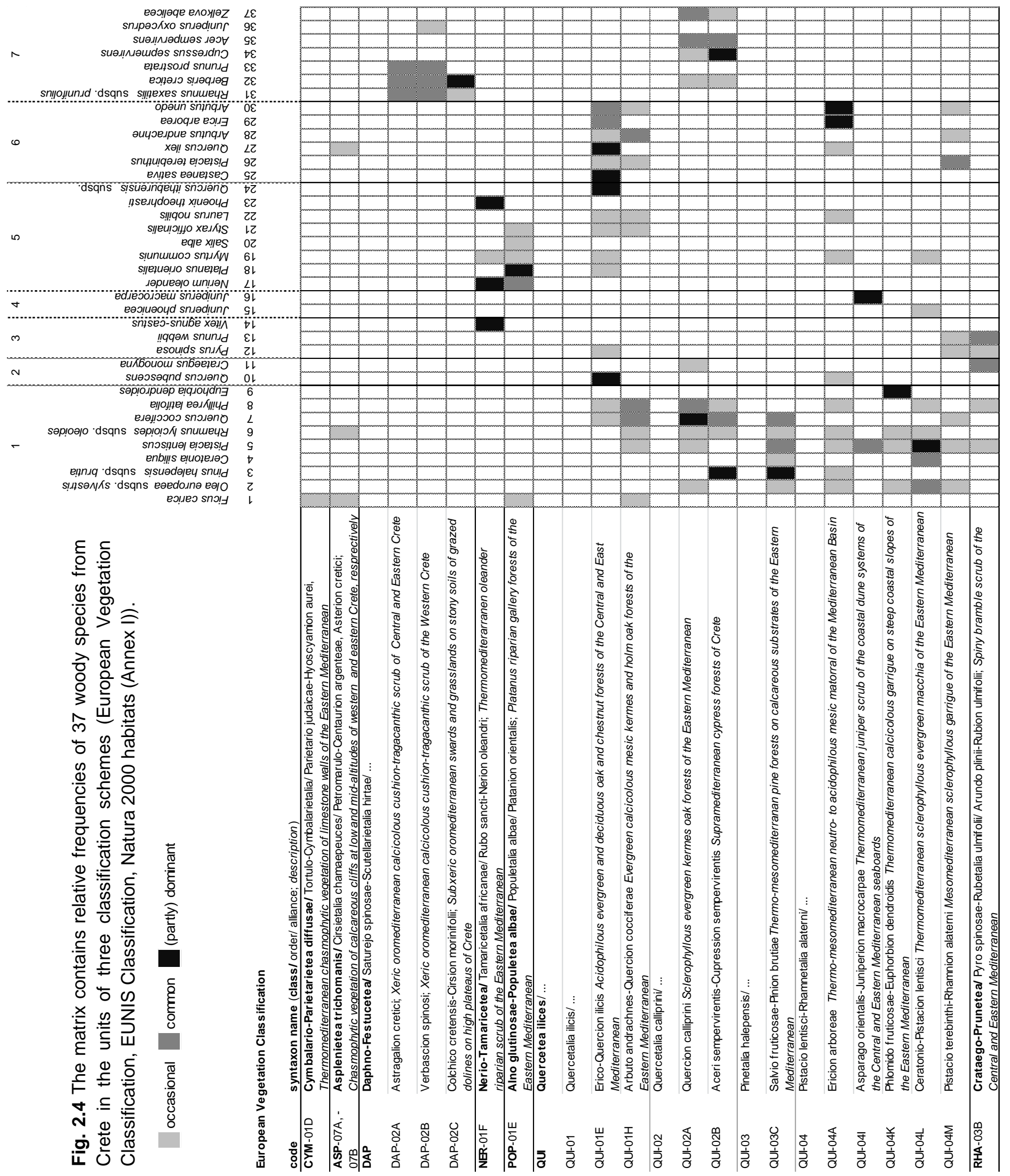




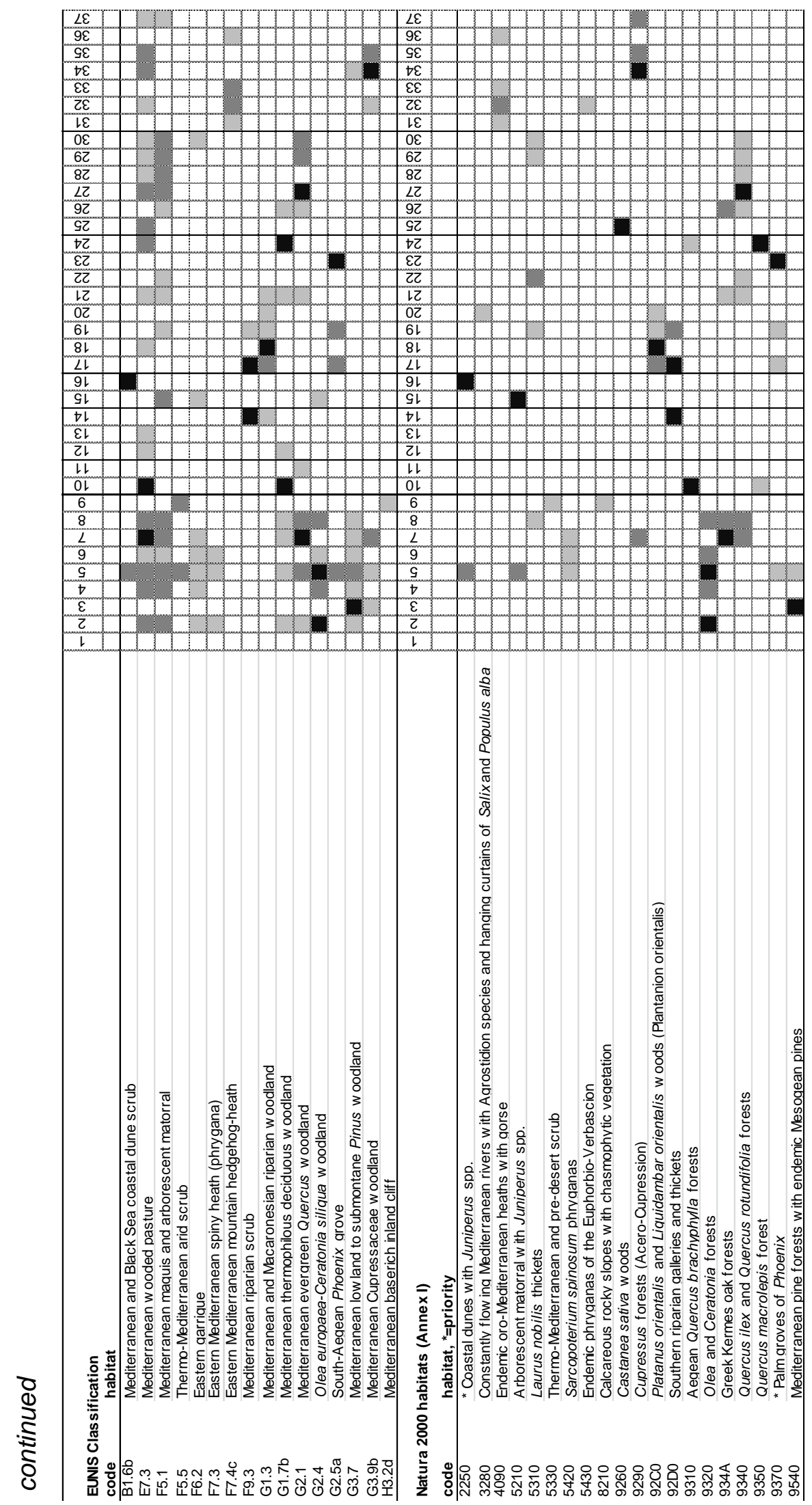


species group patterns were supported by a distinct distribution of most groups (Figure A 2.1) and by boxplots showing variation of raw data (Figure A 2.2).

\section{Discussion}

\section{Quantifying ecological affinities}

Our study quantified and confirmed ecological affinities (macroclimate, topography, geology) of the woody species of Crete. A sufficiently high number of reliable records enabled us to attribute sound ecological information to common species and to display the niche width of the species in landscape and regional context. This standardises and validates expert knowledge (Böhling et al. 2002; Fielding and Turland 2005; Jahn and Schönfelder 1995). Therewith our study supports the (re)assessment of ecological indicator values of species, regarding macroclimatic parameters. We generated novel datasets for species affinities to established topographic indices and displayed spectra of occupied geological substrates. Both aspects were poorly regarded in ecological indicator systems. Thus this type of data may substantiate new ecological indicator values for a couple of site features. Olthoff et al. (2016) compiled similar ecological spectra for woody species in a Palencia region, Spain. They covered different ecological gradients and a set of forest species. In contrast, we worked on an environmentally diverse island with longer (and steeper) ecological gradients (humid to arid, coastal to mountain ecosystems, etc.). Our selection of species is not restricted to forests and thus describes general woody vegetation patterns. Olthoff et al. (2016) displayed ecological response curves along the main axis of multivariate space including the results of compositional data, while we concentrated on the spectra of environmental conditions. By the similarity of these site spectra, species interactions can be indirectly discussed, although species composition and direct species interactions are not available from our dataset.

Other studies quantified macroclimatic preferences for continental endemics (Crisp et al. 2001) or reviewed multiple scales (Suggitt et al. 2017). Bilton et al. (2016) defined macroclimatic niches for species groups and assessed climate-change effects. Miller and Knouft (2006) characterised sites spectra of a fruit tree using environmental data extractions for a wide species range. Major climatic parameters of various trees were displayed on European level (San-Miguel-Ayanz et al. 2016). While the latter study improves our understanding of species niches and continental-scale distribution, it does not support local-scale applications of the information. In contrast our study addresses the regional level and allows for various applications. For the management of woodlands especially for rugged mountain landscapes relief parameters are important (Barry and Blanken 2016; Guisan et al. 1998). According to Fois et al. (2017) topography explains best the distribution of endemic plants in the island of Sardinia (Italy). The topographic position of sites may also control soil parameters, e.g. soil moisture, ground water level, pH-values, etc. (Kopecký and Čížková 2010; Kosmas et al. 1993; 
Sørensen et al. 2006). Accordingly, topographic indices have been used for landscape-based modelling (Jones et al. 2010; McGarigal et al. 2009; Slavich et al. 2014). Our study is probably the first to relate bedrock types to woody species on a wider scale and across diverse habitats. The full spectrum of geological units has only been analysed for relatively few species (Austin et al. 1990; Leuschner et al. 2006), and many ecological studies merely compare siliceous and calcareous bedrock or address a single type of bedrock (Alvarez et al. 2009; Safford et al. 2005; Salmerón-Sánchez et al. 2014). Geological units are fundamental to site conditions, but alone, they are insufficient to predict plant distribution. In Crete, as elsewhere, chemical and structural bedrock and relief features, erosivity, (micro)relief, soil formation and topoclimate also play a role (Neff et al. 2006; Wang et al. 2004; for general information on rock type and plant relations see Kruckeberg 2002). We found that the range of bedrock types, along with other parameters related to climate and topography, were the main factors affecting variation in niche width.

\section{Ecological groups and co-occurrence patterns}

The ecological species groups found in the present study reflect azonal and zonal vegetation. Zonal patterns follow chiefly macroclimatic parameters that vary (mostly linearly) along the altitudinal gradient (Bergmeier 1995). Climatic events such as frost, known to limit altitudinal species ranges (Larcher 2006), are likely to differentiate groups of mountain plant species. Apart from extreme temperature ranges, altitudinal gradients vary in water supply. As water trickles away in the Cretan karst mountains (indicated by a low cti), trees and shrubs are subjected to decreased topographic water availability despite increased precipitation. Some species occupy rather distinct niches, made visible by their ecological spectra. Zelkova abelicea, a tertiary relict species and regional endemic (Kozlowski et al. 2014), turned out to be a tree of shady mountain slopes, which confirms field observations (Egli 1997; Søndergaard and Egli 2006). Species in groups [2] and [3] mostly occupy medium altitudes of west, south-central and central Crete; for group [6] medium altitudes apply. Species of the lowest vegetation zone, adapted to a pronounced Mediterranean climate, are represented by group [4]. Altitudinal zonation patterns in tree distribution are not always clearly visible. For instance, Cupressus sempervirens has a wide elevation range but occurs as a prevalent native forest tree only in the western mountains and scattered in the lowlands (Bauer and Bergmeier 2011). Even generalist species form distinct groups; especially group [1] comprises many widespread species, mostly found at low altitudes, where beside the Mediterranean climate (Aerts 1995; Larcher 2006; Mitrakos 1980), millennia of human impact favoured species resilient against drought, fire, cutting and browsing (Greuter 1975; Groves and Di Castri 1991; Jouffroy-Bapicot et al. 2016). Consequently, species such as Pistacia lentiscus and Quercus coccifera are common in various habitats. The latter is dominant in various shrub communities (Tsiourlis et al. 2009) but is also a tree of woodland remnants in a South Aegean habitat type of national significance (Dimopoulos et al. 
2006). Other species groups are restricted to specific rock types even though the limited resolution of geological maps may blur the picture; for instance, base-rich outcrops with Arbutus andrachne scattered in phyllite-quartzite areas were disregarded, as were sandy soils suitable for Juniperus macrocarpa. Present records do not always reflect potential distribution. For instance, Quercus ilex thrives as dominant forest tree in some phyllite-quartzite areas in western Crete (Bauer and Bergmeier 2011), but frequent burning and cutting has transformed most such woodlands into maquis of Arbutus unedo, Erica arborea and a variety of (dwarf) shrubs. In our dataset $Q$. ilex records on these latter siliceous rocks are outnumbered by those on various limestones, where single trees can be found on cliffs or in deep valleys along shaded streams. This example shows that complex interactions of environmental variables and parameters that could not be recorded such as land use influence the overall validity of our results. A few ecological species groups comprise related taxa suggesting phylogenetic niche conservatism (Prinzing et al. 2001), e.g. junipers in group [4] with extensive root-systems and reduced leaves or the Ericaceae of group [6], which share specific mycorrhiza giving advantages on base-poor soils. Group [5] features the highest cti, usually with water table up to the rooting zone and azonal vegetation dominated by Nerium, Platanus or Phoenix, representing some of the rarest and most vulnerable woodland types (Bergmeier and Goedecke 2017; Décamps and Décamps 2001).

The ecological species groups found in the present study were largely in accordance with units of the widely applied European habitat schemes, EUNIS and Natura 2000, and with phytosociological systems. Most woody species groups belong to Mediterranean pine and oak woodlands and associated maquis, Quercetea ilicis (Mucina et al. 2016; Figure 2.4), corroborating the indicator values of species for abiotic site attributes. Our ecological species groups also support the unique character of low-level vegetation units, e.g. a downy oak forest type on profound soils was described as phytosociological association Oenantho pimpinelloidis-Quercetum brachyphyllae (Zohary and Orshan 1966) Barbéro and Quézel 1980, which comprises the two species of group [2]. The authors treat these two species as distinct regional taxa (Quercus brachyphylla, Crataegus azarella), whereas in the taxonomic reference we used they are merged to more widely circumscribed taxa. Our methodology in conjunction with genetic analyses, applied to vegetation in a wider area, could address unsolved taxonomic and syntaxonomic issues related to oak woods and beyond.

EUNIS habitats are characterised, at various levels, by a wide array of parameters (biogeography, abiotic environment, vegetation structure, prevailing plant life form, land use, etc.). A crosscheck with our woody species groups revealed 16 EUNIS level 3 habitats, most of which being in fact habitat complexes with several co-occurring woody species (Figure 2.4). Land use-related units (e.g., wooded pastures) feature various ecological species groups, indicating varying significance of abiotic 
parameters. Natura 2000 habitats, defined in an expert-based (and political) process, are also based on multiple parameters of which plant species composition is arguably the most important one. Several of the twenty Natura 2000 habitat types to which we assigned Cretan trees and shrubs were narrowly defined with only few co-occurring woody species (Figure 2.4). The species groups revealed by our approach correspond to habitat schemes significant for land management and conservation. Zonal differentiation was only partly supported by our approach, as rather widespread generalists and specialists are separated and because the restriction to all woody species neglects differentiating low shrubs and herbs. The use of further plant species with clear altitudinal limits may improve zonal separation. Bazan et al. (2015) related classified compositional data with macroclimate and could support zonal patterns. Vegetation plot data in conjunction with environmental variables and management information may uncover (a)biotic interactions in relation to vegetation units (Corney et al. 2004). We confirmed general vegetation patterns although our approach was based on species records. Its application in other regions and across regions, especially where plot data are unavailable, could help to understand vegetation patterns on various scales.

\section{Conclusion and outlook}

Our quantification of environmental parameters provides a methodology for the ecological description of woody species distribution patterns in the South Aegean. We generated detailed spectra of occupied geological substrates and new data on macroclimatic and topoclimatic affinities. Our ecological species groups are influenced by the selection of environmental variables, by the generalisation level and by the classification method. The co-occurrence patterns found in the present study complement and summarize ecological findings and corroborate expert systems. As woody species are part of succession series and of climax vegetation, a quantified ecological characterisation improves our understanding of present-day (potential) natural vegetation and vegetation dynamics, setting the stage for a geobotanical characterisation and landscape description (Blasi et al. 2000; Bölöni et al. 2011; Lechner et al. 2016). Our data can only supplement niche and distribution models, where (a)biotic interactions apply (Austin et al. 1990; Guisan and Zimmermann 2000), but the present results provide an approximation of species-environment relations. Beyond this, interactions between environmental variables and between co-occurring species are not directly addressed by our approach. Unlike in most above mentioned models, we used simplified ecological spectra for presence-only data, which hardly allows for the quantification of interactions. For comparison of ecological spectra and co-occurrence we consider ecological heatmaps particularly helpful, because this plot type effectively summarises large amounts of information, can be understood intuitively and may include a classification tree. For widespread woody species, our study deepens the understanding of common and deviating abiotic affinities. Ecological differences of widespread and locally restricted species can be underlined using ecological spectra (Hand et al. 
2017; Lavergne et al. 2004). Apart from trees, which are generally well-known, the approach is expandable to other groups of organisms. An extension of the approach beyond the study area, or to isolated metapopulations, especially in conjunction with genetic analyses, may reveal ecotypes, speciation processes and even cryptic taxa (Goedecke and Bergmeier 2017; Rissler and Apodaca 2007; Sattler et al. 2007).

\section{Acknowledgements}

EB and FG were supported by the Greek Ministry of Environment and the European Commission in the Natura 2000 mapping and monitoring project, thanks to all contributing authorities and coworkers. RJ was funded by Deutsche Forschungsgemeinschaft (DFG: Scho 2-1, 2-2). Ktimatologio SA gave permission to use their satellite-image service. Prof. W. Greuter (Berlin) generously contributed distribution data of his working group (1981-1987), funded by DFG (Gr 676/3-1). Locations of mountain species were delivered by B. Egli (Schaffhausen, Switzerland) and L. Fazan (Fribourg, Switzerland). Processing of geological data was supported by C. Manthey (Bochum), C. Kalaitzidis (MAICh, Chania) and Prof. U. Kull (Stuttgart). P. Mahdavi, I. Schmiedel and L. Sutcliffe (all Goettingen) commented on an earlier manuscript version. The critical comments and suggestions of the editor P. le Roux and three unknown referees helped us to improve the final version of the manuscript significantly. 


\section{Chapter 3: $\quad$ Platanus orientalis woodlands of Crete - diversity, distribution and conservation status}

Bergmeier, E. \& Goedecke, F. (2017) Platanus orientalis woodlands of Crete diversity, distribution and conservation status. In: Achille, G. (ed.) Scritti in onore di Franco Pedrotti. Collana Natura e aree protette 31: TEMI, Trento, pp 29-45. 


\section{Platanus orientalis woodlands of Crete - diversity, distribution and conservation status}

\section{Abstract:}

Platanus orientalis, the Oriental plane, forms the most prominent riparian woods in Crete and the Aegean. The woodlands represent a Natura 2000 habitat type (92C0) of which Greece hosts by far the major part in Europe, both in terms of area and number of sites. The present paper provides a survey of the variation of Platanus woodlands in Crete, with respect to species composition, distribution and ecology. A total of 81 relevés have been distinguished into three plant associations, two of them described as new: Euphorbio characiae-Platanetum orientalis and Hyperico hirciniPlatanetum orientalis. The former comprises woodlands of rocky stream valleys and alluvial fans without or with periodical surface water flow. The latter is restricted to shady ravines and valleys with seasonal or permanent water in schistose landscapes of western Crete. The third association, Equiseto telmateiae-Platanetum orientalis, is the most widespread and was found in valleys with seasonal or permanent water flow, chiefly associated with calcareous rock and base-rich sediments. Based on an assessment of the quality and conservation status of 74 Platanus woodlands throughout Crete, about one third turned out to be in good condition, and two thirds in unfavourable conservation status. Widespread and far-reaching adverse effects were water abstraction (noticed in $54 \%$ of the woodlands), water and soil pollution including waste and garbage disposal ( $32 \%)$, further the effects of fragmentation and disturbance of the riparian woods through plantations and roads (69\%) and invasive plants (42\%, chiefly Arundo donax and Oxalis pes-caprae). Widespread but less significant impacts were disturbances caused by non-intensive grazing, local erosion and leisure activities.

Keywords: Greece, habitat type, Natura 2000, phytosociology, plane, plant association, riparian vegetation, vegetation classification 


\section{Introduction}

Platanus orientalis, the Oriental plane, is the well-known broad-canopy tree providing shade to numerous platías in villages of Greece and elsewhere in the eastern Mediterranean. As a native tree, it occurs from eastern Sicily through the southern Balkan Peninsula, the islands of the Aegean and Anatolia to the Caucasus, N Iran and further east to central Asia and Afghanistan. In Italy it is considered an archaeophyte (Rosati et al. 2015). P. orientalis forms woodlands near springs and as gallery forest along streams, often in ravines and at the bottom of valleys where water supply is not constrained by the Mediterranean summer drought. Platanus seedlings may be abundant in suitable places but the establishment of the seedlings depends on a number of fortunate circumstances such as the local topography with occasionally flooded but not severed or eroded fluvial terraces, moist soil, shady ground, proper weather, and the absence of overgrazing, conditions that, if unsuitable, will prevent successful regeneration from seeds in years. On the other hand, $P$. orientalis is well adapted to the riparian environment. The trees resprout readily if damaged by flood, storm or cutting, and thus withstand mechanical disturbance caused by torrential waters, landslides, or through pollarding, a treatment formerly common to harvest leaves at times when other fodder for livestock was unavailable.

According to the IUCN Red List of Threatened Species Platanus orientalis is considered to be endangered in parts of its range because of changing water courses for irrigation purposes and the increased expansion of agriculture (World Conservation Monitoring Centre 1998). Platanus woodlands have been listed as habitat type 92C0, "Platanus orientalis and Liquidambar orientalis woods (Platanion orientalis)", in Appendix I of the Habitats Directive of the European Union (European Commission - DG Environment 2013). Within the EU, the habitat type occurs in S Bulgaria, Cyprus, Greece and Italy (where it is presently restricted to rather small areas in Sicily; Brullo and Spampinato 1990; Pedrotti and Gafta 1996). Greece accounts for by far the largest number of sites and surface area of this habitat type. Although the official area estimates for the habitat type in Greece appear much exaggerated (according to the European Environment Agency (2015), an area of $866 \mathrm{~km}^{2}$, but with an average width of gallery forest of $25 \mathrm{~m}$ the given forest area would amount to a total length of $34640 \mathrm{~km}$ !), Greece bears prime responsibility for the habitat type and its conservation among the member states and Europe-wide (Dimopoulos et al. 2006).

In the island of Crete (S Aegean, Greece), Platanus orientalis occurs as a native tree throughout the island but is much more common in the west and scattered in the east. It is found in Crete up to over $1000 \mathrm{~m}$ (Jahn and Schönfelder 1995), and to $1300 \mathrm{~m}$ in the southern mainland of Greece, but occurs at higher altitudes chiefly as small groups of trees or as single trees. Although Platanus forms impressive woods in the Aegean the species composition of the woodland ecosystems has not yet 
been studied on the basis of a sufficient number of sample plots. Five relevés of plane woodland with the rare wetland endemic Carex cretica from W Crete were published by Bergmeier and Abrahamczyk (2007). Further floristic and ecological notes with reference to Platanus woodlands from Crete were provided by Rechinger and Rechinger Moser (1951), Gradstein and Smittenberg (1977), Fielding and Turland (2005), and Bergmeier and Abrahamczyk (2008).

The Platanus woods of Crete are mainly riparian and arranged in continuous or frequently discontinuous 5-25(-40) $\mathrm{m}$ wide bands of some hundreds of meters, typically along V-shaped valleys and ravines, or on coastal plains, accompanied by rangelands with phrygana or by macchia, deciduous or evergreen woodland, or cultivated land (Figure 3.1). The water flow of the streams may be seasonal or permanent, or there may be no surface waters except for events of torrential rainfall. Groundwater flow, however, permanently accessible to the tree roots, is a precondition for plane woodlands. Alluvial deposits are sandy or silty, or commonly rocky on talus fans, in steeper valleys,
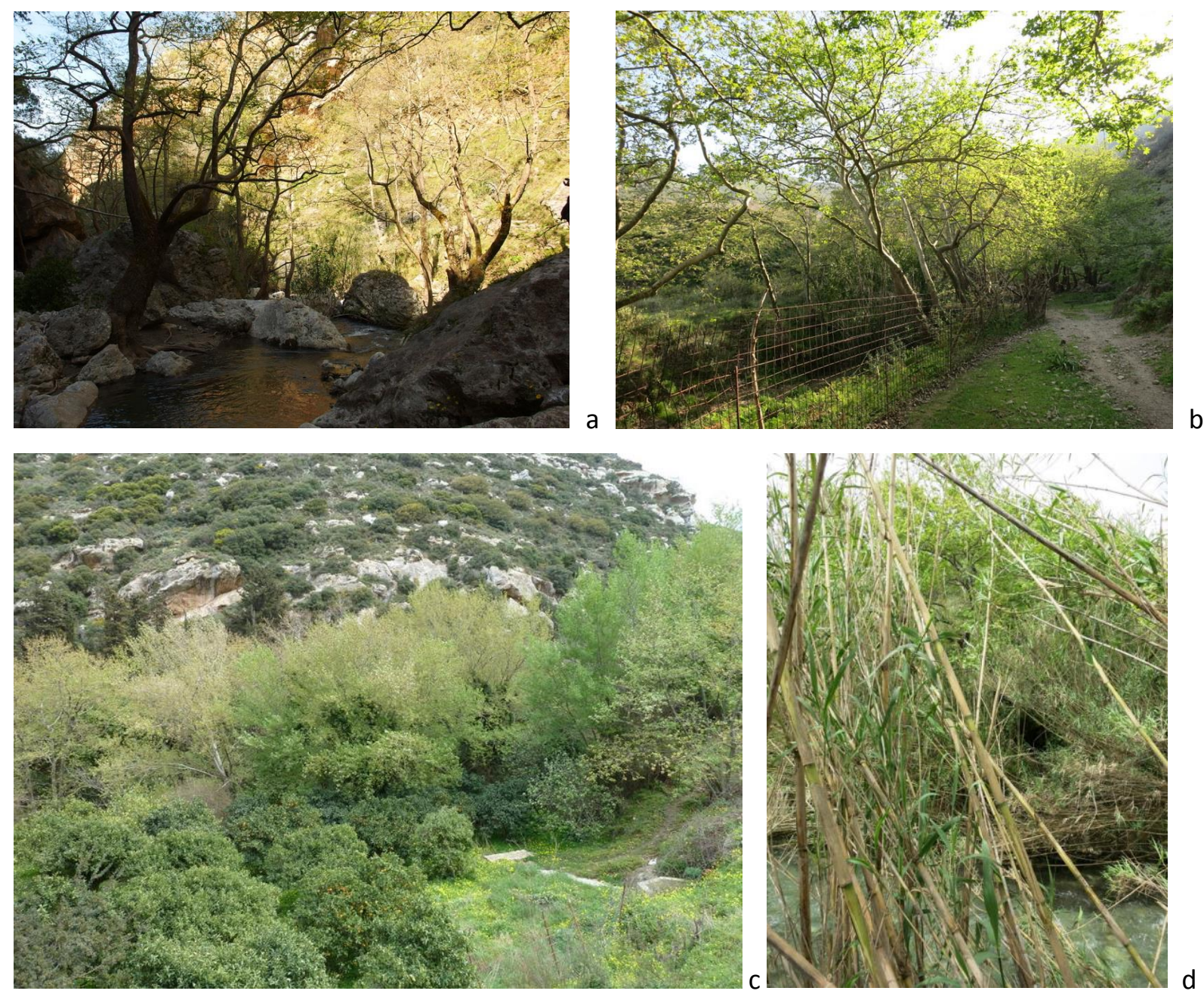

Figure 3.1 Platanus orientalis woodlands in Crete: a) in a ravine, b) pollarded trees in a valley pasture used for pig grazing, c) along a stream with adjacent Citrus plantations, d) along a lowland stream with Arundo donax; all photos from April 2015 by F. Goral (a), I. Schmiedel (b, d) and C. Barnick (c). 
and along permanent streams. Boulders may be carried in torrents. Platanus woods occur in environments of calcareous and siliceous rock, near springs, on alluvial plains and in valleys deepened in landscapes of marble and marl, schist, and sandstone (Dimopoulos and Bergmeier 2008).

Many Cretan Platanus woodlands are situated in sites of the Natura 2000 conservation network and are thus under statutory protection (Bergmeier et al. 2006; Dimopoulos et al. 2005, 2006). Nevertheless, the distribution and present conservation status of the riparian woods is not well known, neither which impacts affect the ecosystems and their species composition and to what extent. The aims of the present paper are therefore

- to explore the variation in vascular plant species composition and to describe the plant communities of Platanus orientalis woodlands in Crete;

- to provide a survey of the current quality and conservation status and of the impacts affecting the present state and the future of the Platanus woodland ecosystems.

Franco Pedrotti dedicated a lifelong scientific interest to the ecology, phytosociology and conservation of riparian forests (e.g. Pedrotti 1984, 1995; Pedrotti and Gafta 1996). This paper is devoted to our friend Franco on occasion of his $80^{\text {th }}$ anniversary, trusting that it will be acknowledged by the jubilarian, and conducive to the knowledge and conservation of the riparian woodlands of Crete and Europe.

\section{Materials and methods}

Relevés of Platanus orientalis woodlands were extracted from the database of Cretan vegetation (Bergmeier 2012). Platanus woodlands were represented in the database by 81 relevés recorded mostly between 1999 and 2015, incidentally or mainly within the frame of a number of projects, among them the documentation and mapping of Natura 2000 sites. Specifically, the relevés resulted from fieldwork carried out by E. Bergmeier (33 relevés), S. Abrahamczyk (25), G. Ilgenfritz (11), W. Wolf (8), and F. Goedecke (4).

Extraction criteria were a Platanus canopy of at least $35 \%$, completeness and reliability of species recording, of the assessment of structural details, and the availability of precise geographical data of the plots with latitude and longitude coordinates. Obviously planted Platanus groves were not included. The plot size of the relevés was generally about (60-)100-300 $\mathrm{m}^{2}$, with a few smaller plots included due limited accessibility of the sites, and larger plots accepted provided that scaledependent homogeneity criteria were fulfilled. Plant species cover-abundance data were estimated 
using the extended Braun-Blanquet scale (e.g. Dierschke 1994). The nine scale values were later transformed in mean cover percentage values $(1,2,3,4,8,18,38,63,88 \%)$. Bryophytes were deleted from the dataset prior to analysis, as this plant group had been considered only in a subset of the relevés. The 81 relevés were exported from the vegetation database management system Turboveg (Hennekens and Schaminée 2001) and classified by means of the divisive cluster analysis tool Two-way Indicator Species Analysis (TWINSPAN; e.g. Gauch and Whittaker 1981). TWINSPAN was run under JUICE 7.0 (Tichý 2002), using four "pseudospecies cut levels" $(0,2,8,38)$. Of the four relevé clusters resulting from the hierarchical subdivision of the dataset at the second level, the first two were re-combined (i.e. to first subdivision level) in order to improve the interpretability of that entity and the floristic distinctness of the clusters. Hence, three relevé clusters were maintained which are easily distinguished by differential plant species. A synoptic table was generated to show the three clusters and their species composition. The nomenclature of the vascular plants follows Dimopoulos et al. (2013).

The local conservation status for the habitat type 92C0 ("Platanus orientalis and Liquidambar orientalis woods (Platanion orientalis)") was assessed in 74 Platanus woods throughout Crete in 2014 and 2015 using threshold quality criteria of the plant species inventory, habitat structures, and adverse effects. Adverse effects on forest habitats were grouped to (1) Damage to the water regime, (2) Pollution of the habitat, soil and water resources, (3) Disturbance of the forest vegetation and damage to the structure, (4) Occurrence of invasive species, (5) Fragmentation and overuse of the habitat. The conservation status per polygon of Platanus woodland was assigned to one of three classes: good, inadequate, bad. The latter two classes may be combined as 'unfavourable'. If any of the adverse effects were significantly affecting the quality of a polygon of Platanus woodland, the overall conservation status for the polygon was considered inadequate. Two or more serious negative impacts resulted in a bad conservation status. The conservation status assessment was carried out mostly in Natura 2000 sites, in the framework of the mapping and monitoring project of Cretan habitat types listed in Appendix I of the Habitats Directive, here specifically of the habitat type 92(0). 


\section{Results and Discussion}

\section{Plant communities and diversity}

Most of our relevés of riparian Platanus woodlands were from the provinces of Chania and Rethimno in $W$ and WC Crete, respectively (Figure 3.2). Our records range from about sea level to $780 \mathrm{~m}$, at thermo- to meso-mediterranean, or planar to submontane levels, thus representing much of the altitudinal range of Platanus woodland in Crete. Almost $90 \%$ of the plots were situated in between 20 and $500 \mathrm{~m}$. Our dataset of 81 relevés comprised well over 2000 species records, with an average of 25.8 species per relevé. Species numbers varied widely between 8 and 70 , reflecting the variation in area and continuity of the ground colonizable by vascular plants. The high total number of recorded plant species (360) comprised to more than half species occurring in one (127) or two (77) relevés only. These were mostly casual plants from adjacent lands.

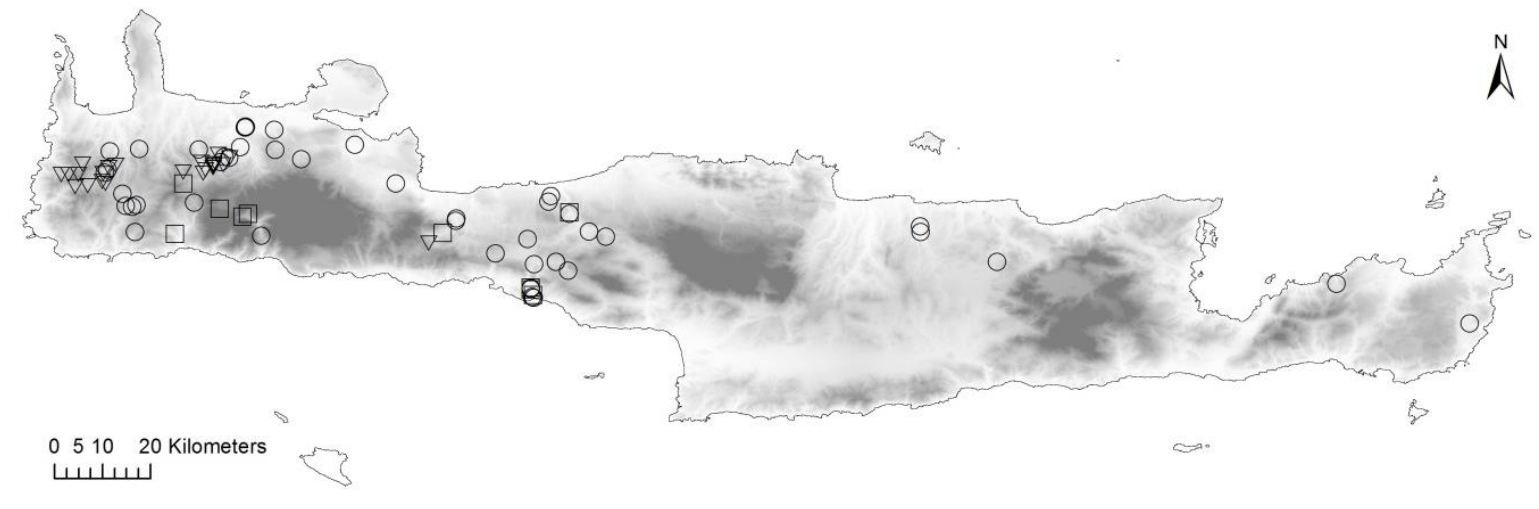

Figure 3.2 Distribution of vegetation records of Platanion orientalis in Crete. The records are grouped and identified as associations 1) Euphorbio characiae-Platanetum orientalis, square $\square$, 2) Equiseto telmateiae-Platanetum orientalis, circle $O$, 3) Hyperico hircini-Platanetum orientalis, triangle $\nabla$.

Apart from $P$. orientalis itself only few species occurred in more than $50 \%$ of the relevés (Hedera helix, Nerium oleander, Dioscorea communis, Rubus sanctus), and 76 species occurred in $10 \%$ or more of the relevés (Table 3.1). Among the 20 most common species were two trees, both deciduous (Platanus orientalis, Ficus carica), two shrubs (Rubus sanctus, Myrtus communis), three woody lianas (Hedera helix, Smilax aspera, Vitis vinifera), two of which evergreen, and the rest mesic herbs with a high proportion of much-branched climbing or trailing vines (Dioscorea communis, Galium aparine, Rubia peregrina), and tuberous (Arisarum vulgare, Arum concinnatum, Cyclamen creticum, D. communis, Oxalis pes-caprae) or rhizomatous (Melissa officinalis, Pteridium aquilinum) perennials. 
The classification of the dataset resulted in three unequally represented woodland types (Table 3.1), here interpreted as phytosociological associations

(1) Euphorbio characiae-Platanetum orientalis ass. nov.

(2) Equiseto telmateiae-Platanetum orientalis Bergmeier 1990

(3) Hyperico hircini-Platanetum orientalis ass. nov.

Table 3.1 Synoptic table of Cretan Platanus orientalis woods, based on 81 relevés, distinguished into the associations Euphorbio characiae-Platanetum orientalis (1), Equiseto telmateiae-Platanetum orientalis (2) and Hyperico hircini-Platanetum orientalis (3). Frequencies of species are in per cent. High frequencies of $40 \%$ or more in an association are in bold print. Non-differential species occurring in 8 or fewer relevés $(<10 \%$ absolute frequency) were omitted. Woody plants in the herb layer are indicated $\mathrm{hl}$, in the shrub layer sl.

\begin{tabular}{|c|c|c|c|}
\hline Association & 1 & 2 & 3 \\
\hline No. of relevés & 10 & 48 & 23 \\
\hline \multicolumn{4}{|c|}{ Trees, shrubs and woody vines } \\
\hline Platanus orientalis & 100 & 100 & 100 \\
\hline Nerium oleander sl & 80 & 81 & 48 \\
\hline Hedera helix & & 73 & 78 \\
\hline Smilax aspera & 30 & 29 & 48 \\
\hline Vitis vinifera & 20 & 33 & 35 \\
\hline Ficus carica & & 35 & 22 \\
\hline Platanus orientalis sl & 20 & 33 & 13 \\
\hline Myrtus communis sl & 10 & 27 & 26 \\
\hline Styrax officinalis sl & 10 & 19 & . \\
\hline Vitex agnus-castus & 20 & 15 & . \\
\hline Arbutus unedo sl & 10 & . & 30 \\
\hline Phillyrea latifolia sl & 10 & . & 26 \\
\hline Laurus nobilis sl & & 8 & 13 \\
\hline Salix alba & . & 13 & 4 \\
\hline Ceratonia siliqua & 20 & 6 & 4 \\
\hline \multicolumn{4}{|c|}{ Differential species of the Euphorbio characiae-Platanetum } \\
\hline Rhagadiolus stellatus & 80 & 2 & 4 \\
\hline Euphorbia characias & 70 & 15 & 9 \\
\hline Catapodium rigidum & 50 & 4 & 9 \\
\hline Aetheorhiza bulbosa & 50 & 4 & 9 \\
\hline Leontodon tuberosus & 40 & . & 4 \\
\hline Galium murale & 40 & . & . \\
\hline Phlomis fruticosa & 40 & 4 & . \\
\hline Dracunculus vulgaris & 40 & 2 & . \\
\hline Satureja thymbra & 40 & 2 & . \\
\hline Bromus sterilis & 40 & 4 & . \\
\hline Geranium molle & 40 & . & . \\
\hline Hypochaeris achyrophorus & 40 & . & . \\
\hline
\end{tabular}




\begin{tabular}{|c|c|c|c|}
\hline Association & 1 & 2 & 3 \\
\hline \multicolumn{4}{|c|}{ Differential species of the Hyperico hircini-Platanetum } \\
\hline Pteridium aquilinum & 10 & 17 & 83 \\
\hline Athyrium filix-femina & . & 6 & 65 \\
\hline Rubia peregrina & . & 21 & 61 \\
\hline Selaginella denticulata & 20 & 8 & 57 \\
\hline $\begin{array}{l}\text { Hypericum hircinum } \\
\text { albimontanum }\end{array}$ & subsp. & 6 & 57 \\
\hline Crepis fraasii & 20 & 10 & 52 \\
\hline Erica arborea & $\cdot$ & 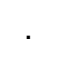 & 48 \\
\hline Ranunculus neapolitanus & 10 & 13 & 43 \\
\hline Castanea sativa hl & . & . & 39 \\
\hline Osmunda regalis & . & 6 & 35 \\
\hline Primula acaulis & . & 2 & 35 \\
\hline Asplenium onopteris & . & 2 & 35 \\
\hline \multicolumn{4}{|c|}{ Diagnostic species of the Platanion orientalis and the Populetalia albae in Crete } \\
\hline Melissa officinalis & 30 & 46 & 48 \\
\hline Parietaria judaica & . & 48 & 13 \\
\hline Arum concinnatum & 30 & 38 & 13 \\
\hline Dorycnium rectum & . & 33 & 35 \\
\hline Adiantum capillus-veneris & . & 25 & 43 \\
\hline Carex pendula & . & 35 & 13 \\
\hline Platanus orientalis hl & . & 25 & 30 \\
\hline Equisetum telmateia & . & 33 & 13 \\
\hline Rumex conglomeratus & 20 & 23 & 17 \\
\hline Lecokia cretica & 10 & 17 & 35 \\
\hline Ficus carica hl & 10 & 15 & 35 \\
\hline Scirpoides holoschoenus & . & 13 & 35 \\
\hline Equisetum ramosissimum & . & 19 & 17 \\
\hline Orobanche hederae & 10 & 19 & 9 \\
\hline Carex divulsa & . & 17 & 17 \\
\hline Helosciadium nodiflorum & . & 13 & 17 \\
\hline Plantago major & . & 19 & 4 \\
\hline Campanula cretica & . & 4 & 30 \\
\hline Nasturtium officinale & . & 13 & 4 \\
\hline Cirsium creticum & . & 10 & 9 \\
\hline Smyrnium olusatrum & . & 15 & . \\
\hline Cyperus longus & . & 8 & 9 \\
\hline Carex remota & . & 4 & 13 \\
\hline Carex cretica & . & . & 22 \\
\hline Carex idaea & . & . & 13 \\
\hline
\end{tabular}




\begin{tabular}{|c|c|c|c|}
\hline Association & 1 & 2 & 3 \\
\hline \multicolumn{4}{|c|}{ Other species of more than $10 \%$ frequency in the dataset } \\
\hline Hedera helix $\mathrm{hl}$ & 30 & 77 & 83 \\
\hline Dioscorea communis & 60 & 56 & 91 \\
\hline Rubus sanctus & 20 & 65 & 78 \\
\hline Geranium purpureum & 60 & 44 & 39 \\
\hline Galium aparine & 40 & 35 & 43 \\
\hline Cyclamen creticum & 40 & 13 & 70 \\
\hline Oxalis pes-caprae & 40 & 42 & 4 \\
\hline Arisarum vulgare & 50 & 21 & 43 \\
\hline Asparagus aphyllus subsp. orientalis & 40 & 19 & 39 \\
\hline Piptatherum miliaceum & 40 & 29 & 9 \\
\hline Poa trivialis subsp. sylvicola & 20 & 25 & 26 \\
\hline Oenanthe pimpinelloides & 10 & 19 & 43 \\
\hline Arundo donax & 20 & 21 & 4 \\
\hline Petromarula pinnata & 20 & 17 & 9 \\
\hline Drimia maritima s. I. & 40 & 4 & 26 \\
\hline Arum creticum & 10 & 4 & 39 \\
\hline Nerium oleander $\mathrm{hl}$ & 10 & 15 & 13 \\
\hline Veronica cymbalaria & 40 & 13 & 4 \\
\hline Theligonum cynocrambe & 40 & 6 & 17 \\
\hline Myrtus communis $\mathrm{hl}$ & 10 & 10 & 22 \\
\hline Epilobium hirsutum & . & 19 & 9 \\
\hline Samolus valerandi & . & 10 & 26 \\
\hline Aristolochia sempervirens & 20 & 8 & 17 \\
\hline Muscari comosum & 10 & 2 & 35 \\
\hline Ficaria verna & 10 & 13 & 13 \\
\hline Lamyropsis cynaroides & 40 & 2 & 17 \\
\hline Anagallis arvensis & 30 & 13 & . \\
\hline Crataegus monogyna & 20 & 6 & 17 \\
\hline Quercus ilex $\mathrm{hl}$ & . & 4 & 30 \\
\hline Polypogon viridis & . & 10 & 17 \\
\hline Ruscus aculeatus & 10 & 13 & 4 \\
\hline Allium subhirsutum & 20 & . & 26 \\
\hline Laurus nobilis $\mathrm{hl}$ & 10 & 10 & 9 \\
\hline Lythrum junceum & & 10 & 13 \\
\hline
\end{tabular}

All three associations may be assigned to the alliance of riparian gallery forests of the eastern Mediterranean (Platanion orientalis I. Kárpáti et V. Kárpáti 1961), the order Populetalia albae Br.-Bl. ex Tchou Yen-Tcheng 1949, and the class of Eurosiberian and Mediterranean riparian gallery forests (Alno-Populetea P. Fukarek \& Fabijanić 1968). 
The Euphorbio characiae-Platanetum orientalis is an association of rather open or disintegrated tree canopy, mainly along streams with episodic or periodic water flow. The association is considered rather common in Crete and more widespread than the present number of records suggests (Figure 3.2). The trees were found to be comparatively low $(9.5 \pm 5.4 \mathrm{~m})$ and showed commonly signs of disturbance by former pollarding and lack of tree rejuvenation. A layer of higher shrubs was not particularly prominent and consisted, if present, of Nerium oleander or scattered Ceratonia siliqua and Pistacia lentiscus. By contrast, heliophilous subshrubs such as Euphorbia characias, Phlomis fruticosa and Satureja thymbra were common and diagnostic for the plant community type. Other differential species of the association included common annual herbs which tolerate moderate shade such as Rhagadiolus stellatus, Catapodium rigidum, Galium murale and Geranium molle, and drought-resistant geophytes (Aetheorhiza bulbosa, Leontodon tuberosus, Dracunculus vulgaris). Other herbs common in the Euphorbio characiae-Platanetum include Geranium purpureum, Drimia maritima s.l. and the thistle Lamyropsis cynaroides. All differential species may be considered grazing indicators and indeed, the recorded stands of this association were all found to be frequented by flocks of sheep and goats. The following relevé constitutes a typical example of the association; it is published here as type relevé of the Euphorbio characiae-Platanetum orientalis: Collector: W. Wolf, 1 May 2000, $100 \mathrm{~m}^{2}$; SW Crete, Province of Chania, N of Sougia, $220 \mathrm{~m}$ a.s.l., $35^{\circ} 16^{\prime} 26^{\prime \prime} \mathrm{N} 23^{\circ} 48^{\prime} 07^{\prime \prime}$ E; Aspect N, Slope $5^{\circ}$, Tree layer $70 \%$, Shrub and subshrub layer $40 \%$, Herb layer 10 \%. Tree layer: Platanus orientalis 4; Shrub layer: Pistacia lentiscus 2b, Ceratonia siliqua 2a, Arbutus unedo 2a, Nerium oleander + , Phillyrea latifolia + , Quercus coccifera + , Pinus brutia r; Subshrub and herb layer: Euphorbia characias 2a, Phlomis fruticosa 2a, Salvia pomifera 2a, Oxalis pes-caprae 2a, Galium aparine 2m, Piptatherum miliaceum 2m, Aetheorhiza bulbosa subsp. microcephala 1, Allium subhirsutum 1, Arisarum vulgare 1, Dioscorea communis 1, Muscari comosum 1, Cyclamen creticum 1, Geranium purpureum 1, Orlaya daucoides 1, Phelipanche mutelii 1, Anemone coronaria +, Aristolochia sempervirens +, Calicotome villosa +, Dracunculus vulgaris + , Drimia maritima s.l. +, Gladiolus italicus +, Leontodon tuberosus +, Olea europaea +, Ornithogalum narbonense + , Prasium majus +, Quercus coccifera + , Satureja thymbra + , Asparagus aphyllus subsp. orientalis r, Bituminaria bituminosa $r$, Cistus creticus $r$, Ebenus cretica $r$, Lathyrus annuus $r$, Ranunculus neapolitanus $r$, Rhagadiolus stellatus $r$, Rumex conglomeratus $r$.

The Equiseto telmateiae-Platanetum orientalis comprised most of the relevés of our dataset (48). It was found widespread between sea level and $600 \mathrm{~m}$ in calcareous areas in western and central Crete, and rarely in eastern Crete (Figure 3.2). The association comprises riparian Platanus woods with various but mostly high canopy cover (66.8 $\pm 14.7 \%)$. The shrub layer averages about $20 \%$ but much denser shrub canopies are not uncommon. The mean tree height was $14.0 \pm 7.5 \mathrm{~m}$, with a maximum of $25 \mathrm{~m}$. The water flow in streams of the Equiseto telmateiae-Platanetum orientalis was mostly 
permanent which is why the association is rare in valleys of southward direction except locally in ravines in the southwest of Crete. Apart from the prevailing Platanus, other trees such as Ficus carica (not uncommon in the subcanopy) and Salix alba (infrequent, sometimes overtopping Platanus) occurred but scattered. Nerium oleander is a regular and often dominant constituent of the understorey. Hedera helix is also common and climbs frequently up to the canopy. Other lianas (Smilax, Vitis) are rather infrequent. Diagnostic for the Equiseto telmateiae-Platanetum, and in contrast to the Euphorbio characiae-Platanetum, is the presence of wetland plants such as Carex pendula and Equisetum telmateia. Table 1 shows that, if compared to the two other associations, own differential species of high frequency are lacking, but the association is nevertheless easily distinguished and the species composition is typical with a combination of plants characteristic of riparian forests in general, such as Melissa officinalis, Brachypodium sylvaticum, Carex pendula, Equisetum telmateia, as well as plants of shady nutrient-rich habitats such as Parietaria judaica and Arum concinnatum. The Equiseto telmateiae-Platanetum orientalis as defined here encompasses rather degraded stands which do not reflect the core of the association, hence the relatively low frequencies of the above-mentioned differential species.

The Hyperico hircini-Platanetum orientalis is restricted to the phyllite-quartzite schist areas in western Crete (Figure 3.2). The region is known for relatively high amounts of precipitation. Many rare species of oceanic general distribution have been recorded Bergmeier and Abrahamczyk 2007, 2008; Blockeel 2007, 2012; Fielding and Turland 2005. The association was recorded between 140 and $780 \mathrm{~m}$ a.s.l. In terms of average tree canopy cover $(70.22 \pm 11.2 \%)$ and mean tree height (15.4 \pm $6.6 \mathrm{~m}$ ) the Hyperico hircini-Platanetum exceeds the other associations. Apart from occasional trees of Quercus ilex and Castanea sativa almost no other trees co-occur with Platanus. In the shrub layer, Nerium oleander is less common, and is almost missing above $300 \mathrm{~m}$. Evergreen shrubs of the adjacent maquis such as Arbutus unedo, Myrtus communis and notably Erica arborea are frequent. Differential species of the ground layer are the tall ferns Pteridium aquilinum, Athyrium filix-femina and Osmunda regalis, and hygrophilous herbs such as Hypericum hircinum subsp. albimontanum. Other herbs of the Hyperico hircini-Platanetum typically occurring in shady or humid habitats include Arum creticum, Campanula cretica, Carex distans, Cyclamen creticum, Primula vulgaris, Rubia peregrina, and another fern - Asplenium onopteris. Two significant invasive plants, the giant grass Arundo donax and the ubiquitous weed Oxalis pes-caprae, are much less common in the Hyperico hircini-Platanetum than in other Platanus woods. The Hyperico hircini-Platanetum provides an important habitat for rare regional endemics such as Carex cretica (Bergmeier and Abrahamczyk 2007) and Scilla cydonia. The following relevé which is a typical example of the association; is selected here as type relevé of the Hyperico hircini-Platanetum orientalis (see also Bergmeier and Abrahamczyk 2007: Relevé 3 in their Table 2): 
Collector: S. Abrahamczyk, 17 May 2005, $150 \mathrm{~m}^{2}$; W Crete, Province of Chania, between Langos and

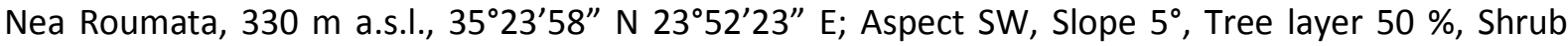
layer 5 \%, Herb layer 60 \%, Moss layer $1 \%$. Tree layer: Platanus orientalis 3, Smilax aspera 1; Shrub layer: Arbutus unedo 1, Erica arborea +, Ficus carica +, Myrtus communis +, Platanus orientalis +; Herb layer: Dorycnium rectum 2b, Carex pendula 2a, Hypericum hircinum ssp. albimontanum 2a, Brachypodium sylvaticum 1, Carex cretica 1, Dioscorea communis 1, Juncus effusus 1, Osmunda regalis 1 , Pteridium aquilinum 1 , Rubia peregrina 1 , Rubus sanctus 1 , Scirpoides holoschoenus 1 , Athyrium filix-femina + , Blackstonia perfoliata + , Campanula cretica + , Carex idaea + , Chamaecytisus creticus +, Crepis fraasii +, Cyclamen creticum +, Cyperus longus subsp. badius +, Epilobium hirsutum + , Hedera helix + , Melissa officinalis + , Poaceae (spec. indet.) + , Polypogon viridis + , Rumex conglomeratus + , Selaginella denticulata + , Sibthorpia europaea + , Adiantum capillus-veneris $r$, Asplenium onopteris r, Ficus carica juv. r, Galium debile r, Sonchus asper r; Moss layer: Eurhynchium hians + , Bryum species + , Funaria species + , Pellia endiviifolia + , Rhynchostegiella tenella + , Fissidens taxifolius +

\section{Conservation status assessment}

The quality evaluation of 74 patches (polygons) of Platanus woodland (60 inside Natura 2000 sites and 14 outside) revealed that about one third of the stands (34 \%) were in a good conservation status, and approximately one fourth (24\%) in a bad. The conservation status of $42 \%$ of the stands was considered inadequate. There was no geographical pattern of habitat quality (Figure 3.3).

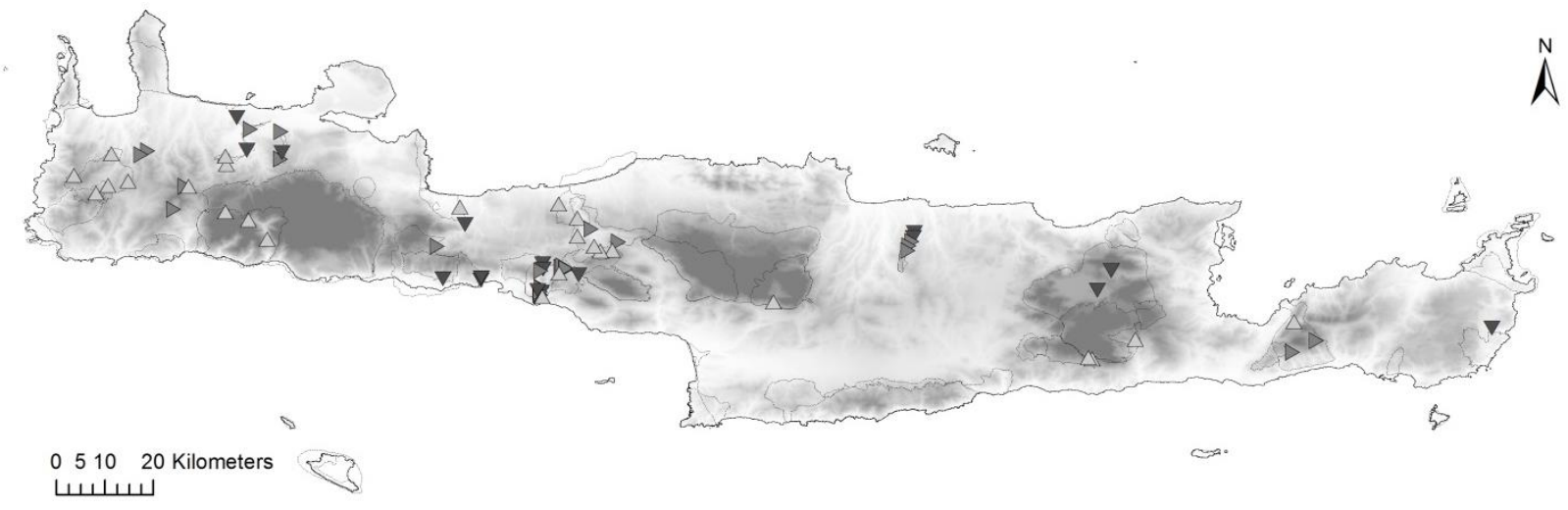

Figure 3.3 Natura 2000 habitat quality assessment of Crete in 2013-2015, distribution of sites of the habitat type 92C0 "Platanus orientalis and Liquidambar orientalis woods (Platanion orientalis)" with quality evaluation: good - bright upright triangle $\Delta$, inadequate - grey turned triangle $\triangleright$, bad - dark upside-down triangle $\nabla$; grey lines indicate protected areas.

Damage to the water regime was registered in 40 forest patches, equal to $54 \%$ of the total. It includes dams and water abstractions mainly for agricultural use. Pollution of the habitat, soil and water resources accounted for 24 polygons (32\%). Disturbance of the woodland vegetation 
anddamage to the structure of the forests was found in half of the surveyed stands. This includes effects of grazing, erosion and fire. Occurrences of invasive species with significant negative effects were observed in 31 plots (42\%). This refers almost exclusively to Arundo donax and/or the nonnative Oxalis pes-caprae, locally Eucalyptus. A total of 51 forest polygons, equal to $69 \%$ of the surveyed stands, were affected by fragmentation and overuse of the habitat, caused by roads and cultivation of riparian ground (chiefly Citrus plantations). Such adverse effects on Platanus forests accumulated frequently and thus resulted in an unfavourable (inadequate or bad) conservation status of about two thirds of the surveyed stands. In only 11 woods (15\%) no visible adverse effects and pressures were detected (Figure 3.4).

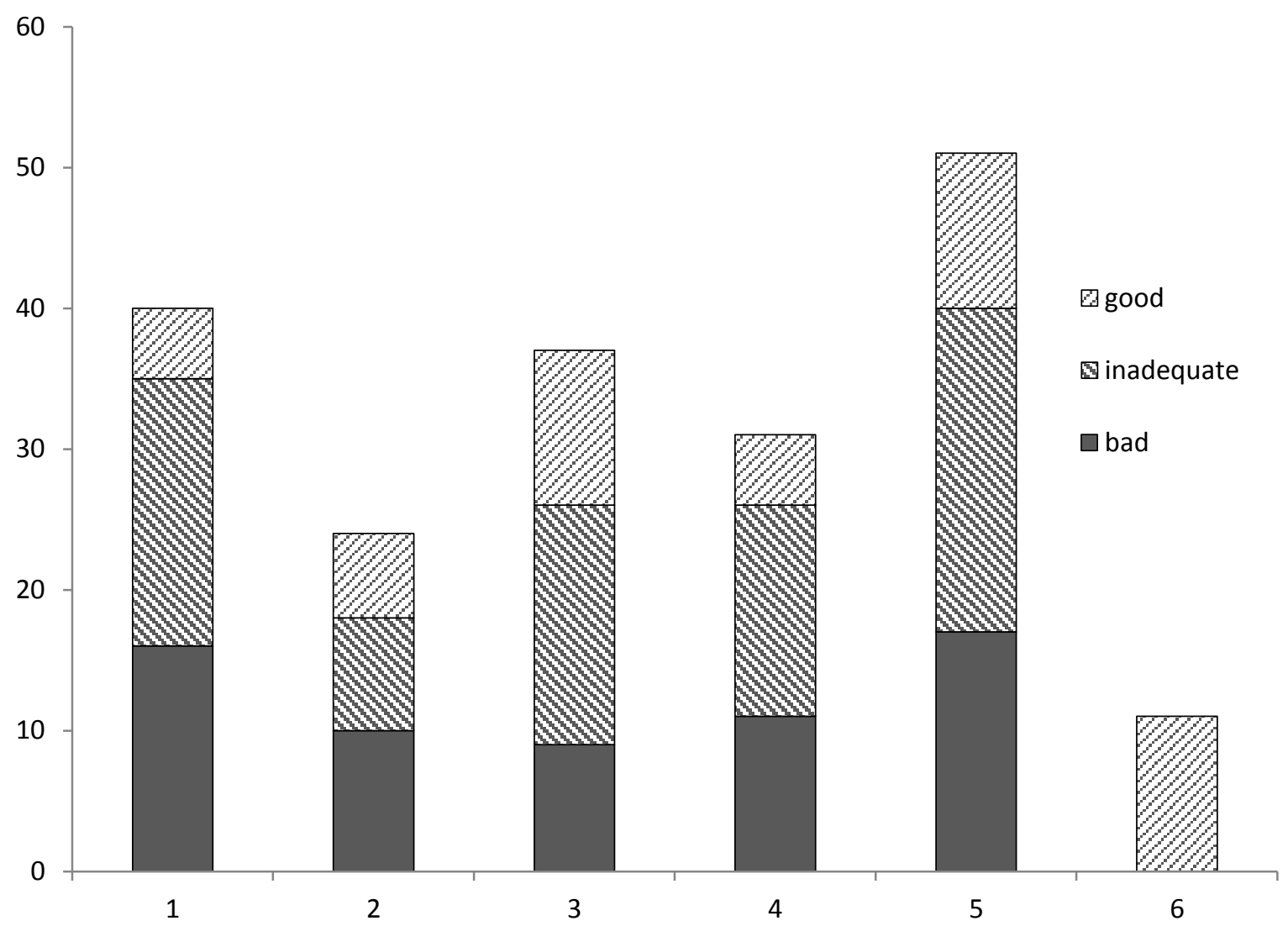

Figure 3.4 Numbers of surveyed sites of Platanus orientalis woodlands in Crete with observed pressures and threats in the categories: (1) Damage to the water regime, (2) Pollution of the habitat, soil and water resources, (3) Disturbance of the forest vegetation and damage to the structure, (4) Occurrence of invasive species, (5) Fragmentation and overuse of the habitat, (6) no pressure and threat recorded. The survey was carried out in 74 sites of Platanus forest; hatchings display the present quality and conservation status of the sites (good, inadequate, bad). 


\section{Conclusions}

Pedrotti and Gafta (1996: 147) listed a number of pressures to riparian vegetation in Italy of which, several, to a variable extent, are also relevant for riparian woodlands in Crete. The most serious impact for Platanus forests and for Cretan wetlands in general is the abstraction of surface and subsurface waters from springs and streams. The water is piped away to irrigate olive and Citrus plantations, and to fill troughs and wells to water sheep and goats. Water consumption by households and touristic infrastructure may also account for some of the water exploitation. To our knowledge, no details on amounts of abstracted water or proportions of its use are available, and there is probably no way of telling. Platanus itself is not at risk though, as the trees will survive, provided the groundwater flow remains accessible for the deep-rooted trees. The three Platanus woodland associations described above are, however, not equivalent from an ecosystem service and ecological point of view. Woodlands of the Euphorbio characiae-Platanetum are characterized by a lower groundwater level and shorter periods of surface water flow per year, if there is surface water at all (personal observations and according to species composition). The assumption seems justified that the proportion and total number of sites of the Euphorbio characiae-Platanetum may increase with increasing water abstraction from springs and headwaters, to the cost of the ecosystems of the Equiseto telmateiae-Platanetum and the Hyperico hircini-Platanetum. The latter two associations both depend on the permanence of surface waters or at least on seasonal flow of water well into springtime.

Qualitative decline and degradation of Platanus woodlands and of the habitat type 92C0 in Crete is indicated by the invasive plants Eucalyptus camaldulensis, Arundo donax and Oxalis pes-caprae, the latter two being particularly common in the lowland and foothill stands which are in the immediate vicinity to villages, arable fields and plantations. Oxalis was introduced decades, Arundo centuries ago. Both species occur now abundantly throughout Crete. Oxalis pes-caprae may occupy considerable parts of nutrient-rich soil in Platanus woodlands. As a spring geophyte it will leave the ground bare and erosion-prone from late April. The rhizomatous bamboo-like grass Arundo donax is much planted and commonly found in disturbed Platanus woods (Figure 3.1d). It collapses in torrential floods, littering large tracts in ravines with thick stem and leaf debris and thus preventing other plant growth. Although the two species are pernicious to riparian woodlands and may cause structural damage through erosion, once established it would be a utopian aim and an obviously useless effort to fight them. Nevertheless, it would be important not to lay out clearings and plantations on slopes above Platanus woodlands, first to prevent soil erosion and, second, to prevent Oxalis bulbils being washed into the valley grounds where the plants would readily establish. Eucalyptus trees of all ages exist locally near fruiting planted trees, on river banks and gravel bars, e.g. at the bridge of Keriti near Alikianos. Although widely planted, Eucalyptus is not as pervasive in 
Crete as it is in the Iberian Peninsula (Andreu et al. 2009) but groups of planted trees should be carefully monitored and controlled.

Another reason why plantations and arable fields should not border Platanus ravines, streams and water courses is to prevent agrochemicals to be washed down and pollute soil and water of the riparian ecosystems. The effect of agrochemicals especially on sensitive plants such as riparian and aquatic bryophytes is already obvious - many streams lack such mosses as a result of water pollution. Pollution and eutrophication may also be caused by solid and organic agricultural waste as well as industrial or chiefly household garbage dumped into ravines and in riparian wood.

A potential threat to planes which has not yet observed in Crete is the dieback of trees caused by the pathogenic fungus Ceratocystis platani, a native to Platanus occidentalis in North America and currently spreading in Europe. Dieback of planted trees of Oriental plane through C. platani has been reported from western and southern Europe. The pathogen recently reached the Peloponnese (Ocasio-Morales et al. 2007) and is likely to spread further.

Platanus orientalis is an unusually popular and familiar tree in the Eastern Mediterranean, every child is able to recognize it. It is the scenery of weddings and many open-air feasts. This popularity makes it a perfect flagship species for nature conservation. Platanus woodlands provide lots of ecosystem services, such as erosion prevention, water conservation and pollution control, and last but not least shade and recreation. They are now declining and vulnerable due to various impacts which are caused just by people who benefit quite essentially from the services of the riparian forest ecosystems. Public awareness must be raised, and water manipulation of the springs and headwaters efficiently controlled to save the diversity and quality of the Platanus woodlands and the services provided by riparian ecosystems.

\section{Acknowledgements}

Special thanks are due to S. Abrahamczyk, G. Ilgenfritz and W. Wolf who collected a considerable proportion of the relevés, and to C. Barnick, U. Bergmeier, F. Goral, P. Mahdavi, I. Schmiedel and W. Wolf who contributed substantially to the site-specific assessment of the conservation status of the habitat type. Mapping and monitoring of the habitat type were part of projects funded by the European Union and the Greek Ministry of Environmental Affairs. The digital elevation model used on the map (Figures 3.2 and 3.3) was kindly provided by the Mediterranean Agronomic Institute of Chania (MAICh, Greece). 


\section{Chapter 4: Ecology and potential distribution of the Cretan endemic tree species Zelkova abelicea}

Goedecke, F. \& Bergmeier, E. Ecology and potential distribution of the Cretan endemic tree species Zelkova abelicea. Journal of Mediterranean Ecology, manuscript accepted $11^{\text {th }}$ October 2017 (letter of acceptance in Appendix) 


\section{Ecology and potential distribution of the Cretan endemic tree species Zelkova abelicea}

\section{Abstract}

Mediterranean mountain forests feature woody species relics such as Zelkova abelicea, an endemic tree species confined to six spatially and genetically distinct populations in Crete (S Aegean, Greece). We used species distribution modelling to predict the potential distribution of Zelkova abelicea. Comparison of coordinate-based geodata extractions for climate and topography revealed pronounced environmental differences for the metapopulations. Main factors for species distribution models were altitude and temperature seasonality (proxy for west-east gradient) whereas topographic conditions had surprisingly little influence on our models. While the most extensive Zelkova metapopulations were found to occur under locally fairly mesic conditions and comprising a wider ecological spectrum, the smaller populations comprising narrower ecological range occurred at lower elevations and further east. For further extrapolation with similar models for known populations, only similar site conditions allowed for a prediction. Differentiated site conditions in the mountains, genetic distinctness and possible environmental adaptations of isolated populations are to be considered in conservation and management. 


\section{Introduction}

A particularity of Mediterranean forests is the conspicuous rate of endemic tree taxa, some of which are considered as relics of a widespread and rich tertiary flora (Mai 1987). As especially isolation by topography is a driving factor for endemism (Steinbauer et al. 2013; Steinbauer et al. 2016; Trigas et al. 2013), Mediterranean mountains and the major Mediterranean islands host many relic tree and shrub populations. For instance, Cedrus libanii subsp. brevifolia is restricted to Cyprus; Abies nebrodensis, Celtis tournefortii subsp. aetnensis and Rhamnus lojaconoi occur only in the Sicilian mountains (Quézel and Médail 2003). Other prominent examples refer to the genus Zelkova (Ulmaceae). Widely distributed under favourable pre-Quaternary climate conditions (Garfi 1997; Quézel and Médail 2003), Zelkova died out in Central Italy in late Pleistocene, after repeated increase and decline along glacial-interglacial cycles (Follieri et al. 1986; Magri 1999). Today two out of six species of the genus worldwide are represented in the Mediterranean basin: Zelkova abelicea in the mountains of Crete and Zelkova sicula in south-eastern Sicily (Di Pasquale et al. 1992; Garfi et al. 2011). Chloroplast and nuclear marker analyses revealed close relation of the two Mediterranean species (Christe et al. 2014). Z. abelicea is listed Endangered by IUCN (Kozlowski et al. 2012), and Z. sicula which occurs in only two single spots is considered Critically endangered (Garfi 2006). Depending on browsing impact and climatic constraints (Garfi et al. 2002), they may grow as tree, treelet or shrub. Compared to co-occurring woody species, both Zelkova species take up a rather distinct ecological niche (Garfi et al. 2011; Søndergaard and Egli 2006). Local climate seems to be crucial, as Zelkova populations of both species are restricted to topographically or edaphically relatively favourable sites where evapotranspiration is rather low and water-supply satisfactory (Garfi et al. 2011; Søndergaard and Egli 2006). Cretan Zelkova abelicea grows in several isolated mountains between $900 \mathrm{~m}$ a.s.l. up to the tree line at about $1800 \mathrm{~m}$ a.s.l. (Kozlowski et al. 2012); Z. sicula occurs at lower elevation (320 to $520 \mathrm{~m}$ a.s.l.) but is confined to gullies, suggesting that this microtopographic position compensates for inadequate rainfall amounts and helps the species to withstand seasonal water stress (Garfi et al. 2011).

Isolated narrow-range plant populations may be genetically impoverished (Booy et al. 2000; Honnay and Jacquemyn 2007) or may show (unexpected) genetic diversity (Bucci et al. 1997; LaBonte et al. 2017; Liu et al. 2006; Mousadik and Petit 1996; Parducci et al. 2001). For example, Spanish populations of widespread European Ulmus species show high genetic variation compared to northern occurrences (Fuentes-Utrilla et al. 2014b). This is interpreted as indicating relict populations, with higher genetic diversity compared to those originating from post-glacial colonisation. Relict populations are thus important for genetic diversity conservation and underline the need to protect glacial refugia in the Mediterranean and elsewhere. Broad genetic diversity also applies to Zelkova abelicea. Isolated subpopulations were found to be genetically differentiated 
(Christe et al. 2014). Haplotypes, the haploid genotype of individual samples, show distinct intraspecific patterns with a strong separation of lineages from different mountain ranges. This supports the assumption of long-term geographical isolation.

This study aims to illuminate the relation among ecology, distribution patterns and isolation of $Z$. abelicea through species distribution modelling. Toolsets for species distribution modelling can support a clearer understanding of species ecology on landscape scale. This approach helps to assess potential and actual distribution areas of species and can be used to explain past and recent range patterns (Elith et al. 2006; Svenning et al. 2011). Furthermore modelling allows to predict suitable sites under changing climate conditions (Garcia et al. 2013; Keenan et al. 2011; Skov and Svenning 2004). Species distribution modelling may complement molecular research or support targeted sampling; it is also useful for conservation and restoration and may even help to reveal hitherto unrecorded populations and cryptic taxa (Dick et al. 2003; Rissler and Apodaca 2007; Sattler et al. 2007). The present study addresses the following questions: How much do isolated populations of Zelkova abelicea differ in ecology, as expressed by abiotic variables? Are these differences related to known genetic patterns? Which environmental factors influence species distribution models most? How do predicted distribution patterns relate to known records? Do combined metapopulation samples improve the predictive value for known neighbouring populations? Consequences for biogeography and management are discussed.

\section{Study area}

Crete is among the largest islands of the Mediterranean and topographically outstanding with alternating high mountain ranges and lowland plains. Three mountain ranges rise over $2000 \mathrm{~m}$ and all are rather isolated, in the geological past even separated by shallow seas. Hard Triassic metamorphic limestones prevail in the high mountains. Mediterranean lowland climate, with mild winters and hot and dry summers, is modified in the mountains, with precipitation increasing, temperatures decreasing, and evapotranspiration reduced (Barry 2008). This favours hardy species adapted to rather mesic conditions. The prevailing westerlies bring about moist air masses which, in combination with a pronounced relief, cause rain shadow effects on the east sides. Northern strong dry etesian winds, called meltemi, occur regularly during summer. The rugged relief, shaped by tectonic events and erosion, promotes mesoclimatic variation (Barry and Blanken 2016). Sheltered sites in poljes, dolines, gorges and below cliffs support a specialised flora (Egli 1989; Egli et al. 1990; Hedderson and Blockeel 2013). Such local-climate conditions in otherwise sun- and wind-exposed environments favour xero-mesic taxa such as Zelkova. 


\section{Methods}

Coordinates of Zelkova abelicea individuals were obtained from collections and field surveys (Table 4.1). Identical coordinates were reduced to one. Occurrences of Zelkova in isolated mountain ranges were considered as (meta)populations. Most records by far are in the west of Crete (Figure 4. 1, Table 4.2). The majority of records are from the western Lefka Ori (W), fewer from the eastern Lefka Ori (E), including the lowest known site near Imbros. The Kedros population (K) is isolated on a single mountain massif in the western central part of Crete. Further east, on Psiloritis (P), only one small population occurs in the Rouvas forest. The east central mountain Dikti (D) harbours the second largest population, comprising 31 scattered records of one to few trees.

Table 4.1: Data collection for Zelkova abelicea populations of Crete. From all collectors additional unpublished records are included.

\begin{tabular}{lllr}
\hline Collector & Publication & Timespan & Number of records \\
\hline & & & \\
L. Fazan et al. & (Fazan et al. 2012; Fazan 2014) & $2010-2016$ & 218 \\
B. Egli & (Egli 1998, 2000) & $1993-1999$ & 13 \\
E. Bergmeier & (Bergmeier 2012) & $1999-2012$ & 11 \\
R. Jahn & - & $1988-2014$ & 39 \\
various & Literature + herbarium specimen & $1988-2014$ & 331 \\
total & & \\
\hline
\end{tabular}

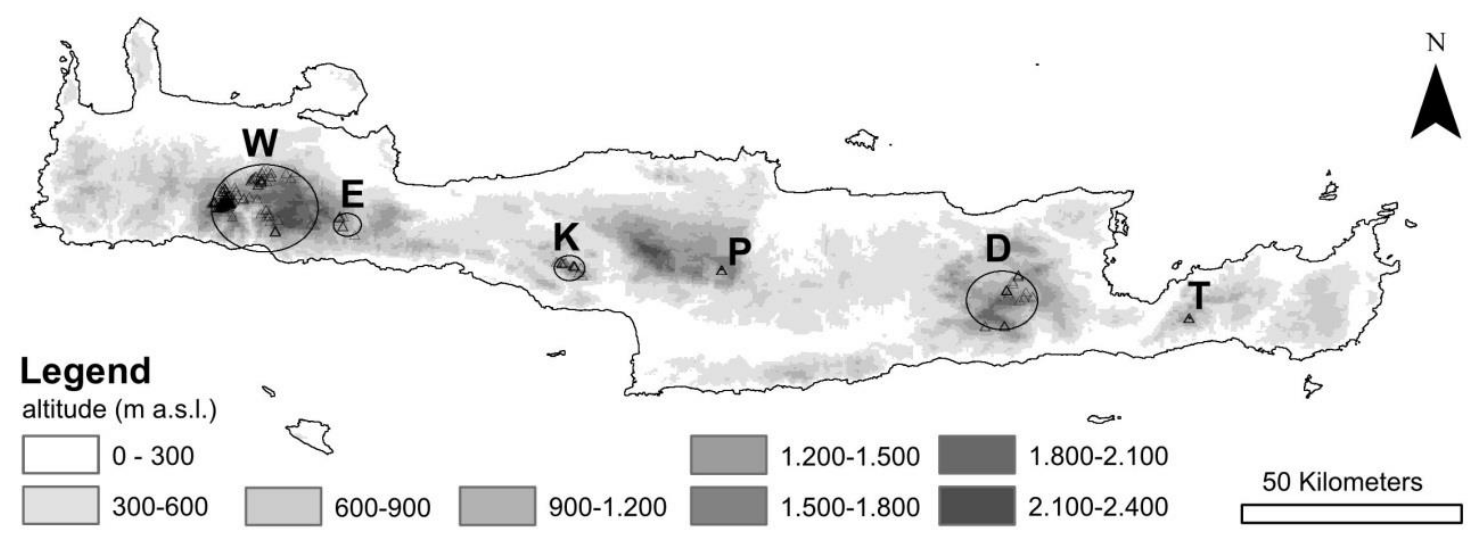

Figure 4.1 Map of distribution and altitudinal patterns for the Zelkova abelicea metapopulations in Crete. Circles circumscribe areas with records, but records in $\mathrm{P}$ and T are given as single points. 
Table 4.2 Populations of Zelkova abelicea in the Cretan mountain ranges with spatial extent, number of records and occupied grid cells (397 m x $397 \mathrm{~m}$ ).

\begin{tabular}{lcccrr}
\hline Population & Mountain range & Longitude & Latitude & Records & Grid cells \\
\hline W & West Lefka Ori & $23.88-24.06^{\circ}$ & $35.26-35.39^{\circ}$ & 256 & 114 \\
E & East Lefka Ori (East & $24.09-24.18^{\circ}$ & $35.25-35.29^{\circ}$ & 14 & 5 \\
K & Imbros) & & & & 18 \\
P & Kedros & $24.59-24.64^{\circ}$ & $35.17-35.20^{\circ}$ & 7 & 1 \\
D & Psiloritis & $24.93^{\circ}$ & $35.18^{\circ}$ & 7 & 18 \\
T & Dikti & $25.47-25.57^{\circ}$ & $35.06-35.17^{\circ}$ & 31 & 3 \\
\hline
\end{tabular}

The smallest number of records is from Thrypti $(T)$, the easternmost mountain range. Coordinates from GPS measures as well as raster data for climate and geomorphology were processed in ArcGIS (ESRI 2013, Table 4.3). A grid resolution of $397 \mathrm{~m}$ was used for modelling, amounting to about 102,000 grid cells. Multiple records per grid cell were used. Further plotting of results and statistical tests were performed in R 3.4.0 (R Development Core Team 2017). For initially 30 environmental variables Spearman correlations were applied (Table A 4.1, psych package, Revelle 2017). Collinear pairs were reduced to one for $\mathrm{R}^{2}>0.6$ with priority on geomorphology and mean values, leaving 7 variables for final analysis (Table 4.3). For these variables coordinate-based geodata extractions were calculated for all records and plotted for populations. Additionally, Kruskal-Wallis tests were performed to reveal significant differences (pgirmess package, Giraudoux 2016).

MaxEnt software version 3.4.0 was used to compute species distribution models (Phillips et al. 2006). Models based on multiple correlations were compiled for a set of environmental variables, resulting

Table 4.3 Environmental factors used to predict species distribution.

\begin{tabular}{|c|c|c|}
\hline Data source & $\begin{array}{l}\text { Original } \\
\text { resolution }\end{array}$ & variables \\
\hline $\begin{array}{l}\text { Chelsa climate data } \\
\text { Version 1.1 (Karger } \\
\text { et al. 2016) }\end{array}$ & 30 ArcSec $=\sim 1 \mathrm{~km}$ & $\begin{array}{l}\text { 1. mean annual precipitation }(\mathrm{mm}) \\
\text { 2. Bio2/ temperature mean diurnal range } \\
\text { (standard deviation *100) } \\
\text { 3. Bio4/ temperature seasonality }\end{array}$ \\
\hline $\begin{array}{l}\text { Digital Elevation } \\
\text { Modell over Europe } \\
\text { (EEA 2015) }\end{array}$ & $30 \mathrm{~m}$ & $\begin{array}{l}\text { (mean of monthly }(\max -\min )) \\
\text { 4. altitude (m a.s.l.) } \\
\text { derived thereof: } \\
\text { 5. slope }\left({ }^{\circ}, \text { Burrough and McDonell 1998) }\right. \\
\text { 6. heatload (McCune and Keon 2002) } \\
\text { 7. cti (compound topographic index, Moore et al. } \\
\text { 1993, Gessler et al. } 1995)\end{array}$ \\
\hline
\end{tabular}


in relative habitat suitability for each grid cell, with or without prior Zelkova records. We applied standard settings which provided results similar to when manually modified. Models were improved by jackknife tests, therewith quantifying the contributions of single variables in models. This resulted in the exclusion of mean annual precipitation, as the latter data layer was covered by other values, and did not add further value to the models. Cross-validation with geographically distinct metapopulations was preferred to random test sample selection. One species distribution model was performed using all known records, to achieve a robust evaluation of the present Zelkova distribution. Extrapolation performance was tested further with combined metapopulations, leaving out the test population. Combinations resulting in sample sizes of $n<80$ were excluded, as such sample numbers constrain internal handling of environmental features in MaxEnt and therefore render model outputs hardly comparable (Morales et al. 2017; Phillips and Dudík 2008). As for some populations only few records were available, metapopulation $W$ with the largest sample number was always included. The general modelling performance according to Area-under-the-Curve (AUC) test was high, with values close to the maximum, but the measure was not suitable to predict extrapolation performance (Lobo et al. 2008). Hence regularised sample predictions were used for the evaluation of test data, the values of which maximize towards 1 , and to describe environmental suitability (Merow et al. 2013). These values were visualised in maps; with values above 0.6 species occurrence is likely.

\section{Results}

\section{Environmental comparison of populations}

In total 332 Zelkova records were used, from (meta)populations ranging between 6 (T) to 256 (W) trees. The six metapopulations of Zelkova abelicea differed in their environmental characteristics (Figure 4.2). As revealed by the amplitude of abiotic values, within the Lefka Ori the largest metapopulation (W) displayed the broadest ecological range. The smaller metapopulations covered narrower ecological amplitudes. Steep sloping terrain was a characteristic of Zelkova populations in the western Lefka Ori (W), Kedros (K) and Dikti (D). Heatload differed among the metapopulations, with lowest values for K. Compound topographic index (cti), indicating relief position preferences, was indifferent among metapopulations. The diurnal range of temperatures was highest in the populations of central Crete, while daily differences were attenuated for the two eastern populations. Temperature seasonality was higher in the three eastern populations Psiloritis (P), Dikti (D) and Thrypti $(T)$. From the western to the eastern populations mean annual precipitation according to rain shadow effects decreased from $900-1000 \mathrm{~mm}$ to 700 - $800 \mathrm{~mm}$ per year. 


\section{Models and prediction values}

In jackknife tests altitude and temperature seasonality were influencing models most, followed by temperature diurnal range, while the other variables contributed to a lesser extent. For a model that included all Zelkova abelicea records the maximum prediction value for any single metapopulation was found for $\mathrm{W}$ (Table 4.4). The wide environmental range of the $\mathrm{W}$ metapopulation was nevertheless not fully covered by this general model.

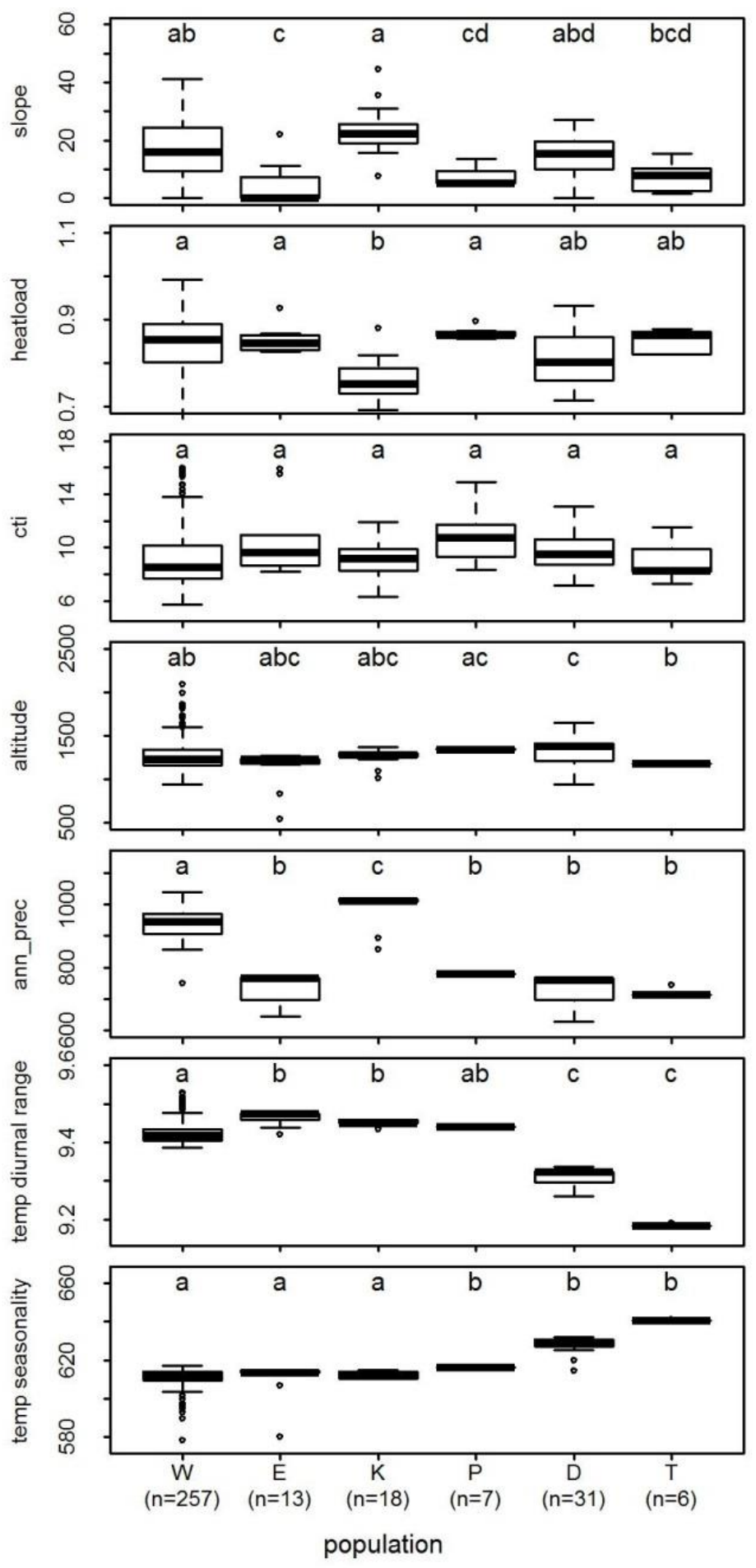

Figure 4.2 Site conditions for six populations of Zelkova abelicea. Values from coordinatebased geodata extractions; populations: $\mathrm{W}=$ W Lefka Ori, $E=E$ Lefka Ori (E Imbros gorge), $\mathrm{K}=$ Kedros, $\mathrm{P}=$ Psiloritis (Rouvas Forest), $\mathrm{D}=\mathrm{Dikti}, \mathrm{T}=$ Thrypti; dissimilar letters $(a, b, c, d)$ indicate significant differences in ranks of the Kruskal-Wallis-Test $(p$-value $=$ 0.05). 
Table 4.4 Sample predictions with tested populations for a species distribution model for all records ( $\mathrm{mx}=$ maximum, $\mathrm{mn}=\mathrm{mean}, \mathrm{sd}=$ standard deviation).

\begin{tabular}{lcccccc}
\hline population & W & E & K & P & D & F \\
\hline $\mathrm{mx}$ & 0.963 & 0.730 & 0.863 & 0.642 & 0.406 & 0.652 \\
$\mathrm{mn}$ & 0.723 & 0.578 & 0.717 & 0.596 & 0.332 & 0.516 \\
$\mathrm{sd}$ & 0.234 & 0.242 & 0.153 & 0.029 & 0.081 & 0.060 \\
\hline
\end{tabular}

Table 4.5 Sample prediction values for combinations of populations (rows) excluding the tested population (columns; $\mathrm{mx}=$ maximum, $\mathrm{mn}=\mathrm{mean}, \mathrm{sd}=$ standard deviation); prediction values $>0.6$ in bold; *as map in Figure 4.3.

\begin{tabular}{|c|c|c|c|c|c|c|c|c|c|c|c|c|c|c|c|}
\hline \multirow{2}{*}{$\begin{array}{l}\text { Pop- } \\
\text { ulation }\end{array}$} & \multicolumn{3}{|l|}{$E$} & \multicolumn{3}{|l|}{$\mathrm{K}$} & \multicolumn{3}{|l|}{$\mathbf{P}$} & \multicolumn{3}{|l|}{ D } & \multicolumn{3}{|l|}{$\mathbf{T}$} \\
\hline & $\mathrm{mx}$ & $\mathrm{mn}$ & $\mathrm{sd}$ & $\mathrm{mx}$ & $\mathrm{mn}$ & $\mathrm{sd}$ & $\mathrm{mx}$ & $\mathrm{mn}$ & $\mathrm{sd}$ & $\mathrm{mx}$ & $\mathrm{mn}$ & $\mathrm{sd}$ & $\mathrm{mx}$ & $\mathrm{mn}$ & sd \\
\hline$W^{*}$ & 0.463 & 0.247 & 0.119 & 0.778 & 0.550 & 0.113 & 0.505 & 0.499 & 0.010 & 0.060 & 0.020 & 0.008 & 0.000 & 0.000 & 0.000 \\
\hline WE & & & & 0.764 & 0.575 & 0.118 & 0.492 & 0.467 & 0.016 & 0.067 & 0.022 & 0.009 & 0.000 & 0.000 & 0.000 \\
\hline WK & 0.596 & 0.282 & 0.151 & & & & 0.496 & 0.481 & 0.025 & 0.053 & 0.017 & 0.007 & 0.000 & 0.000 & 0.000 \\
\hline WP & 0.463 & 0.247 & 0.119 & 0.778 & 0.550 & 0.113 & & & & 0.060 & 0.020 & 0.008 & 0.000 & 0.000 & 0.000 \\
\hline WD & 0.491 & 0.250 & 0.116 & 0.795 & 0.560 & 0.129 & 0.439 & 0.432 & 0.010 & & & & 0.007 & 0.006 & 0.001 \\
\hline WT & 0.452 & 0.244 & 0.111 & 0.779 & 0.539 & 0.129 & 0.441 & 0.433 & 0.012 & 0.083 & 0.034 & 0.019 & & & \\
\hline WEK & & & & & & & 0.535 & 0.515 & 0.012 & 0.057 & 0.018 & 0.008 & 0.000 & 0.000 & 0.000 \\
\hline WEP & & & & 0.773 & 0.598 & 0.120 & & & & 0.065 & 0.022 & 0.009 & 0.000 & 0.000 & 0.000 \\
\hline WED & & & & 0.814 & 0.630 & 0.137 & 0.553 & 0.500 & 0.034 & & & & 0.006 & 0.006 & 0.001 \\
\hline WET & & & & 0.790 & 0.604 & 0.131 & 0.545 & 0.493 & 0.033 & 0.090 & 0.035 & 0.021 & & & \\
\hline WKP & 0.612 & 0.298 & 0.161 & & & & & & & 0.050 & 0.016 & 0.007 & 0.000 & 0.000 & 0.000 \\
\hline WKD & 0.648 & 0.307 & 0.159 & & & & 0.516 & 0.509 & 0.011 & & & & 0.006 & 0.006 & 0.001 \\
\hline WKT & 0.624 & 0.310 & 0.159 & & & & 0.510 & 0.504 & 0.010 & 0.076 & 0.032 & 0.017 & & & \\
\hline WPD & 0.534 & 0.284 & 0.133 & 0.810 & 0.598 & 0.133 & & & & & & & 0.007 & 0.006 & 0.001 \\
\hline WPT & 0.483 & 0.270 & 0.124 & 0.795 & 0.562 & 0.123 & & & & 0.094 & 0.036 & 0.023 & & & \\
\hline WDT & 0.499 & 0.256 & 0.118 & 0.794 & 0.564 & 0.136 & 0.447 & 0.441 & 0.010 & & & & & & \\
\hline WEKP & & & & & & & & & & 0.056 & 0.018 & 0.008 & 0.000 & 0.000 & 0.000 \\
\hline WEKD & & & & & & & 0.638 & 0.588 & 0.032 & & & & 0.006 & 0.006 & 0.001 \\
\hline WEKT & & & & & & & 0.564 & 0.532 & 0.021 & 0.079 & 0.033 & 0.018 & & & \\
\hline WEPD & & & & 0.821 & 0.655 & 0.139 & & & & & & & 0.006 & 0.005 & 0.001 \\
\hline WEPT & & & & 0.797 & 0.627 & 0.134 & & & & 0.098 & 0.036 & 0.024 & & & \\
\hline WEDT & & & & 0.806 & 0.633 & 0.142 & 0.546 & 0.503 & 0.027 & & & & & & \\
\hline WKPD & 0.651 & 0.322 & 0.165 & & & & & & & & & & 0.007 & 0.007 & 0.001 \\
\hline WKPT & 0.639 & 0.330 & 0.168 & & & & & & & 0.065 & 0.031 & 0.014 & & & \\
\hline WKDT & 0.648 & 0.316 & 0.159 & & & & 0.526 & 0.520 & 0.009 & & & & & & \\
\hline WPDT & 0.534 & 0.286 & 0.133 & 0.810 & 0.605 & 0.138 & & & & & & & & & \\
\hline WEKPD & & & & & & & & & & & & & 0.006 & 0.006 & 0.001 \\
\hline WEKPT & & & & & & & & & & 0.065 & 0.029 & 0.015 & & & \\
\hline WEKDT & & & & & & & 0.595 & 0.548 & 0.030 & & & & & & \\
\hline WEPDT $^{*}$ & & & & 0.844 & 0.708 & 0.146 & & & & & & & & & \\
\hline WKPDT & 0.655 & 0.332 & 0.166 & & & & & & & & & & & & \\
\hline
\end{tabular}


As some records were poorly predicted (minimum values), a lower mean prediction value resulted. The best mean values for the extrapolation tests added up for population K (Table 4.5). With only few good predictions with values above 0.6 , and all other populations below this prediction threshold, the model poorly qualified. W was included in all extrapolation models, thus it could not be tested and its overall influence remained high. Combinations with neighbouring metapopulations modified the extrapolation performance slightly. The best results in mean and maximum sample prediction values were obtained from the combination WEPDT, followed by WEPD, WEDT and WED. The poorest results were from WT.

\section{Predicted populations in maps}

Mapped distribution patterns visualise the model-specific site conditions and their suitability for Zelkova (Figure 4.3). Favourable conditions and thus high occurrence probability of Zelkova were indicated by higher values ( 0.6 is frequently used as presence-absence threshold). The three maps exemplify repeatedly occurring predictions for modelled metapopulation combinations: while the distribution patterns of $\mathrm{W}$ and $\mathrm{K}$, derived from $\mathrm{W}$, were well predicted, the others were not (Figure

a) $\mathrm{W}$
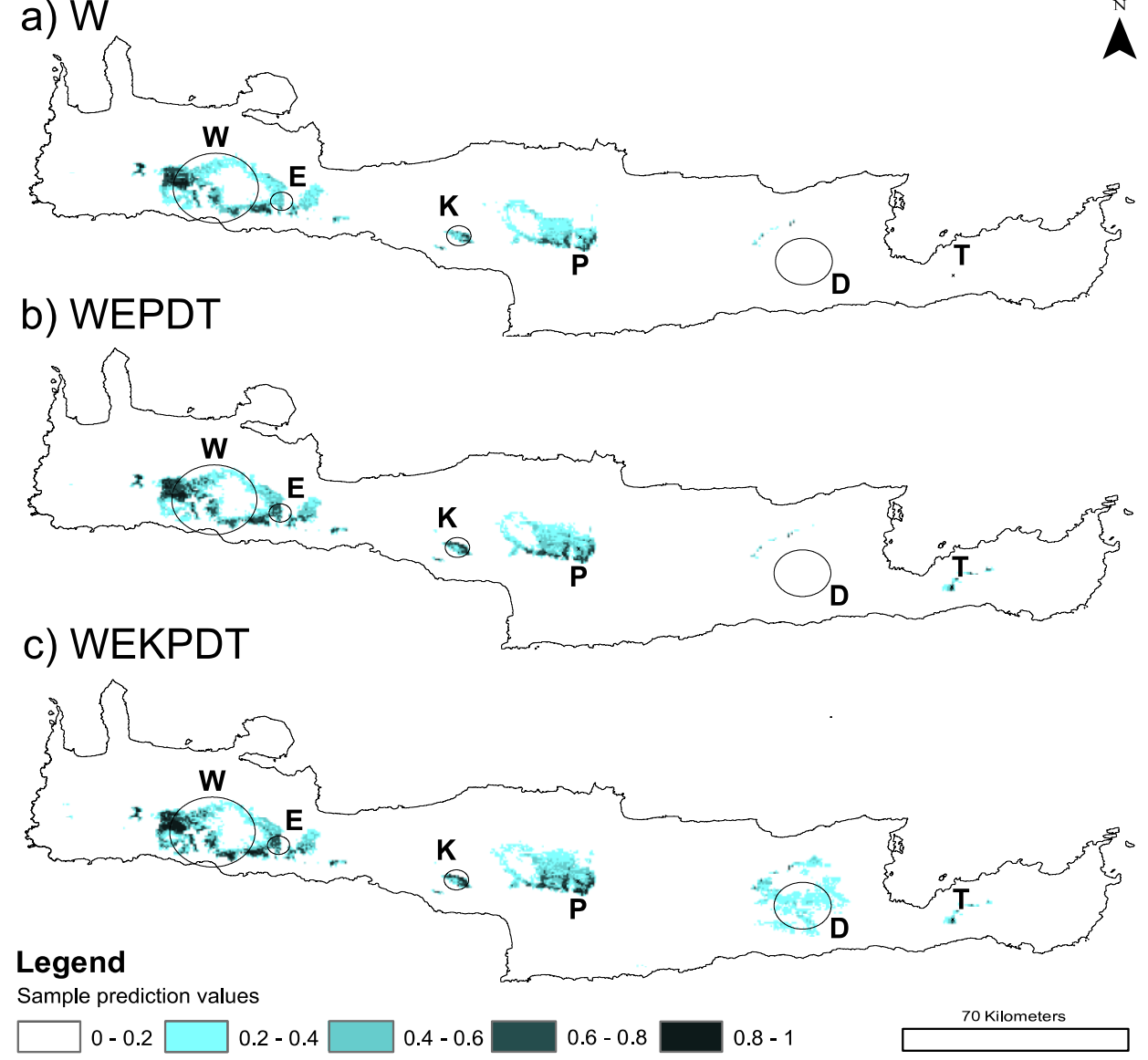

Figure 4.3 Result maps of species distribution modelling (regularized training gain) based on changing combinations of neighbouring populations by using the same set of environmental variables; model based on $\mathrm{W}$ a), WEDPT b) and all six populations in c); values $>0.6$ imply favourable site conditions according to model parameters and likely occurrence. 
4.3a). The map in Figure $4.3 \mathrm{~b}$, based on WEKPT, did not predict population D but it predicted population T, though with rather low values. With all populations included (Figure 4.3c), rather different prediction values applied, some of which were low (D). Populations E, D and T were predicted with low to very low sample prediction values in all three maps. Also in all maps predictions of the Zelkova range were locally overestimated and did not correspond to recent records, for example areas neighbouring west (Apopighadhi range) and east (around Kastro mountain) of the main Lefka Ori metapopulation (W), topmost Agathes mountains east of $E$ and large parts of the Psiloritis range.

\section{Discussion}

\section{Ecology of populations}

Zelkova abelicea needs specific environmental conditions typical for high altitudinal woodlands (Bauer and Bergmeier 2011). Fairly mesic conditions are crucial (Søndergaard and Egli 2006). Such environments are common in the west but less so eastwards due to decreasing rates of precipitation. Beside elevation, a longitudinal gradient is regarded by temperature seasonality in distribution models. We assume less favourable climate conditions towards east to be responsible for scattered or small populations, with frequently dwarfed Zelkova plants. Thus topography-driven climate conditions (topoclimate, mesoclimate) may compensate for less than perfect macroclimatic conditions by mitigating, e.g., irradiation and water stress (Lipscomp and Nilsen 1990a, 1990b; Scherrer et al. 2011). Zelkova abelicea is known for a general preference for such woodland sites (Søndergaard and Egli 2006). The present study even revealed pronounced affinity to low heatload values for the eastern Zelkova populations. As long as there are locally favourable conditions, environments with raised temperature seasonality and lower mean annual precipitation are occupied. The closely related $Z$. sicula is linked to specific topoclimate too (Garfi et al. 2011). Low heatload values as found in Kedros are induced by the orientation of the mountain range, hosting the main population on the windward northern side. The vital Kedros population grows in evergreen woodlands on steep shaded slopes with relatively high precipitation and high potential water run-off (or rather raised percolation). The main Zelkova metapopulation in the western Lefka Ori, an area which receives more precipitation than the other Cretan mountains, is associated with the widest spectrum of site conditions among all populations. Precipitation can be high and steep slopes are colonised there as well. It may be deduced that, together with generally more humid environments, slopes with high potential run-off and permeable soils are preferred by Zelkova abelicea, supporting sizable populations and a broader environmental niche. In drier environments, in contrast, usually moderately sloped or flat terrain, with consequently lower 
potential water run-off and shaded mountain sides, are preferred. As a general rule, populations of Zelkova abelicea were found to be associated with complex but predictable environmental gradients but site condition spectra differ between metapopulations.

\section{Ecological and genetic patterns}

Knowledge about regional ecological and genetic variation is required for many applications (Khadari et al. 2005; Petit et al. 2004; Vander Mijnsbrugge et al. 2010) and may inspire biogeographic and evolutionary research (Thompson 1999). Along environmental gradients, differentiated physiological reactions were recognised for distinct populations of Mediterranean Quercus ilex (Martin-StPaul et al. 2013) and high-Andean pines (Sáenz-Romero et al. 2013), assuming relations between ecology, physiology and genetic variability. Other studies showed that geographic isolation is a driver for species evolution, followed by ecological adaptations of isolated populations (Peterson et al. 1999; Wiens 2004). For Zelkova abelicea, indeed, several genetic markers suggest local patterns of isolated populations (Christe et al. 2014). The authors found that western populations (W, E) are genetically heterogeneous, central populations $(K, P)$ are different but share similarities with that of $D$, and the easternmost population $(T)$ is genetically more pronouncedly separated. We assume that the individual genetic structure of populations may be linked to environmental adaptations. High genetic diversity of the western population corresponds to high diversity of the occupied sites, and a strong genetic separation of the eastern populations comes along with their relative ecological distinctness. Conceivable may be either in situ adaptation to local site conditions or ancient colonisation from genetically and ecologically different lineages. Further research on comparative ecology and functional genetics within and between metapopulations of Zelkova abelicea are necessary.

\section{Environmental variables in models}

Main factors for species distribution models were altitude and temperature seasonality. Topographic conditions had surprisingly little influence on our models; their importance for general distribution was low, though populations showed individual differences. The clear preference of Zelkova abelicea for high elevations supports model compilation. In Mediterranean high mountains specific environmental factors act upon plants, such as low temperatures, snow cover, etc. (Körner 2014), supporting many hardy xero-mesic species such as Zelkova abelicea, many of which being narrow endemics and absent from the lowlands (Bergmeier 2002). Temperature seasonality is known for its fundamental influence on biological processes (Vazquez et al. 2017) and, within the models, expresses an east-west gradient. Annual mean precipitation is based on extrapolation of climate station records and the algorithm comprises a correction for elevation and topographic lee-side effects, but it reduces model performance and was outperformed by the two above mentioned parameters. A reason could be low relevance of overall precipitation patterns for Zelkova abelicea, 
perhaps due to its preference for topoclimatic (mesoclimatic) conditions with factors such as cloud and dew formation, water condensation, snow cover, frost protection, etc. Another reason for weak performance of the dataset can be unreliable or unsuitable annual mean precipitation values for the study area. Climate stations for data extrapolation in the mountains of Crete are lacking. Poor data quality can also be due to underestimated terrain complexity in the algorithm or variability in origins of climatic influences. Coarse grained climate data have been criticised as unsuitable for fine-scale studies like ours (Nadeau et al. 2017).

\section{Distribution maps and extrapolation performance}

Suitable habitats for Zelkova abelicea are scarce in the Cretan mountains and the species is probably declining, boosted by human impact (Egli 1997). Its range may have been less fragmented during more humid periods in the past. In our models the potential distribution range of Zelkova abelicea appears to be overestimated, as especially in western to central Crete some mountains without actual records have been assigned high occurrence probability. Local prediction errors such as near population E may be due to dry lee-side conditions. Further, erroneous distribution gaps cannot be ruled out. Near Imbros Zelkova has only recently been recorded, and especially dwarfed and browsed individuals are easily overlooked. The Psiloritis distribution gap, however, is likely to be actual, and is supported by our models that predict low occurrence probability for most of the mountain range, except for the south-eastern part (Rouvas), where population P occurs in mixed and sheltered stands with Acer sempervirens and Quercus coccifera (Bauer \& Bergmeier 2011).

Heikkinen et al. (2012) reported for MaxEnt models high prediction accuracy for range extrapolations over large areas. This is only partly confirmed by our local study. Scale differences clearly matter, and while the tested model with all records is fairly close in predicting the general distribution pattern, extrapolations fail for populations with markedly different environmental conditions. We assume that marginal ecological conditions deviate too much from the mean and thus hamper model extrapolation. Low prediction accuracy can be due to unbalanced sampling or too simplistic model, as few parameters were included. Our model approximates site conditions but only roughly, while complex environmental conditions may influence mountain plants in many ways, such as by acting upon seedling growth through frost damage (Viveros-Viveros et al. 2009). Low prediction accuracy can thus be due to a lack of environmental as well as biotic data such as of soil parameters, mist and cloud cover frequency, surrounding vegetation, wildfires, grazing intensity and other historical and recent land management. 


\section{Biogeographical implications}

Due to repeated climate change during the Pleistocene and Holocene, changes in plant population numbers, species range and vegetation composition occurred throughout Europe and the Mediterranean (Huntley 1990). As a result of cyclic climate development Mediterranean forests expanded and declined (Combourieu-Nebout 1993). For Zelkova abelicea, as a consequence of changing growth conditions during these cycles, shifts in altitudinal range, retreat to refugia and forest expansion may be assumed. Even so, distinct genetic patterns suggest long-term isolation and limited genetic exchange between metapopulations to the present day (Christe et al. 2014). Similarly, our results show, underlined by prediction patterns, metapopulations in each mountain range to be rather varying in terms of occupied site conditions. Specific abiotic combinations even for nearby metapopulations support the hypothesis of their long-term isolation. This corresponds with the concept of elevation-driven ecological isolation (Steinbauer et al. 2013), enhanced by mountainspecific conditions.

\section{Concluding remarks}

Along an east-west gradient in Crete, Zelkova abelicea shows surprising genetic and site variation. As spectra of site conditions vary among mountains inhabited by Zelkova, metapopulations differ in the range and degree of abiotic parameters. From a methodological point of view, the mountain-specific habitat heterogeneity of Zelkova metapopulations hampers good overall performance of species distribution models. In all Zelkova sites specific topoclimatic conditions are involved that mitigate to some extent unfavourable macroclimatic conditions. Suitable sites are rather rare and require special attention in conservation and forest management. In the Cretan mountains, as emphasised by Bauer \& Bergmeier (2011), current woodland and rangeland degradation as a result of overgrazing is arguably the most fatal impact and counter measures are urgently needed. In spite of the patchy distribution of Zelkova, it is crucial to protect mountain ranges in total, covering complex abiotic conditions, thereby taking account of distributional shift under climate change.

\section{Acknowledgements}

The authors thank L. Fazan, G. Kozlowski, B. Egli and R. Jahn for generous data supply. S. Pasta, L. Fazan and R. Jahn supported this work with lively discussions. N. Kirchhoff and R. Pätsch read an earlier manuscript. Comments by guest editor C. Wellstein and two unknown reviewers brought significant improvements. 
Chapter 5: Geological data significantly reduce the model performance of species distribution models on broad spatial scales. A GIS - based approach from two Mediterranean Islands

Goedecke, F.; Marcenò, C.; Guarino, R.; Jahn, R. \& Bergmeier, E. Geological data significantly reduce the model performance of species distribution models on broad spatial scales. A GIS - based approach from two Mediterranean Islands

Manuscript planned for submission to Diversity and Distributions 


\section{Geological data reduce the model performance of species distribution models on broad spatial scales. A GIS - based approach from two Mediterranean Islands}

\section{Abstract}

Extrapolation of species distribution models is frequently performed for mainland regions, therewith predictions for e.g. unrecorded occurrences of plant species or for difficult terrain can be made. We extended the methodology to isolated regions and applied it to the Mediterranean islands Sicily and Crete. The islands share woody species of the widespread maquis vegetation, belonging to the class Quercetea ilicis. We trained species distribution models in MaxEnt on one island and extrapolated to the other island to test. Precise coordinates were used for 12 woody species, of which four are edaphic specialists and eight are generalists. Additionally bedrock type, topography and macroclimate parameters are included in the models. For these widely-used environmental parameters we describe a selection process, which helps for extrapolation. Models work well chiefly for substrate specialists, while predictions for some species elude from extrapolation. Ecologically and thus spatially restricted specialists perform better then generalists. We discuss several advantages and issues for method; e.g. distinctly different site-conditions for species of the (meta)populations in two isolated regions can hamper extrapolations. Models performed well when climate data and relief were included, whereas performance was lowered for models comprising bedrock types. Differences in the affinity to bedrock types, in the isolated test region can be a reason. 


\section{Introduction}

Islands are important model systems, enabling to understand general biological processes and isolation-related patterns, for sharing "the hard boundary of the sea" (Bramwell and Caujapé-Castells 2011). Mayor evolutionary and biogeographic theories were developed with by investigating island organisms and they still offer research perspectives. Also the Mediterranean basin comprises islands to study, hosting at the same time differentiated floras and common generalists. These common species facilitate ecological comparison and are crucial for manifold applications. To compare ecological patterns species distribution models are an important method. Therefore various algorithms exist (Elith and Leathwick 2009) which usually predict distribution using records of organisms combined with abiotic data such as soil, bedrock type, topography or land use. But modeling distribution in isolated regions can be difficult, i.e. due to varing landscapes configuration across regions. Such environmental variations affect e.g. susceptibility for invasive neophytes (Lambdon et al. 2008).

While niche conservatism is a basic paradigm of species distribution modeling (Peterson et al. 1999; Wiens et al. 2010), Morphologically similar isolated populations can differ in ecological niche but even in genetic constitution (Broennimann et al. 2007; Christe et al. 2014; Violle et al. 2012), particularly effecting evolution and ecology (Johnson and Stinchcombe 2007). To differentiate species environment relations extrapolations are increasingly used in ecological research (Miller et al. 2004). In this context reciprocal extrapolation for split datasets applies for methodological optimization. Several authors modeled distributions of isolated subpopulations of species, e.g. mammals for spatial bins in South America (Radosavljevic et al. 2014) and amphibians in Australia (Elith et al. 2010). Heikkinen et al. (2012) tested reciprocal extrapolation for Finnish forest plants in neighbouring regions. Extrapolation was performed using continental bird data to test predictive performance (Bahn and McGill 2013; Peterson et al. 2007); but also on global scale too detect fungal diseases patterns (Escobar et al. 2014). Martínez-Meyer and Peterson (2006) addressed temporal extrapolation for recent and Last Glacial Maximum tree pollen taxa and discuss niche evolution. Similarly temporal scales were compared in further studies (Maguire et al. 2015; Svenning et al. 2011). The latter examples comprised successful approaches of extrapolations. But when species distribution models are extrapolated outside training regions fundamental issues apply. Especially differences in environmental parameters cause trouble in predictions (Stohlgren et al. 2011; Young et al. 2012).

A complex interplay of various environmental parameters limits the growth conditions of plants and their occurrence; to account therefore a set of environmental variables is usually combined. Climate datasets are mostly integrated therin. They cover different spatial and temporal scales and various 
resolutions; having their pros and cons (García-López and Real 2014; Suggitt et al. 2017). Many ecological studies used climatic data for global scales for modelling. These frequently used highresolution data are based on interpolation of climate station data e.g. Worldclim which integrates elevation to generate climate data surfaces (Hijmans et al. 2005). Karger et al. (2016) improved highresolution calculations using various parameters from global digital terrain models and cross checks with reliable alternative climate data. We aim to support the test of the dataset with this study comparing islands. The two studied islands share the biogeographic region, are similar in general site conditions and comprise a well-studied species-rich flora. Even if environmental conditions overlap, we propose strategies of parameter selection helping to extrapolate species distribution models for isolated populations. The complexity of ecological interactions comprising topography and substrate features (e.g. Copeland and Harrison 2015; Helman et al. 2017; Kessler 2002; Kopecký and Čížková 2010; Meentemeyer et al. 2001), should be regarded in this study as well. Thus we test the influence of topography and bedrocks on extrapolation performance. Following questions are intended to be answered: I) To what extent can a model calibrated on one island be a good predictor of the distribution of a given species on another island? II) Which are the most influential variables in our distribution modeling and are they the same on both islands for a given species? III) Is the observed shifting ecological behaviour (and related occurrence probability) of a given species more influenced by climatic, by geomorphological or by edaphic drivers?

\section{Materials and methods}

\section{Study area}

We chose two of the largest Mediterranean islands as study area. Sicily is located in the Central Mediterranean, while Crete is located in the South-Aegean Sea about $750 \mathrm{~km}$ eastwards. The first has an area of $25,500 \mathrm{~km}^{2}$ while the second covers almost one third of the big neighbour and stretches from east to west for about $250 \mathrm{~km}$. Sicily (Meulenkamp and Sissingh 2003) and Crete (Meulenkamp et al. 1988) are considered to be islands during most of the Tertiary. Therewith sea level and geological uplifts were important factors. Today Sicily's shortest distance to the mainland coast is 3 $\mathrm{km}$ at the strait of Messina, thus biogeographical connection to the Italian mainland applies. Crete is more isolated with a distance of about $100 \mathrm{~km}$ to Peloponnese-Peninsula, whereas arc-forming islands are virtually reducing the distance as stepping-stones for migrating organisms. While volcanism contributes markedly to the Sicilian landscape, on Crete volcanic rocks and basalts are merely absent. Hard limestones and metamorphic rocks prevail in the main Cretan mountain massifs, but have minor proportions on Sicily. Flysch series, Quaternary and Neogene sediments form vast areas in the lower altitudes of both islands. For the island regions coastal areas are facing pronounced Mediterranean summer drought. With higher altitudes precipitation rises and mean 
temperatures decrease, which allows Euro-Siberian taxa to thrive (e.g. Berberis, Betula, Populus). A general climatic gradient is formed within the Mediterranean study region by decreasing precipitation from West to East.

\section{Species data}

Published Atlas Flora Europaea volumes 1-13 show 35\% floristic similarity for the two islands (Junikka et al. 2006). High endemism rates apply for both regions: So Crete hosts $10.4 \%$ (Jahn and Schönfelder 1995) and Sicily even 11.6\% (Brullo et al. 2004). Similar is likewise the set of woody species within the vegetation class Quercetea ilices for both regions. This Vegetation unit comprises woodlands and scrubs, commonly dominating landscapes in the Mediterranean Basin. It is often altered by historical or recent anthropogenic land use (Pignatti 2003; Quézel 2004). Therewith species have particular relevance for climax vegetation of mostly lower altitudinal belts. Thus for 12 Mediterranean woody member species of this syntaxon we collected 4311 geographically resampled records (Table 5.1). These records derive from plot data and floristic data from Crete (Bergmeier 2012; unpublished material) and relevées from Sicily (Appendix Table A 5.2). We applied a broad taxonomic concept merging closely related taxa, which are treated as subspecies or even different species in literature; nomenclature follows (Euro+Med 2006-2017). Subsets of the same species in two regions are considered as (meta)populations. Ecological specialist species and generalist species among the woody species were distinguished based on expert knowledge.

Table 5.1 Taxa used in this study and their records for each island, Nomenclature follows (Euro+Med 2006-2017)

\begin{tabular}{llcc}
\hline Taxon name & Plant family & $\begin{array}{c}\text { Records from } \\
\text { Sicily }\end{array}$ & $\begin{array}{c}\text { Records from } \\
\text { Crete }\end{array}$ \\
\hline Arbutus unedo L. & Ericaceae & 57 & 60 \\
Ceratonia siliqua L. & Fabaceae & 116 & 116 \\
Erica arborea L. & Ericaceae & 135 & 135 \\
Euphorbia dendroides L. & Euphorbiaceae & 166 & 166 \\
$\begin{array}{l}\text { Juniperus oxycedrus subsp. } \\
\text { macrocarpa (Sm.) Ball }\end{array}$ & Cupressaceae & 20 & 20 \\
$\begin{array}{l}\text { Juniperus phoenicea subsp. } \\
\text { turbinata (Guss.) Nyman }\end{array}$ & Cupressaceae & 34 & 34 \\
$\begin{array}{l}\text { Olea europaea L. subsp. europaea } \\
\text { (no cultivars) }\end{array}$ & Oleaceae & 298 & 298 \\
Phillyrea latifolia L. & Oleaceae & 251 & 251 \\
$\begin{array}{l}\text { Pistacia lentiscus L. } \\
\text { Pistacia terebinthus subsp. }\end{array}$ & Anacardiaceae & 433 & 433 \\
terebinthus L. & Anacardiaceae & 133 & 133 \\
Quercus coccifera L. & Fagaceae & 59 & 59 \\
Quercus ilex L. & Fagaceae & 452 & 452 \\
\hline Records per island & & 2154 & 2157 \\
\hline Number of all records & & & $\mathbf{4 3 1 1}$ \\
\hline
\end{tabular}




\section{Data handling in the GIS}

In ARCGIS 10.2 (ESRI 2013) coordinates of species records are handled as point data and environmental datas as a raster format. The programm was also used to create maps for species distributions and prediction results from MaxEnt models described later. For environmental data a 1km-grid was used with 35,634 cells covering both islands (EEA 2012). Climate data were obtained from CHELSA (Karger et al. 2016) for annual mean temperatures (t_mean) and annual precipitation sums (ann_prec). Additionally slope angle (slope) and compound topographic index (cti) were calculated from a digital elevation model (EEA 2015) using the GIS extension by Evans et al. (2014). $C T I$ is a wetness index, which accounts for slope position and the upstream contributing area of the watershed (Gessler et al. 1995, Moore 1991). As proxy for substrates geological maps were integrated. Simplified stratigraphic and lithological units follow map legends (Fierotti 1988; HGME 1959-2002): a) Quaternary and Neogene sediments, b) hard limestones, c) flysch series, d) gypsum, e) volcanites including basalts and pillow lava, and f) metamorphic rocks mostly causing acidic soil reaction. In the GIS the percentage of each geological unit was quantified for the grid cells resulting in individual data layers for each unit. All environmental data layers were handled in the same extant and the same projection. For their import in MaxEnt they were transformed to ASCl-files.

\section{Variable selection}

Environmental differences exist in the study are, but extrapolation of species distribution is problematic for unequally distributed values of abiotic variables on the two islands. To overcome such difficulties only those environmental parameters with a comparable range of values on the two islands were used, according to Anova tests (Figure 5.1, IBM SPSS Statistics for Windows, Version 22, Armond, NY). Secondly, to avoid collinearity only those with $R^{2}<0.6$ in Pearson correlations were included (Appendix Figure A 5.1; R Development Core Team 2017; Revelle 2017). Area Under the Curve (AUC) was used as unreflected usage (Lobo et al. 2008), it remains a measure frequently applied for model evaluation, allowing the comparison of models for the same species in the same area. The proposed order of selection steps gives higher and thus better AUC-values compared to the reverse one. The following variables were used in this study: ann_prec annual precipitation, $t$ _mean annual mean temperatures, slope angle, cti compound topographic index; and the bedrock types: meta metamorphic rocks, lime limestones, basa volcanic and basaltic rocks, sedi Quaternary and Neogene sediments, flys flyschs, a measure for model evaluation. Despite the fact, that AUC is criticised for gyps gypsum. All further available climate variables (for a list see Karger et al. 2016), altitude, heatload index (McCune and Keon 2002) and solar radiation index (Rich et al. 1994) did not fulfil the filtering criteria. 

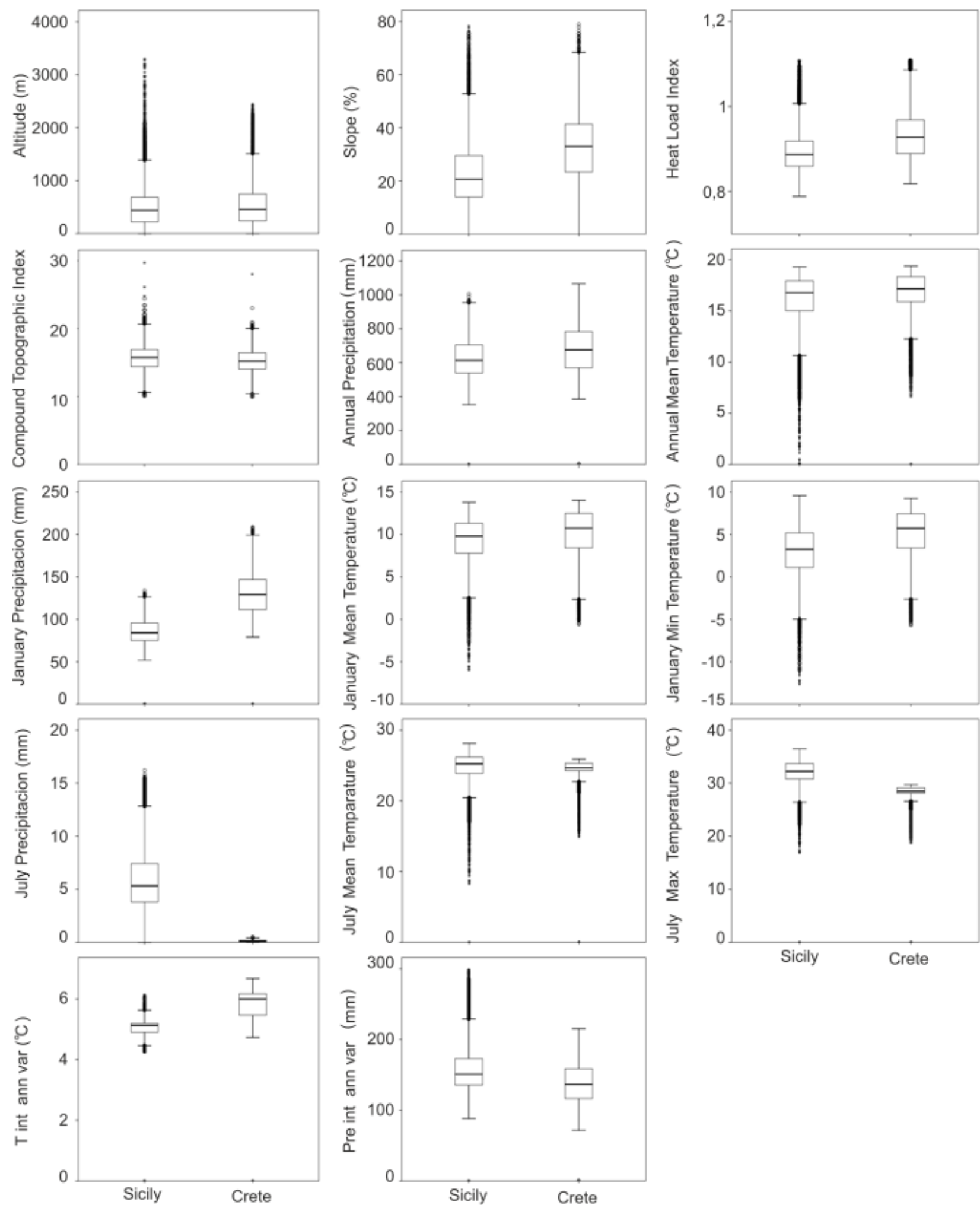

Figure 5.1 Range of environmental variables for the two study regions Sicily (left) and Crete (right) based on values from $1 \mathrm{~km}$ grid cells; Pre int ann var Interannual variation of Precipitation, $T$ int ann var interannual variation of Temperatures. 


\section{Modeling}

For the calculation of species distribution models we used MaxEnt Software version 3.3.4 (Phillips et al. 2006). It gives predicted probabilities of occurrence for the species in raster cells by combining point distributions of species and abiotic raster data for these cells. We calculated two MaxEntmodels for every species, each one trained on either Crete or Sicily. Those records from the second island which were not used for training served as test data. This reciprocal testing allowed the comparison of the prediction values and to infer differences in model performance. AUC-values were used to evaluate extrapolation quality of models, but should as well serve as an indirect measure of the difference in the realised ecological niche. We expect that minor AUC-differences apply, when species are equally extrapolated to the respective test region. Hence a varying AUCvalue between regions is related to diverging abiotic conditions in the training and test region. Additionally different combinations of the three factors climate, topography and geology were tested in models. These environmental factors represent groups of environmental variables: rel relief comprises slope and cti; cli climate contains ann_prec and $t$ _mean; and geol summarises the joint influence of the six distinguished geological units. Single factors and their combinations are used in models and tested according to AUC-values. The individual influence of the 10 environmental variables is evaluated as well by using jacknife tests. They account for relative importance on the test gain of the models.

\section{Results}

In their affinity to bedrock types the selected species differ on both islands (Table 5.2). Further the edaphic specialists from the Ericaceae family Arbutus and Erica occupy metamorphic rocks on Crete in about $70 \%$ of their sites, while in Sicily they cover a wide bedrock spectrum comprising also flyschs. The two Juniperus species growing near the coasts of both islands on predominatly sandy sediments are specialists as well, but in Crete they additionally occupy limestones to larger extant. These limestones are frequently overblown by sands in Crete, which disregarded in the geological basemaps. Generalist species covering similar bedrock spectra on islands are Ceratonia siliqua and Pistacia lentiscus. Generalists cover a wide range of bedrock types on both islands, but some differ markedly in covered substrates. On Crete $60 \%$ of sites where Euphorbia dendroides thrives are on limestones and $25 \%$ on sediment rocks, while in Sicily it occurs on the latter substrate in highest proportions but additionally on limestone, flysch and volcanic rocks. Volcanic rocks are a particularity in Sicily without analogues in Crete. Almost one fifth of Sicilian records of Olea europaea and Phillyrea latifolia are on volcanic rocks; for Quercus ilex this rock type makes 35\% of all sites and for Pistacia terebinthus even 45\%. Pronounced differences apply for occupied substrates of Quercus coccifera: $81 \%$ of sites for Sicily are on sediments, stretching merely near the 
southern coast, while in Crete the species is omnipresent with two third of records on wide-spread hard limestones. But also relief and climatic variables differ for the studied maquis species (Figure A 5.2). Q. coccifera is outstanding for its affinity to high cti and low slope angle; and this species grows in a dry environment with lower annual precipitation and higher temperatures in Sicily compared to Crete. Sicilian juniper sites appear to be similar with high cti, low slope and lowered annual precipitation.

Table 5.2 Woody species on Crete $(\mathrm{Cr})$ and Sicily (Si) with their affinity to bedrock types in \% of records: basa basalts and volcanic rocks, flys mostly Mesozoic flysch series, lime hard Tertiary to Mesozoic limestone, meta mostly acidic metamorphic rocks, sedi Neogene and Quaternary sediments, gyps gypsum.

\begin{tabular}{|c|c|c|c|c|c|c|c|}
\hline \multirow[b]{2}{*}{ Species } & \multirow[b]{2}{*}{ island } & \multicolumn{6}{|c|}{ bedrock types } \\
\hline & & basa & flys & lime & meta & sedi & gyps \\
\hline \multicolumn{8}{|l|}{ Edaphic specialists } \\
\hline \multirow{2}{*}{ Arbutus unedo } & $\mathrm{Cr}$ & 0 & 1 & 16 & 67 & 17 & 1 \\
\hline & $\mathrm{Si}$ & 9 & 33 & 16 & 23 & 19 & 0 \\
\hline \multirow{2}{*}{ Erica arborea } & $\mathrm{Cr}$ & 0 & 0 & 13 & 71 & 15 & 0 \\
\hline & $\mathrm{Si}$ & 13 & 38 & 9 & 19 & 22 & 1 \\
\hline \multirow{2}{*}{ Juniperus oxycedrus subsp. macrocarpa } & $\mathrm{Cr}$ & 0 & 11 & 22 & 0 & 67 & 0 \\
\hline & $\mathrm{Si}$ & 0 & 0 & 16 & 0 & 84 & 0 \\
\hline \multirow{2}{*}{ Juniperus phoenicea subsp. turbinata } & $\mathrm{Cr}$ & 0 & 8 & 30 & 6 & 54 & 0 \\
\hline & $\mathrm{Si}$ & 0 & 5 & 0 & 0 & 95 & 0 \\
\hline \multicolumn{8}{|l|}{ Generalists } \\
\hline \multirow{2}{*}{ Ceratonia siliqua } & $\mathrm{Cr}$ & 0 & 3 & 36 & 14 & 45 & 1 \\
\hline & $\mathrm{Si}$ & 11 & 5 & 32 & 0 & 41 & 11 \\
\hline \multirow{2}{*}{ Euphorbia dendroides } & $\mathrm{Cr}$ & 0 & 4 & 61 & 8 & 25 & 0 \\
\hline & $\mathrm{Si}$ & 20 & 16 & 20 & 0 & 42 & 2 \\
\hline \multirow{2}{*}{ Olea europaea subsp. europaea } & $\mathrm{Cr}$ & 0 & 7 & 39 & 18 & 34 & 0 \\
\hline & $\mathrm{Si}$ & 18 & 14 & 22 & 0 & 42 & 5 \\
\hline \multirow{2}{*}{ Phillyrea latifolia } & $\mathrm{Cr}$ & 0 & 2 & 53 & 24 & 20 & 0 \\
\hline & $\mathrm{Si}$ & 19 & 9 & 26 & 0 & 35 & 12 \\
\hline \multirow{2}{*}{ Pistacia lentiscus } & $\mathrm{Cr}$ & 0 & 5 & 33 & 12 & 49 & 0 \\
\hline & $\mathrm{Si}$ & 14 & 14 & 23 & 0 & 42 & 7 \\
\hline \multirow{2}{*}{ Pistacia terebinthus subsp. terebinthus } & $\mathrm{Cr}$ & 0 & 4 & 44 & 21 & 30 & 0 \\
\hline & $\mathrm{Si}$ & 45 & 2 & 34 & 0 & 19 & 0 \\
\hline \multirow{2}{*}{ Quercus coccifera } & $\mathrm{Cr}$ & 0 & 4 & 63 & 14 & 17 & 0 \\
\hline & $\mathrm{Si}$ & 0 & 7 & 12 & 0 & 81 & 0 \\
\hline \multirow[t]{2}{*}{ Quercus ilex } & $\mathrm{Cr}$ & 0 & 2 & 37 & 44 & 17 & 0 \\
\hline & $\mathrm{Si}$ & 35 & 14 & 23 & 3 & 23 & 2 \\
\hline
\end{tabular}

Further species are rather similar in their affinity to the four relief and climate variables tested (Figure A 5.2). In this study also complex ecological interactions are considered, assessed in species distribution modelling for which results of jacknife tests are displayed here (Table 5.3). Percentages of maximum regularized training gain reflect the importance of environmental variables for the fitting of models to training data. Only for two species environmental variables were the same on both islands, for J. phoenicea subsp. turbinata with annual mean temperatures and for P. latifolia the slope angle were most relevant an (Table 5.3); in contrast the other species differed in 
Table 5.3 Percentages of maximum regularized training gain from species distribution modles evaluated in jacknife tests for Crete $(\mathrm{Cr})$ and Sicily $(\mathrm{Si})$ concerning the influence of single environmental variables: ann_prec annual precipitation sums, $t \_$mean mean annual temperatures, slope angle of slope, cti compound topographic index, geology follows table 5.2.

\begin{tabular}{|c|c|c|c|c|c|c|c|c|c|c|c|c|}
\hline $\begin{array}{l}\frac{\mathscr{c}}{0} \\
\frac{\mathscr{d}}{\infty} \\
\frac{0}{\infty}\end{array}$ & & 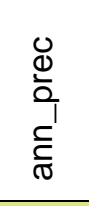 & $\begin{array}{l}\underset{c}{\mathbb{\varpi}} \\
\stackrel{\Phi}{E} \\
\stackrel{+}{\mid}\end{array}$ & $\frac{\frac{0}{0}}{\infty}$ & $\overline{0}$ & $\stackrel{\frac{\pi}{\omega}}{\varepsilon}$ & $\stackrel{\mathscr{E}}{\underline{\underline{E}}}$ & 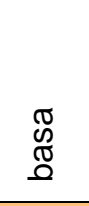 & $\begin{array}{l}\overline{\bar{d}} \\
\text { 心 }\end{array}$ & $\stackrel{\infty}{\gtrless}$ & $\stackrel{\infty}{a}$ & 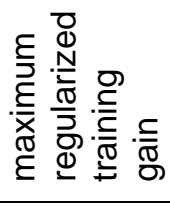 \\
\hline \multirow{2}{*}{ Arbutus unedo } & $\mathrm{Cr}$ & 23.0 & 11.5 & 27.6 & 2.8 & 78.3 & 2.8 & 5.1 & 10.1 & 7.8 & 1.4 & 2.17 \\
\hline & $\mathrm{Si}$ & 49.2 & 3.3 & 18.0 & 4.9 & 31.1 & 0.0 & 1.6 & 21.3 & 19.7 & 9.8 & 0.61 \\
\hline \multirow{2}{*}{ Erica arborea } & $\mathrm{Cr}$ & 33.1 & 16.5 & 18.6 & 4.1 & 78.5 & 2.5 & 4.5 & 13.6 & 0.5 & 2.1 & 2.42 \\
\hline & $\mathrm{Si}$ & 42.7 & 28.2 & 36.8 & 7.3 & 18.2 & 7.3 & 6.8 & 2.5 & 2.5 & 2.7 & 1.10 \\
\hline \multirow{2}{*}{$\begin{array}{l}\text { Juniperus oxycedrus } \\
\text { subsp. macrocarpa }\end{array}$} & $\mathrm{Cr}$ & 0.0 & 68.8 & 3.3 & 0.0 & 2.1 & 0.4 & 4.6 & 2.1 & 0.0 & 2.5 & 2.40 \\
\hline & $\mathrm{Si}$ & 33.9 & 6.3 & 53.6 & 13.5 & 2.6 & 3.1 & 6.3 & 7.3 & 0.9 & 3.1 & 1.92 \\
\hline \multirow{2}{*}{$\begin{array}{l}\text { Juniperus phoenicea } \\
\text { subsp. turbinata }\end{array}$} & $\mathrm{Cr}$ & 2.6 & 53.8 & 4.1 & 0.0 & 4.6 & 5.1 & 5.6 & 6.2 & 8.7 & 2.6 & 1.95 \\
\hline & $\mathrm{Si}$ & 9.8 & 72.1 & 0.0 & 14.8 & 4.1 & 10.7 & 9.0 & 0.8 & 0.0 & 1.2 & 1.22 \\
\hline \multirow{2}{*}{ Ceratonia siliqua } & $\mathrm{Cr}$ & 1.4 & 17.9 & 23.6 & 1.4 & 21.4 & 15.7 & 8.6 & 15.7 & 4.3 & 4.3 & 1.40 \\
\hline & $\mathrm{Si}$ & 32.1 & 33.7 & 15.3 & 8.2 & 5.6 & 3.1 & 4.1 & 11.2 & 0.5 & 6.6 & 0.98 \\
\hline \multirow{2}{*}{$\begin{array}{l}\text { Euphorbia } \\
\text { dendroides }\end{array}$} & $\mathrm{Cr}$ & 2.5 & 16.7 & 30.3 & 1.0 & 7.1 & 36.9 & 5.6 & 14.6 & 3.0 & 3.5 & 1.98 \\
\hline & $\mathrm{Si}$ & 1.4 & 7.7 & 37.5 & 1.4 & 5.3 & 0.0 & 16.3 & 8.2 & 1.4 & 1.4 & 1.04 \\
\hline \multirow{2}{*}{$\begin{array}{l}\text { Olea europaea } \\
\text { subsp. europaea }\end{array}$} & $\mathrm{Cr}$ & 3.9 & 12.7 & 31.4 & 2.0 & 26.5 & 28.4 & 12.7 & 15.7 & 2.9 & 6.4 & 1.02 \\
\hline & $\mathrm{Si}$ & 7.8 & 20.8 & 15.6 & 1.3 & 7.8 & 1.3 & 6.5 & 15.6 & 1.3 & 2.6 & 0.77 \\
\hline \multirow{2}{*}{ Phillyrea latifolia } & $\mathrm{Cr}$ & 16.4 & 10.2 & 39.5 & 5.5 & 33.2 & 33.6 & 10.2 & 21.9 & 6.3 & 5.5 & 1.28 \\
\hline & $\mathrm{Si}$ & 9.7 & 12.9 & 19.4 & 1.6 & 9.7 & 8.1 & 6.5 & 17.7 & 0.0 & 1.6 & 0.62 \\
\hline \multirow{2}{*}{ Pistacia lentiscus } & $\mathrm{Cr}$ & 1.5 & 9.5 & 12.4 & 0.7 & 11.7 & 10.2 & 9.5 & 13.1 & 4.4 & 3.6 & 1.37 \\
\hline & $\mathrm{Si}$ & 17.2 & 25.4 & 9.0 & 3.7 & 6.7 & 3.0 & 6.0 & 11.9 & 1.5 & 3.0 & 0.67 \\
\hline \multirow{2}{*}{$\begin{array}{l}\text { Pistacia terebinthus } \\
\text { subsp. terebinthus }\end{array}$} & $\mathrm{Cr}$ & 17.8 & 9.9 & 34.9 & 5.3 & 34.2 & 23.7 & 7.9 & 9.2 & 4.6 & 3.9 & 1.52 \\
\hline & $\mathrm{Si}$ & 5.3 & 35.6 & 3.0 & 3.0 & 3.8 & 12.9 & 35.6 & 21.2 & 3.0 & 4.5 & 1.32 \\
\hline \multirow{2}{*}{ Quercus coccifera } & $\mathrm{Cr}$ & 15.4 & 9.1 & 42.3 & 4.9 & 31.7 & 55.3 & 9.8 & 23.6 & 36.6 & 52.8 & 1.23 \\
\hline & $\mathrm{Si}$ & 20.0 & 56.4 & 23.6 & 4.3 & 3.6 & 5.7 & 7.9 & 18.6 & 1.1 & 4.3 & 1.40 \\
\hline \multirow{2}{*}{ Quercus ilex } & $\mathrm{Cr}$ & 27.7 & 12.8 & 31.4 & 6.4 & 57.4 & 12.8 & 6.4 & 13.8 & 4.8 & 3.2 & 1.88 \\
\hline & $\mathrm{Si}$ & 6.1 & 15.3 & 33.7 & 4.6 & 1.5 & 6.1 & 30.6 & 21.4 & 2.0 & 4.1 & 0.98 \\
\hline
\end{tabular}

combinations of variables, so for $A$. unedo and E. arborea over $78 \%$ of the training gain was explained by metamorphic rocks on Crete, while for Sicily precipitation was the most important variable instead. In this case the magnitude of records found on this bedrock is similar to the magnitude of training gain in models. Situation differs for the junipers, attributed to the group of specialist species, they occupy coastal sediments in both regions, while in models ann_prec, $t$ _mean and slope are most relevant. The major ecological variable for the kermes oak ( $Q$. coccifera) was 


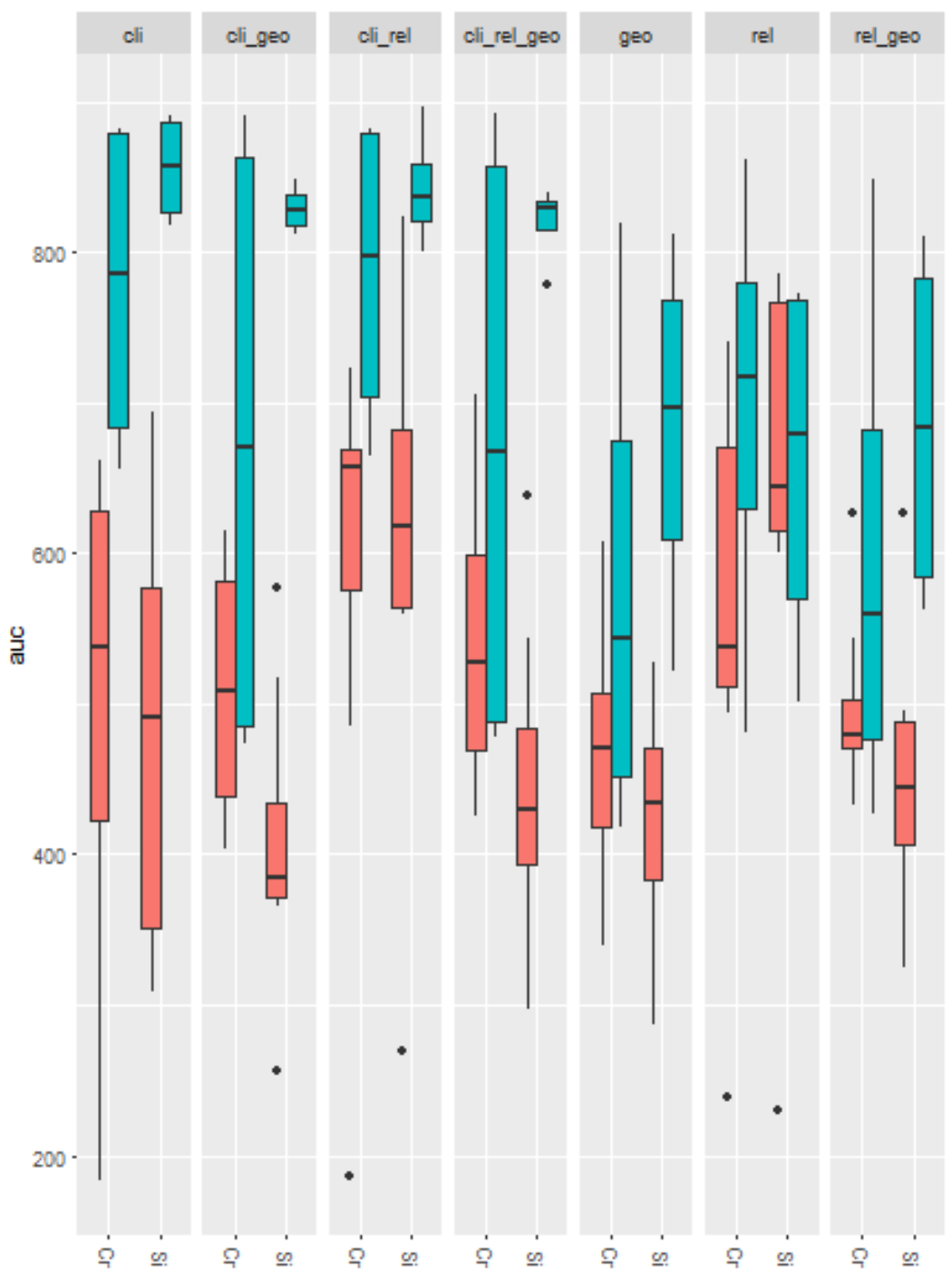

Figure 5.2 Boxplots displaying variation in test AUC-values (x 1000) for woody species trained on Crete $(\mathrm{Cr})$ and Sicily (Si) for 7 combinations of environmental parameters (cli - climate, geo geology, rel - relief). Blue bars indicate ecological specialist species, red bars comprise models for generalists.

a)

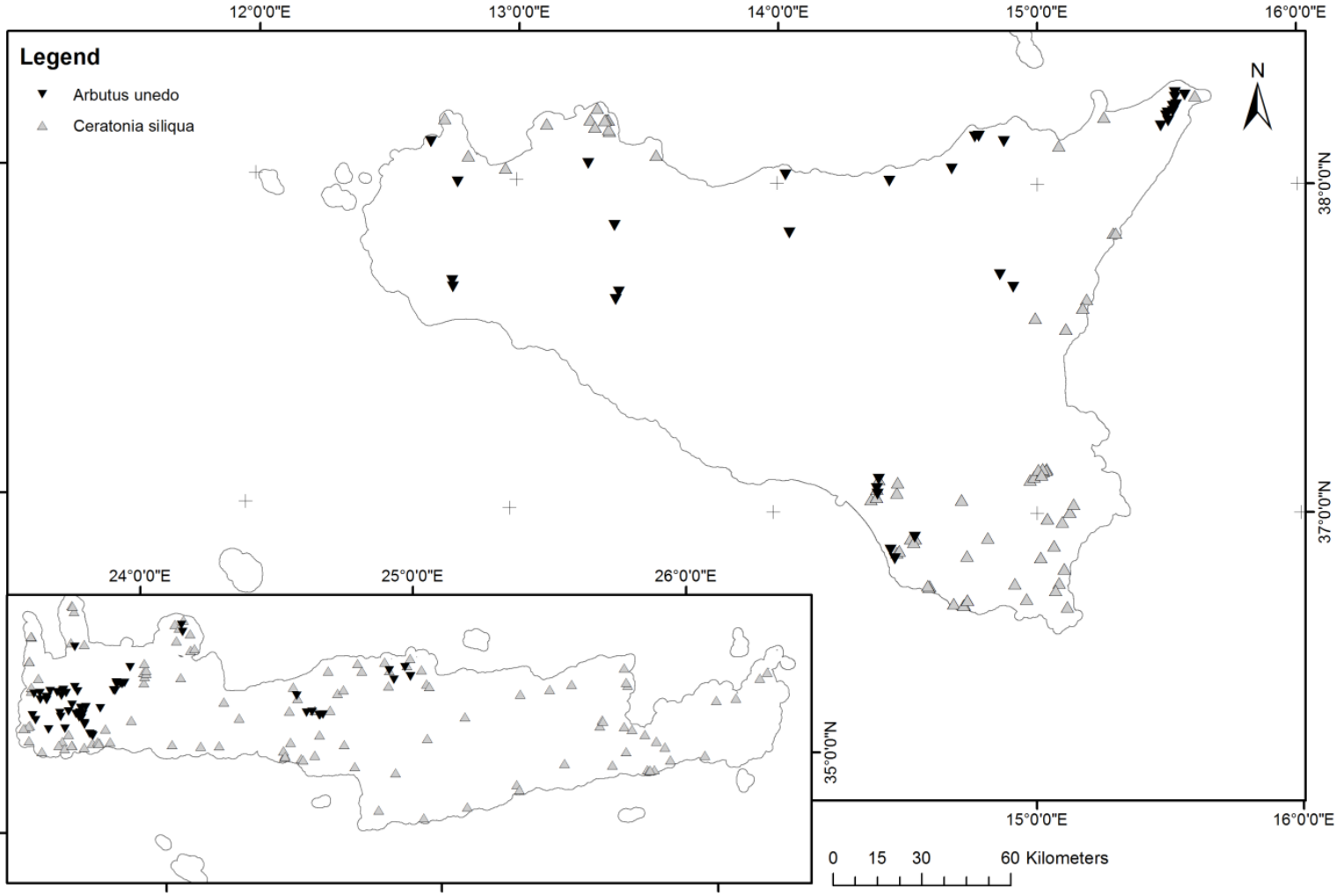


b)

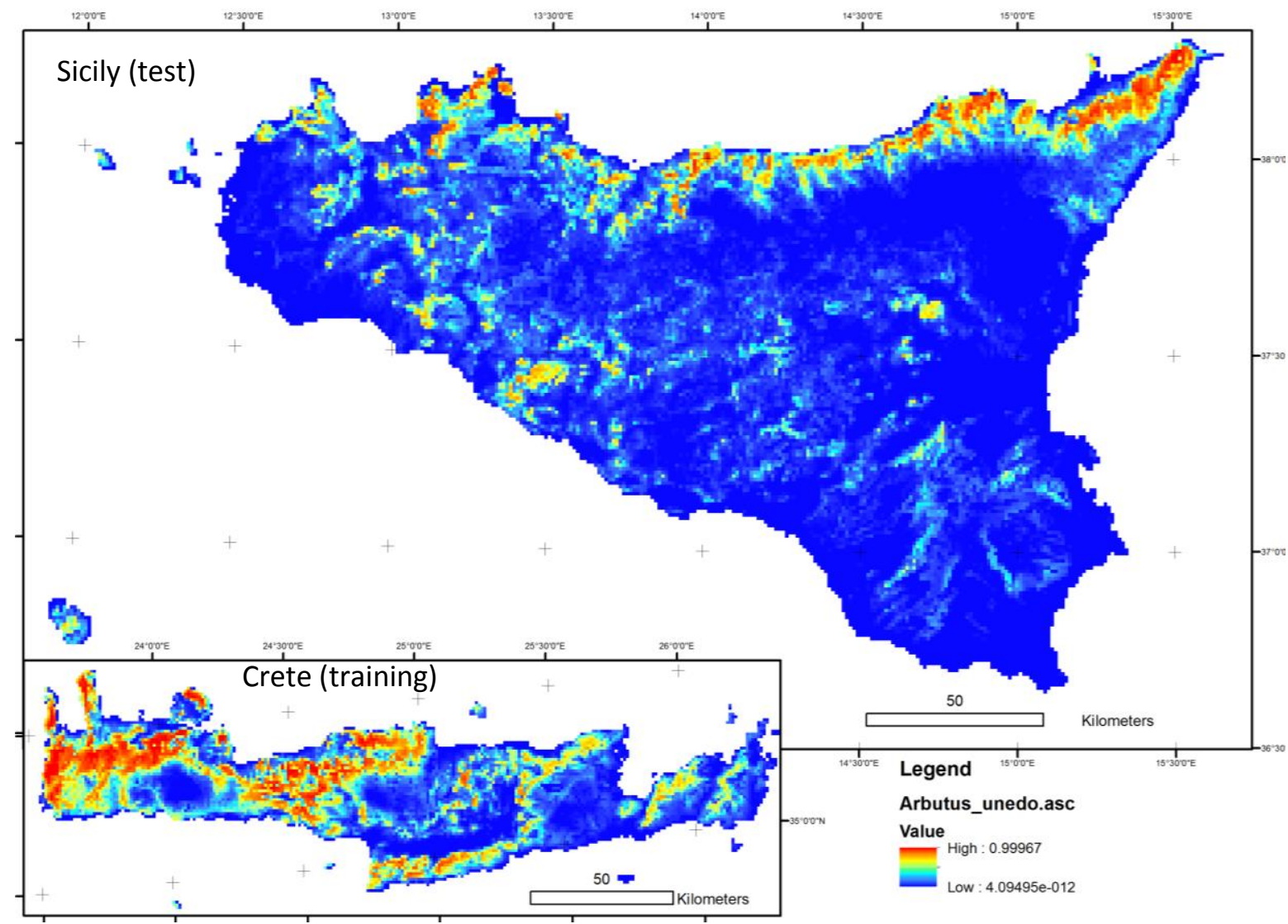

c)

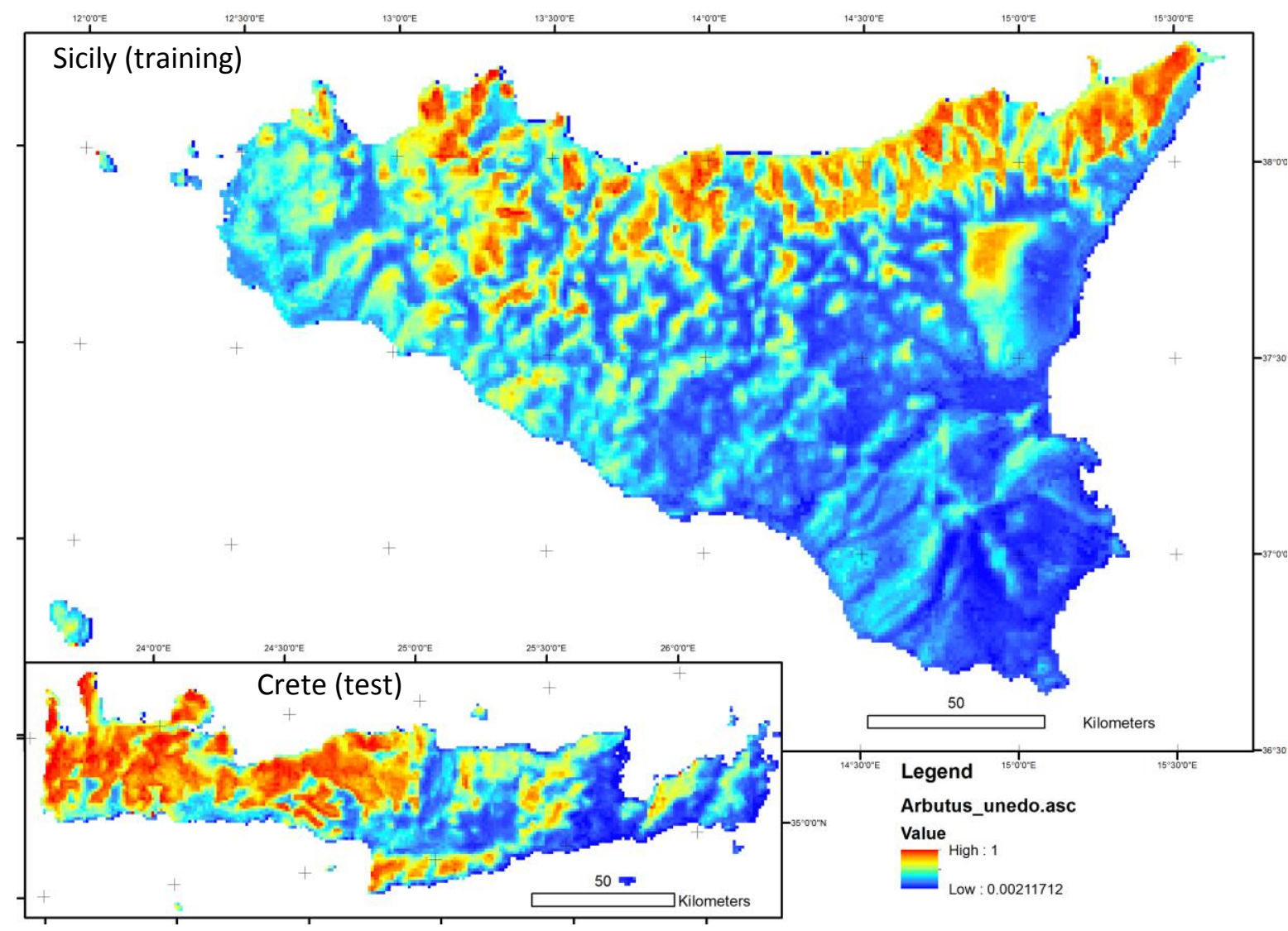


d)

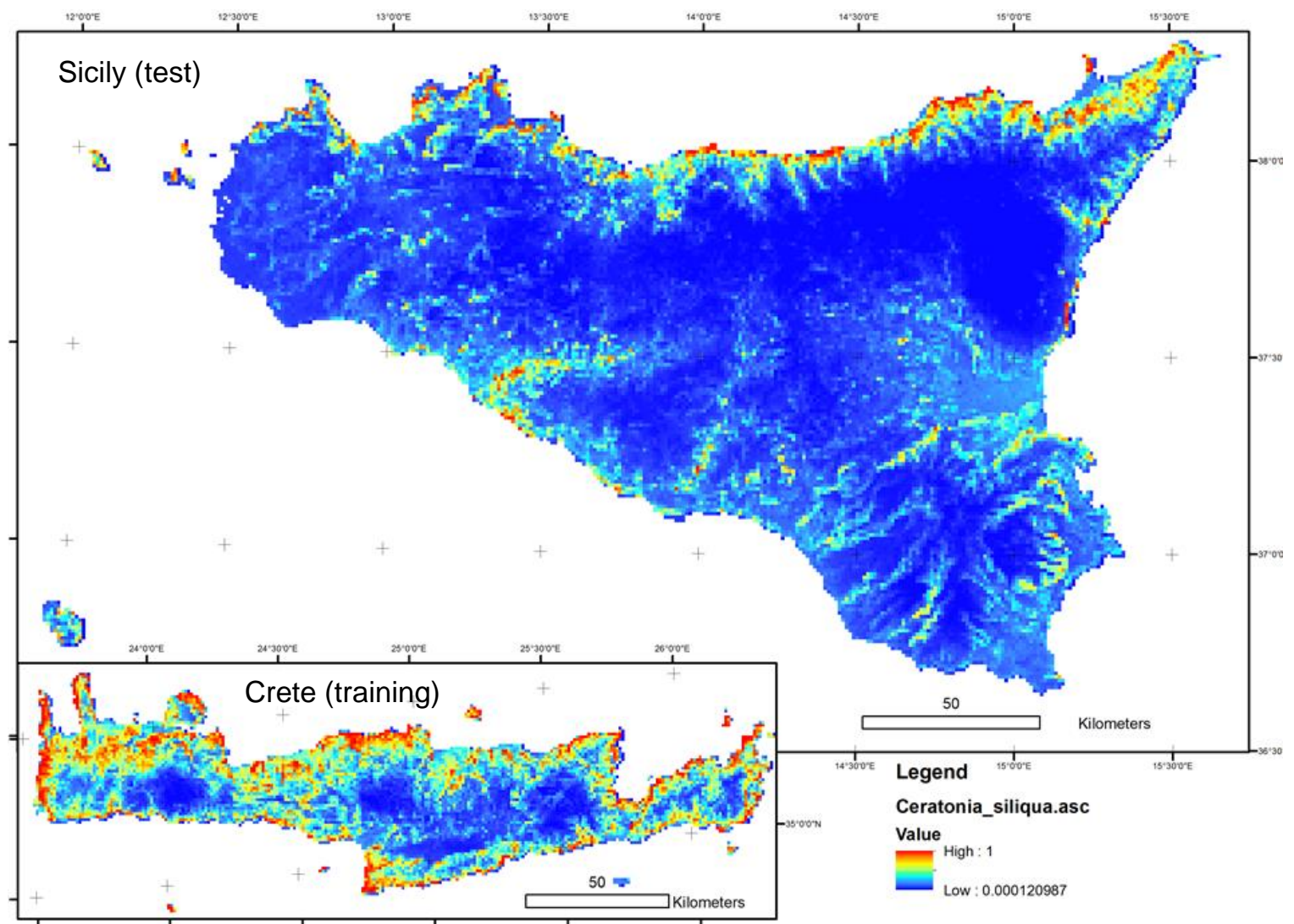

e)

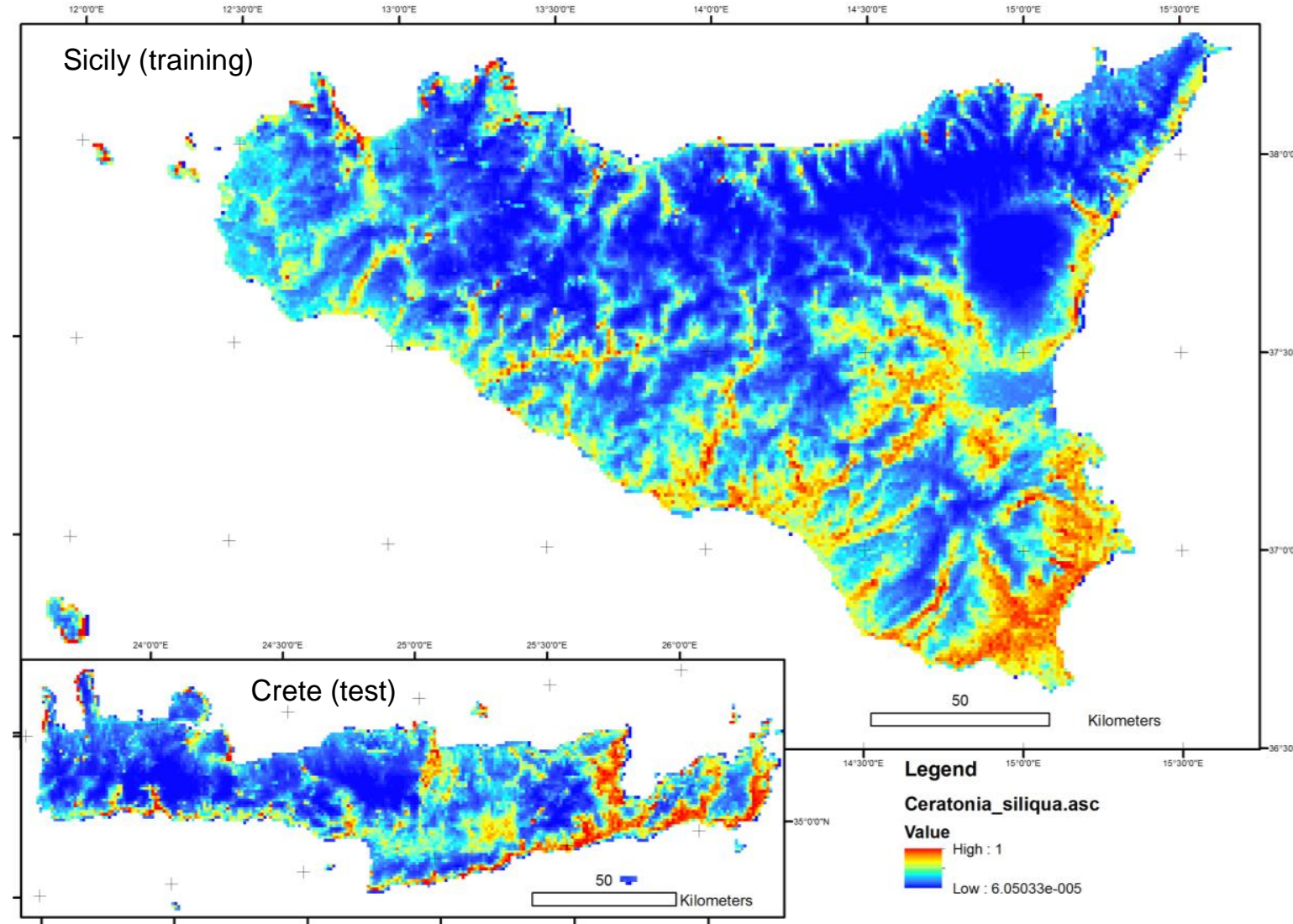

Figure 5.3 Maps for species distribution models trained for Crete (b,d) and Sicily (c,e) and extrapolated to the test island in each case; a, resampled records for both species, b, c: $A$. unedo (edaphic specialist), c,d: C. siliqua (generalist); warmer colours indicate higher probability of species' occurrence. 
t_mean in Sicilian models, but bedrock types had high influence on the Cretan model. Most of the occupied bedrocks are relevant for its distribution, as the species is so wide spread on the latter island. Metamorphic bedrock best supported Cretan models for the second oak Quercus ilex (even though several rock types were occupied), while for Sicily volcanic bedrock and sediments were the most important. Flysch and gypsum generally had low influence on models, but merely the fitting of training data for $Q$. coccifera on Crete and $A$. unedo on Sicily were based on these bedrocks.

Test AUC values were used as an estimate of extrapolation and to compare subsets from the regions as well as ecological generalists and specialists. All tested combinations of environmental variables and maquis species are indicated in the Appendix table A 5.1. Best overall extrapolations are found among the junipers and the two other specialist species. Lowest AUC-values apply for the extrapolation of $Q$. coccifera in the modelling based on "climate" only, "climate+relief" and "relief" only. Among the generalist species Euphorbia dendroides featured good AUC values of 0,723 and 0.824 for the extrapolations to Sicily and to Crete respectively, when climate and relief were considered. Pistacia terebinthus and Quercus ilex performed well in extrapolations using relief features only. The general trends from this table are visualised in boxplots (Figure 5.2); models trained for ecological specialists outperformed those for generalists. Highest mean AUC-values were calculated for specialist's species including climate data in the models, while lowest AUC-values apply, when geology is used. When combinations of different ecological variables are concerned, models trained on Sicily performed better in the extrapolation of specialist's species, while generalists are better predicted by Cretan training points; for models applying only relief parameters the reverse was observed.

Exemplary cases of prediction maps display a specialist and a generalist species with their predicted distribution based on all environmental variables for either Cretan or Sicilian records (Figure 5.3). The model trained on Crete for the edaphic specialist $A$. unedo gives robust results but may underestimate some occurrences in the east of the Sicilian test area (Figure 5.3a). The second image is based on Sicilian records and gives a blurred picture of the delineations of the potential species' distribution (Figure 5.3b), Sicilian and Cretan populations are predicted therewith, but the area is overestimated. Similarly, maps perform well for the training region but extrapolation to the test region is limited for the generalists (Figure $5.3 \mathrm{~d}+\mathrm{e}$ ). For those the potential area in the test region is too small for both extrapolations. 


\section{Discussion}

\section{Quality of extrapolation}

Extrapolation performance for models trained for one island and tested for another island led to good results for few maquis species. Models for taxa with restriction to very particular environments performed best, while other species with a broad ecological niche performed weaker. This is supported by several other studies (Araújo and Guisan 2006; Brotons et al. 2004; Hernandez et al. 2006; McPherson and Jetz 2007). So generally the quality of extrapolation depends on species records and their occupied site conditions. We consider differences in availability of sites to be related to particular ecological environments on individual islands. Together with shifting ecological behaviour it could be a possible reasons for limited extrapolation performance. Technical constraints are connected: because the used MaxEnt algorithm contains a selection procedure, which takes the most suitable ecological variables explaining input distribution of training points; different driving variables apply and extrapolation outputs vary. When the selection of variable combinations is bound too tightly to training data, models may suffer from overfitting, which is a likely reason for the low performance of extrapolation in case of generalists models. Overfitting is especially problematic when ecological conditions vary across the study region. Studied species prefer combinations of site conditions, which do not correspond to those of the training data (Radosavljevic et al. 2014). Additionally overfitting depends on e.g. modeling algorithm, sample selection, complexity of environmental data and their choice. In our study the best prediction results apply for specialist species related to specific coastal conditions. These rather extreme environmental characteristics are restricted in total area and occur on both islands.

Some species, such as $Q$. coccifera, eluded from extrapolation by their very different ecology in the training and the test region In Sicily the species is restricted to sedimentous substrates near the southern coast (Pignatti 1998) where sites have low slope angles and high cti mostly according to our results. Macroclimate in the south of Sicily is hot and dry. Thus the oak species may be restricted to those sites, where topography and bedrock compensate water deficits. Contrary to this assumption $Q$. coccifera occurs together with Juniperus phoenicea subsp. turbinata and is described for sandy substrates with low carbon content and low water holding capacity (Pignatti 1998). On Crete $Q$. coccifera covers various substrates, a wide ecological amplitude and reaches from the coast to almost 1600m a.s.I. (Bauer and Bergmeier 2011; Goedecke et al. 2018; Jahn and Schönfelder 1995; Tsiourlis et al. 2009). Hypothetically also in Sicily the species could have had a wider distribution in earlier times and be reduced to few recent sites due to past extinction events. Alternatively competition could have hindered the spread of the oak species from founder populations along the coast. In a similar way ecological filtering, could constrain expansion of the 
species to an unsuitable surrounding. An example for a species captivated under special ecological conditions is Zelkova sicula, endemic to southern Sicily (Garfi et al. 2011). The strong affinity of Sicilian $Q$. coccifera for sediments and the completely different ecological variables applying for sites, could suggest distinct ecological or even genetic position of the Sicilian taxon. To test this hypothesis, a detailed genetic analysis is needed.

Our results were partially influenced by the availability of different site conditions on both islands. In Sicily gypsum and volcanic rocks represent in total about $10 \%$ of the land surface but are rare on Crete. The exclusion of the records from these two bedrock units could have improved the performance of the model, but this was not the purpose of our approach. Instead, by considering the whole edaphic range of both islands we did not lose the completeness of spatial cover and we accounted for shifts in the species' ecological behaviour.

A crucial point for the extrapolation concerns sampling bias. As Owens et al. (2013) discuss environmental conditions covered by sampled records for the training area do not match the potentially covered ecological range for modeled taxa. The numbers of records per species and island show a wide range (20 to 452). We cannot exclude, that sampled records do not suit to a range of values, which is wide enough for the training and the test region. $Q$. ilex and $P$. lentiscus have the highest sums of records, covering wide ecological spectra and therewith give high site heterogeneity. For the to latter generalists, heterogeneity could hamper model fitting for the training region, and even more ecological heterogeneity and shifted ecological behaviour could decrease extrapolation performance. The fewest records though were available for the two Juniperus species, being ecologically specialized and rare. Their distribution models performed well for the two islands and outperformed those of other species with higher numbers of records.

\section{Driving environmental conditions on the two islands}

The data from global extrapolation of climate stations (Karger et al. 2016) offer a high resolution and were successfully used on large scales. We showed that on regional level such widely used climate data work well to predict species distributions. Caution applies, as few interpolated climate stations are available for a pronounced mountain relief with complex terrain. The regional application of global climate data was discussed by other authors (Beaumont et al. 2016; Nadeau et al. 2017). Our selection of variables for species distribution models resulted in few independent ones, which were expected to generalise conditions sufficiently for both islands and help for extrapolation. Not least because the study of Peterson \& Nakazawa (2008) observing the failure of over-complex bioclimatic variables from global climate models in extrapolations, we preferred simple macroclimate parameters such as mean temperatures and precipitation sums. Other collinear bioclimatic variables were neglected. Beside general applicability in this study and even 
though altitudinal and topographic corrections are implemented within global climate models (e.g. Karger et al. 2016), climate data should be further tested for suitability in fine-scale applications. Suchlike was performed by Daly et al. (2010), who installed an array of climate data loggers to correct climate models for complex mountain topography. Their study revealed relative independence of macro-climate and topoclimate, highlighting the importance of topography. Topography is important especially in mountain areas, bearing complex interactions and a wide range of site features. This is frequently underestimated in coarse scale climate models related to climate station records (Barry 2008; Berry et al. 2016; Körner 2014; Scherrer et al. 2011; Scherrer and Körner 2009).

Relief parameters such as slope values and cti describe only parts of the regional topography but are crucial for the understanding of species ecology. Three modeled species in our study showed best extrapolation performance when only "relief" (P. terebinthus, Q. ilex) or "relief + climate" ( $E$. dendroides) were used. As a part of distribution modeling for Californian woody species topography revealed its importance in contrast to macroclimate (Franklin 1998) and also distributions of grasses and ferns were well predicted by topography (Slavich et al. 2014). Other authors discussed the importance of climate and topography on plant diversity patterns (Fois et al. 2017; Irl et al. 2015) and a meta-study revealed topographic features, such as wind and sun exposure, essential for seedling-survival and species distribution across continents (McIntire et al. 2016). Special cases of topographic complexity apply for karstic landscapes with talus cones, deep valley incisions, poljes, dolines, etc., occurring scattered and on a wide scale on both studied islands (Di Maggio et al. 2012; Egli 1989). Because species thrive there under else unsuitable conditions, such structures can affect predictions. The latter example shows, that the affinity to a certain bedrock can be related e.g. to its erosivity or featured landforms.

Our results revealed that models including geology do not perform well for all species. One reason for the weak performance can be the quality of geological data. Refering to the resolution of the used maps and their focus on stratigraphic units various surface conditions were disregarded. In the West of Sicily and various parts of Crete the formation of soil pockets is not captured in mapping beacause of their small-scaled distribution. Similarly overblown sand preferred by J. oxycedrus subsp. macrocarpa is disregarded. Another difficuly resulting from the application of mapping units: coarse grouping applies for bedrock types in our study, this allowed for a supra-regional application, but led to a high heterogeneity within each of the bedrock types. Such heterogeneity of rocks influences soil conditions for plants (Neff et al. 2006). Partly bedrocks relate to soil types, but alone they are not sufficient for a quantification of substrate parameters (Bockheim and Gennadiyev 2010; Minasny et al. 2008). One important soil parameter is the $\mathrm{pH}$-value in Mediterranean landscape context (Chytrý et al. 2010). Low pH-values and acidic soil conditions can occur over 
metamorphic rocks but also over flysch, volcanic rocks and sediments. But also high precipitation as in mountain can cause acidification of substrates through leaching effects. Therewith $\mathrm{pH}$-values can be low in else well-buffered surroundings. Along with aged soils in woodlands low pH-values could develop as well (Wilson et al. 1997). Reversely high pH-values and high phosphorous content can occur over generally poor bedrock when dust immissions apply (Macleod 1980; Suchodoletz et al. 2013; Yaalon 1997). Wide spread species with an affinity to such substrate conditions may thus also occur over else unsuitable bedrocks, especially when dust accumulates in hollows. The diverse Mediterranean study area features a pronounced heterogeneity of soil formation in relation to bedrock, climate and topography. This complexity could reduce the applicability of coarse and simplified geological units as proxies for substrate conditions. Beside quality of base data and coarse mapping units an overfitting to certain bedrocks may hamper extrapolation in models.

\section{The role of shifting ecological behaviour of species in models}

For the studied species a flexible selection of variables was applied within the MaxEnt algorithm, but rarely the same variables were selected as important for the independent training regions. The variables selected should describe the range of ecological conditions covered by the training data. When these variables vary between regions, the site conditions applying for the set of training records are different. Strong driving variables feature the occurrence of specialists' species, e.g. high t_mean and low ann_prec in the case of the two coastal junipers led to best extrapolations for both regions. For generalists diffuse patterns for environmental variables apply, this makes the algorithm to select several suitable variables for the models; for the training region this helps to fit the ecological range of values, as prediction maps display; but for deviating ecological conditions in the test region, this kind of overfitting disables extrapolations. Thus MaxEnt-models may capture the range of environmental conditions for the training region. But these models are only suitable for extrapolation, when strong driving variables describing site conditions apply for the training and the test region.

Geological units applied in models reduced their extrapolation performance across all species tested. Available and occupied bedrocks are different for both islands, which involves overfitting effects and disables extrapolation. Differences are pronounced for Q. coccifera, P. latifolia or $E$. dendroides, which also led to low AUC-values in models for both training regions. The vague affinity to bedrocks is indicated by percentages of featured bedrocks but also by their role in models represented by jacknife tests. For specialist species such as $A$. unedo and E. arborea a strong edaphic affinity applies only for the fitting of training points from the Cretan region. The records on Sicily are better represented by annual precipitation sums. The species distribution models for $A$. unedo is a special case, because it is frequent on metamorphic rocks on Crete, where sufficient 
water is available. Various locations in the Sicilian mountains are not covered in the distribution model. There the species benefits from high precipitation on mountain tops or good water availability for an affinity to local edaphic conditions. Other studies describe the species for having oceanic preferences. The species is wide-spread in the west Mediterranean and also along the Atlantic coast from Morocco to Ireland, where it thrives on sandstone and limestone bedrock with good water supply (Mesléard and Lepart 1991; Sealy 1949). Volcanic rocks and gypsum are virtually exclusive for Sicily. This hampers extrapolations of some species, for which these bedrocks play a role in models according to jacknife tests.

There can be manifold reasons for the occurrence of distinct ecological site spectra for the tested plant species in the two regions. Phenotypic plasticity of species may be important as well as adaptation to particular site conditions connected to shifts on genetic level. According to their phenotype plant species can adapt to various site conditions without prior genetic changes. This can be explained in many cases by epigenetic processes (Chen 2007; Herrera and Bazaga 2009; Zhang et al. 2013). On the other hand genetic differentiation on intraspecific level is not unlikely and often related to the latter phenomenon (Zhang et al. 2013). For the Mediterranean islands studied the occurrences of many endemic species species can be correlated with evolutionary processes (Beierkuhnlein 2007; Steinbauer et al. 2013). For the Cretan study area post-isolation range expansion caused by mountain uplift was successfully tested by Trigas et al. (2013). Therewith the authors indirectly link the potential for ecological and genetic differentiation to the mountain uplift in the region. A reason for limited performance in extrapolations may thus be individual genetic patterns of Mediterranean tree populations, which were revealed by several studies (Fineschi et al. 2004; Fuentes-Utrilla et al. 2014b; Papageorgiou et al. 2014; Petit et al. 2003). According to Christe et al. (2014) haplotypes of Z. abelicea differ along isolated mountains within Crete. Because elaborated technical procedures are needed to test phenotypical and genetic patterns, for many species the level of intraspecific differentiation is jet unknown (Zhang et al. 2013).

The mentioned uplift process for Crete may also feature ecological differences for the maquis species in our study: species like $Q$. coccifera, $P$. latifolia and $P$. terebinthus show higher altitudinal ranges on Crete compared to Sicily (indicated here by temperature variability). The mass uplift of Etna is related to specific site conditions and may be unsuitable for some species, exceptions are e.g. Q. ilex, P. terebinthus. The niche of species may also shift along with an exposure of species to new environmental conditions as Broennimann et al. (2007) proved for an invasive species on continental scale. Several studies suggest that changes in altitudinal ranges, occupied bedrocks and a combination of ecological site conditions result in speciation, especially when isolation is involved (Ali and Aitchison 2014; Gillespie and Roderick 2014; Kruckeberg 2002; Steinbauer et al. 2013; Steinbauer et al. 2016; Steinbauer 2017). Similarly, for the studied species we foremost expect an 
effect of isolation and individual island conditions on epigenetic and intraspecific genetic differentiation which could disable extrapolation performance.

In conjunction to our study testing ecological generalists and specialists, also range size is considered to be limiting for the accuracy of species distribution modelling, in such a way that wide spread species having a broad ecological amplitude may tend to be more difficult to model, compared to species with a small range and narrow niche (Hernandez et al. 2006; McPherson and Jetz 2007; Stockwell and Peterson 2002). The latter authors propose to enhance performance of species distribution models, by specific geographical resampling of records to obtain more differentiated models for regions. This could also help to extrapolate models within the study setting, e.g. by excluding unsuitable records from isolated sub-populations. Another procedure to improve extrapolation results involves the restriction of the model area, to train the model only on the cells having a common climatic range on both islands, as applied in other studies (Heinrichs et al. 2016; Horsák et al. 2010). We found no significant improvement in the model's predictions, due to data abatement and to loss in the ecological response curves of the training data and therewith support the findings of other studies (Thuiller et al. 2004). Another shortfall in such procedure comes from the limitations of using AUC-values for evaluating the model outputs, because these values are related to all grid cells in the data frame. When the area differs AUC-values should not be compared (Lobo et al. 2008).

\section{Conclusions}

The use of species distribution models for reciprocal extrapolation to neighbouring islands allowed for the indirect comparison of species niches across regions. The inclusion of bedrocks in models hampered their performance in comparison to models with climatic and topographic variables only. Especially wide-spread generalists performed weakly. The models for edaphic specialists performed better for each of the islands; but rather for their relation to specific climatic and topographic conditions than their relation to bedrock types. One reason for the general failure in extrapolation is that the geological units are heterogeneous representations of surface conditions. Such conditions could be better covered by soil types. Secondly we suspect interplay of different availability of bedrock types and a broad edaphic niche for species, which is not fully covered by records in the training region. Such niche differences could be explained by phenotype (epigenetic regulation) or genetic variation. 
Chapter 6:

Synthesis 


\section{Analyses opportunities addressed}

The last four chapters each presented a case study of data analyses either based on species occurrences or compositional data. In the following section these studies are discussed in a wider context. The first of these sections discusses the several analysis aspects of the performed studies, the subsequent ones addresses their limitations, further analysis ideas and future perspectives.

\section{Approaching plant species ecology}

Species' ecological patterns are displayed in manifold ways in this thesis: while in chapter 3 ecology is indirectly assessed through vegetation units, the studies in chapters 4 and 5 comprised information about distinct differences between metapopulations. The overview in chapter 2 visualizes patterns of environmental affinities for the majority of Cretan phanerophytes. For the latter, ecological trends are generally applicable for the whole Mediterranean area. That means regional results reflect patterns on wider scales; e.g. the Mediterranean tertiary relicts Styrax officinalis and Laurus nobilis (Mai 1987; Schmid 1970) occur in Crete and elsewhere in relatively humid ravines and on lower slopes (Di Pietro and Germani 2007). The chapters 2 and 5 deal with the ecology of wide spread woody maquis species. For example the coastal junipers (Juniperus macrocarpa syn. J. oxycedrus subsp. macrocarpa, J. turbinata syn. Juniperus phoenicea subsp. turbinata) are stress tolerators, welladapted to low precipitation and co-occur along coasts around the Mediterranean (Baquedano and Castillo 2007; Meddour et al. 2017; Muñoz-Reinoso 2004; Paradis et al. 2014; Pedrotti 2013; RubioCasal et al. 2010); Erica arborea reaches East African mountain heathlands (Knapp 1973; White 1981); and Platanus orientalis occurs eastwards until the Himalaya (Rosati et al. 2015). Therewith the observed ecological patterns for wide spread species may be relevant for practitioners and scientists. On the other hand ecological affinities of some portrayed species differ markedly in Crete compared to other areas, e.g. Quercus ithaburensis subsp. macrolepis from the small and somewhat isolated local (meta)population has a narrow ecological spectrum compared to the centres of occurrence (Dufour-Dror and Ertas 2004; Pantera et al. 2008). Also other studies shared the observation that marginal metapopulations compared to those with a wider range are limited in niche breadth. Quézel (1979a) portrayed the ecological niches of 54 woody taxa for the Mediterranean region and he frames the narrower ecological amplitude of the French compared to the circum-mediterranean occurrences. The latter study allows for comparison with results in chapter 2 and 5 as it displays a similar set of environmental variables. Ecological niches may differ along with (gradual) changes in site conditions within the wider distribution area; and between isolated populations. Intraspecific differences will be addressed later in this chapter.

Species ecology can be inferred indirectly from vegetation, as done in chapter 3 , but also from species distribution patterns and ranges (Cox and Moore 2010; Frey and Lösch 2010). The focus of 
chapter 2, 4 and 5 was on landscape-related ecological patterns, whereas site conditions were displayed and compared; species` co-occurrences were displayed. Especially altitudinal patterns may generally mirror ecological affinities on wider scales. For the patterns on Crete though caution applies as probably mass elevation of the Cretan mountains caused an upward shift (see Chapter 5 for details). For many species a shifted ecological range to higher elevations could be observed in comparison to other regions (Steinbauer et al. 2017; Trigas et al. 2013). Niches for some of the mountain species may thus apply rather locally; further studies are needed to quantify altitudinal shifts.

Ecological filtering processes are frequently mentioned as drivers for species patterns in landscapes and in plant community context; thereafter ecological factors hamper the establishments of species and shape their distribution (Catry et al. 2006; Cingolani et al. 2007; Kraft et al. 2015; Steinbauer et al. 2017). Such processes may as well underlie the patterns described the presented studies. Ecological adaptation to extreme conditions, i.e. coastal habitats exposed to salt, drought and high solar radiation are inhabitat by few specialised species only. Merely two junipers are included in the group of coastal species (Tamarix ssp. could thrive there as well but the genus was disregarded for its unclear taxonomy and deficient data; Villar et al. 2014). Filtering processes could be particularly important in such extreme sites; they would prevent most other seedlings of woody species from establishment. Many planted trees, when watered, may grow in such coastal spots as well, but die off if their roots do not reach ground water and human assistance is stopped. Whenever planting in such coastal spots is necessary, e.g. for wind protection, the use of local taxa with good adaptations should be preferred. Few woody species grow well in high altitudes, some being specialised to specific slope expositions. Especially for sites with extreme conditions, the results of chapter 2 may support practitioners in their choice of appropriate species for ecological restoration.

Plant-environment relations can also feature the assignment of ecological indicator values. Indicator values imply site attributes i.e. soil reaction, affinity to macroclimate and to wetness (Böhling et al. 2002; Ellenberg 1974), but they usually do not feature (micro) topography. Many studies describe the affinity of species (groups) to particular topography (Fois et al. 2017; Hedderson and Blockeel 2013; Schnittler et al. 2010), while an assignment of numerical topographic indices to species was not done. Chapter 2 revealed a strong affinity to extreme topography for some species. Topographic features may thus serve as a basis for specific ecological indicator values. For example the used compound topographic index provides a theoretical quantification of available surface waters and may be used for testing of existing indicator values for moisture or for the assignment of new ecological indicators accounting for topography. 
Affinities to rock types are discussed in chapters 2 and 5. According to the study in chapter 2 a group of downy oak and hawthorn appeared frequently on ophioliths on Crete. For some plants a strong affinity to such specific bedrocks was found in our study e.g. to gypsum or ophiolites; which confirms study results from other regions (Kruckeberg 2002; Stevanovic et al. 2003). Among the woody species studied in chapter 2 and 5 , none is exclusively constrained to one of these two bedrock types. For gypsum this confirms unpublished results for Sicily (personal communication Riccardo Guarino). Few woody species are good indicators for ophioliths (serpentine) in the wider area, exceptions are Quercus trojana subsp. euboica and Genista spp. (Horvat et al. 1974; Stevanovic et al. 2003). In serpentine areas in the Rhodope mountains other oak species (Q. pubescens, $Q$. frainetto, $Q$. cerris) may thrive on serpentine rocks (Pavlova et al. 1998). For the Western Balkan Pinus sylvestis, P. nigra, Quercus robur, Ostrya carpinifolia, Forsythia europaea, Syringa officinalis and several oaks are described on this rock type (Horvat et al. 1974). Interestingly, the affinity of oaks to serpentine/ophiolite, is a phenomenon which applies across continents (Abbate et al. 1993; Ernst 1974; Harrison 1999; Roberts and Proctor 1992; Tyndall 2005). Because soils over serpentines contain heavy metals, a basic tolerance and phylogenetic conservatism can be assumed for the genus. GIS-based assignments of geological substrates, soil types, topographic features, etc. is generally promising for applications on various scales and for datasets of species records (e.g. Paulo et al. 2015; San-Miguel-Ayanz et al. 2016). For the species in chapter 5 a strong affinity to specific bedrocks (edaphic specialists), allows for a better extrapolation. Species covering a wide spectrum of bedrock types, have a broad ecological niche, which reduces the potential of extrapolation when geology does not match in training and test areas. Additionally intraspecific variation could apply, which is discussed in the next paragraphs.

\section{Intraspecific ecological variation}

Intraspecific variation is addressed in various studies dealing with plants and plant communities, thereby it may be challenging to distinguish between variation of phenotype or genotype (Herrera and Bazaga 2010; Violle et al. 2012). A good experimental setting is helpful to compare such variation. Thus in chapter 4 we use the isolation of the Cretan mountains, forming a Creto-montane archipelago (parallel to Afro-montane archipelago, see White 1981); for which a separation on floristic level (Greuter 1971; Rikli and Rübel 1923) and on haplo-type level applies for the studied species (Christe et al. 2014). Already Greuter (1972) highlighted the islands' evolutionary significance, because of endemics and wide-spread species being genetically (and ecologically) distinct in the isolated Cretan mountains. In the frame of the study we applied the term (meta)population in a sense, that spatially structured and isolated occurrences of taxa are addressed; even though further definitions exist, e.g. related to animal populations and fragmentation (Hanski and Gilpin 2008). 
In the Cretan mountains Zelkova abelicea differs in its haplotypes in the main mountains (Christe et al. 2014), which stimulated the study in chapter 4. Similar patterns were studied for the endemic Jurinea pinnata in the Baetic ranges on the Iberian peninsula by Salmerón-Sánchez et al. (2014), who proposed that geographic isolation in mountain ranges is important for intraspecific genetic structuring. Whereas on a wider scale for the whole Baetic-Rifan complex climate and lithology, were most influential for the distribution of endemic species diversity, and merely climatic variables for the patterns of non-endemic species (Molina-Venegas et al. 2013). Even though various studies describe a high genetic diversity for many Mediterranean woody species (Petit et al. 2003), the high genetic variation of Zelkova abelicea is surprising on this small scale. But therewith the study of Criste et al. (2014) confirms results of Papageorgiou et al. (2014), who used dense haplotype sampling for Fagus sylvatica in a Greek refugial region, and who related it to fine-scale ecological and topographic isolation barriers. The authors explain the patterns merely by migrations from distinct founder populations and isolation by topography and dispersal barriers (Papageorgiou et al. 2014). Suchlike could suit as well for $Z$. abelicea, as our study in chapter 4 revealed ecological dissimilar sites for the metapopulations. Even though the study of Christe et al. (2014) presented differences in terms of haplotypes for the Cretan mountains, their sampling covered only a selection of sites. Tendencies in spatial separation of haplotypes in the mountain ranges are visible, but denser sampling is needed for sound interpretation.

Spatial patterns of Zelkova haplotypes (chapter 4) could also support the concept of Steinbauer et al. (2013; 2016), who claimed altitudinal isolation to be a key factor for diversification and propose topographic features as potential driver. Additionally for each of the Cretan mountains individual abiotic conditions apply (at least in terms of occupied sites for Zelkova); thereby the isolated metapopulations face individually differentiated site conditions along natural gradients. Other authors displayed the distribution of endemics in the isolated mountains (Greuter 1971; Jahn and Schönfelder 1995), which can be explained by isolation, ancient migrations along the South Aegean island arc and the ecological gradient. Ecological differences of single mountains could support ecological radiation processes, applying on several scales (Rainey and Travisano 1998; Sudhaus 2004), and could also explain diversification of metapopulations on haplo-type level. A pronounced isolation for Zelkova can be explained by dispersal limitations related to low fertility of the seeds; and - even if the fruits are winged - they are not travelling far (Egli 1997; Kozlowski et al. 2014). If dispersal barriers and low fertility are old phenomena, a reduced genetic exchange can be assumed and thus long-term separation of metapopulations. The fact, that isolation of the Cretan mountains happened "recently" in geological and evolutionary terms, and a repeated connection of the isolated peaks during glacial-interglacial cycles, could support the assumption that merely intraspecific genetic differentiation was introduced. Maybe genetic differentiation could also result in distinct 
sub-species for some taxa (e.g. Greuter and Grau 1980). The speed of genetic differentiation may vary for taxa (Petit et al. 2005). Population dynamics over time include isolation and reunion, which can be assessed (e.g. for a Chilean Mediterranean tree species by Pérez et al. 2017). Such estimations of times of species isolations are extremely helpful for the reconstruction of biogeographic processes and could be valuable in the Mediterranean study region. Various studies tested haplotypes across populations, sometimes also with a relation to ecological patterns (Hampe et al. 2003; Petit et al. 2003; Petit et al. 2005; Thompson 1999). Approaches in terms of landscape genetics could apply for the studied species and their metapopulations in various regions (Balkenhol et al. 2009) and they could therewith address the genetic component of spatial patterns in a more precise way; additionally eco-physiological measurements, tree ring analysis and the application of functional genetics should be helpful.

In chapter 5 ecological differences between two islands Sicily and Crete were studied for maquis species and the consequences for the regional extrapolation of species distribution models were discussed. Good extrapolation results for specialised species underlined ecological similarities in occupied site conditions for those species on both islands. Distribution of generalists was more difficult to extrapolate for their dissimilar ecological niches. They may occupy different habitats in isolated regions with e.g. divergent climatic and edaphic conditions. This could be explained with a broad phenotypical flexibility of wide-spread species or differentiation on genetic level.

Intraspecific ecological differentiation should be considered for future plant ecological and vegetation ecological studies, especially for isolated metapopulations in the Mediterranean. Genetic diversity is high among ancient Mediterranean species occurrences, especially in comparison to areas occupied in the post-glacial period, as various examples expressed (Petit et al. 2005); in this context several studies revealed genetic diversity in metapopulations of wild species (e.g. Bucci et al. 1997; Ducci et al. 1999; Fuentes-Utrilla et al. 2014b; Fuentes-Utrilla et al. 2014a; Thompson 1999); and among fruit trees and vines (Gristina et al. 2017; Khadari et al. 2005; Zohary and Hopf 2012). The described variation of occupied site conditions, having a genetic basis or not, can hamper results of species distribution models. When ecological differentiation applies, extrapolated predictions of species occurrences should be consulted with caution (chapters 4, 5). The high intraspecific genetic diversity in the Mediterranean is often disregarded but should be considered more frequently in e.g. conservation, restoration, planning and management of protected sites, plant breeding or pest control.

\section{Ecological species groups, vegetation and landscapes}

The description and classifications of the land surface has a long tradition in geosciences. Approaches may vary depending on applications, political borders, scale levels, and also used base data can be 
quite different: Abiotic attributes apply as data basis on the global scale (Weigelt 2014) and on country or regional scale (Bunce et al. 1996; Drachenfels 2010). The separation to biogeographic units (realms, regions, etc.) on the basis of species distribution is another basic concept (e.g. Kreft and Jetz 2010, Frey and Lösch 2010). In conjunction to such patterns based on species turn-over, floristic dissimilarity and environmental gradients were assessed (König et al. 2017; Rueda et al. 2010). Distributions of species or habitats may also reveal landscape-ecological units and differences across spatial scales (Bölöni et al. 2011; Korsch 1999; Schmiedel 2014; Wasowicz et al. 2014). In chapter 2 the distribution maps of ecologically similar species revealed patterns on a landscape scale (Figure A 2.1). The identified ecological species groups share similar site conditions; species forming these groups reflect patches of contrasting conditions on this regional scale. These patterns do not represent landscape units ready for application, but they allow for an ecological interpretation. The use of high-resolution species distribution data with reasonable density may thus be a good basis for a rather objective ecological landscape classification. On this spatial scale data gaps and sampling bias influence results more than in large-scale analyses. In addition, land use effects are probably more pronounced on finer scales and have to be considered. Korsch (1999) performed a similar analysis but he generated species groups based on ecological indicator values, hemerobic index and similar chorology. This way, just like in chapter 2 , the ecological affinity of species to strong ecological drivers found expression in wider landscape patterns. Generally, the approach using clusters of ecologically similar species could serve as a method to classify land surface on various scales.

Zonation patterns of plant species along (climatic) gradients can be explained by ecophysiology and adaptative traits (Körner 1998, 2012; Larcher 2006; Way and Oren 2010). Such traits apply for tree species in relation to e.g. climate change adaptations (Bugmann 1996), ecological strategies such as competitiveness (Swaine and Whitmore 1988) or community ecology and functional assemblies (Cingolani et al. 2007; Kraft et al. 2008; McGill et al. 2006). Even though results of chapter 2 do not allow for a direct interpretation of functional groups, we can assume that functional similarity applies for several species within the proposed ecological species groups, as this is one fundamental basis for the occupation of similar ecological niches. Functional similarity can as well explain shared habitats and species abundance, which can be explained by various studies across ecosystems (e.g. Cornwell and Ackerly 2010, Mahdavi \& Bergmeier 2016, Maire et al. 2012). The latter studies approached species groups chiefly by species traits; in contrast the study in chapter 2 integrates site attributes and species' similarity in complex ecological spectra including climate, geomorphology and geology. The initial selection of these variables and the classification of ecological spectra resulted in a restriction to important ecological drivers. The proposed classification was based on a composite of site attributes and not on direct measures of species or species composition from plot data. Anyway, trends in ecological similarity got obvious, which confirmed field experience and habitat schemes. 
Woody species were chosen in all presented studies for being frequent elements of climax vegetation. A high species diversity of woody species is an indicator for a high diversity of other organism groups across trophic levels (Barrico et al. 2018; Kati et al. 2004). This implies that the cooccurrence of multiple woody species within a spatial unit (e.g. landscape patch, grid cell, district) is an indicator for biological diversity. Thus for the study in chapter 2 the spatial pattern of ecological groups feature biodiversity patterns. In relation to this it has to be considered, that species groups restricted to extreme environmental conditions are rare in landscapes and thus host fewer but specialised species. In addition, co-occurrence of these groups could serve as an indicator for niche diversity and for biodiversity.

The co-occurrence of plant species is the basis for the description of vegetation units, the latter may thus serve as proxies for a combination of site conditions. Therewith vegetation units are ecologically related to the ecology of comprised species. This relation was displayed by the comparison of ecologically similar groups and units from vegetation and habitat schemes in chapter 2 . Moreover, in this context the classification of species composition data from vegetation plots is a common strategy helping to understand ecology and to assess typical species. Chapter 3 covers a numerical classification of Platanus orientalis woodlands, revealing two new plant associations and confirming a third one. All three vegetation units have a specific floristic composition and particular ecological properties. This showed the potential to describe vegetation units even in else well-studied Europe. Recently, also the European vegetation classification (Mucina et al. 2016), gave new insights for syntaxa (alliances, orders and classes). Therewith a unified system was established on continental scale. The proposed associations in chapter 3 have relevance for the local differentiation of the alluvial forests and extend this new system as subordinate units within the alliance Platanion.

This alliance is wide-spread and species composition of the Cretan woodlands is similar to other parts of the distribution area, including those with the Tertiary relict Liquidambar orientalis (Dimopoulos and Bergmeier 2008; Öztürk et al. 2008; Pedrotti and Gafta 1996); while the northernmost occurrences of this vegetation types comprise more elements of temperate riparian forests (Horvat et al. 1974). A syntaxonomical overview for alluvial forests and alder carrs is given by Douda et al. (2016). This important study for Europe includes the Platanion, whereas two associations from older studies, Petasito-Platanetum and Nerio-Platanetum, were verified; their relation to the proposed types in chapter 3 should be discussed to avoid synonymies as both apply for Crete according to the published maps. Similar to the latter study various reclassifications and re-evaluations of formerly described syntaxa were performed for Europe in the last years, and more are expected (Chytrý et al. 2016; Willner et al. 2018). For the Platanion a wider overview is necessary but should not be limited to the European part of the distribution area of Platanus orientalis. Such a study would help to 
understand the distribution of associations and vegetation ecology of this frequently threatened vegetation type.

\section{Limitations}

\section{Environmental data and their bias}

For the understanding of species and vegetation ecology a multitude of environmental variables applies. The presented studies (chapters 2, 4, 5) comprised a selection of available variables from measurements, remote sensing and interpolation. Main driving factors were selected, others were neglected and further environmental aspects remain unrecorded. They may all influence species niches, the quality of extrapolation and analysis options. The reduction of variables to few important ones though can have various reasons. In case of the species-environment heatmap in chapter 2 the set of variables was reduced to a set of few, allowing for a better interpretation of the clustered matrix presented. Redundant information in the matrix was further decreased by merging some categorical variables to similar pairs based on similarity in a classification. A simplified set of environmental conditions was displayed in the heatmap and in a similar way in multivariate plots. The both plots are simplified also in terms of data distributions, e.g. unlike reaction curves which comprise the range of values. Simplification of the heatmap manifests as well in the use of few colours to display ecological affinities. Additional information of SD for each data cell in the heatmap would be an improvement. The grouping of species in the heatmap may suggest strict separation of species in the groups, in reality species occurrences are overlapping. Especially species with wide ecological amplitude may co-occur with species from various clusters, e.g. Pistacia lentiscus, a common maquis element, frequently co-occurs with many other lowland species like palms, pines and junipers. The ecological classification in chapter 2 results in a simplification of the complexity of vegetation patterns and groups do not fully match with real world plant communities.

Complex patterns of environmental conditions are indirectly assessed through the classification of vegetation plot data in the study in chapter 3 . The use of compositional data has the advantage that the broad spectrum of ecological conditions, covered by the sum of relevées, can be characterised by repeated occurrences of characteristic species. Distinct vegetation units comprise complex environmental conditions, which are not directly assessed by measurements but explained by species ecology and (few) observed or measured site conditions. Thus, this kind of vegetation unit comprises a multitude of information shaping their species composition, including measureable and hardly measurable variables (e.g. land use, extreme events in the past, etc.). Location-based data extractions using GIS for vegetation plots could help to integrate spatially explicit information and therewith substantiate plant-sociological classifications. Such quantifications of site conditions could 
improve ecological differentiation of vegetation units; e.g. for the study in chapter 3 mean CTI-values for the three associations could probably support ecological separation, such index values are impossible to assess from header data of the relevées.

The complexity of climate is partly underestimated in presented ecological surveys. For the studies (chapters 2, 4, 5) few climate variables were favoured instead of many collinear ones. The choice of mean temperatures and precipitation sums can be critical as their extreme values are not regarded (Blasi 1998). Partly this was compensated by the study by bioclimatic variables (Hijmans et al. 2005; Karger et al. 2016). Other approaches successfully integrated effects of climatic variation in models (Boulard et al. 2017). Climatic gradients are steep especially in the mountainous Mediterranean study areas and thus global climate datasets can underestimate topographic, regional and local effects (Nadeau et al. 2017). Interpolation of macroclimatic data relies on a small number of stations in the Cretan study area, which further complicates modelling. Instead of downscaled data from global climate models, ecological studies could also use values from climatic indices or bioclimatic stratification, which may better integrate the climatic complexity (Blasi 1998; Soteriades et al. 2017). Generally the use of climate variables outperformed the use of geology, which was discussed in detail in chapter 5.

Datasets created to serve large scale studies, turned out to be useless for ecological assessments in the presented studies. So the high resolution of $500 \mathrm{~m}$ for the European LUCAS survey datasets on soil properties (Ballabio et al. 2016) was promising for the performed fine scale studies, but delivered nonsense results for the Cretan study area e.g. high sand content for the topsoil layer in the mountains. The soil attributes assessed by the LUCAS dataset may apply for coarse grained analyses and in other regions, but the failure for Crete shows that an extrapolation from few data points to wider scales is not applicable in every context. Such publicly available datasets need to be tested for study areas. Similarly, derivatives of the DEM can be affected by intrinsic satellite scanning and algorithm bias (Ouédraogo et al. 2014). In pre-processing a sink-fill procedure is used to delete artificial zero values from the DEM; for modeling mean values for each grid cell were used which compensates for single false measurements.

\section{Coordinates and identity of taxa}

A major problem for location-based methodologies is imprecision of coordinates. Merging records from different sources and authors needs careful handling in terms of coordinate systems and projections in the GIS. As Budic et al. (2016) displayed, the quality of species distribution models decreases, when projections of raster data are incorrect and do not match coordinates of species records. In all four presented studies (chapter 2, 3, 4, 5) various datasets were handled and 
transformed into uniform geographic projections to reduce projection bias. Further reasons for imprecision is temporal disturbance of the GPS signals, which applied for signal jamming in the $1990^{\text {th }}$ during the Balkan wars; this could have corrupted locations of species records for the period. Also weak satellite connection under canopies, in gorges and due to overcast sky can bias coordinates of recorded species and plots. For the Cretan study region coordinates were corrected by strict selection and crosschecks to aerial imagery. Nevertheless, some records may have been attributed to improper sites. This was partly compensated by large numbers of record. However, it is recommended to interpret trends and no single attributions.

Identification skills may also bias results of collections and surveys (Ahrends et al. 2011), which was compensated in the studies by data from experts with local field-experience. Additionally the selection of well-known woody species reduced taxonomic problems: unclear taxa were excluded e.g. Tamarix spp., or treated on species level e.g. Ulmus minor ssp. canescens as U. minor. Nevertheless, ecological (and genetic) differences could apply affecting ecological assessments and models (which is discussed in this chapter). Another form of data bias may be generated, when sites are repeatedly visited by surveys, e.g. to visit rare species, thus in the presented studies (chapter 2, 4 and 5) sampling strategies were applied (Ahrends et al. 2011; Dormann et al. 2007). Anyway, data gaps appeared as well as areas with denser sampling, which partly reflect the patchy distribution of woodlands in the study areas. Patchiness can be problematic for the quality of species distribution models and the assessment of ecological niches. Environmental conditions in patches with woody plants can be very different in comparison to neighbouring sites, but in models a homogenous extrapolation applies, when such differences are not captured in spatial data in the GIS (Bakkestuen et al. 2009; Mclnerny and Purves 2011).

\section{Data selection and algorithms}

In analysis attempts using models and large species datasets and composition data bases, a main issue applies as over-complex and over-simplified models may be limiting (Merow et al. 2014). The used MaxEnt algorithm (chapter 4,5 ) is sensitive to over-complex data input, as thereby interactions and collinearity may disqualify results (Dormann et al. 2013; Syfert et al. 2013; Wisz et al. 2013). It is a limitation of this model type, that (few) independent driving parameters are included, although species and ecological conditions interact for sites in complex way. Results in chapter 4 and 5 also showed that the choice of spatially isolated (meta)populations affects predictions of species distribution models. This is another week point in models, which often assume homogenous genetic structure and evenly distributed ecological behaviour for organisms. Such fundamental phylogeographical problems were addressed in reviews (e.g. Avise 2009, Weiss and Ferrand 2010). 
Other studies conclude, that sample size has a strong influence on models (Wisz et al. 2008). In chapter 4 ecological affinities of metapopulations were assessed for isolated mountain ranges, whereas few records were available for some of them. The MaxEnt algorithm would not deliver comparable modeling results, when too small numbers of records were used. Thus, these few records were added to neighbouring populations, which extended the modeled ecological space of larger metapopulations by smaller (marginal) ones and thus introduces higher heterogeneity. This way, these small populations could not be directly modeled and the quality of overall results is limited. Alternative modelling algorithms could have been used, maybe in combination with repeated random sampling from the bigger populations to allow for even sample numbers. Such a balanced sampling might allow for a more robust analysis of the ecology and potential distribution of small and isolated (meta)populations.

The case studies contained selection procedures for environmental data, which had the aim to set objective criteria for ecological assessments and help for the extrapolation of models. The initial choice though influences the selection, e.g. alternative datasets for climate data are available. Similarly, MaxEnt was the only algorithm tested for modeling, even though a variety of improved algorithms exist. An advantage of MaxEnt is the integration of presence-only records, as well as numerical and categorical data. A promising alternative procedure is the use of multiple modeling algorithms and their combined evaluation, e.g. for small datasets (Breiner et al. 2015; 2018). Besides the choice of the algorithm, the quality and the resolution of data are important for modeling studies (Gotelli et al. 2009; Guisan et al. 2007; Hurlbert and Jetz 2007; Seo et al. 2009), the availability of raster data not least defines the used grid cell size. For Models in MaxEnt a uniform grid cell size must be applied, which was about $1 \mathrm{~km}$ for the study in chapter 4 , attributable to the original climatic data resolution. Models with a grid size of about $400 \mathrm{~m}$ were performed in chapter 4 , which was a compromise accounting for the original climatic data resolution and for the fine-scaled DEM of about $30 \mathrm{~m}$ resolution. For the mesic species studied, which depend on exposition, finer resolution then 1 $\mathrm{km}$ seemed reasonable. Even if the highest resolution was not integrated in the models, it was used to describe site conditions in boxplots. Smaller grid cell sizes are recommended for future studies. The working scale and the size of grid cells may influence the selection of environmental variables in models for species richness and species distributions (Marcantonio et al. 2017; Thuiller et al. 2003). Further theoretical implications on environmental variables acting across landscape scale are addressed by Wu et al. (2000). 


\section{Further perspectives}

\section{Availability and joint analysis of ecological data}

Location-based approaches depend on quality and quantity of species data and environmental data; their amount is constantly growing, and large datasets come from new sources, such as collaborative networks, social media and ecological initiatives. The integration of public data from amateurs bears risks in terms of data quality, but at the same time offers a great potential; e.g. decentralised processing and online crosschecks through experts. Also mobile devices further develop and allow for affordable and easy-to-use applications (Schrader et al. 2017; Teacher et al. 2013). Such technical advances and the interaction of scientists and amateurs may fundamentally change peoples' perception of scientific work and the way data is assessed and handled (Byrne and Pickard 2016; Graham and Zook 2011). Technical developments allow for a new quality of raw data and data products; e.g. by using LIDAR (light detection and ranging) for the assessment of (micro)relief, vegetation structure, etc. (Höfle and Rutzinger 2011; Omasa et al. 2008; Shan and Toth 2009; Suárez et al. 2005). Lift-off perspectives for the assessments of organism record and environmental data come from semi-automated devices like data trackers and drones (Carrivick et al. 2013; Lonneville et al. 2014). Multitudes of available biological and environmental datasets share the fact, that they can be spatially linked on fine scales. This can boost ecological exploration and stimulates new ecological questions; some options are discussed in the following paragraphs.

\section{Metapopulations and community ecology}

In the case of Zelkova abelicea, ecological site conditions differ between (meta)populations (chapter 4). Isolation of Zelkova could be further tested using other trials of genetic and functional genetic analyses. Also in chapter 5 a differentiated ecology of generalist species on the tested islands was assumed. Further genetic analyses may reveal distinct (meta)population structures. Similarly, ecological and genetic differentiations were already investigated for wide-spread European tree species (Köckemann et al. 2009; Papageorgiou et al. 2014; Rose et al. 2009). Details on genetic structure and age estimation for specific mutations, in combination with strong isolation barriers, may reveal insights to ongoing evolutionary processes and likewise to the history of isolation. The impact of marine barriers (Crete, Sicily, other islands, mainland regions, etc.) and orographic isolation on ecology and genetics can be tested. Such isolation effects could be checked also in terms of trait variation of endemics and related non-endemic species, as Hand et al. (2017) did in Mediterranean context. Related to this, measures for endemism rates using phylogeny (e.g. phylogenetic endemism; Rosauer et al. 2009) could highlight centres of endemism, speciation and old refugial areas, but need advances and wider application of genetic sampling and analysis. The assessment of spatial genetic patterns for Mediterranean species is still deficient and further comparative studies are needed. The 
conservation of taxa based on proveniences is a major element of ex-situ conservation (e.g. handling in germplasm) but for a long time many in-situ nature conservation schemes ignored aspects of genetic differentiation; this situation is changing stepwise (Heywood 2014). Both in-situ and ex-situ conservation can benefit from in-depth analyses of site features (chapters $2,4,5$ ), as ecological patterns for taxa reveal insights into regional or landscape-based differentiation. Such genetic and ecological differentiations should be widely considered in terms of global biodiversity protection goals (CBD 2012).

GIS-based approaches could be used to define, modify and substantiate ecological indicator values of species or their local proveniences. An European initiative currently tests and extends ecological indicator values for wider scales (Dengler et al. 2016). Based on universal environmental parameters also new ecological indicator values can be featured, which hitherto eluded from expert assessment for technical reasons. In chapter 2 the affinity of woody plant species to site conditions was assessed in a simple approach using a classification of a matrix of species and environment data. The patterns displayed were related to vegetation units. The approach could be used on wider scales and with various taxa and even (plant) communities; but due to its simplification it is no alternative to modeling approaches, which use advanced algorithms and may integrate interactions between organisms.

\section{Biotic interactions, soils and further ecological factors}

Interactions between taxa may appear aboveground and belowground and comprise e.g. competition and facilitation (Cuesta et al. 2010; Das Gupta et al. 2015; Kardol and Wardle 2010; Violle et al. 2010). Interactions are often disregarded in modelling attempts for species; not least because some wide spread algorithms merely use presence-only or presence-absence data. For the analysis of species interactions, more complex modelling approaches and the use of compositional datasets are advantageous (Ashcroft et al. 2017; Gomes et al. 2018). Co-occurring species could compete for resources and thus models could be corrected accordingly (Araújo and Guisan 2006; Cabral and Kreft 2012; Cabral and Schurr 2010; Wisz et al. 2013). High-resolution species records could help to give rough estimates, but there with only virtual co-occurrence and interaction can be assessed and not tested properly (see chapter 2). Positive and negative biotic interactions have impact on the global scale (Wisz et al. 2013). For the Cretan study area Bosque et al. (2014) observed facilitation for woody mountain species. The latter examples underline that the relation between organisms can be rather complicated and simple models may only explain parts of the ecological space.

Also soil related studies consider biotic interactions; e.g. Teste et al. (2017) showed that differences in mycorrhysation and the origin of soils influence plant growth and also drive diversity in species- 
rich Mediterranean woodlands. Various species responses may depend on factors related to soil organisms. A study using river corridor plants revealed below-ground interactions and explains distribution patterns by the occurrence of fungi (Nobis et al. 2015). Generally, there are manifold interactions of soil biota and plant cover (Kardol and Wardle 2010; van der Heijden et al. 1998); a North American study even attributes invasive earthworm activity to be a driver of changes in forest vegetation (Hale et al. 2006). In addition to biotic interactions various soil properties can influence plant ecology. Soil properties from maps can deliver good result in combination with climatic data to predict woody species' distribution (Coudun et al. 2006; Leathwick and Whitehead 2001). Models accounting for the complexity of the land surface, addressing other scientific fields such as avalanche and permafrost prediction, can help explaining hidden ecological phenomena connected to topographic features in mountain landscapes (Salzmann 2006). The study of Geroy et al. (2011) found the aspect of slopes to be a crucial factor for soil formation; and organic carbon storage and water availability are affected by bulk density and stoniness of landscapes (Román-Sánchez et al. 2018). Vincent et al. (2018) calculated soil attributes and predicted soil types for complex landscape features. The integration of advanced soil models and soil organisms could improve the application of ecological niche modelling and species distribution modelling; e.g. instead of raw topographic values from DEM robust results of soil models could be included in ecological assessments and models, some mycorrhiza can be integrated in plant species predictions due to symbiotic relations.

Generally the influence of soil reactions on the occurrence of plant species is fundamental; but also reverse relations apply, because vegetation cover has a strong impact on soil formation. Many soil parameters depend on particular species compositions. Such plant-soil feedbacks need more attention in ecology (Jones et al. 1997; Kulmatiski et al. 2008; Shachak et al. 2008). Especially in patchy landscapes the relation between vegetation, soil properties and their age-assessment are important (Badalamenti et al. 2018; Dupouey et al. 2002; Innangi et al. 2015). The examples in this paragraph highlight the dependence of ecological patterns on interactions with other organisms and the environment; better cooperation between separated disciplines could result in improved scientific approaches.

Beside the interactions of taxa, also human impact is a crucial parameter for the understanding of recent distribution of species (Fois et al. 2017). Fine-grain information for human land-use (livestock rates, grazing intensity, urbanisation parameters, etc.) can be helpful when an estimation of anthropogenic land use should be integrated in ecological research, therefore e.g. remote sensing data could help (Carmel and Kadmon 1999; Hostert et al. 2003). For the study area such information was not available but could support management decisions, e.g. by the assessment of grazing impact on species distribution and vegetation. Besides grazing, various aspects of human interference have 
shaped vegetation and plant distributions for millennia. Today fast changes in land use take place but also quick climatic alterations (Pachauri and Meyer 2015; Pereira et al. 2004).

\section{Changes in time}

Species are considered to react to climate change in various ways: Studies revealed constant dynamics in environmental variables in deep time being major drivers of species extinctions, habitat shift and range shift (Jackson and Overpeck 2000; Rödder et al. 2013; Rodríguez-Sánchez and Arroyo 2008). As the latter study underlined, under widely unfavourable conditions species distribution is often reduced and restricted to particular regions or sites and recent distributions may still reflect regression patterns. Around the Mediterranean several refugial areas exist, where species probably repeatedly survived unfavourable climatic conditions of the past (Bennett et al. 1991; Papageorgiou et al. 2014; Quézel and Médail 2003). Datasets of floristic and plant-sociological data could be used to assess structure and suitability of such refugia. In this context, beside recent climatic data, also paleoclimatic data and future climatic scenarios may be integrated (e.g. Rodríguez-Sánchez and Arroyo 2008). Uncertainty of these climate data must be considered, but predictions may allow for a general understanding of dynamics in species and vegetation (Sinclair et al. 2010). Not only single species change their range in time, but there is also evidence that species assemblages go back to various dynamic events (Kondraskov et al., 2015). However, when past species co-occurrences are analysed caution applies (Grimm et al. 2016; Grimm and Potts 2015). Research in refugia and their conservation must have high priority, when their overall high genetic diversity and long term survival of species are considered (Hampe and Petit 2005). This way in the Mediterranean mountains not only single species are preserved but communities with several rare elements of boreo-temperate distribution (Brullo et al. 2012; Weiss and Ferrand 2010). The protection of refugia also needs high priority, because they are meant to buffer some of the adverse effects of climate change in the future (Harrison and Noss 2017).

While a property of refugial areas is a relative environmental stability in particular sites, other areas can be prone to changes in species composition. Where disturbance applies, e.g. along coasts and on river banks, in urban and in agricultural landscapes, species turnover is likely, with invasive species arriving. The latter may take place within decades or few years (Bardsley and Edwards-Jones 2007; Groves and Di Castri 1991). Invasion patterns and processes based on recent data can be described, analysed and spatially predicted using floristic and plant sociological datasets. Local and wide-scale studies assessed susceptibility for invasive species (Lazzaro et al. 2016; Lloret et al. 2005; Steinbauer 2017; Wagner et al. 2017). Species distribution models including future climate change could also help to understand changes in species ranges, but an over-interpretation should be avoided (Sinclair 
et al. 2010). An assessment linking habitats across landscapes to relative stability and susceptibility to invasions is lacking. This could be most relevant for management and conservation.

\section{Habitats and diversity in landscapes}

Conservation and management decisions may benefit from results of distribution modelling. In this context the presented studies comprise patterns for the potential distribution of single plant species helpful for applications in the study area. Beside single species, habitat types and plant communities hosting specific species compositons are relevant in the frame of conservation. Distribution models can be used to predict also habitat types supporting mapping and monitoring (Amici et al. 2014; Culmsee et al. 2014; Jiménez-Alfaro et al. 2018; Pottier et al. 2013; Taminskas et al. 2013). The studied woody taxa of this thesis are key species of habitat types. Thus their distribution patterns may already indicate potential habitat distribution. But these data as parts of typical species lists could be integrated as well in more complex habitat models. Stacked results from single species distribution models can also feature biodiversity patterns (Calabrese et al. 2014). Suchlike can be performed based on records from floristic and plant-sociological databases in order to assess phytodiversity on landscape scale. For the study area such phytodiversity patterns can be compared to published maps based on the distributions of records in data bases (Jahn 2003; Raimondo et al. 2003). Biodiversity is often distributed in patches, frequently related to natural or antropogenic fragmentation. Fragmentation and complexity of landscapes influences diversity of species groups and can be analysed in conjunction with large datasets of species (Moser et al. 2002; Schmiedel et al. 2015; Schmiedel and Culmsee 2016). Fragmentation and connectivity of species' (meta)populations and habitat patches is an important issue in conservation. It can be integrated in semi-automated algorithms used for conservation and management planning (Ball et al. 2009; Ball and Possingham 2000). This algorithm may use information from landscape metrics, e.g. accounting for fragmentation, in conjunction with species, habitat and biodiverstity distributions to deliver objective delineations for protected areas. However, the fundaments of such algorithms and of distribution models are field surveys and expert knowledge on various aspects of biodiversity. That means investments in technical solutions in future should not rise at the cost of education and expert training.

\section{Concluding remarks}

The Mediterranean study region hosts a high environmental and biological diversity and therewith offers excellent research perspectives to solve ecological and biogeographical questions. This natural wealth supported the investigations of ecological patterns and processes for plant taxa and vegetation in this thesis. All presented studies share the application of floristic or plant-sociological 
datasets from the region, and they integrated location-based extractions of environmental data, classification and species distribution modelling. Methodological limitations deriving for example from bias in ecological background data, uncertainty of coordinates and algorithms were discussed. Generally, ecological complexity of sites can be difficult to estimate; models and exact measures may be easily overestimated in their overall meaning within species 'ranges and across scales. In this context, the presented studies could show differing site conditions occupied by isolated metapopulations of species, which may involve ecological and genetic intraspecific variation. In addition to the exemplary ecological studies and methodological limitations presented, further analysis options and (near) future developments in this context were discussed for the region, for woodland species and beyond. The produced datasets and results can be used to support such future studies.

Woody species were studied in this thesis, which helped to understand vegetation patterns in landscapes. With numerical methods they support the characterisation and differentiation of Mediterranean woodlands, being of high ecological importance (Merlo and Croitoru 2005). Woodland habitats as those of the studied Platanion are examples of vegetation types protected for their high importance. Even if the understanding of the term habitat differs, the integration of habitat-concepts helps to assess conservation priorities and to quantify changes (Brooks et al. 2002; Harding et al. 2001; Maes et al. 2012). Parts of the latest results of the conservation status assessment for Crete are presented, comprising only one of dozens of habitats assessed for protected areas. The exhaustive mapping and monitoring results are delivered to the environmental authorities of the Greek state and the European Commission. However, local authorities being in charge with site management, should be more involved, trained and financed, to be able to reduce the diverse adverse effects acting on habitats and species (not just the protected). Therefore also a wide public interest for nature and its conservation is needed, which is hopefully increased through innovative initiatives and projects (e.g. Mediterranean Agronomic Institute of Chania 2018; WWF Mediterranean Programme Office 2018). Natural resources in many parts of the Mediterranean are under pressure by land use change, climate change, expanding urban and touristic infrastructure, etc. - thus, local people, authorities and scientists, as well as stakeholders of industry and tourism must communicate and act responsibly for the sake of nature and man. 


\section{References}

Abbate G, Fascetti S, Blasi C, Michetti L, Avena GC (1993) I querceti carducifogli delle ofioliti lucane. Ann Bot Roma 51:367-378

Abs C, Ewald J, Walentowski H, Winter S (2008) Untersuchungen zur Schattentoleranz von Baumarten auf Grundlage der Datenbank bayerischer Naturwaldreservate. Tuexenia 28:23-40

Aerts R (1995) The advantages of being evergreen. Trends Ecol Evol 10:402-407

Ahrends A, Rahbek C, Bulling MT, Burgess ND, Platts PJ, Lovett JC, Kindemba VW, Owen N, Sallu AN, Marshall AR (2011) Conservation and the botanist effect. Biol Conserv 144:131-140

Akman Y, Barbéro $M$, Quézel P (1978) Contribution à l'étude de la végétation forestière d'Anatolie méditerranéenne. Phytocoenologia 5:1-79, 189-346

Ali JR, Aitchison JC (2014) Exploring the combined role of eustasy and oceanic island thermal subsidence in shaping biodiversity on the Galápagos. J Biogeogr 41:1227-1241

Alvarez N, Thiel-Egenter C, Tribsch A, Holderegger R, Manel S, Schönswetter P, Taberlet $P$, Brodbeck S, Gaudeul M, Gielly L, Küpfer P, Mansion G, Negrini R, Paun O, Pellecchia M, Rioux D, Schüpfer F, van Loo M, Winkler M, Gugerli F (2009) History or ecology? Substrate type as a major driver of spatial genetic structure in Alpine plants. Ecol Lett 12:632-640

Amici V, Geri F, Bonini I, Rocchini D (2014) Ecological niche modelling with herbarium data: a framework to improve Natura 2000 habitat monitoring. Appl Ecol Env Res 12:645-659

Amigues S, Greuter W (2004) L'aconit du mont Saint-Jean: solution d'une énigme historique de botanique crétoise. Bot Chron 16:5-11

Andreu J, Vilà M, Hulme PE (2009) An assessment of stakeholder perceptions and management of noxious alien plants in Spain. Environ Manag 43:1244-1255

Araújo MB, Guisan A (2006) Five (or so) challenges for species distribution modelling. J Biogeogr 33:1677-1688

Aronson MFJ, Handel SN, La Puma IP, Clemants SE (2015) Urbanization promotes non-native woody species and diverse plant assemblages in the New York metropolitan region. Urban Ecosyst 18:31-45

Ashcroft MB, King DH, Raymond B, Turnbull JD, Wasley J, Robinson SA (2017) Moving beyond presence and absence when examining changes in species distributions. Global Change Biol 23:2929-2940

Austin MP, Nicholls AO, Margules CR (1990) Measurement of the realized qualitative niche. Environmental niches of five Eucalyptus species. Ecol Monogr 60:161-177

Austin MP, van Niel KP (2011) Improving species distribution models for climate change studies. Variable selection and scale. J Biogeogr 38:1-8

Avise JC (2009) Phylogeography. Retrospect and prospect. J Biogeogr 36:3-15

Azzaroli A, Guazzone G (1979) Terrestrial mammals and land connections in the Mediterranean before and during the Messinian. Palaeogeogr Palaeocl 29:155-167

Badalamenti E, Pasta S, La Mantia T, La Mela Veca DS (2018) Criteria to identify old-growth forests in the Mediterranean. A case study from Sicily based on literature review and some management proposals. Feddes Repert 129:25-37

Bahn V, McGill BJ (2013) Testing the predictive performance of distribution models. Oikos 122:321331

Bakkestuen V, Halvorsen R, Heegaard E (2009) Disentangling complex fine-scale ecological patterns by path modelling using GLMM and GIS. J Veg Sci 20:779-790 
Balkenhol N, Waits LP, Dezzani RJ (2009) Statistical approaches in landscape genetics. An evaluation of methods for linking landscape and genetic data. Ecography 32:818-830

Ball I, Possingham HP (2000) Marxan (v1.8.2): Marine reserve design using spatially explicit annealing. A manual prepared for The Great Barrier Reef Marine Park Authority, 69 pp.

Ball IR, Possingham HP, Watts M (2009) Marxan and relatives: Software for spatial conservation prioritisation. In: Moilanen A, Wilson KA, Possingham HP (eds) Pages in Spatial conservation prioritisation: Quantitative methods and computational tools.: Oxford University Press, Oxford, UK, pp. 185-195

Ballabio C, Panagos P, Monatanarella L (2016) Mapping topsoil physical properties at European scale using the LUCAS database. Geoderma 261:110-123

Baquedano FJ, Castillo FJ (2007) Drought tolerance in the Mediterranean species Quercus coccifera, Quercus ilex, Pinus halepensis, and Juniperus phoenicea. Photosynethica 45:229-238

Barbagallo C (1983) Vegetazione di alcuni boschi di sughera della Sicilia meridionale. Boll Accad Gioenia Sci Nat Catania 16:289-296

Barbagallo C, Brullo S, Fagotto F (1979) Boschi di Quercus ilex L. del territorio di Siracusa e principali aspetti di degradazione. Pubbl Ist Bot Univ Catania:1-24

Barbéro M, Chalabi N, Nahal I, Quézel P (1976) Les formations à conifères Méditerranéens en Syrie littorale. Ecol Medit 2:87-99

Barbéro M, Loisel R, Quézel P (1992) Biogeography, ecology and history of Mediterranean Quercus ilex ecosystems. Vegetatio 99-100:19-34

Barbéro M, Quézel P (1976) Les groupements forestiers de Grèce Centro-Méridionale. Ecol Medit 2:3-86

Barbéro M, Quézel P (1980) La végétation forestière de Crète. Ecol Medit 5:175-210

Bardsley DK, Edwards-Jones G (2007) Invasive species policy and climate change: social perceptions of environmental change in the Mediterranean. Environ Sci Policy 10:230-242

Barrico L, Castro H, Coutinho AP, Gonçalves MT, Freitas H, Castro P (2018) Plant and microbial biodiversity in urban forests and public gardens. Insights for cities' sustainable development. Urban For Urban Gree 29:19-27

Barry RG (2008) Mountain weather and climate, 3rd ed. Cambridge University Press, Cambridge, New York, $506 \mathrm{pp}$.

Barry RG, Blanken P (2016) Microclimate and local climate. Cambridge University Press, New York, NY, $316 \mathrm{pp}$.

Barthlott W, Hostert A, Kier G, Küper W, Kreft H, Mutke J, Rafiqpoor MD, Sommer JH (2007) Geographic patterns of vascular plant diversity at continental to global scales. Erdkunde 81:305316

Bartolo G, Brullo C, Marcenò C (1982) La vegetazione costiera della Sicilia sud-orientale. Contributo alla interpretazione delle fasce di vegetazione delle coste mediterranee. Quaderni CNR Ser $\mathrm{AQ} / 1 / 226$

Bartolo G, Brullo S, Lo Cicero E, Marcenò C, Piccione V (1978) Osservazioni fitosociologiche sulla pineta a Pinus halepensis di Vittoria (Sicilia meridionale). Arch Bot Biogeogr Ital 54:137-154

Bartolo G, Brullo S, Minissale P, Spampinato G (1986) Osservazioni fitosociologiche sulle pinete a Pinus halepensis del bacino del Fiume Tellaro (Sicilia sud-orientale). Boll Accad Gioenia Sci Nat Catania 18:225-270

Bartolo G, Brullo S, Minissale P, Spampinato G (1990) Contributo alla conoscenza dei boschi a Quercus ilex della Sicilia. Acta Bot Malac 15:203-215 
Bauer E-M, Bergmeier E (2011) The mountain woodlands of western Crete - plant communities, forest goods, grazing impact and conservation. Phytocoenologia 41:73-105

Bazan G, Marino P, Guarino R, Domina G, Schicchi R (2015) Bioclimatology and vegetation series in Sicily: a geostatistical approach. Ann Bot Fenn 52:1-18

Bazan G, Marino P, Schicchi R, Surano N (2006) Analisi geostatistica integrata come metodo per la conoscenza del bioclima della Sicilia. 10a Conferenza nazionale ASITA:253-258

Beaumont L, Graham E, Duursma DE, Wilson PD, Cabrelli A, Baumgartner JB, Hallgren W, EsperónRodríguez M, Nipperess DA, Warren DL, Laffan SW, VanDerWal J (2016) Which species distribution models are more (or less) likely to project broad-scale, climate-induced shifts in species ranges? Ecol Model 342:135-146

Beierkuhnlein C (2007) Biogeographie, 1. Aufl. UTB GmbH, Stuttgart, 397 pp.

Bennett KD, Tzedakis PC, Willis KJ (1991) Quaternary refugia of North European trees. J Biogeogr 18:103-115

Bergmeier E (1995) Die Höhenstufung der Vegetation in Südwest-Kreta (Griechenland) entlang eines 2450 m-Transektes. Phytocoenologia 25:317-361

Bergmeier E (2002) The vegetation of the high mountains of Crete - a revision and multivariate analysis. Phytocoenologia 32:205-249

Bergmeier E (2012) KRITI - the vegetation of Crete database. Biodivers Ecol 4:384

Bergmeier E, Abrahamczyk S (2007) Ecology and distribution of the Aegean wetland endemics Carex cretica and Lathyrus neurolobus. Nova Hedwigia Suppl. 131:207-219

Bergmeier E, Abrahamczyk S (2008) Current and historical diversity and new records of wetland plants in Crete, Greece. Willdenowia 38:433-453

Bergmeier E, Blockeel T, Böhling N, Fournaraki C, Gotsiou P, Jahn R, Lansdown R, Turland NJ (2011) An inventory of the vascular plants and bryophytes of Gavdopoula island (S Aegean, Greece) and its phytogeographical significance. Willdenowia 41:179-190

Bergmeier E, Dimopoulos P, Fischer P (2006) Monitoring und Management von Lebensraumtypen und Pflanzenarten der FFH-Richtlinie in Griechenland - Grundlagen, Empfehlungen und Perspektiven. Naturschutz und Biologische Vielfalt 26:245-262

Bergmeier E, Goedecke F (2017) Platanus orientalis woodlands of Crete - diversity, distribution and conservation status. In: Achille G (ed) Scritti in onore di Franco Pedrotti. Collana Natura e aree protette 31: TEMI, Trento, pp. 29-45

Bergmeier E, Jahn R, Jagel A (1997) Flora and vegetation of Gávdos (Greece), the southernmost European island. I. Vascular flora and chorological relations. Candollea 52:305-358

Bergmeier E, Kypriotakis Z, Jahn R, Böhling N, Dimopoulos P, Raus T, Tzanoudakis D (2001) Flora and phytogeographical significance of the islands Chrisi, Koufonisi and nearby islets (S Aegean, Greece). Willdenowia 31:329-356

Berry ZC, Gotsch SG, Holwerda F, Muñoz-Villers LE, Asbjornsen H (2016) Slope position influences vegetation-atmosphere interactions in a tropical montane cloud forest. Agr Forest Meteorol 221:207-218

Biltekin D, Popescu S-M, Suc J-P, Quézel P, Jiménez-Moreno G, Yavuz N, Çağatay MN (2015) Anatolia: A long-time plant refuge area documented by pollen records over the last 23 million years. Rev Geophys 215:1-22

Bilton MC, Metz J, Tielbörger K (2016) Climatic niche groups. A novel application of a common assumption predicting plant community response to climate change. Perspect Plant Ecol 19:6169 
Birnbaum P, Ibanez T, Pouteau R, Vandrot H, Hequet V, Blanchard E, Jaffré T (2015) Environmental correlates for tree occurrences, species distribution and richness on a high-elevation tropical island. AoB Plants 7:plv075, 15pp. (online)

Blasi C (1998) Clima e fitoclima. In: Pignatti S (ed) I boschi d'Italia. Sinecologia e biodiveristà: UTET, Torino, pp. 33-68

Blasi C, Carraza ML, Frondoni R, Rosati L (2000) Ecosystem classification and mapping: a proposal for Italian landscapes. Appl Veg Sci 3:233-242

Blockeel TL (2007) Notes on some rare and newly recorded bryophytes from Crete, Greece. J Bryol 29:197-198

Blockeel TL (2012) Notes on the bryophytes of the schistose valleys of western Crete, including Asterella africana new to Greece, and an assessment of the conservation status of Rhamphidium purpuratum and Jungermannia handelii. J Bryol 34:292-296

Blondel J, Aronson J (2010) The Mediterranean region. Biological diversity in space and time, 2nd ed. Oxford University Press, Oxford, New York, 376 pp.

Bockheim JG, Gennadiyev AN (2010) Soil-factorial models and earth-system science. A review. Geoderma 159:243-251

Böhling N, Greuter W, Raus T (2002) Zeigerwerte der Gefäßpflanzen der Südägäis (Griechenland). Braun-Blanquetia 32:1-108

Bölöni J, Botta-Dukát Z, Illyés E, Molnár Z (2011) Hungarian landscape types: classification of landscapes based on the relative cover of (semi-) natural habitats. Appl Veg Sci 14:537-546

Bonnano G, Veneziano V (2016) New insights into the distribution patterns of Mediterranean insular endemic plants. The Sicilian islands' group. Flora 224:230-243

Booy G, Hendriks RJJ, Smulders MJM, Groenendael JM, Vosman B (2000) Genetic diversity and the survival of populations. Plant Biol 2:379-395

Bosque M, Adamogianni M-I, Bariotakis M, Fazan L, Stoffel M, Garfi G, Gratzfeld J, Kozlowski G, Pirintsos S (2014) Fine-scale spatial patterns of the Tertiary relict Zelkova abelicea (Ulmaceae) indicate possible processes contributing to its persistence to climate changes. Reg Environ Change 14:835-849

Bottema S, Sarpaki A (2003) Environmental change in Crete: a 9000-year record of Holocene vegetation history and the effect of the Santorini eruption. Holocene 13:733-749

Boulard D, Castel T, Camberlin P, Sergent A-S, Asse D, Bréda N, Badeau V, Rossi A, Pohl B (2017) Bias correction of dynamically downscaled precipitation to compute soil water deficit for explaining year-to-year variation of tree growth over northeastern France. Agr Forest Meteorol 232:247264

Bradsworth N, White JG, Isaac B, Cooke R (2017) Species distribution models derived from citizen science data predict the fine scale movements of owls in an urbanizing landscape. Biol Conserv 213:27-35

Bramwell D, Caujapé-Castells J (2011) The biology of island floras. Cambridge University Press, Cambridge, UK, New York, 522 pp.

Braun-Blanquet J (1928) Pflanzensoziologie. Grundzüge der Vegetationskunde. Springer, Berlin, 330 pp.

Breiner FT, Guisan A, Bergamini A, Nobis MP, Anderson B (2015) Overcoming limitations of modelling rare species by using ensembles of small models. Methods Ecol Evol 6:1210-1218

Breiner FT, Nobis MP, Bergamini A, Guisan A, Isaac N (2018) Optimizing ensembles of small models for predicting the distribution of species with few occurrences. Methods Ecol Evol 20:7 pp. (online) 
Breton C, Tersac M, Bervillé A (2006) Genetic diversity and gene flow between the wild olive (oleaster, Olea europaea L.) and the olive. Several Plio-Pleistocene refuge zones in the Mediterranean basin suggested by simple sequence repeats analysis. J Biogeogr 33:1916-1928

Broennimann O, Treier UA, Müller-Schärer H, Thuiller W, Peterson AT, Guisan A (2007) Evidence of climatic niche shift during biological invasion. Ecol Lett 10:701-709

Brogniez D de, Ballabio C, Stevens A, Jones, R. J. A., Montanarella L, van Wesemael B (2015) A map of the topsoil organic carbon content of Europe generated by a generalized additive model. Eur $\mathrm{J}$ Soil Sci 66:121-134

Brooks TM, Mittermeier RA, Mittermeier CG, da Fonseca GAB, Rylands AB, Konstant WR, Flick P, Pilgrim J, Oldfield S, Magin G, Hilton-Taylor C (2002) Habitat loss and extinction in the hotspots of biodiversity. Conserv Biol 16:909-923

Brotons L, Thuiller W, Araújo MB, Hirzel AH (2004) Presence-absence versus presence-only modelling methods for predicting bird habitat suitability. Ecography 27:437-448

Brullo C, Brullo S, Giusso del Galdo G, Guarino R, Siracusa G, S. Sciandrello (2012) The class QuercoFagetea sylvaticae in Sicily: An example of boreo-temperate vegetation in the Central Mediterranean region. Ann Bot Roma 2012:19-38

Brullo S (1984) Contributo alla conoscenza della vegetazione delle Madonie (Sicilia settentrionale). Boll Accad Gioenia Sci Nat Catania 17:219-258

Brullo S, Cirino E, Longhitano N (1995) Vegetazione della Sicilia: quadro sintassonomico. Atti Convegni Lincei Roma 115:285-305

Brullo S, Costanzo E, Tomaselli V (2001a) Etude phytosociologique sur les peuplements à Laurus nobilis dans les Monts Iblei (Sicile sud-orientale) Phytocoenologia. Phytocoenologia 31:249-270

Brullo S, Di Martino A (1974) Vegetazione dell'Isola Grande dello Stagnone (Marsala). Boll Stud Inform Giard Bot Palermo 26:15-62

Brullo S, Gianguzzi L, La Mantia A, Siracusa G (2008) La classe Quercetea ilicis in Sicilia. Boll Accad Gioenia Sci Nat Catania 41:1-124

Brullo S, Giusso del Galdo G, Guarino R (2001b) The orophilous communities of the Pino-Juniperetea class in the Central and Eastern Mediterranean area. Feddes Repert 112:261-308

Brullo S, Guarino R (2000) Contribution to the knowledge of flora and vegetation of Khrisi islet (Crete, SE Mediterranean sea) 10:265-282

Brullo S, Guarino R, Ronsisvalle GA (2000) La vegetazione del litorale di Manfria, presso Gela (Sicilia), area soggetta a vincolo archeologico. Arch Geobot 4:91-107

Brullo S, Guarino R, Siracusa G (1999) Revisione tassonomica delle querce caducifoglie della Sicilia. Webbia 54:1-72

Brullo S, Marcenò C (1985) Contributo alla conoscenza della classe Quercetea ilicis in Sicilia. Not Fitosoc 19:183-228

Brullo S, Minissale P, Rossello F, Spampinato G (2004) Considerazioni su una check-list aggiornata della flora sicula. In: Anon. (ed) Aggiornamento delle conoscenze floristiche d'Italia. Gruppo di Lavoro per la Floristica. Orto Botanico 11-12 novembre 2004. Riassunti delle comunicazioni, Società Botanica Latina, Rome, pp. 84-86

Brullo S, Minissale P, Spampinato G (1997) La classe Cisto-Micromerietea nel Mediterraneo centrale e orientale. Fitosociologia 32:29-60

Brullo S, Ronsisvalle GA (1975) La vegetazione dei Gorghi Tondi e del Lago Preola, presso Mazara del Vallo (Sicilia occidentale). Not Fitosoc 10:45-67

Brullo S, Spampinato G (1990) La vegetazione dei corsi d'acqua della Sicilia. Boll Accad Gioenia Sci Nat Catania 23:119-252 
Bucci G, Vendramin GG, Lelli L, Vicario F (1997) Assessing the genetic divergence of Pinus leucodermis Ant. endangered populations. Use of molecular markers for conservation purposes. Theor Appl Genet 95:1138-1146

Budic L, Didenko G, Dormann CF (2016) Squares of different sizes: effect of geographical projection on model parameter estimates in species distribution modeling. Ecol Evol 6:202-211

Bugmann $\mathrm{H}$ (1996) Functional types of trees in temperate and boreal forests: classification and testing. J Veg Sci 7:359-370

Bunce RGH, Barr CJ, Clarke RT, Howard DC, Lane AMJ (1996) ITE Merlewood Land Classification of Great Britain. J Biogeogr 23:625-634

Burrough PA, McDonell RA (1998) Principles of Geographical Information Systems. Oxford University Press, New York, 190 pp.

Byrne D, Pickard AJ (2016) Neogeography and the democratization of GIS. A metasynthesis of qualitative research. Inf Comm Soc 19:1505-1522

Cabral JS, Kreft H (2012) Linking ecological niche, community ecology and biogeography. Insights from a mechanistic niche model. J Biogeogr 39:2212-2224

Cabral JS, Schurr FM (2010) Estimating demographic models for the range dynamics of plant species. Global Ecol Biogeogr 19:85-97

Calabrese JM, Certain G, Kraan C, Dormann CF (2014) Stacking species distribution models and adjusting bias by linking them to macroecological models. Global Ecol Biogeogr 23:99-112

Caraveli H (2000) A comparative analysis on intensification and extensification in mediterranean agriculture. Dilemmas for LFAs policy. J Rural Stud 16:231-242

Carmel Y, Kadmon R (1999) Effects of grazing and topography on long-term vegetation changes in a Mediterranean ecosystem in Israel. Plant Ecol 145:243-254

Carrivick JL, Smith MW, Quincey DJ, Carver SJ (2013) Developments in budget remote sensing for the geosciences. Geology Today 29:138-143

Catry FX, Rego FC, Bugalho MN, Lopes T, Silva JS, Moreira F (2006) Effects of fire on tree survival and regeneration in a Mediterranean ecosystem. For Ecol Man 234 S:197-202

CBD (2012) Convention on Biological Diversity. Global Strategy for Plant Conservation: 2011-2020, Richmond

Chen ZJ (2007) Genetic and epigenetic mechanisms for gene expression and phenotypic variation in plant polyploids. Annu Rev Plant Biol 58:377-406

Christe C, Kozlowski G, Frey D, Bétrisey S, Maharramova E, Garfí G, Pirintsos S, Naciri Y (2014) Footprints of past intensive diversification and structuring in the genus Zelkova (Ulmaceae) in south-western Eurasia. J Biogeogr 41:1081-1093

Chytrý M, Danihelka J, Axmanová I, Božková J, Hettenbergerová E, Li C-F, Rozbrojová Z, Sekulová L, Tichý L, Vymazalová M, Zelený D (2010) Floristic diversity of an eastern Mediterranean dwarf shrubland. The importance of soil pH. J Veg Sci 21:1125-1137

Chytrý M, Hennekens SM, Jiménez-Alfaro B, Knollová I, Dengler J, Jansen F, Landucci F, Schaminée JHJ, Aćić S, Agrillo E, Ambarlı D, Angelini P, Apostolova I, Attorre F, Berg C, Bergmeier E, Biurrun I, Botta-Dukát Z, Brisse H, Campos JA, Carlón L, Čarni A, Casella L, Csiky J, Ćušterevska R, Stevanović ZD, Danihelka J, Bie E de, Ruffray Pd, Sanctis M de, Dickoré WB, Dimopoulos P, Dubyna D, Dziuba T, Ejrnæs R, Ermakov N, Ewald J, Fanelli G, Fernández-González F, FitzPatrick U, Font X, GarcíaMijangos I, Gavilán RG, Golub V, Guarino R, Haveman R, Indreica A, Gürsoy DI, Jandt U, Janssen JAM, Jiroušek M, Kącki Z, Kavgacı A, Kleikamp M, Kolomiychuk V, Krstivojević Ćuk M, Krstonošić $D$, Kuzemko A, Lenoir J, Lysenko $T$, Marcenò $C$, Martynenko $V$, Michalcová D, Erenskjold Moeslund J, Onyshchenko V, Pedashenko H, Pérez-Haase A, Peterka T, Prokhorov V, 
Rašomavičius V, Rodríguez-Rojo MP, Rodwell JS, Rogova T, Ruprecht E, Rūsiṇa S, Seidler G, Šibík J, Šilc U, Škvorc Ž, Sopotlieva D, Stančić Z, Svenning J-C, Swacha G, Tsiripidis I, Turtureanu PD, Uğurlu E, Uogintas D, Valachovič M, Vashenyak Y, Vassilev K, Venanzoni R, Virtanen R, Weekes L, Willner W, Wohlgemuth T, Yamalov S (2016) European Vegetation Archive (EVA). An integrated database of European vegetation plots. Appl Veg Sci 19:173-180

Chytrý M, Otýpková Z (2003) Plot sizes used for phytosociological sampling of European vegetation. J Veg Sci 14:563-570

Cingolani AM, Cabido M, Gurvich D, Renison D, Díaz S (2007) Filtering processes in the assembly of plant communities: Are species presence and abundance driven by the same traits? J Veg Sci 18:911-920

Cohen M, Bilodeau C, Alexandre F, Godron M, Andrieu J, Grésillon E, Garlatti F, Morganti A (2015) What is the plant biodiversity in a cultural landscape? A comparative, multi-scale and interdisciplinary study in olive groves and vineyards (Mediterranean France). Agr Ecosyst Environ 212:175-186

Combourieu-Nebout N (1993) Vegetation response to upper Pliocene glacial/ interglacial cyclicity in the Central Mediterranean. Quaternary Res 40:228-236

Copeland SM, Harrison SP (2015) Identifying plant traits associated with topographic contrasts in a rugged and diverse region (Klamath-Siskiyou Mts, OR, USA). Ecography 38:569-577

Corney PM, Le Duc MG, Smart SM, Kirby KJ, Bunce RGH, Marrs RH (2004) The effect of landscapescale environmental drivers on the vegetation composition of British woodlands. Biol Conserv 120:491-505

Cornwell WK, Ackerly DD (2010) A link between plant traits and abundance. Evidence from coastal California woody plants. J Ecol 98:814-821

Coudun C, Gégout J-C, Piedallu C, Rameau J-C (2006) Soil nutritional factors improve models of plant species distribution. An illustration with Acer campestre (L.) in France. J Biogeogr 33:1750-1763

Cox CB, Moore PD (2010) Biogeography. An ecological and evolutionary approach, 8th ed. Wiley, Hoboken, NJ, 498 pp.

Coxen CL, Frey JK, Carleton SA, Collins DP (2017) Species distribution models for a migratory bird based on citizen science and satellite tracking data. Global Ecol Conserv 11:298-311

Creutzburg N, Drooger CW, Meulenkamp JE, Papastamatiou J, Seidel E, Tataris A (1977) Geological map of Crete (1:200.000). IGME, Greece

Crisp MD, Laffan S, Linder HP, Monro A (2001) Endemism in the Australian flora. J Biogeogr 28:183198

Cuesta B, Villar-Salvador P, Puértolas J, Rey-Benayas JM, Michalet R (2010) Facilitation of Quercus ilex in Mediterranean shrubland is explained by both direct and indirect interactions mediated by herbs. J Ecol 98:687-696

Culmsee H, Schmidt M, Schmiedel I, Schacherer A, Meyer P, Leuschner C (2014) Predicting the distribution of forest habitat types using indicator species to facilitate systematic conservation planning. Ecol Indic 37:131-144

Daly C, Conklin DR, Unsworth MH (2010) Local atmospheric decoupling in complex topography alters climate change impacts. Int J Climatol 30:1857-1864

Das Gupta S, MacKenzie MD, Quideau SA (2015) Using spatial ecology to examine above and belowground interactions on a reclaimed aspen stand in northern Alberta. Geoderma 259260:12-22

Décamps H, Décamps O (2001) Mediterranean riparian woodlands. Tour du Valat, Arles, 139 pp. 
Dengler J, Hüllbusch E, Bita-Nicolae C, Chytrý M, Didukh YP, Diekmann M, Dierschke H, Englisch T, Ermakov N, Feldhaar H, Fosaa AM, Frank D, Gillet F, Guarino R, Hennekens S, Hill MO, Jeleska S, Jiménez-Alfaro B, Julve P, Kącki Z, Karrer G, Nobis MP, Ozinga WA, Pignatti S, Raus T, Řezníčková E, Ruprecht E, Šilc U, Steinacher M, Theurillat J-P, Tichý L, Jansen F (2016) Ecological Indicator Values of Europe (EIVE) 1.0:. A powerful open-access tool for vegetation scientists. http://www.evsmeeting2016.it/category/abstracts:1 p. (online)

Dengler J, Jansen F, Glöckler F, Peet RK, Cáceres M de, Chytrý M, Ewald J, Oldeland J, Lopez-Gonzalez G, Finckh M, Mucina L, Rodwell J, Schaminée JHJ, Spencer N (2011) The Global Index of Vegetation-Plot Databases (GIVD): a newresource for vegetation science. J Veg Sci 22:582-597

Dengler J, sPlot Core Team (2014) sPlot: the first global vegetation-plot database and opportunities to contribute in IAVS. IAVS Bull 2014:34-37

Di Maggio C, Madonia G, Parise M, Vattano M (2012) Karst of Sicily and its conservation. J Cave Karst Stud 74:157-172

Di Pasquale G, Garfi G, Quézel P (1992) Sur la présence d'un Zelkova nouveau en Sicile sud orientale (Ulmaceae). Biocosme Mésogéen 8-9:401-409

Di Pietro R, Germani D (2007) Considerazioni cenologiche e fitosociologiche preliminari sulla presenza di Styrax officinalis L. nei Monti Cornicolani (Lazio centrale). Fitosociologia 44 Suppl. 1:219-223

Dick CW, Abdul-Salim K, Bermingham E (2003) Molecular systematic analysis reveals cryptic tertiary diversification of a widespread tropical rain forest tree. Am Nat 162:691-703

Dierschke H (1994) Pflanzensoziologie. Grundlagen und Methoden. Eugen Ulmer, Stuttgart, 683 pp.

Dimopoulos P, Bergmeier E (2008) Riparian woody vegetation in Greece. In: Arizpe D, Mendes A, Rabaça JE (eds) Sustainable riparian zones. A management guide.: Generalitat Valenciana, Valencia, pp. 85-88

Dimopoulos P, Bergmeier E, Fischer P (2005) Monitoring and conservation status assessment of habitat types in Greece: fundamentals and exemplary cases. Ann Bot Roma V:8-20

Dimopoulos P, Bergmeier E, Fischer P (2006) Natura 2000 Habitat Types of Greece Evaluated in the Light of Distribution, threat and Responsibility. Biol Environ 106:175-187

Dimopoulos $P$, Raus $T$, Bergmeier E, Constantinidis T, latroú G, Kokkini S, Strid A, Tzanoudakis D (2013) Vascular Plants of Greece. An annotated checklist. Englera 31:1-372

Dimopoulos $P$, Raus $T$, Bergmeier E, Constantinidis T, latroú G, Kokkini S, Strid A, Tzanoudakis D (2016) Vascular plants of Greece. An annotated checklist. Willdenowia 46 Suppl.:301-347

Dormann CF, Elith J, Bacher S, Buchmann C, Carl G, Carré G, García Marquéz JR, Gruber B, Lafourcade B, Leitão PJ, Münkemüller T, McClean C, Osborne PE, Reineking B, Schröder B, Skidmore AK, Zurell D, Lautenbach S (2013) Collinearity: a review of methods to deal with it and a simulation study evaluating their performance. Ecography 36:27-46

Dormann CF, McPherson JM, Araújo MB, Bivand R, Bolliger J, Carl G, Davies RG, Hirzel A, Jetz W, Kissling D, Kühn I, Ohlemüller R, Peres-Neto PR, Reineking B, Schröder B, Schurr FM, Wilson R (2007) Methods to account for spatial autocorrelation in the analysis of species distributional data. A review. Ecography 30:609-628

Douda J, Boublík K, Slezák M, Biurrun I, Nociar J, Havrdová A, Doudová J, Aćić S, Brisse H, Brunet J, Chytrý M, Claessens H, Csiky J, Didukh Y, Dimopoulos P, Dullinger S, FitzPatrick U, Guisan A, Horchler PJ, Hrivnák R, Jandt U, Kącki Z, Kevey B, Landucci F, Lecomte $H$, Lenoir J, Paal J, Paternoster D, Pauli H, Pielech R, Rodwell JS, Roelandt B, Svenning J-C, Šibík J, Šilc U, Škvorc Ž, Tsiripidis I, Tzonev RT, Wohlgemuth T, Zimmermann NE, Schwabe-Kratochwil A (2016) Vegetation 
classification and biogeography of European floodplain forests and alder carrs. Appl Veg Sci 19:147-163

Drachenfels O von (2010) Überarbeitung der Naturräumlichen Regionen Niedersachsens. Informationsdienst Naturschutz Niedersachen 30:249-252

Ducci F, Proietti R, Favre J-M (1999) Allozyme assessment of genetic diversity within the relic Sicilian fir Abies nebrodensis (Lojac.) Mattei. Ann For Sci 56:345-355

Dufour-Dror JM, Ertas A (2004) Bioclimatic perspectives inthe distribution of Quercus ithaburensis Decne. subspecies in Turkey and in the Levant. J Biogeogr 31:461-474

Dupouey JL, Dambrine E, Laffite JD, Moares C (2002) Irreversible impact of past land use on forest soils and biodiversity. Ecology 83:2978-2984

EEA (2012) Reference grid. http://www.eea.europa.eu/data-and-maps/data/eea-reference-grids-1. Accessed 10th January 2017

EEA (2015) Digital Elevation Model over Europe (EU-DEM). http://www.eea.europa.eu/data-andmaps/data/eu-dem. Accessed 14th March 2017

Egli BR (1989) Ecology of dolines in the mountains of Crete (Greece). Bielefelder Ökol Beitr 4:59-63

Egli BR (1991) The special flora, ecological and edaphic conditions of dolines in the mountains of Crete. Bot Chron 10:325-335

Egli BR (1997) A project for the preservation of Zelkova abelicea (Ulmaceae), a threatened endemic tree species from the mountains of Crete. Bocconea 5:505-510

Egli BR (1998) Effects of grazing on the natural forests of western Crete. In: Papanastasis VP, Peter D (eds) Ecological Basis of Livestock grazing in Mediterranean Ecosystems, pp. 103-106

Egli BR (2000) Forest vegetation of Western Crete. Bot Chron 13:1-21

Egli BR, Gerstberger P, Greuter W, Risse H (1990) Horstrissea dolinicola, a new genus and species of umbels (Umbelliferae, Apiaceae) from Kriti (Greece). Willdenowia 19:389-399

Elith J, Graham CH, Anderson RP, Dudík M, Ferrier S, Guisan A, Hijmans RJ, Huettmann F, Leathwick JR, Lehmann A, Li J, Lohmann LG, Loiselle BA, Manion G, Moritz C, Nakamura M, Nakazawa Y, Overton JM, Townsend Peterson A, Phillips SJ, Richardson K, Scachetti-Pereira R, Schapire RE, Soberón J, Williams SE, Wisz MS, Zimmermann NE (2006) Novel methods improve prediction of species' distributions from occurrence data. Ecography 29:129-151

Elith J, Kearney M, Phillips S (2010) The art of modelling range-shifting species. Methods Ecol Evol 1:330-342

Elith J, Leathwick JR (2009) Species Distribution Models: Ecological Explanation and Prediction Across Space and Time. Annu Rev Ecol Evol S 40:677-697

Ellenberg H (1974) Zeigerwerte der Gefäßpflanzen Mitteleuropas. Scripta Geobotanica 9:1-97

Ellison AM (2002) Macroecology of mangroves. Large-scale patterns and processes in tropical coastal forests. Trees 16:181-194

Ernst W (1974) Schwermetallvegetation der Erde. G. Fischer, Stuttgart, 194 pp.

Escobar LE, Lira-Noriega A, Medina-Vogel G, Townsend Peterson A (2014) Potential for spread of the white-nose fungus (Pseudogymnoascus destructans) in the Americas: use of Maxent and NicheA to assure strict model transference. Geospat Health 9:221-229

ESRI (2013) ArcGIS for Desktop: Release 10.2 Redlands, CA: Environmental Systems Research Institute

Euro+Med (2006-2017) Euro+Med PlantBase - the information resource for Euro-Mediterranean plant diversity. http://ww2.bgbm.org/EuroPlusMed/. Accessed 10th Oktober 2017

European Commision Joint Research Centre (2012) EFSA Spatial Data Version 1.1 Data Properties and Processing. Publication Office of the European Union, Luxembourg, $50 \mathrm{pp}$. 
European Commission - DG Environment (2013) Interpretation Manual of European Union Habitats. EUR 28., Brussels, $144 \mathrm{pp}$.

European Environment Agency (2015) EIONET - European Environment Information and Observation Network. https://www.eionet.europa.eu/

Evans JS, Oakleaf J, Cushman SA, Theobald D (2014) An ArcGIS Toolbox for Surface Gradient and Geomorphometric Modeling, version 2.0-0.

Faccenna C, Becker TW, Auer L, Billi A, Boschi L, Brun JP, Capitanio FA, Funiciello F, Horvàth F, Jolivet L, Piromallo C, Royden L, Rossetti F, Serpelloni E (2014) Mantle dynamics in the Mediterranean. Rev Geophys 52:283-332

Fazan L (2014) Investigating the response to climate in two Mediterranean tree species growing in the mountains of Crete (Greece): Zelkova abelicea and Cupressus sempervirens. Msc-thesis, Université de Genève, Switzerland, 69 pp.

Fazan L, Stoffel M, Frey DJ, Pirintsos S, Kozlowski G (2012) Small does not mean young. Age estimation of severely browsed trees in anthropogenic Mediterranean landscapes. Biol Conserv 153:97-100

Fielding J, Turland NJ (2005) Flowers of Crete. Royal Botanic Gardens, Kew, London, 650 pp.

Fierotti G (1988) Carta dei suoli della Sicilia (Scala 1:2.500.000). Assessorato Territorio ed Ambiente Regione Siciliana, Università degli Studi di Palermo, Facoltà di Agraria, Istituto di Agronomia Generale, Cattedra di Pedologia

Filella I, Peñuelas J (2003) Partitioning of water and nitrogen in co-occurring Mediterranean woody shrub species of different evolutionary history. Oecologia 137:51-61

Fineschi S, Cozzolino S, Migliaccio M, Vendramin GG (2004) Genetic variation of relic tree species: the case of Mediterranean Zelkova abelicea (Lam.) Boisser and Z. sicula Di Pasquale, Garfí and Quézel (Ulmaceae). For Ecol Man 197:273-278

Fois M, Fenu G, Cañadas EM, Bacchetta G (2017) Disentangling the influence of environmental and anthropogenic factors on the distribution of endemic vascular plants in Sardinia. PLOS ONE 12:e0182539, 14pp. (online)

Follieri M, Magri D, Sadori L (1986) Late Pleistocene Zelkova extinction in Central Italy. New Phytol 103:269-273

Franklin J (1998) Predicting the distribution of shrub species in southern California from climate and terrain-derived variables. J Veg Sci 9:733-748

Franklin J, Davis FW, Ikegami M, Syphard AD, Flint LE, Flint AL, Hannah L (2013) Modeling plant species distributions under future climates: how fine scale do climate projections need to be? Global Change Biol 19:473-483

Frey W, Lösch R (2010) Lehrbuch der Geobotanik. Pflanze und Vegetation in Raum und Zeit, 3. Aufl. Spektrum Akademischer Verlag, München, 548 pp.

Fridley JD (2009) Downscaling Climate over Complex Terrain. High finescale $(<1000 \mathrm{~m})$ spatial variation of near-ground temperatures in a montane forested landscape (Great Smoky Mountains). J Appl Meteor Climatol 48:1033-1049

Fu P, Rich PM (2002) A geometric solar radiation model with applications in agriculture and forestry. Comput Electron Agr 37:25-35

Fuentes-Utrilla P, Valbuena-Carabaña M, Ennos R, Gil L (2014a) Population clustering and clonal structure evidence the relict state of Ulmus minor Mill. in the Balearic Islands. Heredity 113:2131 
Fuentes-Utrilla P, Venturas M, Hollingsworth PM, Squirrell J, Collada C, Stone GN, Gil L (2014b) Extending glacial refugia for a European tree: genetic markers show that Iberian populations of white elm are native relicts and not introductions. Heredity 112:105-113

Furnari F (1965) Boschi a Quercus suber L. e di Quercus ilex L. e le garighe del Rosmarino-Ericion in territorio di Santo Pietro. Boll Ist Bot Univ Catania 3:1-31

Garcia K, Lasco R, Ines A, Lyon B, Pulhin F (2013) Predicting geographic distribution and habitat suitability due to climate change of selected threatened forest tree species in the Philippines. Appl Geogr 44:12-22

García-López L, Real R (2014) Modelación de la distributión de una especies (Glis glis Linnaeus, 1766) para precedir cómo podría afectarle el cambio climático. Comparativa CliMond vs. Worldclim. In: Cámara Artigas R, Rodríguez Pérez B, Muriel Gómez JL (eds) Biogeografía de sistemas litorales. Dinámica y conservación: self published, Sevilla, pp. 275-278

Garfi G (1997) Première contribution à l'étude de Zelkova sicula (Ulmaceae), une relique de la flore tertiaire, endémique de la Sicile sud-orientale. PhD-Thesis, University of Aix-Marseille III, France, $470 \mathrm{pp}$.

Garfi G (2006) The IUCN Red List of Threatened Species. Zelkova sicula. http://www.iucnredlist.org/details/61678/0. Accessed 17th March 2017

Garfi G, Barbéro M, Tessier L (2002) Architecture and growth patterns of Zelkova sicula (Ulmaceae) in southeast Sicily as a response to environmental conditions. J Medit Ecol 3:65-76

Garfi G, Carimi F, Pasta S, Rühl J, Trigila S (2011) Additional insights on the ecology of the relic tree Zelkova sicula di Pasquale, Garfi et Quézel (Ulmaceae) after the finding of a new population. Flora 206:407-417

Garve E (1994) Atlas der gefährdeten Farn- und Blütenpflanzen in Niedersachsen und Bremen. Kartierung 1982-1992. Teil 1. A - K. Niedersächsisches Landesamt für Ökologie, Hannover, 478 pp.

Gauch HG, Whittaker RH (1981) Hierarchical classification of community data. J Ecol 69:135-152

Gavin DG, Fitzpatrick MC, Gugger PF, Heath KD, Rodríguez-Sánchez F, Dobrowski SZ, Hampe A, Hu FS, Ashcroft MB, Bartlein PJ, Blois JL, Carstens BC, Davis EB, Lafontaine Gd, Edwards ME, Fernandez M, Henne PD, Herring EM, Holden ZA, Kong W-S, Liu J, Magri D, Matzke NJ, McGlone MS, Saltre F, Stigall AL, Tsai Y-HE, Williams JW (2014) Climate refugia: joint inference from fossil records, species distribution models and phylogeography. New Phytol 204:37-54

GBIF (2017) Global Biodiversity Information Faciltiy. http://www.gbif.org/. Accessed 6th February 2017

Geroy IJ, Gribb MM, Marshall HP, Chandler DG, Benner SG, McNamara JP (2011) Aspect influences on soil water retention and storage. Hydrol Process 25:3836-3842

Gessler PE, Moore ID, McKenzie NJ, Ryan PJ (1995) Soil-landscape modelling and spatial prediction of soil attributes. Int J Geogr Inf Syst 9:421-432

Ghosh S, Scharenbroch BC, Burcham D, Ow LF, Shenbagavalli S, Mahimairaja S (2016) Influence of soil properties on street tree attributes in Singapore. Urban Ecosyst 19:949-967

Giakoumi S, Sini M, Gerovasileiou V, Mazor T, Beher J, Possingham HP, Abdulla A, Çinar ME, Dendrinos P, Gucu AC, Karamanlidis AA, Rodic P, Panayotidis P, Taskin E, Jaklin A, Voultsiadou E, Webster C, Zenetos A, Katsanevakis S, Thrush S (2013) Ecoregion-Based Conservation Planning in the Mediterranean: Dealing with Large-Scale Heterogeneity. PLoS ONE 8:e76449, 15pp. (online)

Giam X, Ng TH, Yap VB, Tan HTW (2010) The extent of undiscovered species in Southeast Asia. Biodivers Conserv 19:943-954

Gianguzzi L (1999) Vegetazione e bioclimatologia dell'isola di Pantelleria (Canale di Sicilia). BraunBlanquetia 22:1-70 
Gianguzzi L, La Mantia A (2008) Contributo alla conoscenza della vegetazione e del paesaggio vegetale della R.N.O. "Monte Cofano" (Sicilia Occidenale). Fitosociologia 45:3-45

Gillespie RG, Roderick GK (2014) Geology and climate drive diversification. Nature 509:297-298

Giraudoux P (2016) pgirmess. A package for data analysis in ecology. http://giraudoux.pagespersoorange.fr/. Accessed 17th March 2017

Goedecke F, Bergmeier E (2017) Ecology and potential distribution of the Cretan endemic tree species Zelkova abelicea. Accepted manuscript. J Medit Ecol

Goedecke F, Jahn R, Bergmeier E (2018) Quantified ecology and co-occurrence of Mediterranean woody species in a landscape context. Plant Ecol 219:481-496

Gomes VHF, IJff SD, Raes N, Amaral IL, Salomão RP, Souza Coelho L de, Almeida Matos FD de, Castilho CV, Andrade Lima Filho D de, López DC, Guevara JE, Magnusson WE, Phillips OL, Wittmann F, Jesus Veiga Carim M de, Martins MP, Irume MV, Sabatier D, Molino J-F, Bánki OS, da Silva Guimarães JR, Pitman NCA, Piedade MTF, Mendoza AM, Luize BG, Venticinque EM, Leão Novo EMM de, Vargas PN, Silva TSF, Manzatto AG, Terborgh J, Reis NFC, Montero JC, Casula KR, Marimon BS, Marimon B-H, Coronado ENH, Feldpausch TR, Duque A, Zartman CE, Arboleda NC, Killeen TJ, Mostacedo B, Vasquez R, Schöngart J, Assis RL, Medeiros MB, Simon MF, Andrade A, Laurance WF, Camargo JL, Demarchi LO, Laurance SGW, Sousa Farias E de, Nascimento HEM, Revilla JDC, Quaresma A, Costa FRC, Vieira ICG, Cintra BBL, Castellanos H, Brienen R, Stevenson PR, Feitosa Y, Duivenvoorden JF, Aymard C GA, Mogollón HF, Targhetta N, Comiskey JA, Vicentini A, Lopes A, Damasco G, Dávila N, García-Villacorta R, Levis C, Schietti J, Souza P, Emilio T, Alonso A, Neill D, Dallmeier F, Ferreira LV, Araujo-Murakami A, Praia D, do Amaral DD, Carvalho FA, Souza FC de, Feeley K, Arroyo L, Pansonato MP, Gribel R, Villa B, Licona JC, Fine PVA, Cerón C, Baraloto $C$, Jimenez EM, Stropp J, Engel J, Silveira M, Mora MCP, Petronelli $P$, Maas $P$, ThomasCaesar R, Henkel TW, Daly D, Paredes MR, Baker TR, Fuentes A, Peres CA, Chave J, Pena JLM, Dexter KG, Silman MR, Jørgensen PM, Pennington T, Di Fiore A, Valverde FC, Phillips JF, RivasTorres G, Hildebrand P von, van Andel TR, Ruschel AR, Prieto A, Rudas A, Hoffman B, Vela CIA, Barbosa EM, Zent EL, Gonzales GPG, Doza HPD, Andrade Miranda IP de, Guillaumet J-L, Pinto LFM, Matos Bonates LC de, Silva N, Gómez RZ, Zent S, Gonzales T, Vos VA, Malhi Y, Oliveira AA, Cano A, Albuquerque BW, Vriesendorp C, Correa DF, Torre EV, van der Heijden G, Ramirez-Angulo $\mathrm{H}$, Ramos JF, Young KR, Rocha M, Nascimento MT, Medina MNU, Tirado M, Wang O, Sierra R, Torres-Lezama A, Mendoza C, Ferreira C, Baider C, Villarroel D, Balslev H, Mesones I, Giraldo LEU, Casas LF, Reategui MAA, Linares-Palomino R, Zagt R, Cárdenas S, Farfan-Rios W, Sampaio AF, Pauletto D, Sandoval EHV, Arevalo FR, Huamantupa-Chuquimaco I, Garcia-Cabrera K, Hernandez L, Gamarra LV, Alexiades MN, Pansini S, Cuenca WP, Milliken W, Ricardo J, Lopez-Gonzalez G, Pos E, ter Steege H (2018) Species Distribution Modelling. Contrasting presence-only models with plot abundance data. Sci Rep-UK 8:1003

Gorokhovich Y, Voustianiouk A (2006) Accuracy assessment of the processed SRTM-based elevation data by CGIAR using field data from USA and Thailand and its relation to the terrain characteristics. Proc SPIE 104:409-415

Gotelli NJ, Anderson MJ, Arita HT, Chao A, Colwell RK, Connolly SR, Currie DJ, Dunn RR, Graves GR, Green JL, Grytnes J-A, Jiang Y-H, Jetz W, Kathleen Lyons S, McCain CM, Magurran AE, Rahbek C, Rangel TFLVB, Soberón J, Webb CO, Willig MR (2009) Patterns and causes of species richness. A general simulation model for macroecology. Ecol Lett 12:873-886

Gradstein SR, Smittenberg JH (1977) The hydrophilous vegetation of Western Crete. Vegetatio 34:6586 
Graham CH, VanDerWal J, Phillips SJ, Moritz C, Williams SE (2010) Dynamic refugia and species persistence: tracking spatial shifts in habitat through time. Ecography 33:1062-1069

Graham M, Zook M (2011) Visualizing Global Cyberscapes. Mapping User-Generated Placemarks. J Urban Technol 18:115-132

Greuter W (1967) Beiträge zur Flora der Südägäis 8-9. Bauhinia 3:243-254

Greuter W (1971) Betrachtungen zur Pflanzengeographie der Südägäis. Opera Bot 30:49-64

Greuter W (1972) The relict element of the flora of Crete and its evolutionary significance. In: D.H. Valentine (ed) Taxonomy phytogeography and evolution, pp. 161-177

Greuter W (1975) Die Insel Kreta - eine geobotanische Skizze. Veröffentlichungen des Geobotanischen Instituts ETH, Stiftung Rübel 55:141-197

Greuter W (1979a) The endemic flora of Crete and significance of its protection. In: Antipas B (ed) Praktika synedriou prostasias panidas-hlôridas-biotopôn, pp. 91-97

Greuter W (1979b) The origins and evolution of island floras as exemplified by the Aegean archipelago. In: Bramwell D (ed) Plants and Islands: Academic Press, pp. 87-106

Greuter W (1991) Botanical diversity, endemism, rarity, and extinction in the Mediterranean area: an analysis based on the published volumes of Med-Checklist. Bot Chron 10:63-79

Greuter W (2001) Diverity of Mediterranean island floras. Bocconea 13:55-64

Greuter W, Böhling N, Jahn R (2002) The Cerastium scaposum group (Caryophyllaceae): three annual taxa endemic to Crete (Greece), two of them new. Willdenowia 32:45-54

Greuter W, Grau J (1980) Zum Vorkommen von drei Unterarten der Myosotis refracta Boiss. auf Kreta. Candollea 25:7-10

Grimm G, Denk T, Bouchal JM, Potts AJ (2016) Fables and foibles: a critical analysis of the Palaeoflora database and the Coexistence approach for palaeoclimate reconstruction. Rev Palaeobot Palyno 233:216-235

Grimm GW, Potts AJ (2015) Fallacies and fantasies. The theoretical underpinnings of the Coexistence Approach for palaeoclimate reconstruction. Clim Past Discuss 11:5727-5754

Gristina AS, Michele R de, Garfi G, La Mantia T, Fontana I, Spinelli P, Motisi A, Carimi F (2017) Urgent need for preservation of grapevine (Vitis vinifera $\mathrm{L}$. subsp. vinifera) germplasm from small circumSicilian islands as revealed by SSR markers and traditional use investigations. Genet Resour Crop Evol 64:1395-1415

Grove AT, Rackham O (2001) The Nature of Mediterranean Europe. An ecological history. Yale University Press, New Haven, 384 pp.

Groves RH, Di Castri F (eds) (1991) Biogeography of Mediterranean invasions. Cambridge University Press, Cambridge [England], New York, 485 pp.

Guarino R (1998) La vegetazione dei Monti Peloritani (Sicilia nord-orientale). Tesi di dottorato. Dipartimento di Botanica, Università degli Studi di Catania. 301 pp.

Guarino R, Domina G, Pignatti S (2012) Ellenberg's Indicator values for the Flora of Italy - first update: Pteridophyta, Gymnospermae and Monocotyledoneae. Flora Mediterr 22:197-209

Guarino R, Pasta S (2017) Botanical excursions in Central and West Sicily. Field guide for the 60th IAVS Symposium Palermo, 20-24 June 2017. University Press, Palermo, 604 pp.

Guarino R, Willner W, Pignatti S, Attorre F, Loidi JJ (2018) Spatio-temporal variations in the application of the Braun-Blanquet approach in Europe. Phytocoenologia (published online February 2018)

Guisan A, Graham CH, Elith J, Huettmann F (2007) Sensitivity of predictive species distribution models to change in grain size. Divers Distrib 13:332-340 
Guisan A, Theurillat J-P, Kienast F (1998) Predicting the potential distribution of plant species in an alpine environment. J Veg Sci 9:65-74

Guisan A, Zimmermann NE (2000) Predictive habitat distribution models in ecology. Ecol Model 135:147-186

Guisso del Galdo GP, Marcenò C, Musarella CM, Sciandrello S (2008) La vegetazione costiera della R.N.O. "Torre Salsa" (Siculiana - AG). Inf Bot Ital 40:73-89

Haeupler H, Schönfelder P (2004) Atlas der Farn- und Blütenpflanzen der Bundesrepublik Deutschland, Neuaufl. Ulmer, Stuttgart

Hale CM, Frelich LE, Reich PB (2006) Changes in hardwood forest understorey plant communities in response to European earthworm invasions. Ecology 87:1637-1649

Hampe A, Arroyo J, Jordano P, Petit RJ (2003) Rangewide phylogeography of a bird-dispersed Eurasian shrub: contrasting Mediterranean and temperate glacial refugia. Mol Ecol 12:3415-3426

Hampe A, Petit RJ (2005) Conserving biodiversity under climate change: the rear edge matters. Ecol Lett 8:461-467

Hand R, Grossmann A, Lauterbach D (2017) Endemics and their common congener plant species on an East Mediterranean island. A comparative functional trait approach. Plant Ecol 218:139-150

Hanski I, Gilpin ME (eds) (2008) Metapopulation biology. Ecology, genetics, and evolution. Academic Press, San Diego, 512 pp.

Harding EK, Crone EE, Elderd BD, Hoekstra JM, McKerrow AJ, Perrine JD, Regetz J, Rissler LJ, Stanley AG, Walters EL, Group NHCPW (2001) The scientific foundations of habitat conservation plans. A quantitative assessment. Conserv Biol 15:488-500

Harrison S (1999) Local and regional diversity in a patchy landscape: native, alien and endemic herbs on serpentine. Ecology 80:70-80

Harrison S, Noss R (2017) Endemism hotspots are linked to stable climatic refugia. Ann Bot London 119:207-214

Hedderson TA, Blockeel TL (2013) Oncophorus dendrophilus, a new moss species from Cyprus and Crete. J Bryol 28:357-359

Heikkinen RK, Marmion M, Luoto M (2012) Does the interpolation accuracy of species distribution models come at the expense of transferability? Ecography 35:276-288

Heinrichs S, Walentowski H, Bergmeier E, Mellert KH, Indreica A, Kuzyakov $\mathrm{Y}$, Leuschner C, Petrițan AM, Teodosiu M (2016) Forest vegetation in western Romania in relation to climate variables. Does community composition reflect modelled tree species distribution? Ann For Res 59

Helman D, Osem Y, Yakir D, Lensky IM (2017) Relationships between climate, topography, water use and productivity in two key Mediterranean forest types with different water-use strategies. Agr Forest Meteorol 232:319-330

Hennekens SM, Schaminée JHJ (2001) TURBOVEG, a comprehensive data base management system for vegetation data. J Veg Sci 12:589-591

Hernandez PA, Graham CH, Master LL, Albert DL (2006) The effect of sample size and species characteristics on performance of different species distribution modeling methods. Ecography 29:773-785

Herrera CM, Bazaga P (2009) Quantifying the genetic component of phenotypic variation in unpedigreed wild plants: tailoring genomic scan for within-population use. Mol Ecol 18:26022614

Herrera CM, Bazaga P (2010) Epigenetic differentiation and relationship to adaptive genetic divergence in discrete populations of the violet Viola cazorlensis. New Phytol 187:867-876 
Heywood VH (1999) The Mediterranean region a major centre of plant diversity. In: Heywood VH, Skoula M (eds) Wild food and non-food plants: information network, Chania, pp. 5-13

Heywood VH (2014) An overview of in situ conservation of plant species in the Mediterranean. Flora Mediterr 24:5-24

HGME (1959-2002) Official Geological Maps of Greece 1:50000. Hellenic Institute for Geology and Mineral Exploitation, Athens

Hijmans RJ, Cameron SE, Parra JL, Jones PG, Jarvis A (2005) Very high resolution interpolated climate surfaces for global land areas. Int J Climatol 25:1965-1978

Hoffmann DL, Standish CD, García-Diez M, Pettitt PB, Milton JA, Zilhão J, Alcolea-González JJ, Cantalejo-Duarte P, Collado H, Balbín R de, Lorblanchet M, Ramos-Muñoz J, Weniger G-C, Pike AWG (2018) U-Th dating of carbonate crusts reveals Neandertal origin of Iberian cave art. Science 359:912-915

Höfle B, Rutzinger M (2011) Topographic airborne LiDAR in geomorphology. A technological perspective. Z Geomorphol 55:1-29

Holderegger R, Buehler D, Gugerli F, Manel S (2010) Landscape genetics of plants. Trends Plant Sci 15:675-683

Honnay O, Jacquemyn H (2007) Susceptibility of common and rare plant species to the genetic consequences of habitat fragmentation. Conserv Biol 21:823-831

Horsák M, Chytrý M, Pokryszko BM, Danihelka J, Ermakov N, Hájek M, Hájková P, Kintrová K, Kočí M, Kubešová S, Lustyk P, Otýpková Z, Pelánková B, Valachovič M (2010) Habitats of relict terrestrial snails in southern Siberia. Lessons for the reconstruction of palaeoenvironments of full-glacial Europe. J Biogeogr 37:1450-1462

Horvat I, Glavač V, Ellenberg H (1974) Vegetation Südosteuropas. G. Fischer, Stuttgart, 768 pp.

Hostert P, Röder A, Hill, J., Udelhoven T, Tsiourlis G (2003) Retrospective studies of grazing-induced land degradation: A case study in central Crete, Greece. Int J Remote Sens 24:4019-4034

Huntley B (1990) European post-glacial forests: compositional changes in response to climatic change. J Veg Sci 1:507-518

Hurlbert AH, Jetz W (2007) Species richness, hotspots, and the scale dependence of range maps in ecology and conservation. P Natl Acad Sci-Biol 104:13384-13389

Huston MA (2002) Critical Issues for Improving Predictions. In: Scott JM, Heglund PJ, Morrison ML, Haufler JB, Raphael MG, Wall WA, Samson FB (eds) Predicting species occurrences. Issues of accuracy and scale: Island Press, Washington, DC, pp. 7-33

Hutchinson GE (1957) Concluding remarks. Cold Spring Harbor Sym 22:415-427

Innangi M, d'Alessandro F, Fioretto A, Di Febbraro M (2015) Modeling distribution of Mediterranean beech forests and soil carbon stock under climate change scenarios. Clim Res 66:25-36

Irl SDH, Harter DEV, Steinbauer MJ, Gallego Puyol D, Fernández-Palacios JM, Jentsch A, Beierkuhnlein C, Lau J (2015) Climate vs. topography - spatial patterns of plant species diversity and endemism on a high-elevation island. J Ecol 103:1621-1633

Jackson ST, Overpeck JT (2000) Responses of plant populations and communities to environmental changes of the late Quaternary. Paleobiology 26:194-220

Jahn R (2003) The phytodiversity of the flora of Kriti (Greece) - a survey of the current state of knowledge. Bocconea 16:845-851

Jahn R, Schönfelder P (1995) Exkursionsflora für Kreta. Ulmer, Stuttgart, 446 pp.

Jalas J, Suominen J (eds) (1972-1994) Atlas Florae Europaeae. Vol. 1-10. The Committee for Mapping the Flora of Europe and Societas Biologica Fennica Vanamo, Helsinki, Finnland 
Jalas J, Suominen J, Lampinen R, Kurtto A (eds) (1996) Atlas Florae Europaeae. Vol. 11. The Committee for Mapping the Flora of Europe \& Societas Biologica Fennica Vanamo, Helsinki, Finnland, $310 \mathrm{pp}$.

Jalas J, Suominen J, Lampinen R, Kurtto A (eds) (1999) Atlas Florae Europaeae. Vol. 12. The Committee for Mapping the Flora of Europe \& Societas Biologica Fennica Vanamo, $250 \mathrm{pp}$.

Janssen JAM, Rodwell JS, García Criado M, Gubbay S, Haynes T, Nieto A, Sanders N, Landucci F, Loidi J, Ssymank A, Tahvanainen M, Valderabano A, Acoste A, Aronson M, Arts G, Attorre F, Bergmeier E, Bijlsma R-J, Bioret F, Bita-Nicolae C, Biurrun I, Calix M, Capelo J, Čarni A, Chytrý M, Dengler J, Dimopoulos P, EssI F, Gardfjell H, Gigante D, Guisso del Galdo GP, Hájek M, Jansen F, Jansen J, Kapfer J, Mickolajczak A, Molina J, Molnár Z, Paternoster D, Piernik A, Poulin B, Renaux B, Schaminée JHJ, Šumberová K, Toivonen H, Tonteri T, Tsiripidis I, Tzonev RT, Valachovič M (2016) European Red list of habitats. Part 2: Terrestrial and freshwater habitats. Publication Office of the European Union, Luxembourg, $38 \mathrm{pp}$.

Jiménez-Alfaro B, Girardello M, Chytrý M, Svenning J-C, Willner W, Gégout J-C, Agrillo E, Campos JA, Jandt U, Kącki Z, Šilc U, Slezák M, Tichý L, Tsiripidis I, Turtureanu PD, Ujházyová M, Wohlgemuth T (2018) History and environment shape species pools and community diversity in European beech forests. Nat Ecol Evol 2:483-490

Johnson MTJ, Stinchcombe JR (2007) An emerging synthesis between community ecology and evolutionary biology. Trends Ecol Evol 22:250-257

Jones CC, Acker SA, Halpern CB (2010) Combining local- and large-scale models to predict the distributions of invasive plant species. Ecol Appl 20:311-326

Jones CG, Lawton JH, Shachak M (1997) Positive and negative effects of organisms as physical ecosystem engineers. Ecology 78:1946-1957

Jouffroy-Bapicot I, Vanniere B, Iglesias V, Debret M, Delarras J-F (2016) 2000 years of grazing history and the making of the Cretan mountain landscape, Greece. PLoS ONE 11:e0156875

Junikka L, Uotila P, Lahti T (2006) A phytogeographical comparison of the major Mediterranean islands on the basis of Atlas Florae Europaeae. Willdenowia 36:379-388

Kang SY, McGree J, Mengersen K (2014) The choice of spatial scales and spatial smoothness priors for various spatial patterns. Spat Spatiotemporal Epidemiol 10:11-26

Kardol P, Wardle DA (2010) How understanding aboveground-belowground linkages can assist restoration ecology. Trends Ecol Evol 25:670-679

Karger DN, Conrad O, Böhner J, Kawohl T, Kreft H, Soria-Auza RW, Zimmermann N, Linder HP, Kessler M (2016) CHELSA climatologies at high resolution for the earth's land surface areas (Version 1.0). http://chelsa-climate.org/

Kati V, Devillers P, Dufrêne M, Legakis A, Vokou D, Lebrun P (2004) Hotspots, complementarity or representativeness? Designing optimal small-scale reserves for biodiversity conservation. Biol Conserv 120:471-480

Keenan T, Maria Serra J, Lloret F, Ninyerola M, Sabate S (2011) Predicting the future of forests in the Mediterranean under climate change, with niche- and process-based models. $\mathrm{CO} 2$ matters! Global Change Biol 17:565-579

Kerckhof A, Spalevic V, van Eetvelde V, Nyssen J (2016) Factors of land abandonment in mountainous Mediterranean areas. The case of Montenegrin settlements. SpringerPlus 5:485 (online)

Kessler M (2002) The elevational gradient of Andean plant endemism. Varying influences of taxonspecific traits and topography at different taxonomic levels. J Biogeogr 29:1159-1165 
Khadari B, Grout C, Santoni S, Kjellberg F (2005) Contrasted genetic diversity and differentiation among Mediterranean populations of Ficus carica L.: A study using mtDNA RFLP. Genet Resour Crop Evol 52:97-109

Kier G, Kreft H, Lee TM, Jetz W, Ibisch PL, Nowicki C, Mutke J, Barthlott W (2009) A global assessment of endemism and species richness across island and mainland regions. $\mathrm{P}$ Natl Acad Sci-Biol 106:9322-9327

Kier G, Mutke J, Dinerstein E, Ricketts TH, Küper W, Kreft H, Barthlott W (2005) Global patterns of plant diversity and floristic knowledge. J Biogeogr 32:1107-1116

Knapp R (1973) The Vegetation of Africa. Gustav Fischer Verlag, Stuttgart, 626 pp.

Köckemann B, Buschmann H, Leuschner C (2009) The relationships between abundance, range size and niche breadth in Central European tree species. J Biogeogr 36:854-864

König C, Weigelt P, Kreft H (2017) Dissecting global turnover in vascular plants. Global Ecol Biogeogr 26:228-242

Kopecký M, Čížková Š (2010) Using topographic wetness index in vegetation ecology. Does the algorithm matter? Appl Veg Sci 13:450-459

Körner C (1998) A re-assessment of high elevation treeline positions and their explanation. Oecologia 115:445-459

Körner C (2012) Alpine treelines. Functional ecology of the global high elevation tree limits. Springer, Basel, $220 \mathrm{pp}$.

Körner C (2014) Alpine Plant Life. Functional Plant Ecology of High Mountain Ecosystems, 2., Softcover reprint of the original 2nd ed. 2003. Springer, Berlin, 349 pp.

Korsch H (1999) Chorologisch-ökologische Auswertungen der Daten der floristischen Kartierung Deutschlands. Schriftenr Vegetationskunde 30:1-200

Kosmas CS, Danalatos NG, Moustakas N, Tsatiris B, Kallianou C, Yassoglou N (1993) The impacts of parent material and landscape position on drought and biomass production of wheat under semiarid conditions. Soil Technol 6:337-349

Kottek M, Grieser J, Beck C, Rudolf B, Rubel F (2006) World map of the Köppen-Geiger climate classification updated. Meteorol Z 15:259-263

Kozlowski G, Frey D, Fazan L, Egli BR, Bétrisey S, Gratzfeld J, Garfi G, Pirintsos S (2014) The Tertiary relict tree Zelkova abelicea (Ulmaceae): distribution, population structure and conservation status on Crete. Oryx 48:80-87

Kozlowski G, Frey D, Fazan L, Egli BR, Pirintsos S (2012) IUCN Red List of Threatened Species. Zelkova abelicea. http://www.iucnredlist.org/details/30319/0. Accessed 17th March 2017

Kraft NJB, Adler PB, Godoy O, James EC, Fuller S, Levine JM, Fox J (2015) Community assembly, coexistence and the environmental filtering metaphor. Funct Ecol 29:592-599

Kraft NJB, Valencia R, Ackerly DD (2008) Functional traits and niche-based tree community assembly in an Amazonian Forest. Science 322:580-582

Kreft H, Jetz W (2010) A framework for delineating biogeographical regions based on species distributions. J Biogeogr 37:2029-2053

Kruckeberg AR (2002) Geology and plant life. The effects of landforms and rock types on plants. University of Washington Press, Seattle, $362 \mathrm{pp}$.

Ktimatologio (2016) Digital Web Map Service. Geodetic Department, Ktimatologio S.A. (Hellenic Cadastre), Athens

Kull U (2011) Sammlung geologischer Führer. - Bd. 104 Kreta. Borntraeger, Berlin, 322 pp.

Kulmatiski A, Beard KH, Stevens JR, Cobbold SM (2008) Plant-soil feedbacks. A meta-analytical review. Ecol Lett 11:980-992 
Kurtto A, et al. (eds) (2004-2018) Atlas Florae Europaeae. Vol. 13-17. The Committee for Mapping the Flora of Europe \& Societas Biologica Fennica Vanamo, Helsinki, Finnland

LaBonte N, Tonos J, Hartel C, Woeste KE (2017) Genetic diversity and differentiation of yellowwood [Cladrastis kentukea (Dum.Cours.) Rudd] growing in the wild and in planted populations outside the natural range. New Forest 9:12pp (online)

Lambdon PW, Lloret F, Hulme PE (2008) Do alien plants on Mediterranean islands tend to invade different niches from native species? Biol Invasions 10:703-716

Larcher W (2006) Temperature stress and survival ability of Mediterranean sclerophyllous plants. Plant Biosyst 134:279-295

Lavergne S, Thompson JD, Garnier E, Debussche M (2004) The biology and ecology of narrow endemic and widespread plants: a comparative study of trait variation in 20 congeneric pairs. Oikos 107:505-518

Lavoie C (2013) Biological collections in an ever changing world. Herbaria as tools for biogeographical and environmental studies. Perspect Plant Ecol 15:68-76

Law R, Illian J, Burslem DFRP, Gratzer G, Gunatilleke CVS, Gunatilleke IAUN (2009) Ecological information from spatial patterns of plants. Insights from point process theory. J Ecol 97:616-628

Lazzaro L, Viciani D, Dell'Olmo L, Foggi B (2016) Predicting risk of invasion in a Mediterranean island using niche modelling and valuable biota. Plant Biosyst 151:361-370

Leathwick JR, Whitehead D (2001) Soil and atmospheric water deficits and the distribution of New Zealand's indigenous tree species. Funct Ecol 15:233-242

Lechner AM, McCaffrey N, McKenna P, Venables WN, Hunter JT, Goslee S (2016) Ecoregionalization classification of wetlands based on a cluster analysis of environmental data. Appl Veg Sci 19:724735

Leuschner C, Meier IC, Hertel D (2006) On the niche breadth of Fagus sylvatica. Soil nutrient status in 50 Central European beech stands on a broad range of bedrock types. Ann For Sci 63:355-368

Lionello P (ed) (2012) The Climate of the Mediterranean Region. Elsevier, Amsterdam, 590 pp.

Lipscomp MV, Nilsen ET (1990a) Environmental and physiological factors influencing the natural distribution of evergreen and deciduous ericaceous shrubs on northeast- and southwest- facing slopes of the Southern Appalachian mountains. I. Irradiance tolerance. Amer J Bot 77:108-115

Lipscomp MV, Nilsen ET (1990b) Environmental and physiological factors influencing the natural distribution of evergreen and deciduous ericaceous shrubs on northeast- and southwest- facing slopes of the Southern Appalachian mountains. II. Water relations. Amer J Bot 77:517-526

Liu Y, Wang Y, Hongwen H (2006) High interpopulation genetic differnetiation and unidirectional linear migration patterns in Myricaria laxiflora (Tamaricaceae), an endemic riparian plant in the Three Gorges Valley of the Yangtze river. Amer J Bot 93:206-215

Lloret F, Médail F, Brundu G, Camara I, Moragues EVA, Rita J, Lambdon P, Hulme PE (2005) Species attributes and invasion success by alien plants on Mediterranean islands. J Ecol 93:512-520

Lobo JM, Jiménez-Valverde A, Real R (2008) AUC: a misleading measure of the performance of predictive distribution models. Global Ecol Biogeogr 17:145-151

Lonneville B, Roo B de, Stal C, Wit B de, Wulf A de, Maeyer P de (2014) Accurate and cost-efficient 3D modelling using motorized hexacopter, helium balloons and photo modelling. A Case Study. In: loannides M, Magnenat-Thalmann N, Fink E, Žarnić R, Yen A-Y, Quak E (eds) Digital Heritage. Progress in Cultural Heritage: Documentation, Preservation, and Protection: Springer, Cham, pp. 410-417

Lorent $\mathrm{H}$, Sonnenschein R, Tsiourlis G, Hostert P, Lambin E (2009) Livestock Subsidies and Rangeland Degradation in Central Crete. Ecol Soc 14:1708-3087 
Lowe A, Harris SE, Ashton P (2004) Ecological genetics. Planning and application. Blackwell, Oxford, $344 \mathrm{pp}$.

Ludwig JA, Tongway DJ (1995) Spatial organisation of landscapes and its function in semi-arid woodlands, Australia. Landscape Ecol 10:51-63

Macleod DA (1980) The origin of the red Mediterranean soils in Epirus, Greece. J Soil Sci 31:125-136

Maes J, Paracchini ML, Zulian G, Dunbar MB, Alkemade R (2012) Synergies and trade-offs between ecosystem service supply, biodiversity, and habitat conservation status in Europe. Biol Conserv 155:1-12

Magri D (1999) Late Quaternary vegetation history at Lagaccione near Lago di Bolsena (central Italy). Rev Geophys 106:171-208

Maguire KC, Nieto-Lugilde D, Fitzpatrick MC, Williams JW, Blois JL (2015) Modeling Species and Community Responses to Past, Present, and Future Episodes of Climatic and Ecological Change. Annu Rev Ecol Evol S 46:343-368

Mahdavi P, Bergmeier E (2016) Plant functional traits and diversity in sand dune ecosystems across different biogeographic regions. Acta Oecol 74:37-45

Mai DH (1987) Development and regional differentiation of the European vegetation during the Tertiary. Plant Syst Evol 162:79-91

Maire V, Gross N, Börger L, Proulx R, Wirth C, da Silveira Pontes L, Soussana J-F, Louault F (2012) Habitat filtering and niche differentiation jointly explain species relative abundance within grassland communities along fertility and disturbance gradients. New Phytol 196:497-509

Manel S, Holderegger R (2013) Ten years of landscape genetics. Trends Ecol Evol 28:614-621

Manel S, Schwartz MK, Luikart G, Taberlet P (2003) Landscape genetics. Combining landscape ecology and population genetics. Trends Ecol Evol 18:189-197

Marcantonio M, Martellos S, Altobelli A, Attorre F, Tordoni E, Ongaro S, Rocchini D, Da Re D, Chiarucci A, Bacaro G (2017) How does spatial scale affect species richness modelling? A test using remote sensing data and geostatistics. Ann Bot Roma 7:11-24

Marcenò C, Guarino R (2015) A test on Ellenberg indicator values in the Mediterranean evergreen woods (Quercetea ilicis). Rend Fis Acc Lincei 26:345-356

Marcenò C, Ottonello D (1991) Osservazioni fitosociologiche su alcune leccete dei Monti di Palermo (con appendice floristica). Atti Accad Sci Lett Arti Palermo:119-143

Marcenò C, Ottonello D, Romano S (2002) Inquadramento fitosociologico dei popolamenti a Celtis tournefortii Lam. di Caltabellotta (Sicilia sud-occidentale). Fitosociologia 39:109-113

Marino P, Castiglia G, Bazan G, Domina G, Guarino R (2014) Tertiary relict laurophyll vegetation in the Madonie mountains (Sicily). Acta Bot Gallica 161:47-61

Martínez-Meyer E, Peterson AT (2006) Conservatism of ecological niche characteristics in North American plant species over the Pleistocene-to-Recent transition. J Biogeogr 33:1779-1789

Martin-StPaul NK, Limousin J-M, Rodríguez-Calcerrada J, Ruffault J, Rambal S, Letts MG, Misson L (2013) Photosynthetic sensitivity to drought varies among populations of Quercus ilex along a rainfall gradient. Funct Plant Biol 39:25-37

Matthäs U (1988) Die laubwerfenden Eichenarten Kretas. Cramer, Vaduz, 171 pp.

McCune B, Keon D (2002) Equations for potential annual direct incident radiation and heat load. J Veg Sci 13:603-606

McGarigal K, Tagil S, Cushman SA (2009) Surface metrics. An alternative to patch metrics for the quantification of landscape structure. Landscape Ecol 24:433-450

McGill B, Enquist B, Weiher E, Westoby M (2006) Rebuilding community ecology from functional traits. Trends Ecol Evol 21:178-185 
McInerny GJ, Purves DW (2011) Fine-scale environmental variation in species distribution modelling. Regression dilution, latent variables and neighbourly advice. Methods Ecol Evol 2:248-257

McIntire EJB, Piper FI, Fajardo A, McGlone M (2016) Wind exposure and light exposure, more than elevation-related temperature, limit tree line seedling abundance on three continents. J Ecol 104:1379-1390

McNeill JR (1992) The Mountains of the Mediterranean World. Cambridge University Press, Cambridge, $448 \mathrm{pp}$.

McPherson JM, Jetz W (2007) Effects of species' ecology on the accuracy of distribution models. Ecography 30:135-151

Médail F (2017) The specific vulnerability of plant biodiversity and vegetation on Mediterranean islands in the face of global change. Reg Environ Change 17:1775-1790

Médail F, Diadema K (2009) Glacial refugia influence plant diversity patterns in the Mediterranean Basin. J Biogeogr 36:1333-1345

Médail F, Quézel P (1997) Hot-spots analysis for conservation of plant biodiversity in the Mediterranean basin. Ann Missouri Bot Gard 84:112-127

Médail F, Quézel P (1999) Biodiversity hotspots in the Mediterranean basin: setting global conservation priorities. Conserv Biol 13:1510-1513

Meddour R, Meddour-Sahar O, Zeraia L, Mucina L (2017) Syntaxonomic synopsis of the forest and tall scrub vegetation of Northern Algeria. Lazaroa 38:127-163

Mediterranean Agronomic Institute of Chania (2018) Zelkova abelicea. http://www.abelitsia.gr/en/. Accessed 23 March 2018

Meentemeyer RK, Moody A, Franklin J (2001) Landscape-scale patterns of shrub-species abundance in California chaparral. The role of topographically mediated resource gradients. Plant Ecol 156:19-41

Merlo M, Croitoru L (2005) Valuing Mediterranean forests. Towards total economic value. CABI, Wallingford, Oxfordshire, U.K., Cambridge, Mass., 406 pp.

Merow C, Bois ST, Allen JM, Xie Y, Silander JA (2017) Climate change both facilitates and inhibits invasive plant ranges in New England. P Natl Acad Sci USA (Proceedings of the National Academy of Sciences of the United States of America) 114:E3276-E3284, 9 pp. (online)

Merow C, Smith MJ, Edwards TC, Guisan A, McMahon SM, Normand S, Thuiller W, Wüest RO, Zimmermann NE, Elith J (2014) What do we gain from simplicity versus complexity in species distribution models? Ecography 37:1267-1281

Merow C, Smith MJ, Silander JA (2013) A practical guide to MaxEnt for modeling species' distributions. What it does, and why inputs and settings matter. Ecography 36:1058-1069

Mesléard F, Lepart J (1991) Germination and seedling dynamics of Arbutus unedo and Erica arbórea on Corsica. J Veg Sci 2:155-164

Meulenkamp JE, Sissingh W (2003) Tertiary palaeogeography and tectonostratigraphic evolution of the Northern and Southern Peri-Tethys platforms and the intermediate domains of the AfricanEurasian convergent plate boundary zone. Palaeogeogr Palaeocl 196:209-228

Meulenkamp JE, Wortel MJR, van Wamel WA, Spakman W, Hoogerduyn Strating E (1988) On the Hellenic subduction zone and the geodynamic evolution of Crete since the late Middle Miocene. Tectonophysics 146:203-215

Meusel H, Jäger EJ, Rauschert S, Weinert E (1978) Vergleichende Chorologie der zentraleuropaischen Flora. Gustav Fischer, Jena, 579 pp.

Meyer C, Weigelt P, Kreft H (2016) Multidimensional biases, gaps and uncertainties in global plant occurrence information. Ecol Lett 19:992-1006 
Miller AJ, Knouft JH (2006) GIS-based Charcterization of the geographic distribution of wild and cultivated populations of the Mesoamerican fruit tree Spondias purpurea (Anacardiaceae). Amer J Bot 93:1757-1767

Miller JR, Turner MG, Smithwick EAH, Dent CL, Stanley EH (2004) Spatial extrapolation: the science of predicting ecological patterns and processes. Bioscience 54:310-320

Minasny B, McBratney AB, Salvador-Blanes S (2008) Quantitative models for pedogenesis - A review. Geoderma 144:140-157

Minissale G, Sciandrello S, Spampinato G (2007) Analisi della biodiversità vegetale e relativa cartografia della Riserva Naturale Orientata "Pantalica, Valle dell'Anapo e Torrente Cava Grande" (Sicilia sudorientale). Quad Bot Amb Appl 18:241-303

Minissale P, Sciandrello S (2005) La vegetazione di Piano Stella presso Gela (Sicilia meridionale), un biotopo meritevole di conservazione. Quad Bot Amb Appl 16:129-142

Mitrakos K (1980) Plant life under Mediterranean climatic conditions. Port Acta Biol Ser A 16:33-44

Molina-Venegas R, Aparicio A, Pina FJ, Valdés B, Arroyo J (2013) Disentangling environmental correlates of vascular plant biodiversity in a Mediterranean hotspot. Ecol Evol 3:3879-3894

Molina-Venegas R, Aparicio A, Slingsby JA, Lavergne S, Arroyo J (2015) Investigating the evolutionary assembly of a Mediterranean biodiversity hotspot: deep phylogenetic signal in the distribution of eudicots across elevational belts. J Biogeogr 42:507-518

Molinier R, Molinier R* (1955) Observations sur la végétation litorale de l'Italie occidentale et de la Sicile. Arch Bot Biogeogr Ital 31:129-161

Moore ID, Gessler PE, Nielsen GA, Peterson GA (1993) Soil attribute prediction using terrain analysis. Soil Sci Soc Am J 57:443-447

Morales NS, Fernandez IC, Baca-Gonzalez V (2017) MaxEnt's parameter configuration and small samples: are we paying attention to recommendations? A systematic review. PeerJ 5:e3093 16pp. (online)

Moser D, Zechmeister HG, Plutzar C, Sauberer N, Wrbka T, Grabherr G (2002) Landscape patch shape complexity as an effective measure for plant species richness in rural landscapes. Landscape Ecol 17:657-669

Mousadik AE, Petit RJ (1996) High level of genetic differentiation for allelic richness among populations of the argan tree Argania spinosa (L.) Skeels endemic to Morocco. Theor Appl Genet 92:832-839

Mucina L, Bültmann H, Dierßen K, Theurillat J-P, Raus T, Čarni A, Šumberová K, Willner W, Dengler J, Gavilán García R, Chytrý M, Hájek M, Di Pietro R, lakushenko D., Pallas J, Daniëls FJA, Bergmeier E, Santos Guerra A, Ermakov N, Valachovič M, Schaminée JHJ, Lysenko T, Didukh YP, Pignatti $S$, Rodwell JS, Capelo J, Weber HE, Solomeshch A, Dimopoulos P, Aguiar C, Hennekens SM, Tichý L (2016) Vegetation of Europe: Hierarchical floristic classification system of vascular plant, bryophyte, lichen, and algal communities. Appl Veg Sci 19 Suppl.:3-264

Mucina L, Dengler J, Bergmeier E, Čarni A, Jahn R, Matevski V (2009) New and validated high-rank syntaxa from Europe. Lazaroa 30:267-276

Muñoz-Reinoso JC (2004) Diversity of maritime juniper woodlands. For Ecol Man 192:267-276

Mutke J, Kreft H, Kier G, Barthlott W (2010) European Plant Diversity in the Global Context. In: Settele J, Penev L, Georgiev T (eds) Atlas of biodiversity risk: Pensoft Pub, Sofia, Bulgaria, pp. 4-5

Myers N, Mittermeier RA, Mittermeier CG, da Fonseca GA, Kent J (2000) Biodiversity hotspots for conservation priorities. Nature 403:853-858

Nadeau CP, Urban MC, Bridle JR (2017) Coarse climate change projections for species living in a finescaled world. Global Change Biol 23:12-24 
Nainggolan D, Vente J de, Boix-Fayos C, Termansen M, Hubacek K, Reed MS (2012) Afforestation, agricultural abandonment and intensification. Competing trajectories in semi-arid Mediterranean agro-ecosystems. Agr Ecosyst Environ 159:90-104

Neff JC, Reynolds R, Sanford RL, Fernandez D, Lamothe P (2006) Controls of bedrock geochemistry on soil and plant nutrients in southeastern utah. Ecosystems 9:879-893

Nikolakopoulos KG, Kamaratakis EK, Chrysoulakis N (2006) SRTM vs ASTER elevation products. Comparison for two regions in Crete, Greece. Int J Remote Sens 27:4819-4838

Nobis A, Błaszkowski J, Zubek S (2015) Arbuscular mycorrhizal fungi associations of vascular plants confined to river valleys. Towards understanding the river corridor plant distribution. J Plant Res 128:127-137

Ocasio-Morales RG, Tsopelas P, Harrington TC (2007) Origin of Ceratocystis platani on native Platanus orientalis in Greece and its impact on natural forests. Plant Dis 91:901-904

Olthoff A, Martínez-Ruiz C, Alday JG (2016) Distribution patterns of forest species along an AtlanticMediterranean environmental gradient. An approach from forest inventory data. Forestry 89:4654

Omasa K, Hosoi F, Uenishi TM, Shimizu Y, Akiyama Y (2008) Three-dimensional modeling of an urban park and trees by combined airborne and portable on-ground scanning LIDAR remote sensing. Environ Model Assess 13:473-481

Orain R, Lebreton V, Ermolli ER, Combourieu-Nebout N, Sémah A-M (2013) Carya as marker for tree refuges in southern Italy (Boiano basin) at the Middle Pleistocene. Palaeogeogr Palaeocl 369:295-302

Ouédraogo MM, Degré A, Debouche C (2014) Synthèse bibliographique : le modèle numérique de terrain de haute résolution, ses erreurs et leur propagation. Biotechnol Agron Soc Environ 18:407-421

Owens HL, Campbell LP, Dornak LL, Saupe EE, Barve N, Soberón J, Ingenloff K, Lira-Noriega A, Hensz CM, Myers CE, Peterson AT (2013) Constraints on interpretation of ecological niche models by limited environmental ranges on calibration areas. Ecol Model 263:10-18

Öztürk M, Çelik A, Güvensen A, Hamzaoğlu E (2008) Ecology of Tertiary relict endemic Liquidambar orientalis Mill. forests. For Ecol Man 256:510-518

Pachauri RK, Meyer L (2015) Climate change 2014. Synthesis report. Intergovernmental Panel on Climate Change, Geneva, 151 pp.

Panagos P, Borrelli P, Meusburger K, Alewell C, Lugato E, Montanarella L (2015) Estimating the soil erosion cover-management factor at the European scale. Land Use Policy 48:38-50

Pantera A, Papadapoulos A, Fotiades G, Papanastasis VP (2008) Distribution and phytogeographical analysis of Quercus ithaburensis ssp. macrolepis in Greece. Ecol Medit 34:73-84

Papageorgiou AC, Tsiripidis I, Mouratidis T, Hatziskakis S, Gailing O, Eliades N-GH, Vidalis A, Drouzas $A D$, Finkeldey $R$ (2014) Complex fine-scale phylogeographical patterns in a putative refugial region for Fagus sylvatica (Fagaceae). Bot J Linn Soc 174:516-528

Paradis G, Panagiotis C, Piazza C (2014) Contribution à la connaissance de la végétation thérophytique du littoral rocheux de la Corse (Saginetea maritimae, Tuberarietea guttatae, Sisymbrietea officinalis). Doc Phytosoc Ser 3, 2014:352-391

Parducci L, Szmidt AE, Madaghiele A, Anzidei M, Vendramin GG (2001) Genetic variation at chloroplast microsatellites (cpSSRs) in Abies nebrodensis (Lojac.) Mattei and three neighboring Abies species. Theor Appl Genet 102:733-740 
Parra-Quijano M, Iriondo JM, Torres E (2012) Review: Applications of ecogeography and geographic information systems in conservation and utilization of plant genetic resources. Span J Agric Res 10:419-429

Pasta S (1997a) Analisi fitogeografica della flora delle isole minori circumsiciliane. Tesi di dottorato in "Biosistematica ed Ecologia Vegetale" (IX Ciclo), Universita degli studi di Firenze, 2 vol pp.

Pasta S (1997b) Checklist della flora vascolare siciliana. Laboratorio di Fitogeografia, Dipartimento di Biologia Vegetale dell'Universita degli Studi di Firenze, 127 pp.

Paulo JA, Palma JNH, Gomes AA, Faias SP, Tomé J, Tomé M (2015) Predicting site index from climate and soil variables for cork oak (Quercus suber L.) stands in Portugal. New Forest 46:293-307

Pavlova DK, Kozuharova EK, Dimitrov DS (1998) The serpentine flora in the eastern Rhodopes mountains (Bulgaria). In: Tsekos I, Moustakas M (eds) Progress in Botanical Research: Proceedings of the 1st Balkan Botanical Congress: Springer Netherlands, Dordrecht, pp. 133-136

Pearson RG, Raxworthy CJ, Nakamura M, Townsend Peterson A (2007) Predicting species distributions from small numbers of occurrence records: a test case using cryptic geckos in Madagascar. J Biogeogr 34:102-117

Pedrotti F (1984) Foreste ripariali lungo la costa adriatica dell'Italia. Coll Phytosoc 9:143-154

Pedrotti F (1995) Nota sulla vegetazione degli ambienti umidi della bassa Valsugana (Trentino). Doc Phytosoc 15:417-449

Pedrotti F (2013) Plant and vegetation mapping. Springer, Berlin, New York, 293 pp.

Pedrotti F, Gafta D (1996) Ecologia delle forestale ripariali e paludose dell'Italia. Università degli Studi, Camerino, 165 pp.

Pereira HM, Daily GC, Roughgarden J (2004) A framework for assessing the relative vulnerability of species to land-use change. Ecol Appl 14:730-742

Pérez F, Hinojosa LF, Peralta G, Montenegro P, Irarrázabal C, Cossio M (2017) Genetic patterns of Myrceugenia correifolia, a rare species of fog-dependent forests of Mediterranean Chile. Is it a climatic relict? Front Plant Sci 8:1097, 10pp. (online)

Perring F, Walters SM (eds) (1990) Atlas of the British flora, 3rd ed. Botanical Society of the British Isles, London, $441 \mathrm{pp}$.

Peterson AT (2007) Why not WhyWhere: The need for more complex models of simpler environmental spaces. Ecol Model 203:527-530

Peterson AT, Nakazawa Y (2008) Environmental data sets matter in ecological niche modelling. An example with Solenopsis invicta and Solenopsis richteri. Global Ecol Biogeogr 17:135-144

Peterson AT, Papeş M, Eaton M (2007) Transferability and model evaluation in ecological niche modeling. A comparison of GARP and Maxent. Ecography 30:550-560

Peterson AT, Soberón J (2012) Integrating fundamental concepts of ecology, biogeography, and sampling into effective ecological niche modeling and species distribution modeling. Plant Biosyst 146:789-796

Peterson AT, Soberón J, Sánchez-Cordero V (1999) Conservatism of ecological niches in evolutionary time. Science 285:1265-1267

Petit RJ, Aguinagalde I, Beaulieu J-L de, Bittkau C, Brewer S, Cheddadi R, Ennos R, Fineschi S, Grivet D, Lascoux M, Mohanty A, Muller-Starck G, Demesure-Musch B, Palme A, Martin JP, Rendell S, Vendramin GG (2003) Glacial refugia: hotspots but not melting pots of genetic diversity. Science 300:1563-1565

Petit RJ, Bialozyt R, Garnier-Géré P, Hampe A (2004) Ecology and genetics of tree invasions: from recent introductions to Quaternary migrations. For Ecol Man 197:117-137 
Petit RJ, Hampe A, Cheddadi R (2005) Climate changes and tree phylogeography in the Mediterranean. Taxon 54:877-885

Phillips SJ, Anderson RP, Schapire RE (2006) Maximum entropy modeling of species geographic distributions. Ecol Model 190:231-259

Phillips SJ, Dudík M (2008) Modeling of species distributions with Maxent: new extensions and a comprehensive evaluation. Ecography 31:161-175

Pignatti S (1978) Evolutionary trends in Mediterranean flora and vegetation. In: van der Maarel E (ed) Plant Species and Plant Communities. Proceedings of the International Symposium held at Nijmegen 1976, pp. 157-167

Pignatti S (ed) (1998) I boschi d'Italia. Sinecologia e biodiveristà. UTET, Torino, 671 pp.

Pignatti S (2003) The Mediterranean Ecosystem. Bocconea 16:29-40

Pignatti S, Menegoni P, Pietrosanti S (2005) Bioindicazione attraverso le piante vascolari.Valori di indicazione secondo Ellenberg (Zeigerwerte) per le specie della Flora d'Italia. Braun-Blanquetia 39:1-97

Plieninger T, Gaertner M, Hui C, Huntsinger L (2013) Does land abandonment decrease species richness and abundance of plants and animals in Mediterranean pastures, arable lands and permanent croplands? Environ Evid 2:3, 7 pp. (online)

Poli E, Lo Giudice R, Ferito N (1979) La vegetazione della valle S. Giacomo (Etna). Atti Acc Gioenia Sci Nat Catania 10:253-319

Poppendieck H-H (2011) Der Hamburger Pflanzenatlas. Dölling und Galitz, München, 568 pp.

Pottier J, Dubuis A, Pellissier L, Maiorano L, Rossier L, Randin CF, Vittoz P, Guisan A, Field R (2013) The accuracy of plant assemblage prediction from species distribution models varies along environmental gradients. Global Ecol Biogeogr 22:52-63

Prinzing A, Durka W, Klotz S, Brandl R (2001) The niche of higher plants. Evidence for phylogenetic conservatism. Proc Biol Sci 268:2383-2389

Purschke O, Dengler J, Bruelheide H, Hennekens S, Jandt U, Chytrý M, Jansen F, Jiménez-Alfaro B, Kattge J, Lenoir J, Pillar, V. de Patta, Sandel B, Winter M, The sPlot Consortium (2015) sPlot - the new global vegetation-plot database for addressing trait-environment relationships across the world's biomes. Geophys Res Abstr 17:EGU2015-15727-2 (online)

Quézel P (1979a) La région méditerranéenne francaise et ses essences forestières. Signification écologique dans le contexte circum-méditerranéen. Forêt Méditerr 1:7-18

Quézel P (1979b) Les écosystèmes forestiers crétois et chypriotes. Essai de comparaison et d'interprétation phyto-écologique. Chron Internat RFF 31:440-450

Quézel P (1988) Esquisse phytogéographique de la végétation climacique potentielle des grandes îles méditerranéennes. Bull Ecol 19:121-127

Quézel P (2004) Large-Scale Post-Glacial Distribution of Vegetation Structures in the Mediterranean Region. In: Mazzoleni S, Pasquale DG, Mulligan M, Martino PD, Rego F (eds) Recent Dynamics of the Mediterranean Vegetation and Landscape, pp. 1-12

Quézel P, Médail F (2003) Écologie et biogéographie des forêts du bassin méditerranéen. Elsevier, Paris, $571 \mathrm{pp}$.

R Development Core Team (2017) R: A Language and Environment for Statistical Computing. R Foundation for Statistical Computing, Vienna, Austria. http://www.R-project.org. Accessed 17th March 2017

Rackham O, Moody JA (1996) The making of the Cretan landscape. Manchester University Press, Manchester \& New York, 237 pp. 
Radosavljevic A, Anderson RP, Araújo MB (2014) Making better Maxent models of species distributions. Complexity, overfitting and evaluation. J Biogeogr 41:629-643

Raimondo FM (1977) Primo rinvenimento di Ulmus glabra Huds. sulle Madonie (Sicilia Settentrionale). Webbia 31:261-277

Raimondo FM (1992) Struttura, evoluzione e distribuzione dei boschi naturali. In: AA. VV. I Boschi di Sicilia, Palermo, pp. 25-34

Raimondo FM, Schicchi R, Surano N, Di Martino A (2003) Biodiversity and important plant areas in the Palermo province (N Sicily). Bocconea 16:839-844

Rainey PB, Travisano M (1998) Adaptive radiation in a heterogeneous environment. Nature 394:6972

Rechinger KH, Rechinger-Moser F (1951) Phytogeographica Aegaea. Denkschr Österr Akad Wiss Math-Nat K1 p2, 105:1-208

Regato P, Salman R (2008) Mediterranean mountains in a changing world. Guidelines for developing actions plans. IUCN, Gland, $88 \mathrm{pp}$.

Reger B, Häring T, Ewald J (2014) The TRM model of potential natural vegetation in mountain forests. Folia Geobot 49:337-359

Revelle W (2017) psych. A package for personality, psychometric, and psychological research. http://personality-project.org/r/psych/. Accessed 17th March 2017

Rich PM, Dubayah R, Hetrick WA, Saving SC (1994) Using viewshed models to calculate intercepted solar radiation. Applications in ecology. Amer Soc Photogrammetry Rem Sens:524-529

Rikli M, Rübel E (1923) Über Flora und Vegetation von Kreta und Griechenland. Vierteljahrsschrift der Naturforschenden Gesellschaft in Zürich:103-227

Rissler L, Apodaca JJ (2007) Adding more ecology into species delimitation: ecological niche models and phylogeography help define cryptic species in the black salamander (Aneides flavipunctatus). Syst Biol 56:924-942

Rivas-Martínez S (1996-2009) Centro de Investigaciones Fitosociológicas, Madrid, climate plots. http://webs.ucm.es/info/cif/plot. Accessed 30th March 2018

Roberts BA, Proctor J (eds) (1992) The ecology of areas with serpentinized rocks. A world view. Springer, Dordrecht, $440 \mathrm{pp}$.

Rödder D, Lawing AM, Flecks M, Ahmadzadeh F, Dambach J, Engler JO, Habel JC, Hartmann T, Hörnes D, Ihlow F, Schidelko K, Stiels D, Polly PD (2013) Evaluating the significance of paleophylogeographic species distribution models in reconstructing Quaternary range-shifts of Nearctic chelonians. PLoS ONE 8:e72855, 19pp. (online)

Rodríguez-Sánchez F, Arroyo J (2008) Reconstructing the demise of Tethyan plants. Climate-driven range dynamics of Laurus since the Pliocene. Global Ecol Biogeogr 17:685-695

Román-Sánchez A, Vanwalleghem T, Peña A, Laguna A, Giráldez JV (2018) Controls on soil carbon storage from topography and vegetation in a rocky, semi-arid landscapes. Geoderma 311:159166

Ronsisvalle GA, Signorello P (1977) Interesse naturalistico e fitosociologico delle faggete del Bosco di Malabotta (Montalbano Elicona, Monti Peloritani). Boll Accad Gioenia Sci Nat Catania 13:62-71

Rosati L, Masi A, Giardini M, Marignani M (2015) Under the shadow of a big plane tree: Why Platanus orientalis should be considered an archaeophyte in Italy. Plant Biosyst 149:185-194

Rosauer D, Laffan SW, Crisp MD, Donnellan SC, Cook LG (2009) Phylogenetic endemism. A new approach for identifying geographical concentrations of evolutionary history. Mol Ecol 18:40614072 
Rose L, Leuschner C, Köckemann B, Buschmann H (2009) Are marginal beech (Fagus sylvatica L.) provenances a source for drought tolerant ecotypes? Eur J Forest Res 128:335-343

Rubio-Casal AE, Leira-Doce P, Figueroa ME, Castillo JM (2010) Contrasted tolerance to low and high temperatures of three tree taxa co-occurring on coastal dune forests under Mediterranean climate. J Arid Environ 74:429-439

Rueda M, Rodríguez MÁ, Hawkins BA (2010) Towards a biogeographic regionalization of the European biota. J Biogeogr 37:2067-2076

Sáenz-Romero C, Lamy J-B, Loya-Rebollar E, Plaza-Aguilar A, Burlett R, Lobit P, Delzon S (2013) Genetic variation of drought-induced cavitation resistance among Pinus hartwegii populations from an altitudinal gradient. Acta Physiol Plant 35:2905-2913

Safford HD, Viers JH, Harrison SP (2005) Serpentine endemism in the California flora. A database of serpentine affinity. Madroño 52:222-257

Salmerón-Sánchez E, Martínez-Nieto MI, Martínez-Hernández F, Garrido-Becerra JA, MendozaFernández AJ, Carrasco CG de, Ramos-Miras JJ, Lozano R, Merlo ME, Mota JF (2014) Ecology, genetic diversity and phylogeography of the Iberian endemic plant Jurinea pinnata (Lag.) DC. (Compositae) on two special edaphic substrates. Dolomite and gypsum. Plant Soil 374:233-250

Salzmann N (2006) The use of results from regional climate models for local-scale permafrost modelling in complex high-mountain topography - possibilities, limitations and challenges for the future. Geographisches Institut der Universität Zürich, 169 pp.

San-Miguel-Ayanz J, Rigo D de, Caudullo G, Houston Durrant T, Mauri A (eds) (2016) European Atlas of Forest Tree Species. Publication Office of the European Union, Luxembourg, 202 pp.

Sattler T, Bontadina F, Hirzel AH, Arlettaz R (2007) Ecological niche modelling of two cryptic bat species calls for a reassessment of their conservation status. J Appl Ecol 44:1188-1199

Scarascia-Mugnozza G, Oswald H, Piussi P, Radoglou K (2000) Forests of the Mediterranean region. Gaps in knowledge and research needs. For Ecol Man 132:97-109

Schaffers AP, Sýkora KV (2000) Reliability of Ellenberg indicator values for moisture, nitrogen and soil reaction. A comparison with field measurements. J Veg Sci 11:225-244

Scherrer D, Körner C (2009) Infra-red thermometry of alpine landscapes challenges climatic warming projections. Global Change Biol 16:2602-2613

Scherrer D, Schmid S, Körner C (2011) Elevational species shifts in a warmer climate are overestimated when based on weather station data. Int J Biometeorol 55:645-654

Schmid E (1970) Die Abgrenzung der Vegetationsgürtel im Mittelmeergebiet. Feddes Repert 81:203213

Schmidli J, Goodess CM, Frei C, Haylock MR, Hundecha Y, Ribalaygua J, Schmith T (2007) Statistical and dynamical downscaling of precipitation. An evaluation and comparison of scenarios for the European Alps. J Geophys Res 112:D04105, 20pp. (online)

Schmiedel I (2014) Vascular plant species richness at the landscape scale: Patterns and processes. PhD-Thesis, Goettingen, $230 \mathrm{pp}$.

Schmiedel I, Bergmeier E, Culmsee H (2015) Plant species richness patterns along a gradient of landscape modification intensity in Lower Saxony, Germany. Landscape Urban Plan 141:41-51

Schmiedel I, Culmsee H (2016) The influence of landscape fragmentation, expressed by the 'Effective Mesh Size Index', on regional patterns of vascular plant species richness in Lower Saxony, Germany. Landscape Urban Plan 153:209-220

Schnittler M, Unterseher M, Pfeiffer T, Novozhilov YK, Fiore-Donno AM (2010) Ecology of sandstone ravine myxomycetes from Saxonian Switzerland (Germany). Nova Hedwigia 90:277-302 
Schrader J, Pillar G, Kreft H (2017) Leaf-IT. An Android application for measuring leaf area. Ecol Evol 32:307

Schröder F-G (1998) Lehrbuch der Pflanzengeographie. Quelle \& Meyer, Wiesbaden, 457 pp.

Schwabe A, Kratochwil A, Pignatti S (2007) Plant indicator values of a high-phytodiversity country (Italy) and their evidence, exemplified for model areas with climatic gradients in the southern inner Alps. Flora 202:339-349

Sealy R (1949) Arbutus Unedo. J Ecol 37:365-388

Seidel E, Kreuzer H, Harre W (1982) A late Oligocene/early Miocene high pressure belt in the external Hellenides. Geol Jahrb 23:165-206

Seo C, Thorne JH, Hannah L, Thuiller W (2009) Scale effects in species distribution models. Implications for conservation planning under climate change. Biol Lett 5:39-43

Shachak M, Boeken B, Groner E, Kadmon R, Lubin Y, Meron E, Ne'Eman G, Perevolotsky A, Shkedy Y, Ungar ED (2008) Woody species as landscape modulators and their effect on biodiversity patterns. Bioscience 58:209-221

Shan J, Toth CK (2009) Topographic laser ranging and scanning. Principles and processing. CRC Press/Taylor \& Francis Group, Boca Raton, 590 pp.

Shneyer VS, Kotseruba VV (2015) Cryptic species in plants and their detection by genetic differentiation between populations. Russ J Genet Appl Res 5:528-541

Siart C, Bubenzer O, Eitel B (2009) Combining digital elevation data (SRTM/ASTER), high resolution satellite imagery (Quickbird) and GIS for geomorphological mapping: A multi-component case study on Mediterranean karst in Central Crete. Geomorphology 112:106-121

Sinclair SJ, White MD, Newell GR (2010) How useful are species distribution models for managing biodiversity under future climates? Ecol Soc 15:8, 13pp. (online)

Skov F, Svenning J-C (2004) Potential impact of climatic change on the distribution of forest herbs in Europe. Ecography 27:366-380

Slavich E, Warton DI, Ashcroft MB, Gollan JR, Ramp D, Elith J (2014) Topoclimate versus macroclimate. How does climate mapping methodology affect species distribution models and climate change projections? Divers Distrib 20:952-963

Søndergaard P, Egli BR (2006) Zelkova abelicea (Ulmaceae) in Crete: floristics, ecology, propagation and threats. Willdenowia 36:317-322

Sørensen R, Zinko U, Seibert J (2006) On the calculation of the topographic wetness index: evaluation of different methods based on field observations. Hydrol Earth Syst Sc 10:101-112

Sortino M, Giaccone G (1968) Flora e vegetazione della fascia costiera del Golfo di Castellammare (TP). Lav Ist Bot Giard Col Palermo 24:1-49

Sortino M, Marcenò C (1974) La vegetazione del litorale di Licata (Sicilia meridionale). Boll Stud Inform Reale Giard Col Palermo 26:111-115

Soteriades AD, Murray-Rust D, Trabucco A, Metzger MJ (2017) Understanding global climate change scenarios through bioclimate stratification. Environ Res Lett 12:084002, 11pp. (online)

Stein A, Beck J, Meyer C, Waldmann E, Weigelt P, Kreft H (2015) Differential effects of environmental heterogeneity on global mammal species richness. Global Ecol Biogeogr 24:1072-1083

Steinbauer MJ (2017) A generalization of the taxon cycle. J Biogeogr 44:1110-1112

Steinbauer MJ, Field R, Grytnes J-A, Trigas P, Ah-Peng C, Attorre F, Birks HJB, Borges PAV, Cardoso P, Chou C-H, Sanctis M de, Sequeira MMd, Duarte MC, Elias RB, Fernández-Palacios JM, Gabriel R, Gereau RE, Gillespie RG, Greimler J, Harter DEV, Huang T-J, Irl SDH, Jeanmonod D, Jentsch A, Jump AS, Kueffer C, Nogué S, Otto R, Price J, Romeiras MM, Strasberg D, Stuessy T, Svenning J-C, 
Vetaas OR, Beierkuhnlein C (2016) Topography-driven isolation, speciation and a global increase of endemism with elevation. Global Ecol Biogeogr 25:1097-1107

Steinbauer MJ, Irl SDH, Beierkuhnlein C (2013) Elevation-driven ecological isolation promotes diversification on Mediterranean islands. Acta Oecol 47:52-56

Steinbauer MJ, Irl SDH, González-Mancebo JM, Breiner FT, Hernández-Hernández R, Hopfenmüller S, Kidane $Y$, Jentsch A, Beierkuhnlein C (2017) Plant invasion and speciation along elevational gradients on the oceanic island La Palma, Canary Islands. Ecol Evol 7:771-779

Stevanovic V, Tan K, latroú G (2003) Distribution of the endemic Balkan flora on serpentine I. Obligate serpentine endemics. Plant Syst Evol 242:149-170

Stöck M, Sicilia A, Belfiore NM, Buckley D, Lo Brutto S, Lo Valvo M, Arculeo M (2008) Post-Messinian evolutionary relationships across the Sicilian channel. Mitochondrial and nuclear markers link a new green toad from Sicily to African relatives. BMC Evol Biol 8:56-75

Stockwell DRB, Peterson AT (2002) Effects of sample size on accuracy of species distribution models. Ecol Model 148:1-13

Stohlgren TJ, Jarnevich CS, Esaias WE, Morisette JT (2011) Bounding species disistribution models. Curr Zool 57:642-647

Stork NE (1993) How many species are there? Biodivers Conserv 2:215-232

Strid A (2016) Atlas of the Aegean flora. Englera 33 (1 \& 2):700 + 878pp.

Strid A, Strid B (2009-2013) Flora Graeca Sibthorpiana. Annotated re-issue Vols. 1-10. Gantner, Ruggell

Strid A, Tan K (2003) Flora Hellenica, Nymphaeaceae to Platanaceae. Vol. 2. Gantner, Ruggell, 511 pp.

Suárez JC, Ontiveros C, Smith S, Snape S (2005) Use of airborne LiDAR and aerial photography in the estimation of individual tree heights in forestry. Comput Geosci 31:253-262

Suchodoletz H von, Glaser B, Thrippleton T, Broder T, Zang U, Eigenmann R, Kopp B, Reichert M, Ludwig Z (2013) The influence of Saharan dust deposits on La Palma soil properties (Canary Islands, Spain). Catena 103:44-52

Sudhaus W (2004) Radiation within the framework of evolutionary ecology. Org Divers Evol 4:127134

Suggitt AJ, Platts PJ, Barata IM, Bennie JJ, Burgess MD, Bystriakova N, Duffield S, Ewing SR, Gillingham PK, Harper AB, Hartley AJ, Hemming DL, Maclean IMD, Maltby K, Marshall HH, Morecroft MD, Pearce-Higgins JW, Pearce-Kelly P, Phillimore AB, Price JT, Pyke A, Stewart JE, Warren R, Hill JK (2017) Conducting robust ecological analyses with climate data. Oikos 92:699-708

Svenning J-C, Fløjgaard C, Marske KA, Nógues-Bravo D, Normand S (2011) Applications of species distribution modeling to paleobiology. Quaternary Sci Rev 30:2930-2947

Swaine MD, Whitmore TC (1988) On the definition of ecological species groups in tropical rain forests. Vegetatio 75:81-86

Syfert MM, Smith MJ, Coomes DA (2013) The effects of sampling bias and model complexity on the predictive performance of MaxEnt species distribution models. PLoS ONE 8:e55158, 10 pp. (online)

Taminskas J, Petrošius R, Šimanauskienè R, Satkūnas J, Linkevičienè R (2013) Prediction of change in wetland habitats by groundwater. Case study in Northeast Lithuania. Estonian J Earth Sci 62:5772

Teacher AGF, Griffiths DJ, Hodgson DJ, Inger R (2013) Smartphones in ecology and evolution. A guide for the app-rehensive. Ecol Evol 3:5268-5278

Ter Braak CJF, Šmilauer P (2012) Canoco reference manual and user's guide: software for ordination, version 5.0. Microcomputer Power, Ithaca, USA, 496 pp. 
Teste FP, Kardol P, Turner BL, Wardle DA, Zemunik G, Renton M, Laliberté E (2017) Plant-soil feedback and the maintenance of diversity in Mediterranean-climate shrublands. Science 355:173-176

Thompson JD (1999) Population differentiation in Mediterranean plants: insights into colonization history and the evolution and conservation of endemic species. Heredity 82:229-236

Thuiller W, Araújo MB, Lavorel S (2003) Generalized models vs. classification tree analysis. Predicting spatial distributions of plant species at different scales. J Veg Sci 14:669-680

Thuiller W, Brotons L, Araújo MB, Lavorel S (2004) Effects of restricting environmental range of data to project current and future species distributions. Ecography 27:165-172

Tichý L (2002) JUICE, software for vegetation classification. J Veg Sci 13:451-453

Traina N, Marcenò C (2001) Condizioni attuali del popolamento floristico del fiume Oreto (Sicilia Nord-Occidentale). Naturalista Siciliana 25:227-254

Trigas P, Panitsa M, Tsiftsis S, Moreau CS (2013) Elevational gradient of vascular plant species richness and endemism in Crete. The effect of post-isolation mountain uplift on a continental island system. PLoS ONE 8:e59425, 13 pp. (online)

Troia A, Raimondo FM, Geraci A (2012) Does genetic population structure of Ambrosina bassii L. (Araceae, Ambrosineae) attest a post-Messinian land-bridge between Sicily and Africa? Flora 207:646-653

Troia A, Raimondo FM, Mazzola P (2011) Mediterranean island biogeography: Analysis of fern species distribution in the system of islets around Sicily. Plant Biosyst 146:576-585

Tsiourlis G, Konstantinidis P, Xofis P (2009) Syntaxonomy and Synecology of Quercus coccifera Mediterranean Shrublands in Greece. J Plant Biol 52:433-447

Tyndall RW (2005) Twelve years of herbaceous vegetation change in oak savanna habitat on a Maryland serpentine barren after Virginia Pine removal. Castanea 70:287-297

van der Heijden MGA, Boller T, Wiemken A, Sanders IR (1998) Different arbuscular mycorrhizal fungal species are potential determinants of plant community structure. Ecology 79:2082-2091

Vander Mijnsbrugge K, Bischoff A, Smith B (2010) A question of origin: Where and how to collect seed for ecological restoration. Basic Appl Ecol 11:300-311

Vazquez DP, Gianoli E, Morris WF, Bozinovic F (2017) Ecological and evolutionary impacts of changing climatic variability. Biol Rev Camb Philos Soc 92:22-42

Venturella G (2004) Climatic and pedological features of Sicily. Bocconea 17:47-54

Venturella G, Mazzola P, Raimondo FM (1990) Aspetti distributivi e sinecologici di Ostrya carpinifolia Scop. in Sicilia. Quad Bot Amb Appl 1:211-246

Villar JL, Alonso MÁ, Vicente A, Juan A, Crespo MB (2014) The genus Tamarix (Tamaricaceae ) in Crete (Greece). Willdenowia 44:321-326

Vincent S, Lemercier B, Berthier L, Walter C (2018) Spatial disaggregation of complex soil map units at the regional scale based on soil-landscape relationships. Geoderma 311:130-142

Violle C, Enquist BJ, McGill BJ, Jiang L, Albert CH, Hulshof C, Jung V, Messier J (2012) The return of the variance. Intraspecific variability in community ecology. Trends Ecol Evol 27:244-252

Violle C, Pu Z, Jiang L (2010) Experimental demonstration of the importance of competition under disturbance. P Natl Acad Sci U S A 107:12925-12929

Viveros-Viveros H, Sáenz-Romero C, Vargas-Hernández JJ, López-Upton J, Ramírez-Valverde G, Santacruz-Varela A (2009) Altitudinal genetic variation in Pinus hartwegii Lindl. I. Height growth, shoot phenology, and frost damage in seedlings. For Ecol Man 257:836-842

Wagner V, Chytrý M, Jiménez-Alfaro B, Pergl J, Hennekens S, Biurrun I, Knollová I, Berg C, Vassilev K, Rodwell JS, Škvorc Ž, Jandt U, Ewald J, Jansen F, Tsiripidis I, Botta-Dukát Z, Casella L, Attorre F, 
Rašomavičius V, Ćušterevska R, Schaminée JHJ, Brunet J, Lenoir J, Svenning J-C, Kącki Z, Petrášová-Šibíková M, Šilc U, García-Mijangos I, Campos JA, Fernández-González F, Wohlgemuth T, Onyshchenko V, Pyšek P (2017) Alien plant invasions in European woodlands. Divers Distrib 23:969-981

Wang S-J, Li R-L, Sun C-X, Zhang D-F, Li F-Q, Zhou D-Q, Xiong K-N, Zhou Z-F (2004) How types of carbonate rock assemblages constrain the distribution of karst rocky desertified land in Guizhou Province, PR China. Phenomena and mechanisms. Land Degrad Dev 15:123-131

Warnes GR, Bolker B, Bonebakker L, Gentleman R, Huber W, Liaw A, Lumley T, Maechler M, Magnusson A, Moeller S, Schwartz M, Venables B (2016) gplots: Various R Programming Tools for Plotting Data. R package version 3.0.1. https://CRAN.R-project.org/package=gplots

Wasowicz P, Pasierbinski A, Przedpelska-Wasowicz EM, Kristinsson H (2014) Distribution patterns in the native vascular flora of Iceland. PLoS ONE 9:e102916, 14pp. (online)

Way DA, Oren R (2010) Differential responses to changes in growth temperature between trees from different functional groups and biomes. A review and synthesis of data. Tree Physiol 30:669-688

Weigelt P (2014) The Macroecology of Island Floras. In: Biodiversity and Ecology Series B: Selbstverlag Georg August Universität Göttingen, 12:1-273

Weiss S, Ferrand N (eds) (2010) Phylogeography of Southern European Refugia. Evolutionary perspectives on the origins and conservation of European biodiversity. Springer, Dordrecht, 377 pp.

White F (1981) The history of the Afromontane archipelago and the scientific need for its conservation. African J Ecol 19:33-54

Wiens JA (2004) Speciation and ecology revisited. Phylogenetic niche conservatism and the origin of species. Evol 58:193-197

Wiens JA, Ackerly DD, Allen AP, Anacker BL, Buckley LB, Cornell HV, Damschen El, Jonathan Davies T, Grytnes J-A, Harrison SP, Hawkins BA, Holt RD, McCain CM, Stephens PR (2010) Niche conservatism as an emerging principle in ecology and conservation biology. Ecol Lett 13:13101324

Willner W, Bergmeier E, Biurrun I, Dengler J, Jansen F (2018) A survey of vegetation survey papers. Phytocoenologia 48:1-6

Wilmanns O (1998) Ökologische Pflanzensoziologie. Eine Einführung in die Vegetation Mitteleuropas, 6., neu bearb. Aufl. Quelle \& Meyer, Wiesbaden, 405 pp.

Wilson BR, Moffat AJ, Nortcliff S (1997) The nature of three ancient woodland soils in southern England. J Biogeogr 24:633-646

Wisz MS, Hijmans RJ, Li J, Peterson AT, Graham CH, Guisan A (2008) Effects of sample size on the performance of species distribution models. Divers Distrib 14:763-773

Wisz MS, Pottier J, Kissling WD, Pellissier L, Lenoir J, Damgaard CF, Dormann CF, Forchhammer MC, Grytnes J-A, Guisan A, Heikkinen RK, Høye TT, Kühn I, Luoto M, Maiorano L, Nilsson M-C, Normand S, Öckinger E, Schmidt NM, Termansen M, Timmermann A, Wardle DA, Aastrup P, Svenning J-C (2013) The role of biotic interactions in shaping distributions and realised assemblages of species. Implications for species distribution modelling. Biol Rev Camb Philos Soc 88:15-30

World Conservation Monitoring Centre (1998) Platanus orientalis. The IUCN Red List of Threatened Species. Version 2015.2. www.iucn redlist.org. Accessed 29th August 2015

Wu J, Jelinski DE, Luck M, Tueller PT (2000) Multiscale Analysis of Landscape Heterogeneity: Scale Variance and Pattern Metrics. Geogr Inf Sci 6:6-19 
WWF Mediterranean Programme Office (2018) Island wetlands. http://www.wwf.gr/en/areas/islandwetlands. Accessed 23 March 2018

Yaalon DH (1997) Soils in the Mediterranean region: what makes them different? Catena 28:157-169

Yang W, Ma K, Kreft H (2013) Geographical sampling bias in a large distributional database and its effects on species richness-environment models. J Biogeogr 40:1415-1426

Yang W, Ma K, Kreft H (2014) Environmental and socio-economic factors shaping the geography of floristic collections in China. Global Ecol Biogeogr 23:1284-1292

Young NE, Stohlgren TJ, Evangelista PH, Kumar S, Graham J, Newman G (2012) Regional data refine local predictions: modeling the distribution of plant species abundance on a portion of the central plains. Environ Monit Assess 184:5439-5451

Zdruli P (2014) Land Resources of the Mediterranean. status, pressures, trends and impacts on future regional development. Land Degrad Dev 25:373-384

Zhang Y-Y, Fischer M, Colot V, Bossdorf O (2013) Epigenetic variation creates potential for evolution of plant phenotypic plasticity. New Phytol 197:314-322

Zohary D, Hopf M (2012) Domestication of plants in the Old World, 4. Ed. Oxford University Press, Oxford, $316 \mathrm{pp}$.

Zohary M, Orshan G (1965) An outline of the Geobotany of Crete. Israel J Bot (Israel Journal of Botany) 14 Suppl.:1-49 


\section{Acknowledgements}

This thesis tells a short story, but was written during an awful long period. Thus I thank my supervisors Prof. Dr. Erwin Bergmeier and Prof. Dr. Holger Kreft for their patience and good support.

My wife Nina Kirchhoff and my family suffered from neglect and my occasionally moody behaviour. Nina also helped out during field surveys, when others had holidays. Thanks for supporting and standing by me.

The Department Vegetation and Phytodiversity Analysis hosted me during many phases of my life - a familiar athmosphere accompanied me there through courses, projects, times of writing and coffee breaks. I really appreciated all support and nice words I received by: Naveed Akhtar, Christine Battmer, Viktor Chepinoga, Hartmut Dierschke, Oliver Fried, Parastoo Mahdavi, Alireza Naqinezhad, Ricarda Pätsch, Inga Schmiedel, Michael Schwerdtfeger, Charlotte Seifert, Brigitte Siegesmund Christian Vogt, Ute Wergen, and many more. Nina Kirchhoff, Ricarda Pätsch, Inga Schmiedel and Laura Sutcliffe helped read half-baked manuscripts and text passages. Many thanks to Nina Kirchhoff, Ricarda Pätsch, Inga Schmiedel and Laura Sutcliffe for repeated proof reading during writing phases.

Ralf Jahn deserves special thanks for providing unlimited access to his excellently managed data base. It was a generous gift to allow me the analysis of data deriving from decades of work in the field, on the computer, in libraries and in herbaria. Many thanks also for the good floristic introduction in the field and the opportunity to use the revised unpublished version of the flora. Further important data contributors and collaborators during various writing phases were Bernhard Egli, Laurence Fazan, Werner Greuter, Chalidon Chalaitzidis, Ulrich Kull and Caroline Mantey. I also like to thank my Sicilian co-authors Riccardo Guarino and Corrado Marcenò for offering me a fruitful cooperation and for widening my perspective.

Andreas Traxler I like to thank for excellent planning and funding during excursions and during extended visits in the biological research station "Zora" in Lentas/Dytikos, Crete. Thank you and all participants of the Exkursions for the informative exciting trips to gorges and inhabitat islets, for good live musik and the unforgetable time we had together sharing beer and "Spaghetti à la Dragonada".

I also thank the field work and the back-office team of the Natura 2000 mapping and monitoring project on Crete for the excellent cooperation and the good time namely: Carl Barnick, Panayotis Dimopoulos, Friedemann Goral, Parastoo Mahdavi, Constantia Patelodimou, Inga Schmiedel, loannis Tsiripidis, Walter Wolf, Fotios Xystrakis. Many thanks to all the coworkers of the Mediterranean Agronomic Institute (MAICh) and the forest service of the Samaria National Park in Chania for accommodation, support and exchange. Valuable logistic support came from Car Rental Crete in Heraklion, by good offers and an uncomplicated way of changing and reparing broken cars.

Further good advises and ideas during planning, writing and conferences came from: Milan Chytry, Salvatore Pasta, Franco Pedrotti, Fransceco Spada, Helge Walentowski, Camilla Wellstein and Stefan Zerbe. Thanks to everyone who helped me and who I did not mention. 


\section{Florian Goedecke}

Born on $16^{\text {th }}$ April 1983 in Wernigerode, Germany

\section{Education}

2011-2018 PhD studies, Department Vegetation \& Phytodiversity Analysis, University of Göttingen, Germany

Qualification courses in project management and project calculation at the Nature Conservation Academy of Lower Saxony (NNA), Schneverdingen, Germany

Certificate 'Teaching and learning in higher education', Hochschuldidaktik, Central Administration, University of Goettingen

2011 Summer School, Organisation of Plant Taxonomy of the Mediterranean, Palermo, Italy

2007-2009 Advanced Biology studies, University of Göttingen; examinations: botany, biochemistry, chemistry; topic of the diploma thesis (translated): Diversity and conservation assessment of riparian forests and shrubs at the Kalamas river, NW Greece.

2006-2007 Erasmus-exchange: Biology studies; University of Manchester, United Kingdom

2003-2006 Basic Biology studies, University of Göttingen

2002-2003 Civil Service, Wernigerode, Germany

2002 Qualification for university studies (Abitur), Ilsenburg, Germany

\section{Work experience}

2017-2018 Freelance work: Synthesis of vascular plant checklists

2010-2017 Teaching assistant and sientific assistant: Computer and field courses, excursions, councelling of thesis works, projects, organisation and administration; Department Vegetation \& Phytodiversity Analysis, Albrecht-von-Haller (AvH) Institute of Plant Science, University of Göttingen

2015 Moderation, lectures and excursions, summer school restoration ecology, Matera, Italy 
Research assistant: Mapping and Monitoring of Natura 2000 habitats in Crete, Greece; Department Vegetation \& Phytodiversity Analysis, AvH Institute, University of Göttingen

2010-2012 Employee: Mapping and monitoring of Natura 2000 habitat types and biotopes on a military area in Saxony-Anhalt; for GISCON, Braunschweig, Germany

Teaching assistant: Biology for medicine students, AvH Institute, University of Göttingen

2009-2010 Assistant of the Editor in Chief of Taxon, Göttingen

2009-2010 Student assistant: botanical sampling and data management in projects, Department Vegetation \& Phytodiversity Analysis, AvH Institute, University of Göttingen

2004-2009 Student assistant: teaching, vegetation sampling, dendrochronology; AvH Institute and Department for Crop Science, University of Göttingen, Germany

\section{Internships}

Nature conservation authority of the district of Göttingen, Germany

2006-2007 Evolution laboratory (P. Kover), fitness measures of Arabidopsis thaliana, University of Manchester, United Kingdom

2006-2007 Herbarium Manchester Museum, United Kingdom

2006 Ecophysiological Measures, Khonin Nuga, Mongolia

2005 Leibniz Institute of Plant Genetics and Crop Plant Research (IPK), Gatersleben, Germany

2003

National collection of pathogenic microorganismns, Robert-Koch-Institute, Wernigerode, Germany

\section{Various}

Reviews for: Plant Ecology, Acta Botanica Fennica

Memberships: Floristisch-Soziologische Arbeitsgemeinschaft (FlorSoz)

Gesellschaft für Ökologie (GfÖ)

Scientific steering comitee for the wood pasture project Neue Hute (Solling) 


\section{Scientific contributions}

\section{Articles in peer-review journals}

2018

Goedecke, F.; Jahn, R.; Bergmeier, E.: Quantified ecology and cooccurrence of Mediterranean woody species in a landscape context. Plant Ecology 10, doi: 10.1007/s11258-018-0810-x

2017

Goedecke F.; Bergmeier, E.: Ecology and potential distribution of the Cretan endemic tree species Zelkova abelicea. Journal of Mediterranean Ecology

to be submitted

Goedecke, F.; Marcenò, C., Guarino, R.; Jahn, R.; Bergmeier, E.: Geological data significantly reduce the model performance of species distribution models on broad spatial scales. A GIS - based approach from two Mediterranean Islands. planned for Diversity and Distributions

\section{Other publications}

2017

Schmiedel, I., Goedecke, F. \& Bergmeier, E.: Ergebnisse der Vegetationsaufnahmen im Wald und Offenland. - In: Nationalparkverwaltung Eifel (ed), Permanente Stichprobeninventur im Nationalpark Eifel. Schriftenreihe zum Nationalpark Eifel 7: 30-66, Schleiden-Gemünd

Bergmeier, E.; Goedecke, F.: Platanus orientalis woodlands of Crete diversity, distribution and conservation status. In: Achille, G. (ed) Scritti in onore di Franco Pedrotti. Collana Natura e aree protette 31: 29-45, TEMI, Trento.

\section{Conference contributions}

Goedecke, F.; Marcenò, C., Guarino, R.; Jahn,R.; Bergmeier E.: Reciprocal extrapolation: woody species distribution on Crete and Sicily. 26 th Congress of the European Vegetation Survey - Abstracts, Bilbao, Spain, p. 50

Goedecke, F.; Goral, F.: Threatened habitats on Crete - conflicts and perspectives. $1^{\text {st }}$ Mediterranean Plant Conservation Week - Book of Abstracts, p. 32, Ulcinj, Montenegro

Goedecke, F.; Jahn, R.; Bergmeier, E.: Mediterranean woody species: Ecology, potential distributions and vegetation patterns; $25^{\text {th }}$ EVSWorkshop Book of Abstracts- Lectures, p. 40, Rome, Italy

Goedecke, F.; Goral, F.; Mahdavi, P.; Bergmeier, E.: Vegetation and Conservation Status assessment in Platanus orientalis woodlands of Crete, Greece; $25^{\text {th }}$ EVS-Workshop Book of Abstracts- Posters, p. 49, Rome, Italy 
Goedecke, F.; Goral, F.; Mahdavi, P.; Bergmeier, E.: Evaluation and threat of coastal sand dune habitats in the Natura 2000 sites of Crete, Greece; 24th EVS-Workshop Book of Abstracts, p. 108, Rennes, France

Goedecke, F.; Bergmeier, E.: Modelling potential species distribution for Crete, Verhandlungen der Gesellschaft für Ökologie 44, p. 126, Hildesheim, Germany

Bergmeier E.; Dimopoulos, P.; Goedecke, F.; Tsiripidis I.: Annual vegetation of coastal habitats in the South Aegean. $22^{\text {nd }}$ EVS - Workshop Book of Abstracts, p. 6., Rome, Italy

Dimopoulos, P.; Tsiripidis, I.; Bergmeier, E.; Goedecke, F.; Kallimanis, A. S.; Mucina L., Panitsa, M., Xystrakis, F., Strid, A.: Assessing the conservation status of habitat types in Greece: methodological issues and links to the Red List evaluation of ecological communities. $22^{\text {nd }}$ EVS- Workshop Book of Abstracts, p. 12, Rome, Italy

Goedecke, F.; Goral, F.; Bergmeier, E.: Characterization and diversity of annual dry grasslands in the South Aegean (Greece). Verhandlungen der Gesellschaft für Ökologie 42, p. 238, Lüneburg, Germany 


\section{Appendix}

\section{Tables:}

Table A 2.1 Number of records of woody species from Crete for geological units............................. II

Table A 4.1 Spearman correlations of environmental parameters..................................................... VI

Table A 5.1 Woody species on Crete and Sicily with their affinity to bedrock types (\% of records)... IX

Table A 5.2 Test AUC-values for the models trained on Crete and on Sicily....................................... X

Table A 5.3 Studies integrating relevées for the Sicilian study area.....................................................XI

\section{Figures:}

Figure A 2.1 Distribution of seven ecological species groups of woody species on Crete.................. III

Figure A 2.2 Abiotic preferences of woody Mediterranean species from Crete............................... IV

Figure A 3.1 Field protocol sheet for the conservation assessment of habitat $92 \mathrm{CO}$ on Crete.......... V

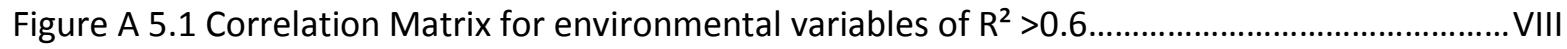

Figure A 5.2 Ecological characterisation of woody species records for Crete and Sicily.................... VIII

\section{Files on included CD:}

thesis: GoedeckeF_2018_Thesis.pdf

publications: Bergmeier_Goedecke_2017_PlatanusOrientalisForestCrete.pdf

Goedecke_Bergmeier_2017_Letter_of_Acceptance.pdf

Goedecke_et_al_2018_QuantifiedEcologyAndCooccurenceCrete.pdf 

Table A 2.1 Number of records of Mediterranean woody species from Crete for geological units.

\begin{tabular}{|c|c|c|c|c|c|c|c|c|c|c|c|c|c|}
\hline & 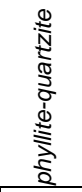 & $\begin{array}{l}0 \\
\frac{1}{0} \\
8 \\
8 \\
8\end{array}$ & 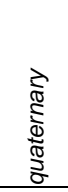 & $\begin{array}{l}\frac{x}{\pi} \\
\frac{2}{2} \\
\frac{d}{d} \\
\frac{\pi}{2} \\
\end{array}$ & $\frac{\sqrt[\pi]{5}}{\stackrel{2}{5}}$ & 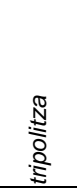 & 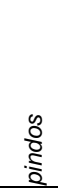 & $\begin{array}{l}\text { i } \\
\text { के } \\
\stackrel{0}{0} \\
\stackrel{5}{2}\end{array}$ & 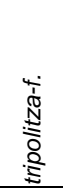 & 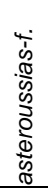 & $\begin{array}{l}\mathscr{2} \\
\stackrel{2}{5} \\
: \frac{1}{5} \\
0\end{array}$ & 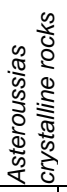 & 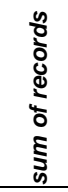 \\
\hline & acidic & sedin & ents & & ard lim & estones & & & yschs & & vari & ous & \\
\hline Acer sempervirens & 16 & 7 & 28 & 213 & 163 & 110 & 14 & 1 & 8 & 1 & 1 & 2 & 564 \\
\hline Arbutus andrachne & 23 & 1 & 1 & 6 & . & 2 & . & . & . & . & . & . & 33 \\
\hline Arbutus unedo & 142 & 18 & 17 & 16 & 11 & 4 & & 1 & . & . & . & . & 209 \\
\hline Berberis cretica & 4 & 1 & 25 & 229 & 136 & 37 & 12 & . & 5 & . & . & 2 & 451 \\
\hline Castanea sativa & 21 & . & 1 & 1 & & & . & . & . & . & . & 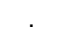 & 23 \\
\hline Ceratonia siliqua & 52 & 122 & 58 & 25 & 34 & 74 & 17 & 3 & 8 & 1 & 4 & 2 & 400 \\
\hline Crataegus monogyna & 12 & 13 & 12 & 22 & 4 & 17 & . & . & 2 & . & 7 & . & 89 \\
\hline Cupressus sempervirens & 10 & 10 & 17 & 135 & 131 & 29 & 3 & 2 & 4 & 1 & 1 & 1 & 344 \\
\hline Erica arborea & 99 & 8 & 12 & 11 & 3 & 2 & 1 & . & . & . & 2 & . & 138 \\
\hline Euphorbia dendroides & 11 & 29 & 16 & 36 & 23 & 50 & 5 & & 7 & . & 3 & 2 & 182 \\
\hline Ficus carica & 21 & 63 & 40 & 38 & 12 & 31 & 10 & 5 & 5 & 1 & 4 & 7 & 237 \\
\hline Juniperus macrocarpa & . & 41 & 18 & . & . & 3 & 14 & 2 & . & 6 & . & . & 84 \\
\hline Juniperus oxycedrus & . & 2 & 1 & 37 & 14 & 2 & & . & . & . & . & . & 56 \\
\hline Juniperus turbinata & 15 & 103 & 31 & 20 & . & 17 & 39 & 4 & 3 & 13 & 6 & 1 & 252 \\
\hline Laurus nobilis & 16 & 20 & 10 & 4 & 1 & 2 & . & . & . & . & 1 & . & 54 \\
\hline Myrtus communis subsp. communis & 24 & 37 & 29 & . & 3 & 3 & 3 & . & 1 & . & 5 & . & 105 \\
\hline Nerium oleander & 60 & 69 & 70 & 13 & 14 & 42 & 12 & 5 & 8 & 2 & 8 & 4 & 307 \\
\hline Olea europaea subsp. sylvestris & 84 & 131 & 47 & 47 & 33 & 109 & 21 & 16 & 18 & 2 & 15 & 11 & 534 \\
\hline Phillyrea latifolia & 78 & 48 & 17 & 31 & 32 & 133 & 10 & 1 & 5 & . & 10 & 1 & 366 \\
\hline Phoenix theophrasti & 7 & 19 & 22 & 2 & & 5 & 3 & 1 & & . & 1 & & 60 \\
\hline Pinus brutia & 37 & 92 & 39 & 63 & 29 & 33 & 32 & 4 & 6 & 3 & 1 & 3 & 342 \\
\hline Pistacia lentiscus & 113 & 380 & 123 & 57 & 73 & 164 & 52 & 17 & 17 & 15 & 8 & 6 & 1025 \\
\hline Pistacia terebinthus & 42 & 42 & 17 & 32 & 18 & 28 & 6 & 3 & 4 & 1 & 4 & & 197 \\
\hline Platanus orientalis & 113 & 77 & 84 & 16 & 16 & 27 & 6 & 4 & 3 & 2 & 9 & . & 357 \\
\hline Prunus prostrata & . & 1 & . & 136 & 99 & 18 & 5 & . & 1 & . & . & . & 260 \\
\hline Prunus webbii & 8 & 31 & 10 & 16 & 11 & 22 & 5 & 6 & 5 & 1 & 1 & 1 & 117 \\
\hline Pyrus spinosa & 80 & 73 & 45 & 55 & 31 & 58 & 15 & 26 & 17 & 1 & 13 & 9 & 423 \\
\hline Quercus coccifera & 98 & 90 & 46 & 175 & 151 & 234 & 20 & 5 & 21 & 3 & 17 & 8 & 868 \\
\hline Quercus ilex & 71 & 17 & 9 & 20 & 10 & 45 & 1 & 1 & 2 & . & 1 & . & 177 \\
\hline Quercus ithaburensis subsp. macrolepis & 2 & 23 & 17 & 3 & & 1 & & 2 & 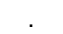 & . & & & 48 \\
\hline Quercus pubescens & 85 & 96 & 43 & 25 & 5 & 32 & 4 & 8 & 11 & . & 35 & . & 344 \\
\hline Rhamnus lycioides subsp. oleoides & 35 & 57 & 21 & 30 & 52 & 117 & 6 & 2 & 6 & . & 17 & 4 & 347 \\
\hline Rhamnus saxatilis subsp. prunifolia & . & . & 1 & 87 & 72 & 14 & 3 & . & . & . & . & 2 & 179 \\
\hline Salix alba & 4 & 10 & 29 & 1 & . & 1 & . & . & . & 1 & . & . & 46 \\
\hline Styrax officinalis & 31 & 55 & 29 & 16 & 2 & 14 & 2 & 1 & 4 & . & 3 & . & 157 \\
\hline Vitex agnus-castus & 8 & 22 & 46 & 7 & 1 & 18 & 3 & 6 & 7 & . & 2 & 4 & 124 \\
\hline Zelkova abelicea & 3 & . & 20 & 82 & 53 & 15 & 20 & . & . & . & . & . & 193 \\
\hline Sum of records & 1425 & 1808 & 1051 & 1707 & 1237 & 1513 & 344 & 126 & 178 & 54 & 179 & 70 & 9692 \\
\hline
\end{tabular}



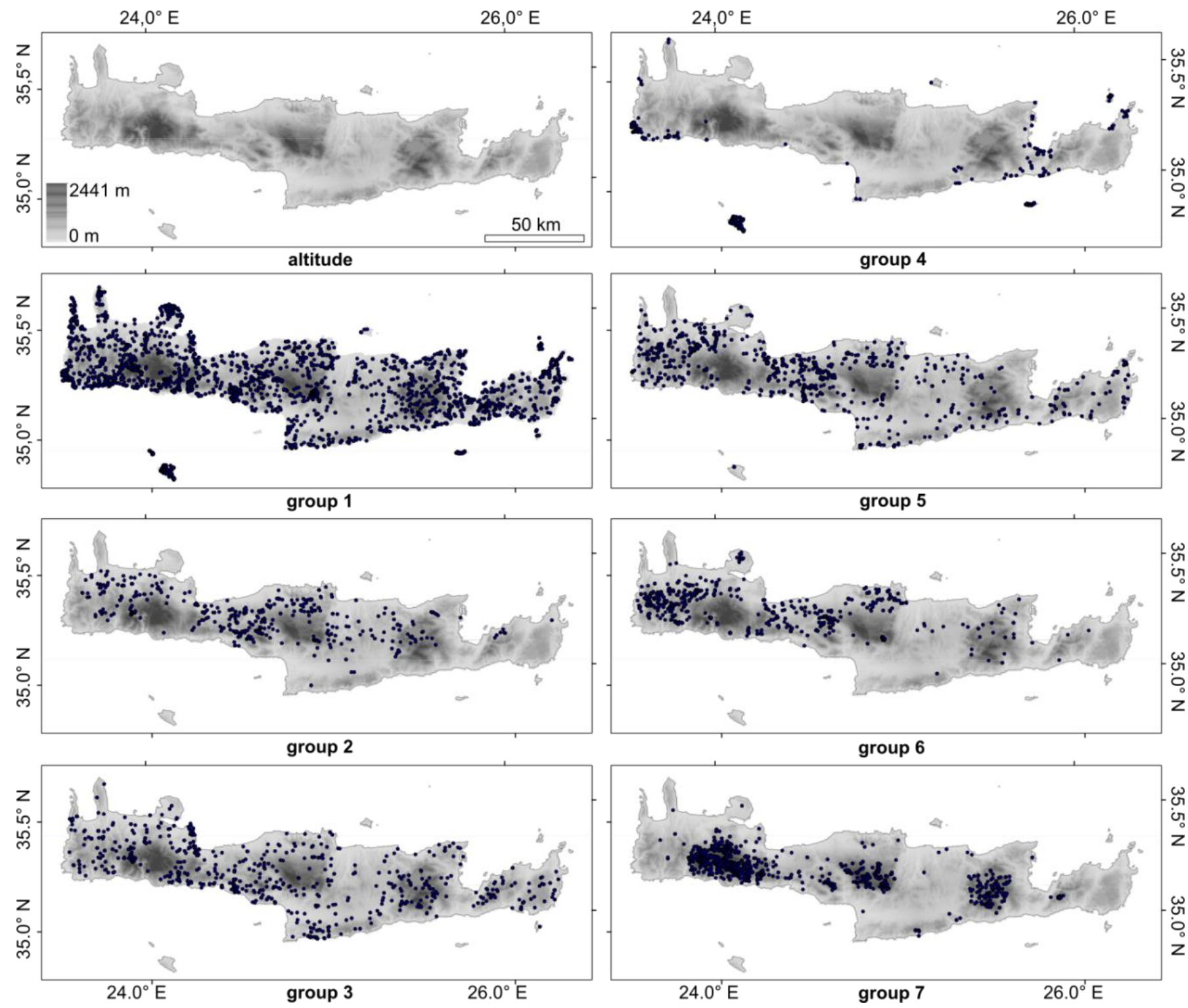

Figure A 2.1 Woody species records on Crete; clustered to groups 1-7 based on ecological spectra of geology, topography, and macroclimate; shading shows altitudinal gradients [m a.s.I.]. 


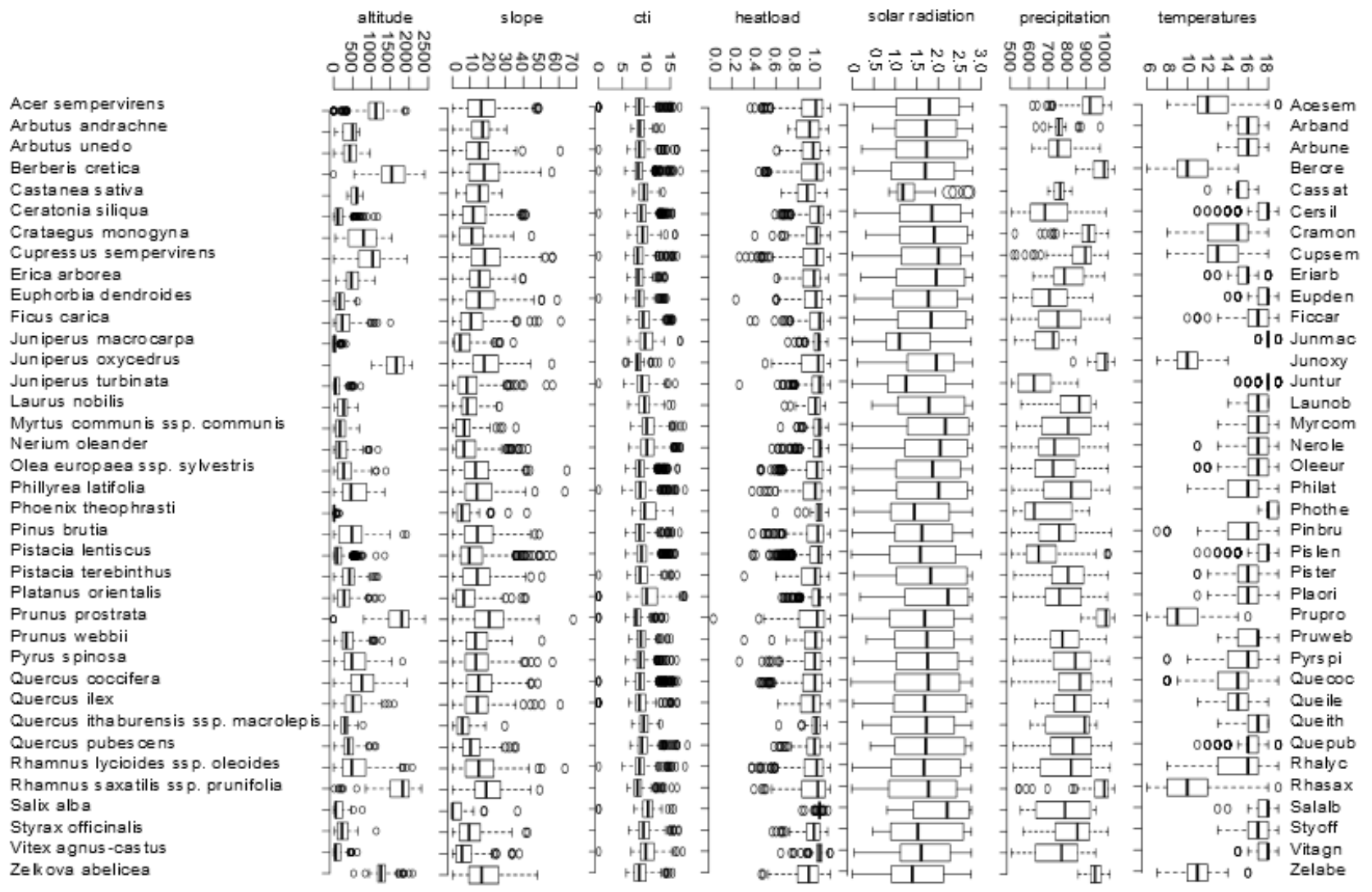

Figure A 2.2 Abiotic preferences of woody Mediterranean species from Crete; as boxplot diagrams; parameters derived from digital elevation model (DEM): altitude [m a.s.I.], slope [ $\left.{ }^{\circ}\right]$, cti [no unit] (compound topographic index) being high in topographically wet areas as valleys and depressions, heatload [no unit] (topographic heatload index), solar radiation [MW/ $/ \mathrm{m}^{2} / \mathrm{year}$ ] as annual energy sum, reduced by relief-based shade; sum of annual precipitation $[\mathrm{mm}]$, annual mean temperatures $\left[{ }^{\circ} \mathrm{C}\right]$. 
Figure A 3.1 Field protocol sheet for the conservation assessment of habitat $92 \mathrm{C} 0$ on Crete.

\begin{tabular}{|c|c|c|c|c|c|c|c|c|c|c|}
\hline \multirow[t]{2}{*}{$\begin{array}{l}\text { Habitat Type } \\
\text { Region: Crete }\end{array}$} & \multirow{2}{*}{\multicolumn{10}{|c|}{$\begin{array}{l}\text { 92CO Platanus orientalis and Liquidambar orientalis woods } \\
\text { (Plantanion orientalis) } \\
\text { Regional description: Forests and woods, for the most part riparian, dominated by Platanus orientalis (oriental plane) or } \\
\text { Liquidambar orientalis (sweet gum), belonging to the Platanion orientalis alliance }\end{array}$}} \\
\hline & & & & & & & & & & \\
\hline \multicolumn{6}{|c|}{ Header data for plot assessment } & \multicolumn{5}{|c|}{ Plot size: $\mathbf{2 0 0} \mathrm{m}^{2}$} \\
\hline \multicolumn{6}{|l|}{ Evaluator: } & \multicolumn{5}{|c|}{ Plot code: } \\
\hline \multicolumn{2}{|l|}{ Date: } & \multicolumn{4}{|c|}{ Old code: } & \multicolumn{5}{|c|}{ Altitude $(\mathrm{m})$ : } \\
\hline \multicolumn{11}{|l|}{ Locality: } \\
\hline \multicolumn{2}{|l|}{$\begin{array}{l}\text { LAT }_{\text {centre: }} \\
\text { LON }_{\text {centre }}:\end{array}$} & \multicolumn{4}{|c|}{$\begin{array}{l}\text { LAT }_{\text {bottomright }}: \\
\text { LON }_{\text {bottomright }}\end{array}$} & \multicolumn{5}{|c|}{$\begin{array}{l}\text { Exposition: } \\
\text { Inclination }\left({ }^{\circ}\right) \text { : }\end{array}$} \\
\hline \multirow[t]{2}{*}{$\begin{array}{l}\text { Relief } \\
\square \text { Plain/Plateau } \\
\square \text { Bottom (valley) }\end{array}$} & \multicolumn{5}{|c|}{$\begin{array}{l}\square \text { Cliff/Rock wall } \\
\square \text { Summit/Crest } \\
\square \text { Sea shore }\end{array}$} & \multicolumn{3}{|c|}{$\square$ Calcareous $\square$ Mixed } & \multicolumn{2}{|c|}{$\square$ Non-calcareous } \\
\hline & Tree & Shrub & Herb & Stone & Rock & Photos & ID & Dir. & \multicolumn{2}{|c|}{ Coord. of Panorama } \\
\hline Cover (\%) & & & & & & Plot & & & \multicolumn{2}{|l|}{ LAT: } \\
\hline Maximum height & & & & & & Pano & & \multicolumn{3}{|c|}{ LON: } \\
\hline \multicolumn{11}{|c|}{$\begin{array}{l}\text { Decide whether main habitat (dominating formation in polygon, if applicable fill table) } \\
\text { OR } \text { co-habitat (not separated as own polygon, if applicable write only main habitat code) }\end{array}$} \\
\hline \multicolumn{2}{|l|}{$\square$ Main habitat } & \multicolumn{2}{|c|}{ Co-habitat } & Co-hab & & Co-habitat & Co-habitat & \multicolumn{2}{|c|}{ Co-habitat } & Co-habitat \\
\hline \multicolumn{2}{|l|}{ Habitat code } & & & & & & & & & \\
\hline \multicolumn{2}{|c|}{ Proportion in polygon (\%) } & & & & & & & & & \\
\hline
\end{tabular}

Typical species ( 6 including the bold species necessary for habitat type in polygon)

\begin{tabular}{|l|l|l|l|l|l|l|l|l|}
\hline & BB $^{2}$ & AFOR $^{2}$ & BB & AFOR & BFOR \\
\hline Adiantum capillus-veneris & & & Myrtus communis & & & & & \\
\hline Aristolochia sempervirens & & & Nerium oleander & & & \\
\hline Athyrium filix-femina & & & Osmunda regalis & & & \\
\hline Berula erecta & & & $\begin{array}{l}\text { Platanus orientalis } \\
\text { (dominant) }\end{array}$ & & & & \\
\hline Brachypodium sylvaticum & & & Primula acaulis & & \\
\hline Campanula cretica & & & Rosa sempervirens & & & & \\
\hline Carex cretica & & & Rumex conglomeratus & & & & \\
\hline Carex divulsa & & & Salix alba & & \\
\hline Carex idaea & & & Samolus valerandi & & & & \\
\hline Carex pendula & & & Styrax officinalis & & \\
\hline Cyclamen creticum & & & Vitis vinifera ssp. sylvestris & & & & & \\
\hline Dorycnium rectum & & & & & & & \\
\hline Equisetum telmateia & & & & & & \\
\hline
\end{tabular}

1 BB: Baun-Blanquet scale for assessment of plot (individuals \& percentage cover): $\mathbf{r}($ rare and $<5 \%),+($ several and $<5 \%), \mathbf{1}$ (frequent and $<5 \%), \mathbf{2}(5-25 \%), \mathbf{3}(25-50 \%), \mathbf{4}(50-75 \%), \mathbf{5}(>75 \%)$

${ }^{2}$ AFOR: Scale for assessment of the whole polygon area (outside the plot): $\mathbf{A}=$ Abundant, $\mathbf{F}=$ Frequent, $\mathbf{O}=$ Occasional, $\mathbf{R}=$ Rare 


\begin{tabular}{|l|l|l|l|l|l|l|l|}
\hline Hedera helix & & & & & & & \\
\hline $\begin{array}{l}\text { Hypericum hircinum ssp. } \\
\text { albimontanum }\end{array}$ & & & & & & \\
\hline Melissa officinalis & & & & & & \\
\hline
\end{tabular}

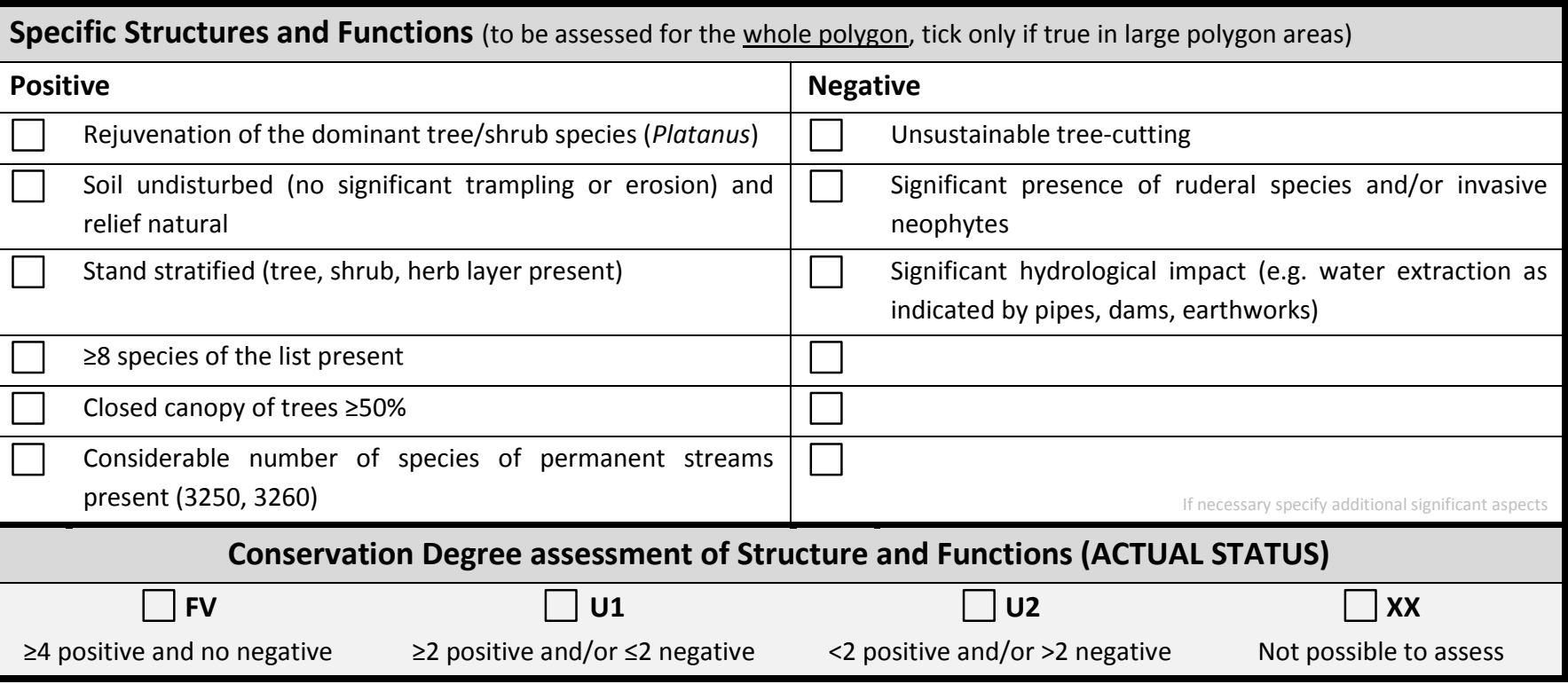

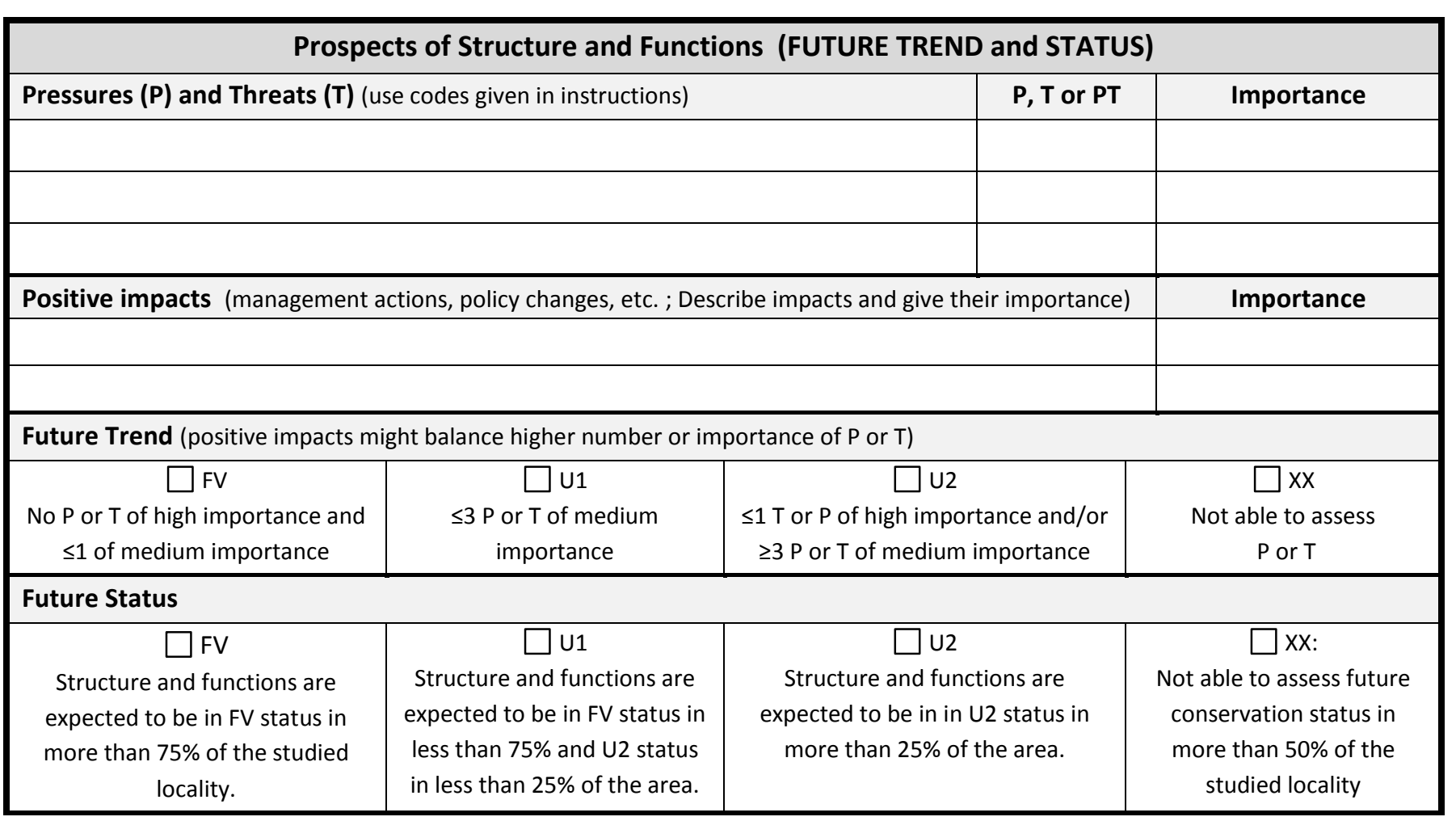

\begin{tabular}{|c|c|c|c|}
\hline \multicolumn{4}{|c|}{ Overall Assessment of Prospects for Structure and Functions } \\
\hline$\square$ Good (G): & $\square$ Poor $(P)$ : & | Bad (B): & Unknown (X) \\
\hline \multicolumn{4}{|c|}{ 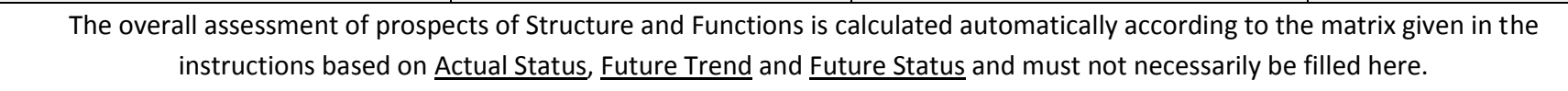 } \\
\hline
\end{tabular}


Table A 4.1 Spearman correlations of environmental parameters, pairs with values $\geq 0.6$ are reduced to one; selected variables in bold font (see Table 4.3 for abbreviations), all further refer to macroclimate (Karger et al. 2016), prec= precipitation, temp= temperature, intanvar= inter-annual variation.

\begin{tabular}{|c|c|c|c|c|c|c|c|c|c|c|c|c|c|c|c|c|c|c|c|c|c|c|c|c|c|c|c|c|c|c|}
\hline & $\frac{\Phi}{\frac{0}{0}}$ & 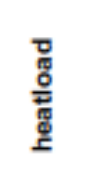 & $\overline{\mathrm{u}}$ & 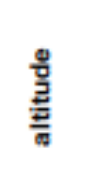 & 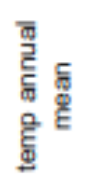 & 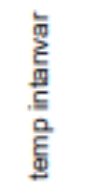 & $\begin{array}{l}\text { \ેे } \\
\overline{0} \\
\text { Eิ }\end{array}$ & 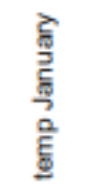 & 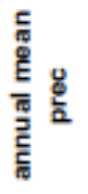 & 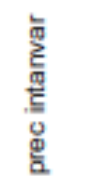 & $\frac{8}{8}$ & $\frac{8}{D}$ & 흠 & $\frac{8}{8}$ & $\frac{8}{8}$ & $\frac{\bar{\sigma}}{\Omega}$ & ஜ묘 & ชั & $\frac{0}{\frac{0}{0}}$ & $\hat{\frac{\pi}{0}}$ & $\frac{6}{\frac{8}{0}}$ & $\frac{10}{\frac{8}{6}}$ & $\frac{7}{\frac{0}{0}}$ & $\frac{m}{\frac{m}{0}}$ & $\frac{N}{\frac{N}{2}}$ & $\frac{\bar{g}}{0}$ & $\frac{}{\frac{2}{0}}$ & $\overline{\frac{0}{0}}$ & 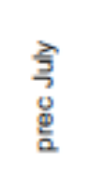 & 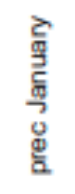 \\
\hline$\overline{\text { slope }}$ & 1.00 & & & & & & & & & & & & & & & & & & & & & & & & & & & & & \\
\hline heatload & -0.02 & 1.00 & & & & & & & & & & & & & & & & & & & & & & & & & & & & \\
\hline cti & -0.39 & -0.02 & 1.00 & & & & & & & & & & & & & & & & & & & & & & & & & & & \\
\hline altitude & 0.36 & -0.03 & -0.16 & 1.00 & & & & & & & & & & & & & & & & & & & & & & & & & & \\
\hline temp annual mean & -0.24 & 0.02 & 0.10 & -0.73 & 1.00 & & & & & & & & & & & & & & & & & & & & & & & & & \\
\hline temp intanvar & -0.25 & -0.17 & 0.16 & -0.14 & 0.31 & 1.00 & & & & & & & & & & & & & & & & & & & & & & & & \\
\hline temp July & -0.28 & 0.01 & 0.11 & -0.71 & 0.98 & 0.40 & 1.00 & & & & & & & & & & & & & & & & & & & & & & & \\
\hline temp January & -0.24 & 0.04 & 0.09 & -0.75 & 1.00 & 0.28 & 0.97 & 1.00 & & & & & & & & & & & & & & & & & & & & & & \\
\hline annual mean prec & 0.27 & -0.27 & -0.02 & 0.14 & -0.31 & -0.18 & -0.36 & -0.28 & 1.00 & & & & & & & & & & & & & & & & & & & & & \\
\hline prec intanvar & 0.25 & -0.18 & -0.06 & 0.17 & -0.33 & -0.31 & -0.41 & -0.31 & 0.89 & 1.00 & & & & & & & & & & & & & & & & & & & & \\
\hline biog 9 & -0.25 & -0.01 & 0.07 & -0.70 & 0.95 & 0.47 & 0.97 & 0.94 & -0.36 & -0.44 & 1.00 & & & & & & & & & & & & & & & & & & & \\
\hline bio8 & -0.31 & 0.01 & 0.10 & -0.72 & 0.91 & 0.42 & 0.91 & 0.91 & -0.37 & -0.42 & 0.93 & 1.00 & & & & & & & & & & & & & & & & & & \\
\hline bio7 & -0.27 & -0.10 & 0.20 & -0.22 & 0.43 & 0.73 & 0.52 & 0.40 & -0.34 & -0.51 & 0.56 & 0.52 & 1.00 & & & & & & & & & & & & & & & & & \\
\hline bio6 & -0.24 & 0.03 & 0.05 & -0.75 & 0.97 & 0.38 & 0.97 & 0.97 & -0.32 & -0.37 & 0.98 & 0.94 & 0.47 & 1.00 & & & & & & & & & & & & & & & & \\
\hline bio5 & -0.24 & -0.01 & 0.08 & -0.70 & 0.95 & 0.46 & 0.98 & 0.94 & -0.36 & -0.43 & 1.00 & 0.93 & 0.56 & 0.98 & 1.00 & & & & & & & & & & & & & & & \\
\hline bio4 & -0.30 & 0.01 & 0.11 & -0.37 & 0.63 & 0.54 & 0.70 & 0.60 & -0.50 & -0.59 & 0.72 & 0.64 & 0.87 & 0.66 & 0.72 & 1.00 & & & & & & & & & & & & & & \\
\hline bio3 & 0.19 & 0.00 & -0.11 & 0.22 & -0.41 & -0.22 & -0.47 & -0.37 & 0.58 & 0.72 & -0.49 & -0.35 & -0.59 & -0.41 & -0.48 & -0.73 & 1.00 & & & & & & & & & & & & & \\
\hline bio2 & -0.09 & 0.06 & -0.03 & -0.22 & 0.19 & 0.23 & 0.16 & 0.23 & 0.34 & 0.20 & 0.18 & 0.29 & 0.19 & 0.22 & 0.18 & 0.02 & 0.39 & 1.00 & & & & & & & & & & & & \\
\hline bio19 & 0.30 & -0.23 & -0.06 & 0.19 & -0.32 & -0.21 & -0.38 & -0.30 & 0.99 & 0.89 & -0.38 & -0.40 & -0.36 & -0.33 & -0.37 & -0.51 & 0.59 & 0.34 & 1.00 & & & & & & & & & & & \\
\hline bio17 & 0.03 & -0.06 & 0.05 & -0.22 & 0.07 & -0.23 & -0.02 & 0.11 & 0.68 & 0.79 & -0.07 & -0.05 & -0.37 & 0.02 & -0.07 & -0.29 & 0.46 & 0.22 & 0.64 & 1.00 & & & & & & & & & & \\
\hline bio16 & 0.32 & -0.22 & -0.05 & 0.22 & -0.36 & -0.20 & -0.41 & -0.33 & 0.98 & 0.88 & -0.40 & -0.43 & -0.36 & -0.36 & -0.40 & -0.53 & 0.59 & 0.32 & 0.99 & 0.60 & 1.00 & & & & & & & & & \\
\hline bio15 & 0.18 & -0.09 & 0.04 & 0.63 & -0.61 & 0.17 & -0.52 & -0.65 & -0.03 & -0.11 & -0.46 & -0.55 & 0.08 & -0.56 & -0.46 & -0.15 & 0.03 & -0.31 & 0.02 & -0.52 & 0.08 & 1.00 & & & & & & & & \\
\hline bio14 & 0.04 & -0.05 & 0.03 & -0.25 & 0.08 & -0.30 & -0.03 & 0.11 & 0.59 & 0.71 & -0.07 & -0.04 & -0.45 & 0.03 & -0.07 & -0.31 & 0.40 & 0.11 & 0.56 & 0.95 & 0.52 & -0.54 & 1.00 & & & & & & & \\
\hline bio13 & 0.29 & -0.25 & -0.05 & 0.18 & -0.34 & -0.22 & -0.40 & -0.31 & 0.99 & 0.89 & -0.40 & -0.42 & -0.36 & -0.35 & -0.39 & -0.51 & 0.56 & 0.29 & 0.99 & 0.64 & 0.99 & 0.02 & 0.56 & 1.00 & & & & & & \\
\hline bio12 & 0.25 & -0.27 & -0.02 & 0.11 & -0.27 & -0.18 & -0.33 & -0.24 & 1.00 & 0.90 & -0.33 & -0.34 & -0.32 & -0.28 & -0.33 & -0.47 & 0.57 & 0.34 & 0.98 & 0.70 & 0.97 & -0.07 & 0.61 & 0.99 & 1.00 & & & & & \\
\hline bio11 & -0.24 & 0.02 & 0.05 & -0.75 & 0.97 & 0.38 & 0.97 & 0.97 & -0.32 & -0.37 & 0.98 & 0.94 & 0.47 & 1.00 & 0.98 & 0.66 & -0.42 & 0.22 & -0.33 & 0.02 & -0.36 & -0.56 & 0.03 & -0.35 & -0.28 & 1.00 & & & & \\
\hline bio10 & -0.25 & -0.01 & 0.07 & -0.70 & 0.95 & 0.47 & 0.97 & 0.94 & -0.36 & -0.44 & 1.00 & 0.93 & 0.56 & 0.98 & 1.00 & 0.72 & -0.49 & 0.18 & -0.38 & -0.07 & -0.40 & -0.46 & -0.07 & -0.40 & -0.33 & 0.98 & 1.00 & & & \\
\hline bio1 & -0.25 & 0.01 & 0.06 & -0.72 & 0.96 & 0.43 & 0.98 & 0.95 & -0.36 & -0.43 & 1.00 & 0.93 & 0.52 & 0.99 & 1.00 & 0.70 & -0.47 & 0.19 & -0.38 & -0.05 & -0.40 & -0.50 & -0.03 & -0.40 & -0.33 & 0.99 & 1.00 & 1.00 & & \\
\hline prec July & 0.06 & -0.05 & 0.05 & -0.21 & 0.03 & -0.36 & -0.07 & 0.07 & 0.61 & 0.73 & -0.11 & -0.08 & -0.48 & -0.01 & -0.11 & -0.34 & 0.37 & 0.06 & 0.57 & 0.95 & 0.53 & -0.53 & 0.98 & 0.57 & 0.63 & -0.01 & -0.11 & -0.07 & 1.00 & \\
\hline prec January & 0.35 & -0.21 & -0.07 & 0.25 & -0.40 & -0.22 & -0.45 & -0.37 & 0.95 & 0.86 & -0.43 & -0.46 & -0.38 & -0.39 & -0.42 & -0.56 & 0.62 & 0.31 & 0.96 & 0.54 & 0.99 & 0.13 & 0.46 & 0.96 & 0.94 & -0.39 & -0.43 & -0.43 & 0.48 & 1.00 \\
\hline
\end{tabular}




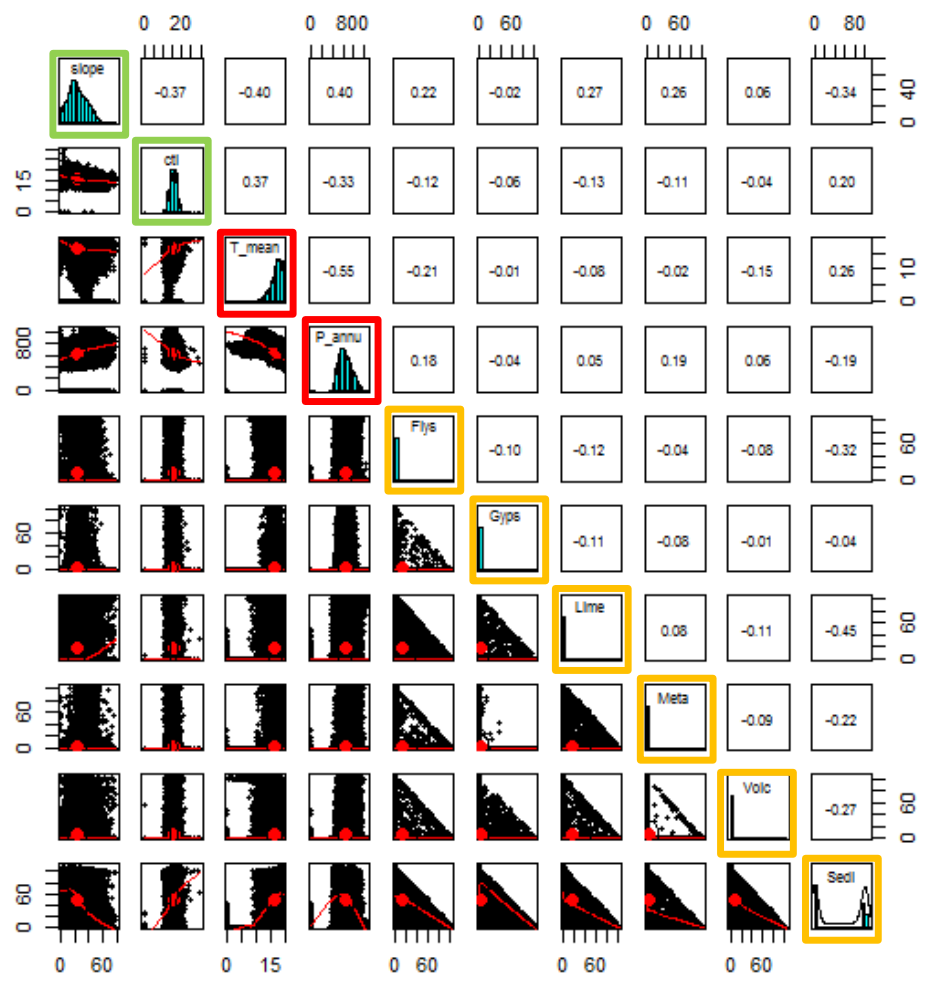

Figure A 5.1 Correlation matrix for environmental variables of $R^{2}>0.6$, mean values had priority.
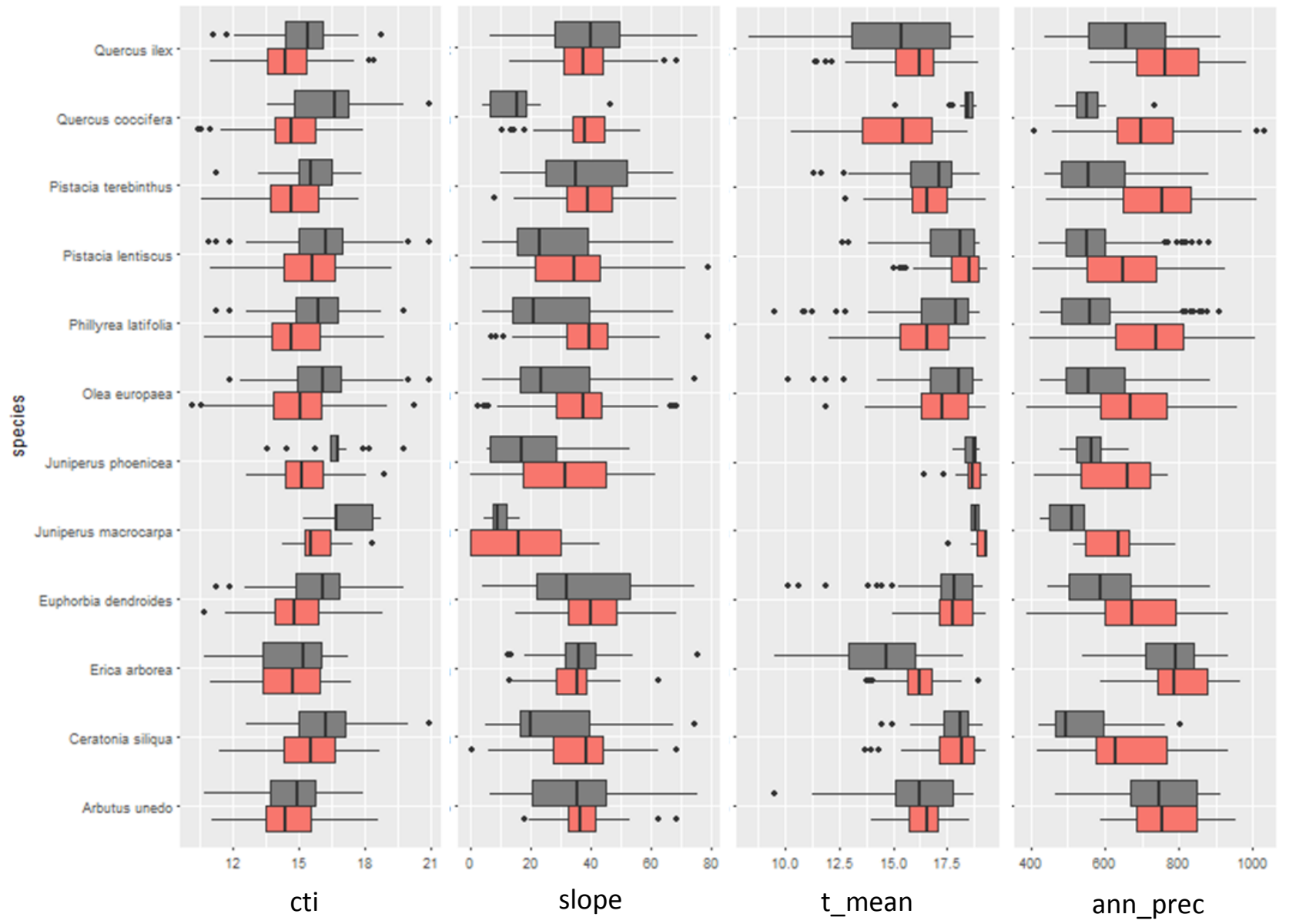

Figure A 5.2 Ecological characterisation of woody species records for (cti compound topographic index [no unit], slope angle [\%], $t$ mean mean temperatures $\left[{ }^{\circ} \mathrm{C}\right]$ and ann_prec annual precipitation [mm]; lower (red) boxes refer to Crete, upper (grey) boxes refer to Sicily. 
Table A 5.1 Test AUC-values (x1000) for the models trained on Crete ( $\mathrm{Cr}$ ) and on Sicily(Si), models are tested with records on the second island. The higher the AUC value the more the cell colour turns to green, while red colour represents low values. Pairs of models are displayed based on the same combination of environmental parameters; cli climatic variables (t_mean+ann_prec), rel relief variables (cti+slope), geo all six bedrock types.

\begin{tabular}{|c|c|c|c|c|c|c|c|c|c|c|c|c|c|c|}
\hline \multirow[b]{2}{*}{$\begin{array}{l}\text { Pairs of data } \\
\text { combinations for } \\
\text { models }\end{array}$} & \multicolumn{14}{|c|}{ Variable combinations in models } \\
\hline & \multicolumn{2}{|c|}{$\begin{array}{l}\text { cli+rel } \\
+ \text { geo }\end{array}$} & \multicolumn{2}{|c|}{$\begin{array}{c}\mathrm{cli} \\
+\mathrm{rel}\end{array}$} & \multicolumn{2}{|c|}{$\begin{array}{c}\mathrm{cli} \\
+\mathrm{geo}\end{array}$} & \multicolumn{2}{|c|}{$\begin{array}{c}\text { rel } \\
+ \text { geo }\end{array}$} & \multicolumn{2}{|c|}{ cli } & \multicolumn{2}{|c|}{ rel } & \multicolumn{2}{|c|}{ geo } \\
\hline Number of variables & \multicolumn{2}{|c|}{10} & \multicolumn{2}{|r|}{4} & \multicolumn{2}{|c|}{8} & \multicolumn{2}{|c|}{8} & \multicolumn{2}{|c|}{2} & \multicolumn{2}{|c|}{2} & \multicolumn{2}{|c|}{6} \\
\hline Training island & $\mathrm{Cr}$ & $\mathrm{Si}$ & $\mathrm{Cr}$ & $\mathrm{Si}$ & $\mathrm{Cr}$ & $\mathrm{Si}$ & $\mathrm{Cr}$ & $\mathrm{Si}$ & $\mathrm{Cr}$ & $\mathrm{Si}$ & $\mathrm{Cr}$ & $\mathrm{Si}$ & $\mathrm{Cr}$ & $\mathrm{Si}$ \\
\hline Test island & $\mathrm{Si}$ & $\mathrm{Cr}$ & $\mathrm{Si}$ & $\mathrm{Cr}$ & $\mathrm{Si}$ & $\mathrm{Cr}$ & $\mathrm{Si}$ & $\mathrm{Cr}$ & $\mathrm{Si}$ & $\mathrm{Cr}$ & $\mathrm{Si}$ & $\mathrm{Cr}$ & $\mathrm{Si}$ & $\mathrm{Cr}$ \\
\hline \multicolumn{15}{|l|}{ Edaphic specialists } \\
\hline Arbutus unedo & 491 & 840 & 664 & 827 & 473 & 848 & 493 & 811 & 656 & 818 & 680 & 772 & 462 & 812 \\
\hline Erica arborea & 478 & 827 & 718 & 846 & 489 & 835 & 427 & 774 & 692 & 829 & 753 & 767 & 418 & 754 \\
\hline $\begin{array}{l}\text { Juniperus oxycedrus } \\
\text { subsp. macrocarpa }\end{array}$ & 892 & 778 & 882 & 800 & 891 & 820 & 849 & 592 & 882 & 891 & 862 & 592 & 819 & 639 \\
\hline $\begin{array}{l}\text { Juniperus phoenicea } \\
\text { subsp. turbinata }\end{array}$ & 845 & 831 & 878 & 896 & 853 & 812 & 627 & 563 & 879 & 885 & 481 & 501 & 626 & 522 \\
\hline Mean value & 677 & 819 & 786 & 842 & 677 & 829 & 599 & 685 & 777 & 856 & 694 & 658 & 581 & 682 \\
\hline \multicolumn{15}{|l|}{ Generalists } \\
\hline Ceratonia siliqua & 636 & 544 & 667 & 679 & 615 & 517 & 544 & 496 & 626 & 595 & 518 & 600 & 532 & 467 \\
\hline \multirow{2}{*}{$\begin{array}{l}\text { Euphorbia } \\
\text { dendroides } \\
\text { Olea europaea } \\
\text { subsp. europaea }\end{array}$} & 706 & 639 & 723 & 824 & 609 & 577 & 626 & 627 & 662 & 694 & 649 & 786 & 498 & 527 \\
\hline & 549 & 414 & 606 & 689 & 524 & 377 & 488 & 395 & 547 & 572 & 538 & 628 & 468 & 393 \\
\hline Phillyrea latifolia & 452 & 297 & 485 & 559 & 446 & 256 & 432 & 325 & 399 & 352 & 494 & 659 & 441 & 287 \\
\hline Pistacia lentiscus & 586 & 464 & 659 & 663 & 572 & 393 & 481 & 471 & 632 & 569 & 538 & 621 & 474 & 453 \\
\hline $\begin{array}{l}\text { Pistacia terebinthus } \\
\text { subsp. terebinthus }\end{array}$ & 506 & 445 & 675 & 565 & 403 & 407 & 472 & 486 & 431 & 348 & 733 & 761 & 339 & 414 \\
\hline Quercus coccifera & 426 & 374 & 186 & 269 & 494 & 373 & 477 & 418 & 183 & 309 & 239 & 230 & 607 & 479 \\
\hline Quercus ilex & 475 & 399 & 655 & 573 & 416 & 366 & 464 & 410 & 527 & 413 & 740 & 784 & 349 & 354 \\
\hline Mean value & 529 & 433 & 570 & 592 & 495 & 393 & 491 & 447 & 483 & 465 & 562 & 638 & 454 & 415 \\
\hline
\end{tabular}


Table A 5.2 Relevées from Sicily integrated in the study.

\begin{tabular}{|c|c|c|c|c|c|c|c|c|c|c|c|c|c|}
\hline 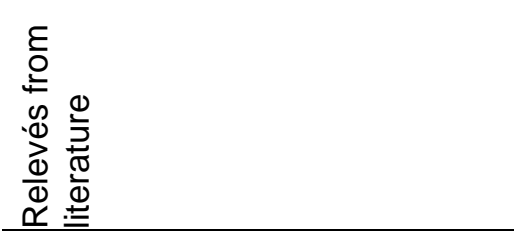 & \begin{tabular}{l}
8 \\
8 \\
\multirow{5}{5}{} \\
$<$
\end{tabular} & $\begin{array}{l}\frac{\pi}{5} \\
: 5 \\
0 \\
0 \\
0\end{array}$ & 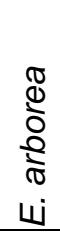 & $\begin{array}{l}\mathscr{8} \\
\frac{d}{0} \\
\frac{0}{d} \\
\frac{1}{d} \\
0 \\
\psi\end{array}$ & 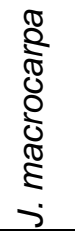 & $\begin{array}{l}\frac{\pi}{\mathbb{2}} \\
\stackrel{5}{5} \\
\frac{5}{5} \\
j \\
j\end{array}$ & $\begin{array}{l}\mathbb{\pi} \\
\mathbb{2} \\
0 \\
0 \\
5 \\
0 \\
0\end{array}$ & 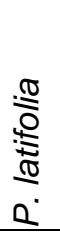 & 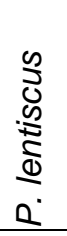 & 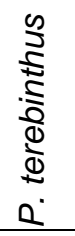 & $\begin{array}{l}\frac{\pi}{0} \\
\frac{0}{3} \\
0 \\
0 \\
0 \\
0\end{array}$ & 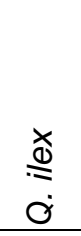 & $\begin{array}{l}\bar{\pi} \\
\stackrel{0}{0} \\
\end{array}$ \\
\hline Barbagallo 1983 & 2 & 2 & & & & & 6 & 7 & 11 & & 3 & 6 & 37 \\
\hline Barbagallo et al. 1979 & & 10 & & 8 & & & 22 & 11 & 38 & 22 & & 16 & 127 \\
\hline Bartolo et al. 1978 & 1 & 5 & & & 1 & 1 & 8 & 6 & 13 & & 7 & 4 & 46 \\
\hline Bartolo et al. 1982 & 3 & 13 & & & 15 & 7 & 19 & 28 & 41 & & 8 & 3 & 137 \\
\hline Bartolo et al. 1986 & & 1 & & & & & 3 & 5 & 5 & & & 2 & 16 \\
\hline Bartolo et al. 1990 & 3 & 3 & 14 & & & & 6 & 8 & 9 & 2 & 4 & 29 & 78 \\
\hline Bazan et al. 2006 & & & & 1 & & & 8 & 9 & 7 & 16 & & 14 & 55 \\
\hline Brullo 1984 & & & 14 & 4 & & & 4 & 3 & 4 & 2 & & 22 & 53 \\
\hline Brullo and Di Martino 1974 & & & & & & & 2 & 4 & 12 & & & & 18 \\
\hline Brullo and Marcenò 1985 & 12 & 30 & 32 & 26 & & & 49 & 28 & 46 & 13 & 9 & 75 & 320 \\
\hline Brullo and Ronsisvalle 1975 & & & & & & & 4 & 5 & 9 & & 7 & 6 & 31 \\
\hline Brullo et al. 1997 & 2 & & 2 & & & & & & & & & & 4 \\
\hline Brullo et al. 2000 & & & & 4 & & & & 5 & 9 & & & & 18 \\
\hline Brullo et al. 2001a+ & & & & & & & & & & 4 & & 4 & 8 \\
\hline Brullo et al. 2008 & 8 & 8 & 9 & 1 & 8 & 27 & 18 & 13 & 10 & 7 & 42 & 151 & 302 \\
\hline Furnari 1965 & & & & & & & & 3 & 3 & & & 3 & 9 \\
\hline Gianguzzi 1999 & 18 & & 27 & 14 & & 1 & 11 & 13 & 31 & 14 & & 53 & 182 \\
\hline Gianguzzi and La Mantia 2008 & 3 & & & 11 & & & 12 & 9 & 17 & 14 & & 14 & 80 \\
\hline Guarino 1998 & 7 & 1 & 32 & 12 & & & 9 & 2 & 13 & & & 18 & 94 \\
\hline Guisso del Galdo et al. 2008 & & & & 9 & & 7 & & 2 & 8 & & & & 26 \\
\hline Marcenò, C., unpublished & & 2 & 3 & 15 & & & 13 & 2 & 7 & 5 & & 9 & 56 \\
\hline Marcenò and Ottonello 1991 & & & 2 & & & & & & & & & 7 & 9 \\
\hline Marcenò et al. 2002 & & & & 4 & & & 3 & & & 2 & & 1 & 10 \\
\hline Minissale and Sciandrello 2005 & 4 & 9 & & 6 & & 8 & 22 & 22 & 28 & & 14 & 12 & 125 \\
\hline Minissale et al. 2007 & & 15 & & 23 & & & 44 & 49 & 86 & 22 & & 56 & 295 \\
\hline Molinier and Molinier 1955 & & 3 & & 4 & & 2 & 5 & & 4 & & & & 18 \\
\hline Poli et al. 1979 & & & & & & & & & & & & 6 & 6 \\
\hline Raimondo 1977 & & & & & & & & & & & & 4 & 4 \\
\hline Raimondo 1992 & & 9 & & 10 & & & 14 & 8 & 8 & 3 & & 20 & 72 \\
\hline Ronsisvalle and Signorello 1977 & & & & & & & & & & & & 1 & 1 \\
\hline Sortino and Giaccone 1968 & & 3 & & 2 & & & 3 & & 3 & & & & 11 \\
\hline Sortino and Marcenò 1974 & & & & 3 & & & & & & & & & 3 \\
\hline Traina and Marcenò 2001 & 1 & & & 1 & & & & & 5 & 4 & & 3 & 14 \\
\hline Venturella et al. 1990 & & & 1 & & & & 3 & 4 & 3 & & & 20 & 31 \\
\hline Unpublished relevées & 1 & 2 & & & 3 & & 1 & & & & & 2 & 11 \\
\hline Total & $\hat{n}$ & $\stackrel{0}{\leftarrow}$ & 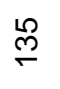 & 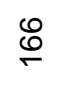 & 尺 & ले & $\stackrel{\infty}{\stackrel{N}{N ~}}$ & $\stackrel{5}{\stackrel{n}{N}}$ & $\stackrel{\mathscr{P}}{\%}$ & $\stackrel{\mathscr{m}}{\sim}$ & ฉి & ָ̊ & 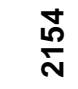 \\
\hline
\end{tabular}

